\title{
Corrective Critiques and Measuring Social Life: Social Capital in Political Communitarianism and Academia
} By

\author{
Joshua George Barton
}

A thesis submitted in fulfilment of the requirement for the degree of Doctor of Philosophy

Victoria University of Wellington 2016 

For my supervisors Kevin and Carol, thank you for all your patience and support 



\section{Abstract}

Over the past quarter of a century social capital has grown from a relatively obscure concept to one routinely applied in a variety of literatures ranging from academic disciplines to international development programmes. Whilst the concept has been the subject of several critiques, these have largely been from a political economic perspective and have primarily discredited the concept by constructing it as having a basis and origins in economics. This thesis aims to offer an alternative analysis of social capital. By drawing on the work of French pragmatism, I treat social capital as a complex, heterogeneous object whose meaning and basis shifts as it has been employed in the enactment of different realities.

Whilst retaining this sensibility, I argue that insight can be gained into political uses of social capital by conceptualising it as part of various corrective critiques of economic liberalism. From a communitarian perspective, liberal policy is deficient because of its individualistic, and economic, foci. The incorporation of these, and other critiques, has resulted in the recent emergence of a 'holistic' approach that identifies human 'wellbeing' as the goal of policy. Social capital, with its promise to make the benefits of social life measurable and calculable, has helped to incorporate the communitarian critique into policy and political discourse both in New Zealand and internationally. However, social capital's relationship to critique within policy and politics has varied. Some authors have constructed it as existing in a reciprocal relationship with existing liberal economic policies, from this perspective both economic growth and social capital are required to improve human wellbeing. For others, however, social capital and wellbeing are damaged by economic growth, and so economic policy requires modification in order to prevent damage to social capital. When the former construction is used, social capital is part of an expansionary critique of policy. From the latter perspective, social capital forms part of a reformist critique of policy.

These arguments are built on an analysis of social capital in texts from a variety of political and scholarly fields. My exploration of social capital in two academic fields, public health and management studies demonstrates that social capital often lacks an evident economic basis, and highlights the variability in the concept's construction. I also explore the history of the concept in New Zealand political and policy texts, discussing its use in the New 
Zealand Institute of Policy Studies and by Prime Minister Jim Bolger in the 1990s, and how this changed as the concept was more thoroughly incorporated into policy during the Fifth Labour Government in the early 2000s. Furthermore, I offer an explanation of social capital's current and central role in national accounting frameworks published by international and national government organisations, which provide the most clearly articulated attempts to measure social life via social capital.

As well as building on the existing critical and analytical literature around social capital, and offering an analysis of the concept within New Zealand, my approach demonstrates the advantages offered by adopting the sensibility of French pragmatic sociology. My analysis supports the argument that texts are a suitable topic of interest from a French pragmatic perspective, and shows the critical insight that can be gained from a more empirically-orientated and less dismissive approach to the concept of social capital. 


\section{Acknowledgements}

I would like to thank my supervisors Kevin Dew and Carol Harrington for all of their invaluable guidance, advice and encouragement over the past four years.

My sincerest thanks to the staff and students of Victoria University of Wellington's School of Social and Cultural Studies, particularly Chamsy El-Ojeili and Sarah Wright for all of your support and for creating a wonderful environment to work and learn in.

Thank you to the politicians and policy makers who I interviewed either formally or informally as part of this thesis. Your insight and time was invaluable in understanding social capital.

I would also like to thank Samantha Keene, Owen Hughes, Julie Howe, Fatimah Hussein, James Gluck, and Morgan Hamlin for their feedback, engagement and proofreading.

Thank you to my parents and siblings for their understanding, patience, and for putting up with me not visiting as often as I would have liked.

Finally, thank you to all of my friends and flatmates, especially Jonathan Douché, Sashi Perera, Misha Amour, and James Barber for their emotional support and encouragement, as well as helping me relax and maintain a life outside of the university, and to Christine Ridding and Derek Douché for helping me when I really needed it. 


\section{Contents}

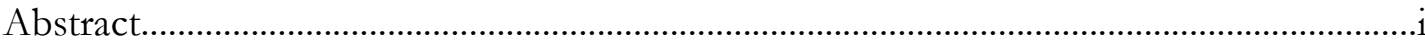

Acknowledgements...........................................................................................................iii

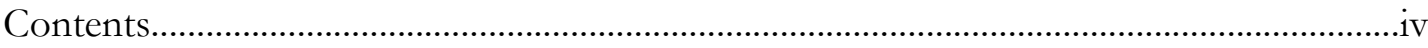

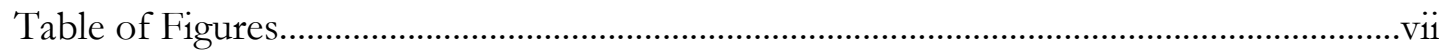

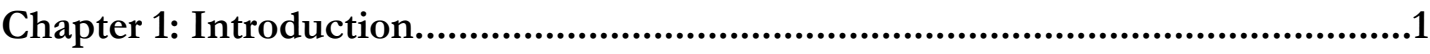

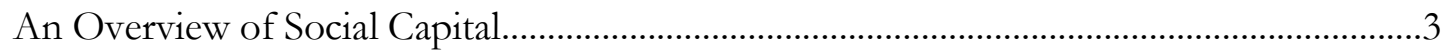

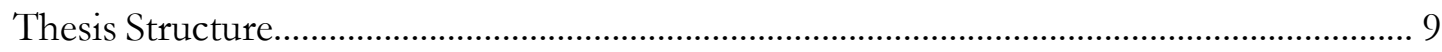

Chapter 2: Critiques of Social Capital...........................................................................11

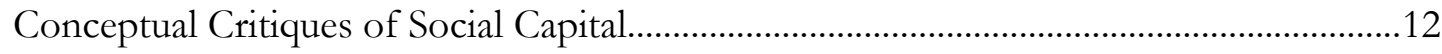

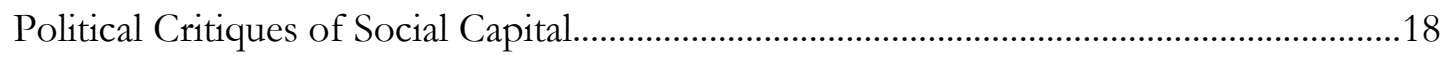

Neoliberalism, the Third Way and Social Capital................................................................23

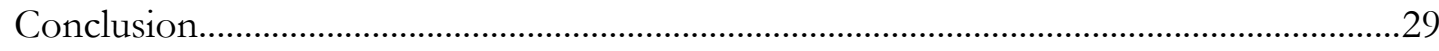

Chapter 3: Sensibilities of French Pragmatism..........................................................31

Post-Actor-Network Theory and Boltanski: Two Branches of French Pragmatic

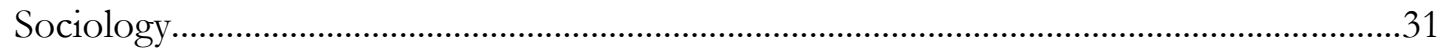

Textual and Discourse Analysis in Pragmatic Sociology........................................................35

Translation, (Im)mutable Mobiles and Critiques...................................................................39

Communitarianism as a Corrective Critique...........................................................................4

Quantification, Knowledge and the Practice of Governance............................................49

Summary

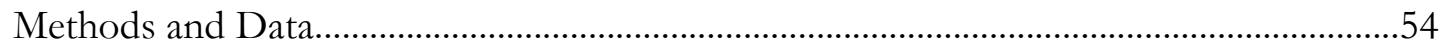

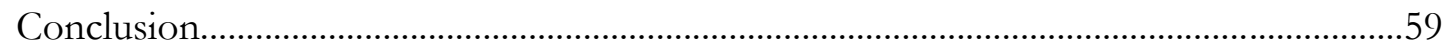


Chapter 4: Conflicting Histories of Social Capital...............................................61

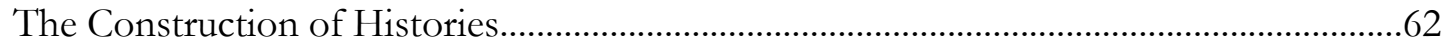

Proponent Histories: The Long(er) Past of Social Capital....................................................63

Proponent Histories: The Short(er) Past of Social Capital..................................................68

Proponent Histories: Founders of Social Capital.....................................................................70

The Socio-political Context of Social Capital..........................................................................75

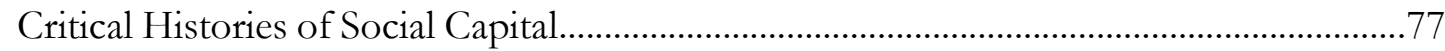

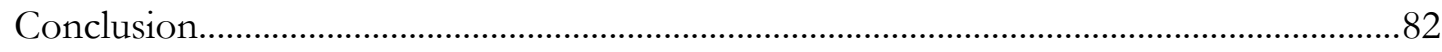

Chapter 5: Social Capital in Public Health and Management Studies.................85

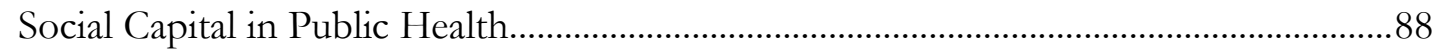

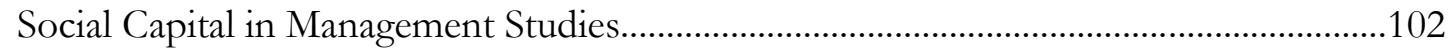

Conclusion: Constructing Social Capital to Address Problems...........................................113

Chapter 6: Communitarian Liberalism and Critique: Social Capital in 1990s New

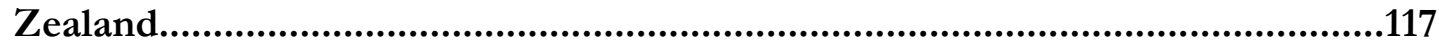

Critique, Community and Productivity: Social Capital in the Institute of Policy Studies

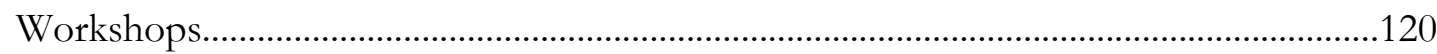

"All that is good in Society": The Social Capital of Jim Bolger........................................128

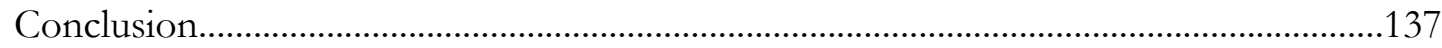

Chapter 7: Social Capital in the $21^{\text {st }}$ Century, Labour and the Third

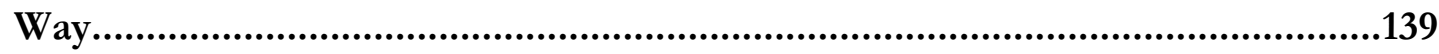

Changing uses of Social Capital during the Fifth Labour Government.............................140

The Role of Government in Labour's Social Capital............................................................146

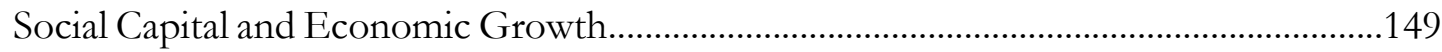

Social Capital in Treasury's Towards an Inclusive Economy.......................................................152 
Social Capital in the Ministry of Social Development.........................................................156

An Inclusive Society: Diversity and Social Capital..............................................................160

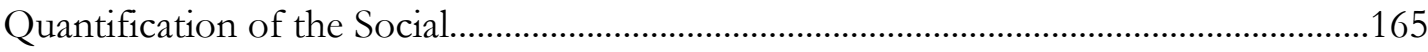

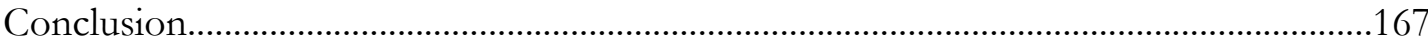

Chapter 8: After the Third Way, Social Capital in National Accounts..................171

GDP and Beyond: The Rise of Alternative National Accounting Frameworks................174

The OECD's The Well-being of Nations and Measurement of Social Capital Project..................179

UNECE/OECD/EuroStat's Measuring Sustainable Development..................................183

New Zealand Treasury's Working Towards Higher Living Standards for All New Zealanders (and

StatsNZ's Framework for Measuring Sustainable Development)...................................................186

Social Capital in the United Nations' World Happiness Reports......................................193

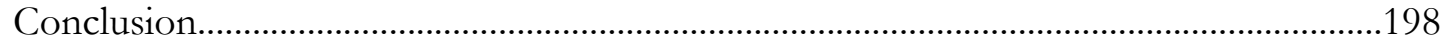

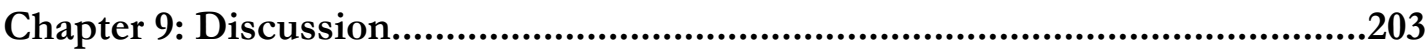

Multiple Realities, Multiple Social Capitals.............................................................................204

Incorporating the Social and Reforming Economic Policy.................................................207

Quantification and Calculation..........................................................................................209

Limitations and Directions for Further Research..............................................................213

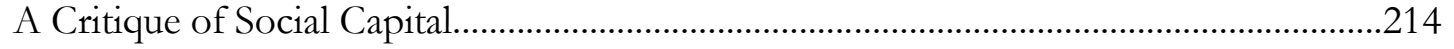

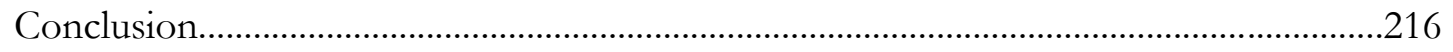

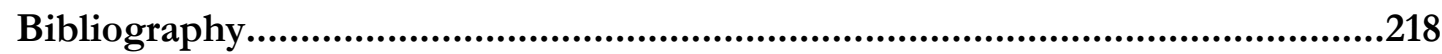

Appendix 1: List of Public Health and Management Studies Articles.................243

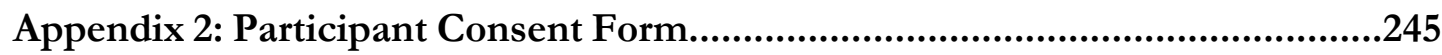

Appendix 3: List of New Zealand Political Speeches..........................................246

Appendix 4: The Growth of Social Capital in the Scholarly literature..................251 


\section{List of Figures and Tables}

Table 1: Selected list of precursors of social capital in proponent histories..........................68

Figure 1: Graph of the expansion of references to social capital...........................................74

Figure 2: New Zealand ministerial speeches using community and social capital by year......

Figure 3: Treasury's diagram depicting the "three main sets of relationships on which an inclusive economy depends" 154

Figure 4: The OECD's Wellbeing of Nations framework..........................................................180

Figure 5: Treasury's Higher Living Standards framework.................................................188

Figure 6: Treasury's Higher Living Standards tool from the conference paper......................191

Figure 7: Percentage of Articles with the 'topic' social capital by Year in Sociology, Public Health, Economics and Management Studies .251

Figure 8: Social Capital publications as percentage of total article publications .252 



\section{Chapter 1: Introduction}

Over the past 30 years, understanding the social as consisting of networks of interconnected, but active actors has become increasingly popular in the social sciences. According to theorists such as Boltanski and Chiapello (2005), it has also become an increasingly popular way for governments and businesses to conceptualise the populations they aim to manage. In this thesis I will explore social capital, one of the more popular ways of conceptualising this new social, from the perspective of French Pragmatic Sociology. My aim is to understand both how social capital has been constructed in various texts, and the reasons why it has proved such a popular concept, without resorting to the over-generalisations and dismissals that are common in critical sociology.

This thesis contributes to the scholarly debate on the meaning of social capital, and the reasons for its popularity. Social capital has been a highly successful 'export' from the social sciences that has received substantial political attention in Anglophone countries. Since the 1980s, it has become a commonly used term in both politics and in a diverse range of social science fields. ${ }^{1}$ After a meteoric rise in the 1990 s, social capital arguably reached its heyday in the early 2000s when it was adopted by various political and policy organisations as a concept deployed to address social problems. However, social capital has not disappeared. It continues to be used various scholarly and policy discourse, and has become an important part of national accounting in addition to attracting ongoing scholarly attention.

For proponents of social capital, the concept has provided a new way of discussing social relations. Thus it contributed to a range of debates, and in particular, can challenge individualistic or economic models of policy. In contrast, for many detractors it has added little beyond an unwanted expansion of economic interests and explanations into the domain of the social sciences. However, despite its popularity and contested status, there have been relatively few in-depth explorations of social capital in either the political or scholarly literature, particularly from a critical perspective. The few critical analyses undertaken, whilst often insightful, have tended to over-emphasise the 'neoliberal' and economic synergies of the concept and downplay other features of the concept's use.

\footnotetext{
${ }^{1}$ The term has even been used in the biological sciences (Silk et al., 2009).
} 
Without dismissing the insights gained from these critiques, I draw on the two branches of French pragmatism, Boltanski's sociology of critique and post-actor-network theory, in order to develop two arguments about social capital. Firstly, I argue that many uses of social capital can be seen as elements of several communitarian 'corrective critiques' that aim to reform the individualistic and economic focus of liberal policy. With its promises of allowing the benefits of social relations to be quantified and calculated, social capital facilitated the incorporation of these critiques into the practice of government. The concept's simple, holistic, and instrumental construction of social life are further recurrent features that added to its appeal, both for governments and scholars in fields that had neglected the importance of social life in their analyses. This promise of a simple, holistic and instrumental measure of social life differentiates social capital from other similar concepts such as social exclusion or social cohesion.

My second argument pertains to the variability of the ways that social capital has been constructed. Whilst the polysemic nature of the concept has been commonly acknowledged, many authors have treated this variation as a weakness in the concept and therefore something to be avoided: whether like Ben Fine who used the 'definitional chaos' of social capital as a stick with which to beat social capital, or like David Halpern who attempted to provide a unified model of social capital approaches. To quote one of the more prominent advocates of social capital, it has arguably become an 'essentially contested concept' which lacks a unified definition, means of measurement or area of application alongside other concepts such as culture, power and rule of law (Woolcock, 2010 , pp. 283 - 286). Unlike such approaches, I accept and work with the heterogeneous nature of social capital, and argue that the varied definitions of social capital should not be taken to indicate that the concept is inherently chaotic or meaningless. Rather, these definitions should be viewed as the result of different authors constructing social capital various ways, depending on the reality that the author is enacting. Authors working from disparate realities have translated the concept of social capital into various literatures to provide a solution to, or explanation for, particular problems. This has resulted in many constructions of social capital, each of which fit the reality the author is working from, and thus addresses a problem specific to that reality. Consequently, social capital in policy and in scholarship should not be treated as a single object. Instead, the concept is heterogeneous, and each use of social capital is constructed from a different assemblage of measurements, theories, definitions, and requirements of the genre of text (such as length or accessibility), and so is a different object. 
My argument also suggests that the polysemy of social capital cannot be reduced to a variation of definitions offered by different theorists. The term has been adopted in response to various issues, from an explanation for the success of managers in management studies, to an element in the debates between psycho-social and material explanations in public health, or the popularist 'all that is good in society' used by some New Zealand politicians. Understandings of the concept have also changed over time. For example, tracing the use of social capital in policy discourse offers an interesting insight into the development of the 'capital approach' to development in which broad 'holistic' understandings of human wellbeing are promoted over narrow economic models of development. Given the concept's variation, care needs to be taken to avoid reducing social capital to any one of the economic or governmental discourses that it has been associated with, particularly the notion of the economisation of the social.

Whilst my pragmatist positioning places this thesis in opposition to many critical analyses of social capital, and means that I will avoid (as much as possible) making normative statements about the concept's worth, I do not intend to defend social capital. In my discussion, I will provide a few normative critiques of social capital arguing that it oversimplifies a complex social life, and at times has also functioned to make particular norms and values appear as objective features of social life. Underlying this is a question as to whether the concept's simplification and quantification are unavoidable elements to both governance, and to a lesser extent scholarly research. Questions that have been raised by both pragmatic sociologists, as well as scholars focusing on the state's tendency for quantification, who have noted that simplification is a necessary, if problematic, process that allows civil servants to address a complex reality.

\section{An Overview of Social Capital}

I do not intend to provide an alternative definition of social capital in this thesis. Given the breadth of the concept such a task would be fruitless and serve only to add to the multitude of definitions of social capital that already exist and often fail to capture the variety of the concept. Furthermore, as Spies-Butcher has noted, the concept has been empirically driven, and consequently social capital theory has lagged behind the application of the concept (Spies-Butcher, 2005, pp. 19 - 20). Rather, as Zuern suggested, the concern around social capital should be less about defining it, but exploring and understanding the messiness of how the concept is deployed (Zuern, 2003). However, in 
order to orientate the reader to the literature being discussed in the rest of this thesis, I will briefly outline some of the more commonly used definitions and prominent works on social capital.

In 1988 James Coleman gave an oft-cited definition of social capital that:

"[...] is defined by its function. It is not a single entity but a variety of different entities, with two elements in common: they all consist of some aspect of social structures, and they facilitate certain actions of actors - whether persons or corporate actors - within the structure. Like other forms of capital, social capital is productive, making possible the achievement of certain ends that in its absence would not be possible. Like physical capital and human capital, social capital is not completely fungible but may be specific to certain activities" (Coleman, 1988, p. S98).

For Coleman, social capital was a capital because it functioned as a resource in the achievement of ends. It was a type of capital that could be possessed by both social groups and individuals. Coleman later used social capital as an element in Foundations of Social Theory, his attempt to provide a general 'foundational' theory of the social sciences that was unabashedly grandiose in its goals (and is a little over 1000 pages long) (Coleman, 1990). In Foundations, Coleman set out to solve Hobbes' problem of order, bridge macro and micro sociology, and to combined rational choice theory with a structuralfunctionalist understanding of sociology (which he generalised to 'economics' and 'sociology' respectively).

For Coleman, the combination of sociology and economics was necessary because both had flaws that the other could fix. Sociology had a good grasp on structural determinants and influences on actors (such as norms, values and regulations) but lacked an 'engine of action' to explain how individuals act. In contrast, economics had a strong engine of action in the utility-maximising individual, but failed to account for social context and its impact on the individual's actions (Coleman, 1988, p. S95). ${ }^{2}$ As a plethora of critics have

\footnotetext{
${ }^{2}$ Critics have tended to focus only on Coleman's use of rational-choice theory. Thus instead of a synthesis, Coleman is seen as promoting a rational-choice variant of sociology (Fine, 2001), or as a correction to rational choice theory (Smith \& Kulynych, 2002). Coleman was a student of Talcott Parsons, and the impact of structural functionalism is evident throughout Foundations, both in terms of the 'engineless' model of social structure that Coleman opposed, but also in the model itself. Particularly with Coleman's discussion of social norms (a central part of Foundations) and their impact on decision making. This breaks with the self-interested rational choice or game-theory model of action where individuals choose how to act based on perceived self-interest and norms do not exist. Coleman did attempt to construct a model where rational actors create norms, however his model assumes a situation where there are no pre-existing norms influencing the individuals involved, resulting in the rationally choosing 'engine of action' being absent from sections of Foundations (Adams, 2010).
} 
noted, in practice this synthesis over-prioritises rational action. It is also similar to a prescription by the rational-choice theorist, Garry Becker (Becker, 1996). Foundations of Social Theory has attracted a substantial number of critiques, including an entire special issue of Theory and Society that emphasised the unrealistic and internally incoherent and overly general model of action that Coleman advanced (Alexander, 1992; Stinchcombe, 1992). ${ }^{3}$ However, whilst Coleman has often been cited in the social capital literature as a founder of social capital (see chapter 4), the framework for explaining social structures, institutions and behaviour Coleman developed in Foundations has been rarely employed elsewhere in the social capital literature.

Robert Putnam is commonly identified as the author who popularised social capital and he has had a substantial impact on the literature. Putnam's work was less theoretically orientated than Coleman's. Instead Putnam contributed to the literature primarily through two empirical studies - one in Italy, Making Democracy Work (Putnam, Leonardi, \& Nanetti, 1993) and one in the USA, Bowling Alone (Putnam, 1995, 2000). As Carpiano noted, Putnam has been inconsistent in his definition and use of social capital between publications in particular varying between a network focus and a community/institution focus (Carpiano, 2006, p. 167). In Making Democracy Work, Putnam echoed Coleman's framing of social capital as an explanation for why the 'tragedy of the commons' did not seem to apply in practice. ${ }^{4}$ Putnam has since moved away from the individual choicebased framework for social capital, based on the assumption of the existence of spontaneous socialisation, that he used in Making Democracy Work (Edwards, 2009). From Bowling Alone onwards, Putnam has associated social capital with a de Tocquevillian-

\footnotetext{
${ }^{3}$ Among other things, Coleman was critiqued for entirely failing to account for a number of social features, particularly those related to inequality. These omissions included failing to recognise that gender as a social norm/fact and thus being quintessentially masculinist (Sica, 1992). Not accounting for the impact of corporate actors on voting patterns (and over stating the case that individuals rationally choose a political party to vote for) (Stinchcombe, 1992). Alexander also argued that his work entirely lacked either nuance or empirical support, which was particularly problematic for a work claiming to comprehensively represent social life (Alexander, 1992). These critiques also expanded to Coleman's claim of developing a broad understanding of 'purposive' and rational action because in practice he only adopts the utility-maximising individual of rational choice economics (Alexander, 1992, p. 206). Consequently, the model of rational action Coleman advances also fails to gel with his advocacy or norms and collective action (Adams, 2010; Alexander, 1992). Stinchcombe and Alexander argued that Coleman's work, both through its lack of inequality and grant theorising represents a nostalgic and sentimental romanticism (Alexander, 1992, p. 203; Stinchcombe, 1992, p. 195).

${ }^{4}$ For Hume, rational individuals would not necessarily cooperate, even if doing so would be for mutual benefit in the long run. Rather they had the incentive to 'defect' from their commitments to the common good if they would still get the benefits from other individuals not defecting. Putnam rejects the possibility of a 'third party' to solve this dilemma. Instead he suggested that high levels of social capital (as defined by Coleman), would facilitate 'spontaneous cooperation'. Individuals would avoid defecting because it would damage their reputation for honesty/reliability - a significant problem for an individual in a high social capital society as they may consequently face social sanctions or similar. These actions would also reinforce the trust and norms that build social capital, maintaining the stock. In societies with an absence of social capital however, this disincentive to defecting is either weaker or does not exist, thus individuals are more likely to default and, furthermore less likely to build social capital (as Spies-Butcher noted, this results in a pair of stable equilibria of high and low social capital societies).
} 
influenced communitarianism. As such he has defined social capital as the "social networks, and the associated norms of reciprocity and trustworthiness" that and is measured at the community and state levels through membership in voluntary associations (Putnam, 2000, pp. 18 - 19; 2007, p. 137; Sander \& Putnam, 2010). Alongside this shift to a communitarian understanding of social capital, Putnam shifted from viewing social capital as lasting centuries with little change in Making Democracy Work, to it emerging and declining in decades as successive generations developed different levels of civility in Bowling Alone (Spies-Butcher, 2005, p. 28). As with the communitarian understanding, Putnam has since retained this generational approach to changes in associations and social capital (Putnam, 2007; Putnam \& Lim, 2010) and again it has resonated more widely in policy and political discourses.

Whilst Coleman's work has often been labelled a type of rational choice theory, based on a methodological individualism, Putnam positioned his later construction of social capital in opposition to individualism or laissez, faire and integrated the concept into a communitarian political programme (Putnam, 2000, p. 24). In Bowling Alone, Putnam was clear that government policies have had an impact on social capital, with it being positively correlated with levels of government spending (Putnam, 2000, p. 281). He also associated structural determinants such as globalisation resulting in lower civic commitment by business leaders, or growing suburbanisation with social capital (Putnam, 2000, p. 283). In the section 'What is to be done?' Putnam turned to the Progressive Era of the 1910s and 1920s in the United States as a potential model for re-building social capital, seeing this period as the an earlier emergence of community against the individualism of the laissez faire 'Gilded Age' of the late $19^{\text {th }}$ century. He offered an agenda for building social capital that included the state advocating for civic education and community service in schools (including re-funding extracurricular activities), incentivising businesses to act to benefit communities (by reducing work hours), and reducing the importance of financial capital on election campaigns (Putnam, 2000 ch. 24). This involved a decentralisation of the federal government, and avoiding the false debate as to whether government is the problem or solution (for Putnam it can be both, depending on whether its policies build social capital).

As will become evident in my analysis of social capital in management studies, Coleman and Putnam are peripheral figures in some approaches to social capital. Instead authors such as Pierre Bourdieu, Nan Lin and Ronald Burt rose to prominence in disciplines that 
have adopted a more network orientated approach to social capital. As with Coleman, Bourdieu began using social capital in the late 1980s, as part of a general explanation of social life that combined micro- and macro- features. For Bourdieu, social capital was one of several different types of resources that individuals could mobilise for personal benefit. Bourdieu defined social capital as:

"[...] the aggregate of the actual or potential resources which are linked $[\ldots]$ to membership in a group - which provides each of its members with the backing of the collectively-owned capital, a 'credential' which entitles them to credit, in the various senses of the word" (Bourdieu, 1986).

Social capital was a resource granted by group membership that individuals can potentially mobilise for personal gain. For Bourdieu, the 'profits' these resources produced formed the basis of group solidarity. Thus, social capital helped to explain inequality, as individuals who lack social capital in a particular situation are excluded from the benefits granted to group members. Ironically, given his Marxist approach, Bourdieu's influence has been most evident in individualistic and rational-choice based approaches to social capital. This was a result of Bourdieu treating social capital as an individual resource, a construction that fitted "easily into strategic models of economic behavior [sic.]" (Sobel, 2002, p. 139). For instance Burt, whilst acknowledging the variation in definitions of social capital, drew on Bourdieu to argue that social capital is a resource that emerges from social structures, but recast Bourdieu's definition as "[t]he advantage created by a person's location in a structure of relationships” (Burt, 2005, pp. 4 - 5). Lin, another network theorist more forcefully defined social capital as individuals" "investment in social relations with expected returns in the marketplace" (Lin, 2001, p. 19 emphasis in original). Like Burt he stated that these investments and returns should only be attributed to individuals, and again drew heavily on Bourdieu.

As I will discuss in the next chapter, critics have argued that social capital's origins lie in economics (Fine, 2001; Fine \& Green, 2000; Somers, 2005; Spies-Butcher, 2005). If this was the case then the concept's subsequent adoption by mainstream economists has been peripheral at best, with few economists using the term. Those who have grappled with the concept, identify social capital as a metaphor, and have debated its usefulness. Solow for instance, argued social capital could not be a form of capital because it promised no return to the individual and does not depreciate with use. Thus it was "an attempt to gain conviction from a bad analogy" (Solow in Sobel, 2002, p. 144). Arrow similarly identified 
it as a bad analogy but elaborated that this was because it required no material sacrifice from the owner, and has no alienability from individuals (since it cannot be possessed it cannot be exchanged) (Arrow, 2000, p. 4).

As these definitions indicate, there are several broad (and ill-defined) approaches to classifying approaches to social capital. Halpern differentiated between micro-level, mesolevel and macro-level constructions as part of a model that included 27 different types of social capital, and advocated combining them all on the grounds that social capital was greater than the sum of its parts (Halpern, 2005, pp. 26 - 28). Kawachi, Subramanian and Kim offered a more basic distinction between the 'social cohesion school', and the 'resources school' (and also advocated for the application of both) (Kawachi, Subramanian, \& Kim, 2008, p. 3) whilst also distinguishing between "version 1.0" social capital defined by its functions and "version 2.0" social capital defined by an agnosticism to the consequences of its outputs (Kawachi et al., 2008, pp. 5 - 6). Others have distinguished between approaches based on the founding theorist drawn upon (commonly Bourdieu, Coleman and Putnam). There are numerous other ways of both grouping and defining social capital, and these can vary substantially between authors. As I stated above, my analysis of social capital in various literatures suggests that, rather than multiple approaches based on particular theorists, different social capitals are constructed by authors in response to different problems.

One frequent (although not universal) tendency in the social capital literature has been to stress the instrumentality of social capital - what Kawachi et al. (2008), and Coleman (Coleman, 1988) referred to as its functions. In both policy and academic frameworks, social relationships are rarely seen as ends in themselves, rather they are instrumental in achieving other ends (Daly \& Silver, 2008, p. 546) regardless of whether the author views these from an overwhelmingly positive, or more agnostic perspective. For this reason, Fine has characterised it as a 'mid-range theory', with social capital inserted as the causal factor between two phenomena already known to be connected (Fine, 2010, p. 27). However, as with most elements of social capital, the outcomes attributed to it have varied. This variation is in part the way social capital has been applied in the scholarly and policy literature. For instance, Burt looked at the benefits of social capital on the

\footnotetext{
${ }^{5}$ Halpern's 27 types of social capital were based along three axes: macro-micro, bonding-linking, and sanctionsnetworks. The range of topics he deemed to be types of social capital were incredibly broad, and ranged from diplomacy and war (macro, bridging, sanctions) to parental relationships (micro, bonding, networks) (Halpern, 2005, p. 27).
} 
individual's career (Burt, 2005), whereas Putnam saw social capital as necessary to curb free-riding and selfish tendencies (Putnam, 2000; Putnam et al., 1993). The New Zealand Prime Minister Jim Bolger understood it as improving community outcomes by allowing government withdrawal, whereas the Labour minister Winnie Laban saw it as important in acknowledging the importance of community participation and association. Kawachi and various co-authors also saw it as an important ecological factor in determining health outcomes (Kawachi \& Berkman, 2001; Kawachi, Kennedy, \& Glass, 1999; Kawachi, Kennedy, \& Wilkinson, 1999; Kawachi et al., 2008; Kennedy, Kawachi, Prothrow-Stith, Lochner, \& Gupta, 1998) and Deuchar used it as an explanation for gang membership and youth crime (Deuchar, 2009). This variation begins to demonstrate caution against problematizing the concept as a whole, and instead advocate for a heterogeneous approach to social capital.

\section{Thesis Structure}

This thesis is divided into 9 chapters, including this introduction and the discussion. Chapter 2 will review the critical approaches to social capital, and from there, discuss why I will avoid using the term 'neoliberalism' in this thesis. Chapter 3 will provide the theoretical and methodological framework for my analysis. I will discuss both post-ANT and Boltanski's 'pragmatic sociology of critique' as well as the tools that I will draw from them. At the end of chapter 3 I will outline the data used and the methods used to explore it. Chapters 4 through 8 constitute the substantive chapters of the thesis. Each of them explores a different facet of social capital, but the main body is divided into two sections. Chapters 4 and 5 focus on international scholarly work on social capital whilst chapters 6,7 and 8 shift the focus away from academia into the use of social capital in political discourses. Chapter 9 will develop my argument and bring my various discussions and analyses together.

Chapters 4 and 5 deal with some of the features of social capital in academia. Chapter 4 offers an analysis of the histories of social capital to help further contextualise the study. In it I will explore how historians with disparate purposes enrol different allies to either legitimise or delegitimise social capital as a concept. Using the division between 'long pasts' and 'short histories' of social capital I will analyse what could be called the mainstream history of social capital, I will also explore other histories that have been offered, including critical histories of the concept. This analysis will highlight the common 
arguments and limitations of critical work. Chapter 5 explores the variation of the concept of social capital in academia by comparing the concept's use in the fields of public health and management studies. I will develop the argument that the differences between the uses of social capital in different academic fields are the result of the diverse issues social capital is used to address. In this chapter I will also challenge the connection between social capital and economics within academia, as well as highlighting the tendency to use social capital as a simplified and quantifiable version of the social.

Chapters 6 through 8 move away from scholarly uses of social capital to focus on the concept's construction in political and policy texts. Chapter 6 will address how social capital was translated into New Zealand's policy context, paying particular attention to the role of Jim Bolger, and the work of the Institute of Policy Studies. Chapter 7 will then discuss the constructions of social capital during the $5^{\text {th }}$ Labour government of New Zealand and how the use of the concept differed from Bolger's use in the 1990s. It will also address the narrowing and decline of social capital's application in the mid-2000s. This will include an analysis of the concept within policy documents, and discuss Labour politicians' understandings of social policy in relation to economic policy. Chapter 8 will move out of the New Zealand context to explore how the concept has been used in national accounting frameworks. Despite the decline in political uses of the concept, social capital has continued to be used by development agencies, and government departments such as the New Zealand Treasury, as one of several capitals which impact on individuals' wellbeing. This is part of a long-term development of wider measures of social progress and critiques of the gross domestic product as a measure of individuals' quality of life.

In chapter 9 I will bring the analyses together in a discussion of social capital. I will address the attempts to measure and quantify social capital, and the insights that can be gained by analysing it as part of a communitarian corrective critique. I will also develop my argument that the appeal of social capital has lay in its instrumental and quantifiable representation of 'the social'. This chapter will also address some of the limitations of this thesis, and areas for future analysis. 


\section{Chapter 2: Critiques of Social Capital}

In the introduction I quoted Woolcock's description of social capital as an 'essentially contested concept'. Whilst his comparison between it and central concepts in the social sciences may have exaggerated, social capital's impact, the concept has been the subject of analysis, both by proponents and critics. In this chapter I discuss the critical work on social capital, focusing on what Boltanski termed 'metacritiques'. Metacritiques aim to connect a specific critique, in this instance a critique of social capital, to a general, underlying theory of domination. They are critiques that have attempted to tackle the concept of social capital as a whole (as opposed to critiques of particular texts, such as Boggs' critique of Putnam (Boggs, 2001)) and from a position of exteriority to the literature (which Spies-Butcher labelled heterodox critiques). Much like this thesis, these metacritiques attempted to tackle the concept in general, as opposed to one or more specific uses of the terms. As many metacritiques have associated social capital with neoliberalism, I will also discuss why I will avoid identifying social capital as neoliberal at the end of this chapter. The discussion of neoliberalism also leads into my discussion of French pragmatism in the next chapter.

To aid in my discussion I will divided critiques into conceptual and political critiques. The former are those aimed at the theoretical or conceptual construction of social capital, particularly its economic or rational-choice origins, whereas the latter focus on the concept's political connections, particularly to neoliberalism. Fine has noted that despite the popularity of the concept, there has been relatively little critical academic attention to the role of social capital, particularly in policy (Fine, 2010, p. 197). However, policy and political analyses do exist. For instance, Ben Spies-Butcher analysed social capital in Australian politics (Spies-Butcher, 2005 ch. 9 - 10), and Fine has provided analysis of social capital at the World Bank (Fine, 2001) as well as a limited update (Fine, 2010 ch. 6). Diane Coole has also offered an analysis of social capital from a Foucaultian governmentality perspective (Coole, 2009). Country-specific critiques also exist such as Cheong, Edwards, Goulboune and Solomos (2007) in the UK or Fitzsimons (2000) in New Zealand. Most other critical attention to social capital are found within critiques of neoliberalism or the Third Way. 


\section{Conceptual Critiques of Social Capital}

Fine has been the most prolific and prominent critic of social capital in the $21^{\text {st }}$ century and recently characterised his interest in it as an unhealthy obsession (Fine, 2010, p. 20). He has published two books and numerous articles on the concept approaching it from a political economic perspective and has offered two conceptual critiques of the concept: that it constitutes economic imperialism in the social sciences, and that it represents the decline in scholarly standards.

Fine's interest in social capital emerged from his work critiquing the economist Gary Becker in the 1990s. Having previously critiqued economists' abandonment of social relations (Fine, 1980), Fine was particularly interested in Becker's application of behavioural economics into other disciplines or what Fine and Becker have termed 'economic imperialism'. This origin of his interest has coloured Fine's analyses, leading him to declare social capital to be a tool of economic imperialism, and to characterise social scientists who do not acknowledge this as either dupes, or complicit in this imperialism for personal gain (Fine, 2001, 2010).

As I noted in the introduction social capital is, for Fine, the latest in a line of attempts by rational choice theorists to colonise the social sciences. It replaced the social exchange theory of Homans and Blau (which Coleman was a peripheral figure in), which he saw as failing to colonise the social sciences. Given the failure of the more overtly rational-choice based social exchange theory, Fine argued that Coleman, Putnam and Becker led a renewed charge by hiding the elements of social capital that would be unacceptable to social scientists, particularly obscuring the economic influences from the concept's history (Fine, 2010, p. 50). This made social capital a 'Trojan Horse' within the social sciences (Fine \& Green, 2000), a claim later repeated by Margret Somers (Somers, 2005). Fine believed that this was:

“[...] essential in order to offer some appeal within an environment that was moving away from neo-liberalism and rational choice, and to appear progressive in relation to it, whilst nonetheless hardly breaking with its emphasis on the virtues of capitalism - though it was explicitly posed in these terms much more rarely than in those of liberal democracy" (Fine, 2010, p. 47). 
This desire to avoid accusations of rational choice theory was also, for Fine, the reason for Putnam's empirical focus (Fine, 2001). Obscuring its rational choice origins allowed social capital to flourish within the social sciences, unlike social exchange theory.

Fine has also paid substantial attention to Gary Becker's use of social capital which he has used to support his characterisation of social capital as a form of economic imperialism. However, Becker has had little impact at all with few texts such as Boulila, Bousrih and Trabelsi (2008), or Mixon, Loftus and Keenel (2004) drawing heavily on his use of social capital. Becker's influence is peripheral even in disciplines working within a rationalchoice behavioural framework such as management studies. ${ }^{6}$ Despite this, Fine recently defended his focus and restated his belief that Becker was at the forefront of social capital research. He argued that the lack of reference to Becker in the literature was not due to a mistake in his analysis but a result of the amnesia of the concept's economic and neoliberal origins (Fine, 2010, p. 37).

Alongside these arguments about economic imperialism, Fine has also claimed that the popularity of social capital reflects a decline in scholarly standards. This claim has recently been given the bulk of Fine's attention, with him stating that social capital represents the 'McDonaldisation' of the social sciences. He argued that the social capital literature is parasitic on the social sciences, drawing on them whilst adding no insights to the subjects that it is used in (Fine, 2010, p. 3). Its success was driven by career-driven 'hackademics' who think that:

"[w] hatever I, or even somebody else, published before, I can publish again as if a new contribution $[\ldots]$ of course, this may be disguised by new case study or empirical analysis, but these could equally have been done, and often have been, before social capital had ever been heard of. In addition social capital opens access to research grants and other marks and perks of academic life" (Fine, 2010, pp. 32 - 33).

A more interesting element of Fine's polemic was that social capital is often used as a 'mid-range theory'; it is a concept that is used as an explanation for the influence of one phenomenon on that is already known to influence another (Fine, 2010, pp. 27 - 28). For Fine, this ability for social capital to be slotted in as a connector between two phenomena

\footnotetext{
${ }^{6}$ When Becker is cited in the management studies social capital literature it is in reference to his work on buman capital as opposed to social capital. These are usually single references establishing the distinction between human capital (as defined by Becker) and social capital (examples include Belliveau, O'Reilly, \& Wade, 1995, p. 1573; Burt, 1997, p. 339; Lin, 1999, p. 29).
} 
highlights its lack of substance, with it always being an unnecessary addition to preexisting theories. The description of social capital as a 'mid-range theory' does seem to approximate the use of social capital in public health, however as I will discuss in chapter 5 , this does not mean that the concept adds nothing to the literature.

A more peripheral issue in Fine's treatment of social capital has been the attempts to measure it. However, in Social Capital vs. Social Theory, Fine discussed the World Bank's attempt to develop a measure of social capital (Fine, 2001, p. ch. 10). He noted that difficulties emerged when moving from the abstract and decontextualized theory of the concept to more nuanced and particular measures of local social capital - something that I will return to throughout this thesis. However, as with much of his critique his argument was derived from a combination of his (mis)conception of Gary Becker as a key theorist in the social capital literature and a focus on the World Bank. Consequently, Fine understood attempts to measure social capital as an application of utility functions from social choice theory, rather than actually attending to existing attempts to measure social capital.

For Fine, the measurement of social capital represented the practical application of social choice theory because the underlying logic to its measurement is that individuals rank groups and then choose their preferred group to belong to. Thus social capital attempts to measure individual choices to gain a picture of social order, leading to a problem since individual preferences are impossible to measure. Despite recognising this problem, economists "shrug shoulders and proceed" anyway (Fine, 2001, p. 181). Drawing on a comment by one participant of the World Bank's email discussion group, who enquired if anything can be learned from the Cambridge capital controversy ${ }^{7}$, Fine argued that the Cambridge controversy established that there is no theoretically agreed measure of capital, and that different forms of capital cannot be aggregated based on production values (which he claims economists do not acknowledge). For Fine, the application of these elements of the controversy to social capital provide a further reason as to why social capital cannot be measured (Fine, 2001, pp. 180 - 182).

\footnotetext{
7 The Cambridge Capital Controversy erupted when Robinson, Sraffa and other English and European economists challenged the neoclassical assumption that the value of capital was calculated by its production function. In neoclassical economics capital's value was assumed to be an aggregable quantity (thus a monetary value of one form of capital was treated as substitutable by the same monetary value of a different form of capital), and the value of capital was an outcome of the expected returns on investment in that capital and the relative scarcity of the form of capital. Fine's argument was that this controversy should indicate that social capital cannot be measured as an aggregate value.
} 
Fine briefly updated his discussion of the measurement of social capital in Theories of Social Capital, commenting on van Deth's early attempt to provide a multi-dimensional approach to measuring social capital. Here he argued that the search for empirical evidence was driven by the need to justify the concept's existence, and stated the impossibility of measuring a non-existent and chaotic concept. Consequently his primary critique in Theories of Social Capital was that social capital lacked a shared method of measurement (Fine, 2010, pp. 194 - 196). In making this critique, Fine failed to recognise that no sociological concept has a shared measure, or shared conceptual understanding. They are all 'non-existent' constructions imposed on social reality to order and structure it, including the concepts he preferred to social capital such as class, gender and ethnicity. This meant that he missed the chance to probe more thoroughly into why social capital is measured, as well as exploring the possible consequences of this measurement.

Overall Fine's work has shown some interesting insights into social capital having briefly acknowledged some of the changes in economics, he also made the connection between social capital and quantification (Fine, 2001 ch. 10; 2007b). However, his two main conceptual critiques - that social capital was developed as a weapon in the economic imperialist colonisation of the social sciences, and that it represents the degradation of scholarly standards - are both problematic and unhelpful. His analysis has been hampered by his dismissive, and over-generalised treatment of the concept, and many of his critiques are unfortunately little more than denunciations. His characterisation of disciplines as in conflict with each other is an unhelpful lens and ignores the long history of interdisciplinary work (such as his identification of management studies as parasitical on other disciplines (Fine, 2010, p. 141)). He has approached his subject matter from a predetermined standpoint, and claims to uncover a 'truth' that underpins the concepts' use. This 'truth' contradicts how users of social capital perceive the concept. Fine justified this contradiction though his argument that the features have all been obscured or ignored by 'social capitalists'. As I will discuss in the next chapter, his work in many ways exemplifies the issues in critical sociology that French pragmatists have challenged.

Fine is not the only political economist to have provided a conceptual critique of social capital. Spies-Butcher $(2005)^{8}$ makes a number of points regarding social capital that I will echo in this thesis. In particular, he noted that social capital was largely defined by

${ }^{8}$ His thesis on social capital was published as a book in 2009 (Spies-Butcher, 2009). 
empirical analyses as opposed to building on a developed theoretical framework. He identified the origins of social capital in branches of methodological economics which were more open to challenges to the economic orthodoxy. This empirical focus has continued since social capital "has been taken up by governmental and bureaucratic organisations at every level (from local to global), partly because it offers the promise of pragmatic policy advice” (Spies-Butcher, 2005, p. 20). Spies-Butcher argued that its empirical origin caused a lack of clarity in the definition of social capital, as conceptual debates have been playing 'catch up' with the empirical literature (Spies-Butcher, 2005, p. 26). This lack of clarity has, he argued, been the driver behind the 'orthodox' critics of social capital. These orthodox critics seek to anchor the current empirical employment of social capital with strong theoretical origins. They are not dismissive of the concept in its entirety (unlike the 'heterodox critics'), and see the concept positively. Rather:

"[t] he discontent of these theorists is focused on the inability of social capital theorists to converge on a single definition or framework, or to display the appropriate level of intellectual rigor" (Spies-Butcher, 2005, p. 30).

Spies-Butcher's primary concern was with exploring the 'heterodox critiques' with him wishing to "examine the ideological implications of the concept by better understanding the concept's genealogy" (Spies-Butcher, 2005, p. 37). Like Fine, his work was a metacritique of social capital, situating (and explaining) its emergence by reference to neoliberalism.

As with Fine, Spies-Butcher argued that social capital originated in economics. However unlike Fine, Spies-Butcher identified the origins of social capital in challenges toward the high-modernism of rational-choice theory within economics. He identified its origins in discussions by methodological economists and new institutional economists who were exploring the limitations of game theory, particularly the prisoner's dilemma. These debates were fuelled by the growing empirical evidence produced by game tournaments to challenge the notion that individuals behaved in the self-interested, rational way predicted by rational-choice theory (Spies-Butcher, 2005 ch. 3). Game tournaments further contributed to a growing recognition within economics for the need to attend to the social context in which economies are embedded (Spies-Butcher, 2011, p. 47). For Spies-Butcher, the resulting changes were a genuine move away from the high-modernism that had characterised rational-choice economics but retained the ideological commitment 
to the market (Spies-Butcher, 2005, pp. 52 - 53 ch. 4). Spies-Butcher associated this move away from rational-choice theory with the growth of neoliberalism, noting that Fine conflated the methodological commitment to modernism in rational choice theory, with a commitment to the market in neoliberalism (Spies-Butcher, 2005, p. 13). As SpiesButcher himself noted, his work avoided generalising the field of economics (or reducing it to rational choice theory), and he comments that he is not dismissive of the entire field. As I will discuss later, he also offers a useful discussion of the concept in Australian politics. However, his work still focused too much on establishing the relationship between social capital and economics, particularly by tracing the concept's history. Consequently, his conclusions did still generalise the concept and largely treated it as a single object that was a vehicle of neoliberalism (or classical liberalism), and as imbued with a belief in spontaneous sociability.

Some critics including Fine (Fine, 2001), Smith and Kulynych (Smith \& Kulynych, 2002) and Tittenbrun (Tittenbrun, 2014) have also argued that the social capital literature failed to differentiate between the factors that increase social capital and the consequences of it which results in the concept possessing a tautologous logic. This echoes early critiques of Putnam's work from other social capitalists (Edwards \& Foley, 1998; Edwards, 2009; Portes, 1998). Portes for instance, argued that this tautology was a result of Putnam detaching social capital from relations and placing it in the community, where it becomes conflated with civic virtues and becomes both cause and effect: "if your town is "civic," it does civic things; if it is "uncivic", it does not" (Portes, 1998, p. 20). Edwards and Foley also critiqued Putnam's use of social capital for being tautologous, adding that Putman also applied a moralistic and narrower understanding of social capital which only focused on the 'good stuff of social capital (Edwards \& Foley, 1998). Thus it lost many of the insights and modifications of neoclassical economics that Coleman achieved with the concept. They argued that the social capital debate has depoliticised civil society since Putnam failed to both accurately define social capital, and showed a lack of interpretation of De Tocqueville and the communitarian tradition (Foley \& Edwards, 1997). Finally they briefly connected Putnam's aggregation of social capital with the problems of the use of the gross domestic product by economists observing that both mask many key features they claim to explain (Edwards \& Foley, 1998, p. 130). 


\section{Political Critiques of Social Capital}

Social capital has received substantial attention within political and policy discourses and some critiques have focused on establishing its connection with particular types of neoliberalism (Coburn, 2000; Navarro, 2002; Smith \& Kulynych, 2002; Somers, 2005). The policy critiques of social capital mirrored the conceptual critiques, with social capital's economic origins replaced by the context of neoliberal policy reforms. For these critics, social capital reflects some surface change in neoliberalism. The role of social capital varies, in some cases its emergence was part of a defence of neoliberalism, for others it was an expansion and embedding of neoliberal concerns into social relations.

Fine offered a prescription of social capital as supporting a second phase of neoliberalism. Whilst he acknowledged that social capital is not neoliberal he argued that:

"[o]n the other hand, social capital, as already hinted, does offer an ideal frame for neoliberal policy in its second phase - to improve the workings of the economy and society more generally by promoting ameliorative action within civil society - and without attention to the broader and deeper forces that both create dysfunction and constrain its correction" (Fine, 2010, p. 10).

In contrast Smith and Kulynych argued that social capital 'economises' social relations and that it embodies an underlying logic of capitalism. Consequently the use of social capital " $[\mathrm{m}]$ akes it more difficult than it otherwise would be to conceptualize political and social life in a vocabulary other than that associated with capitalism" (Smith \& Kulynych, 2002, p. 175). Coburn stated that neoliberalism caused both an increase in inequality and a decline in social capital, but that the social capital literature refuses to recognise this instead it has diverted attention away from issues of inequality and neoliberalism (Coburn, 2000).

Such critiques have been levelled at social capital in the New Zealand context. For instance, Fitzsimons argued that social capital was designed to re-start New Zealand's economic growth that had faltered in the 1990s:

" $[\mathrm{w}]$ hen faced with election type issues, rather than pursue the intellectual purity of their methodological individualism, the neoliberals wanted to recognize community albeit on their own terms; under Social Capital they redefined community as individualised trust arising based [sic.] on an ahistorical, abstract, notion 'spontaneous sociability'. This 
community, it seems, would produce economic value and the neoliberal 'trickle down' effect would, therefore, be reactivated" (Fitzsimons, 2000, p. 2).

Thus social capital:

"[...] is heavily implicated in supporting the neoliberal project by locating the responsibility for economic progress on a notion of community based on methodological individualism" (Fitzsimons, 2000, p. 10).

Four years later Craig and Porter argued that the Fifth New Zealand Labour government's focus on social development:

"[...] is perhaps most powerfully animated by the notions of social investment, raising human and social capital for a wider project of creating a globally competitive and integrated national economy" (Craig \& Porter, 2004, p. 247 emphasis in original).

Later, Craig and Porter identified social capital as well as community, social cohesion and other concepts as part of what they termed 'inclusive liberalism’ (Craig \& Porter, 2004). They argued that inclusive liberalism constituted a 'Polanyian turn' to re-embed neoliberalism, in order to further legitimise and secure the reforms of the 1980s and 1990s. Consequently the inclusive liberal discourse 'slips' from discussing voluntarism and inclusion, to discipline and responsibility all with the end goal of including individuals in a market economy (Craig \& Porter, 2004, pp. 231 - 232). Through this slippage, and the rhetorical alignment between market and community, inclusive liberalism functioned as a project to hold neoliberalism together (Craig \& Porter, 2004, p. 231). They also displayed scepticism as to the sincerity of these social concepts stating that they are "contested, almost phoney forms of the social" (Craig \& Porter, 2004, p. 233). ${ }^{9}$

As I mentioned above, Spies-Butcher explored the use of social capital in Australian politics. He noted the concept's adoption by persons from a range of different political positions - ranging from critics of neoliberalism, to economic think-tanks pushing a market-fundamentalist position and subsequently Mark Latham's Third Way politics. ${ }^{10} \mathrm{He}$ also highlighted the range of opinions on the role of the state, with some authors mobilising social capital as a critique of the state, and others identifying a role for the state

\footnotetext{
${ }^{9}$ Craig and Cotterell later rephrased this as the "re-embedding of markets and marketised governance in shallow, quasiterritorial forms of the social, such as community and local strategy" (Craig \& Cotterell, 2007, p. 500).

${ }^{10}$ Leader of the Australian Labor Party, and Leader of the Opposition, $2003-2005$.
} 
in indirectly building social capital (Spies-Butcher, 2005, pp. 215 - 217). As I will note in chapters 6 and 7, similar variations are also evident in New Zealand uses of the concept.

Spies-Butcher traced the Australian interest in social capital to liberal think-tanks, particularly the Centre for Independent Studies (CIS), where arguments that policy should attend to more than just economic reform began to emerge after the 1993 Australian federal election (Spies-Butcher, 2005, p. 206). Social capital was seen as a new and important area of policy concern that, as with the economy required the withdrawal of the state, an argument based on the liberal belief in spontaneous sociability. Spies-Butcher viewed this expansion primarily as a justification for expanding economic reform (SpiesButcher, 2005, pp. 209 - 212).

A similar civic neoliberal approach to social capital was partially adopted by political parties in Australia, first under the Greens in the 1990s and then Latham's Third Way government (Spies-Butcher, 2005). Spies-Butcher argued that the Third Way was an embrace of civic neoliberalism based on spontaneous sociability emerging from social capital. This translated into devolving policy decision making, an overhaul of the welfare state and the drive toward a post-industrial economy that relied on high levels of social and human capital (Spies-Butcher, 2005, pp. 248 - 251). However, he noted that Latham's adoption of civic neoliberalism was only partial. Latham also adopted a conservative understanding of Australian history to argue that the country had suffered from a dearth of social capital due to the presence of a strong state and small, exclusionary mateship bonds. Thus Latham advised against a devolution of the state where there was insufficient social capital to replace it (Spies-Butcher, 2005, pp. 254 - 255).

Despite introducing the concept, Spies-Butcher argued that the CIS did not popularise social capital in Australia. Rather, Eva Cox popularised it by using it in critiques of neoliberal policy. Spies-Butcher argued that whilst Cox's critique was not aligned with the policy direction of the 1990s, it shared a desire for a less-modernist framework for addressing social concerns with contemporary academic debates. Cox employed the concept to challenge the economic fundamentalism of neoliberalism, arguing (as various others would do) that neoliberal reforms had damaged social capital through an increase in inequality (Cox, 2002, p. 353). Cox instead advocated for a more collectivist politics that recognised the importance of the state in shaping social policy, as well as an arbiter and mediator with community (and constraint on the economy) that was opposed to the 
individualism and competition of the market economy (Cox, 2002, p. 358; Spies-Butcher, 2005, p. 218).

Spies-Butcher drew on the work of Christine Everingham to argue that these differences in definition and understanding of social capital (and related concepts) were dependent on the authors' understandings of the ideal community (Spies-Butcher, 2005, p. 226). This was built around differing interpretations of the liberal tripartite division between the state, civil society and the market in the debate. Spies-Butcher argued that:

"[...] each side [of the debate] developed an analysis which had only two logics, not three. In neither account was civil society simply equated to either the market or the state. However, in both cases civil society shared a common logic with one of these institutions, and not with the other" (Spies-Butcher, 2005, p. 226).

Thus, for critics of neo-liberalism (such as Cox), civil society shared a logic of egalitarianism and deliberation with the state but not the market, and for classical liberals it shared a basis in freedom and spontaneous order with the market and not the state. Spies-Butcher connected this difference with the degree to which the various authors associate social capital with spontaneous action models in game theory seeing classic liberals as acknowledging these origins, whilst others such as Cox being either unaware, or at least not acknowledging them.

Spies-Butcher highlighted the variability in uses of social capital in Australia as well as many of the tendencies that also emerged in New Zealand. As well as addressing this variation, Spies-Butcher also acknowledge the critical uses of social capital in the Australian context. He observed that the meaning of social capital changed over time, with the concept becoming increasingly ambiguous as it became more popular (SpiesButcher, 2005, p. 260). Despite this he concluded that social capital was social theory informed by neoliberalism because "social capital was not so much a move away from the market as it was an extension of the logic of the market to the social as well as the economic realm" (Spies-Butcher, 2005, p. 269).

Social capital's role in policy has also been critically analysed from a Foucaultian perspective, with it often being addressed in passing in the governmentality literature, but these are generally limited comments. Dean gave the concept a short discussion, stating that it demonstrated a form of advanced liberal governance that "attempts to reconfigure social expertise and the objectives of social governance" (Dean, 2010, p. 178). He also 
argued that the distance between social capital and Thatcherism was shorter than either side would likely admit, primarily because of Thatcher's commitment to a form of liberal communitarianism (Dean, 2010, p. 179). Dean noted that the construction of individuals as autonomous and active made society something to be cultivated and governed, as opposed to regulated (Dean, 2010, p. 179). Fyfe made similar observations, connecting the 'neo-communitarianism' of the New Labour government of Tony Blair with the repositioning of the third sector (voluntary work) in government discourse. Unlike some of the other critics I discussed above, Fyfe identified the emergence of the third sector as a significant shift, identifying a combination of neo-liberalism and neo-communitarianism in New Labour. He, like Dean, noted that much of the valorisation of the third sector was evident in discussions by Conservative politicians during the 1980s. He remained critical of the possibility of voluntary and third sector work in instigating any form of social change (Fyfe, 2005).

Diane Coole provided a short genealogy of social capital from a Foucaultian perspective. She argued that political attention to social capital was "best understood as a policy initiative designed to repair the ideological resources of contemporary liberal states" (Coole, 2009, p. 376). For Coole, social capital allowed displaced populations, created by neoliberalism, to be managed. It allowed states to manage declining social cohesion that resulted from growing transient and heterogeneous populations by allowing migrants to be incorporated into their new communities. She also notes that it is a 'post-neo-classicist theory' that recognised economic growth is impacted on by non-market forces and that these non-market forces require governance. Social capital achieved all of this whilst avoiding becoming either a repressive form of power, or advocating for social engineering, largely because it avoided discussing wealth distribution. She also noted that whilst social capital has received substantial attention in political discourses, there is little to no attempt to move beyond the simple measurement or monitoring of it (Coole, 2009).

Finally, social capital's role within Third Way 'inclusive liberalism' has also been critiqued both for being presented as panacea, and as a way to incorporate ethnic minorities into society. Cheong et al. discussed how social capital in the UK was presented as a 'cure' for a lack of cohesion in a multicultural society by the New Labour government. They noted how social capital was imbued with normative judgements that have shifted depending on policy concerns, particularly around the distinction of bridging (between-group) and bonding (in-group) social capital. According to Cheong et al. social capital, as used by the 
UK government, was at best a diversion from problems of race-relations, and at worst a coercive element of an integratory policy. They did however see promise in alternative approaches to social capital that accounted for its relationship with power, class and racism (Cheong et al., 2007).

Many of these critiques offer significant insights into the concept of social capital, and I would suggest that further insight can be gained by developing Spies-Butcher's attempt to approach social capital as having variable meanings for authors working from different political positions. Unlike Spies-Butcher and other critics, I do not see social capital as part of a market liberalism. My argument in this thesis is that the variability of social capital as a concept largely results from the way authors have translated and interpreted it into different realities. The concept's political uses are parts of complex and shifting positions - as Spies-Butcher recognised in his analysis of the Australian political discourse - that includes a communitarian critique of liberalism. Whilst recognising these varied constructions of social capital, I also argue that the quantification and simplification of social capital as a concept have been central to its political success and appeal (although this is by no means ever-present), as it allowed the concept to facilitate the incorporation of the communitarian correct critique into policy.

\section{Neoliberalism, the Third Way and Social Capital}

In the previous section I questioned the association of social capital with a second phase of neoliberalism. In part this questioning was due to the breadth of application of the concept of neoliberalism, particularly as it is often used to refer to a post-1970s epoch of governance. Neoliberalism has become an increasingly popular and ubiquitous term in critical sociology since the 1990s to describe post-1980s governance or capitalism (Boas \& Gans-Morse, 2009). However, given the breadth and variability of uses of neoliberalism, I (and others) question the insightfulness of the concept and am hesitant to use it as an analytical concept. In this section I will briefly outline some elements and issues with the neoliberalism literature, and make my case for why I will use the broader and more neutral 'liberalism' as opposed to 'neoliberalism' in my analysis.

Neoliberalism, much like social capital, has been used in a multitude of different and often conflicting ways. In the 1990s Wendy Larner identified three distinct approaches to neoliberalism: a policy program, a form of governmentality and as an ideology (Larner, 1998). She argued that in the 1990s the most common understanding of neoliberalism 
was of a policy program of state withdrawal, which was a response to the free-market reforms that had occurred in the previous two decades (Larner, 1998). The concept was also equated with economic fundamentalism, as a "shorthand term to refer to the political preference for market mechanisms as a means of ensuring economic and social wellbeing", which coincided with neoliberalism becoming characterised as a-social (Larner, 2005, p. 10). More recently, Flew has identified six different theories of neoliberalism, ranging from a statement about the way things are, to an all-purpose denunciation, an ideology or a form of governmentality (Flew, 2014). Boas and GansMorse in their study of academic texts on neoliberalism identified cases where it was used to denote: a set of economic reform policies (the most common definition), a model for development, a normative ideology, an academic paradigm, and an epoch. Furthermore they noted that of the articles they studied, only 31\% defined how the author was using the concept (Boas \& Gans-Morse, 2009, p. 143). Neoliberalism, much like social capital is a heterogeneous concept. However, unlike social capital it is almost exclusively used to denounce the policies and political positions it refers to.

Another feature that neoliberalism shares with social capital is breadth. Many studies have tended to characterise all post-1980s politics as neoliberal, dividing it into phases correlating with changes in government (Phelan, 2014). Consequently for many critics, the growing rhetoric of community and social (inclusion, capital, exclusion, cohesion) during the 1990s and 2000s either hid or served to protect an otherwise unchanged neoliberal policy programme. For instance, Fairclough saw the Third Way as a form of neoliberalism involving the conservative 'strengthening' of families and communities. It contained a shift away from poverty reduction toward the belief that, if individuals could be included in the labour market, market forces would themselves reduce poverty (Fairclough, 2000). Underpinning this was a belief that economic growth and social development were complementary rather than conflicting (Fairclough, 2000, pp. 48 - 49). Levitas saw New Labour's Third Way as a 'roll in' phase of neoliberalism that offered a “'soft' synthesis of market forces and a reliance on 'community' to mop up the damage done by market forces and replace, mediate or legitimate the policing functions of the state" (Levitas, 2004, p. 43).

Such characterisations of the Third Way as neoliberalism '2.0' been common in New Zealand. Humpage, for instance, has divided neoliberalism into three phases (Humpage, 2015). The roll-back phase from 1984 - 1999 was a 'destructive moment' of neoliberalism 
designed to dismantle Keynesian institutions and the welfare state. In this phase neoliberalism was antagonistic toward the social, seeing individuals as atomistic. The first phase's aggression and internal contradictions inflamed public opinion, and so it was succeeded by a 'roll-out' phase from 1999 - 2008. The roll-out phase was aimed to soften public opposition to neoliberalism, and addressed some of the social problems that emerged during the roll-back phase. This involved " $[\mathrm{g}]$ iving the public a little of what they wanted while at the same time consolidating and embedding most of the broader neoliberal economic agenda" (Humpage, 2015, p. 69). For Humpage, the New Zealand Labour Party's interest in social policy from 1999 - 2008 was primarily driven by concerns over economic progress, and also by political advances by the smaller, left-wing Alliance Party, rather than a genuine interest in social policy or justice. Labour's interest in inclusion was underpinned by a belief that paid employment was key to both social and economic wellbeing. The third phase of neoliberalism, the "roll-over" phase was the result of the economic failures of neoliberalism, particularly with the banking crisis of 2008 . The failures of neoliberalism became evident in 2008 but also allowed it to further entrench itself and deepen reforms by arguing that the failures were the result of the reforms only being partially implemented (Humpage, 2015 ch. 3).

Although Craig and Cotterell (2007) and Craig and Porter (2004) stated that inclusive liberalism' (post-1999 neoliberal policy) was not simply a 'roll out' of neoliberalism but rather involved a changing rationality of liberalism, they downplayed differences between the phases as largely rhetorical, resulting in a similar periodization of neoliberalism. As I noted above, they characterised inclusive liberalism as a project to hold together neoliberalism, particularly involving the 're-embedding' of market governments in a shallow construction of the social (Craig \& Cotterell, 2007). They further argued that this re-embedding placed:

“[...] soft institutional modes of partnership, networks and participation $[\ldots]$ alongside hard institutional reforms inspired by New Public Management and New Institutional Economics, to create a new mode of neoliberalism characterised by capital market norms, institutional complexity and a sinister 'inclusive' supply-side economic and social management." (Craig \& Cotterell, 2007, p. 500).

They, much like Humpage prioritised the neoliberal elements of policy, placing them at the core of political analyses. Other elements of policy - such as social policy or the emergence of partnerships - were constructed as peripheral and changing, and studying them is relevant primarily in order to understand neoliberalism. For Larner and Craig: 
"[...] understanding the specificities of partnership may help inform more adequate conceptualisations of neoliberalism, conceptions which are attentive to the contingency, political complexity and the different versions of neoliberalism found in different places" (Larner \& Craig, 2005, p. 404).

Humpage constructed post-1984 New Zealand politics in a similar way. Whilst she acknowledged the existence of other discourses such as neo-paternalism or neocommunitarianism, she subsumed these into variations of neoliberalism, as opposed to alternative rationalities that existed at the same time (Humpage, 2015, p. 26). Consequently other political positions and concerns are treated as at best peripheral to a coherent core of economic reforms, or at worst an ideological defence of them. These authors all begin from a position that the policy or politics are neoliberal, and then explore the specific instances of neoliberalism in a particular context.

The tendency to characterise all post-1980s politics as neoliberal has recently been challenged both in New Zealand and internationally. For instance, Duncan accepted post1996 policy in New Zealand as 'neoliberalism 2.0' but questioned the characterisation of the post-2008 National government as neoliberal, instead characterising it as right wing (Duncan, 2014). Nicholls has also challenged the expansive application of neoliberalism in New Zealand. She identified the end of the 'heyday' of neoliberalism in 1996, arguing that the $5^{\text {th }}$ Labour government $(1999-2008)$ in particular attempted to move away from neoliberalism. For Nicholls, post-2008 policy reflects a return to reactive preKeynesianism recession policy, as opposed to active market reform programs favouring financial capital that she saw as defining neoliberalism (Nicholls, 2011).

More general critiques of neoliberalism have also emerged. Flew has argued that the concept has become little more than a slogan with little attention given to how it should be used or defined - a 'catch all' denunciatory category for critics (Flew, 2014, p. 51). Recently, Phelan has provided an in-depth discussion of the concept of neoliberalism which discussed similar issues to Flew. For Phelan, the problems of operationalising neoliberalism were most evident:

“[...] when its expanse becomes so broad, its implications and effects so monolithic and totalizing, that the fact of its different articulations is occluded; or sidelined as 'merely' a matter of rhetoric" (Phelan, 2007, p. 328).

These problems were not with the concept per se but "rather as with all categories, the problem lies with how it is articulated and operationalised" (Phelan, 2014, p. 30). 
Furthermore, he has also noted that neoliberalism is rarely (if ever) used in a positive way. An issue that has been exacerbated because there are few (if any) people who would selfidentify as neoliberals, resulting in the term's use being exclusively by critics (Boas \& Gans-Morse, 2009; Phelan, 2007). Similar arguments have been made in relation to the public health literature. Bell and Green have recently suggested that the concept required greater clarity, nuance and specificity if it was to remain insightful for critical public health researchers (Bell \& Green, 2016, p. 241).

Despite these problems, Phelan has argued that the concept of neoliberalism continues to provide insight in to a myriad of social changes from a variety of perspectives (Phelan, 2014). Flew, whilst more critical of the concept, similarly stated that he found accounts of neoliberalism that treat it as a pragmatic political philosophy (a governmentality) as persuasive (Flew, 2014, p. 64), and Bell and Green suggest it could remain useful if viewed as a "partial and incomplete process" in order to raise various questions around public health, as opposed to an explanatory concept (Bell \& Green, 2016, p. 242). I accept that neoliberalism has its uses and will not go so far as to advocate its abandonment. However, given the over-saturation of the term, and its varied meanings, I prefer to avoid employing neoliberalism as an analytic or descriptive concept.

Given the breadth and malleability of neoliberalism as a concept, social capital can of course be labelled as neoliberal. However, I am sceptical of the insights gained from such a claim, given the breadth of both concepts and the opposition to it being labelled as neoliberal by those who use the term social capital (Szreter \& Woolcock, 2004 provide the one instance where proponents identify social capital with neoliberalism). To quote James Ferguson, whilst I may agree that what is referred to as neoliberal should be opposed:

"[...] we have to look more carefully at the "arts of government" that have so radically reconfigured the world in the last few decades, and I think we have to come up with something more interesting to say about them than just that we're against them" (Ferguson, 2009, p. 169).

Rather than claiming that social capital is neoliberal, I am interested in understanding how and why it has been used in different spaces from the perspective of those using it. At times it has been used to justify de-regulatory and free-market policies to support economic growth, but at other times it has been identified as something important that has been destroyed by these same policies. Whilst many current political positions 
demonstrate a continuing liberal rationality, I will avoid treating other political positions and foci as peripheral to economic liberalism. Social policy concerns were consistently constructed by these politicians and policy makers as being of equal importance to economic policy. The social and economic were constructed as distinct domains existing in a reciprocal relationship with the end goal of building human 'wellbeing'. Social capital fitted in to the social domain as a way of discussing (and measuring) the ways that social life improved wellbeing. As chapters 6, 7 and 8 will demonstrate, there are also a multitude of different influences on political decision making ranging from the pragmatic (such as Maharey), to a concern over, and belief in community politics and governance (as with Bolger and Laban).

Instead of neoliberalism, in this thesis I will use 'liberalism' as a descriptive short-hand of the broad philosophy underpinning the political discourses of New Zealand. There are two reasons for this. Firstly, liberalism is can refer to a multitude of (often incompatible) political positions and is acknowledged as lacking a unified policy program, nor necessarily possessing a market-fundamentalist position. Whilst liberalism includes individualistic rights-based liberalism, in which:

"[...] the individual is the only category that need not, often in fact, cannot, be debated. The individual is simply there, whereas everything else - for instance, what criteria for justification are to be applied when determining the collective good, needs to be argued about" (Wagner, 2001b, p. 43).

There are many different forms of liberalism, including communitarian liberalism. Consequently using liberalism allows for an analysis of the influence of a communitarian corrective critique on New Zealand and international policy as well as social capital's role in this critique. In addition to this variation, actors often self-identify as liberals, and liberalism is less negative and denunciative than neoliberalism. Thus, liberalism can be used as a descriptive category for a particular group of political rationalities with a focus on individuals, and a distrust of strong states as opposed to the ill-defined anti-liberal slogan of 'neoliberalism' 


\section{Conclusion}

In this chapter I have discussed the insights and limitations of various critiques of social capital, and have also briefly discussed the reason why I will avoid using the concept of neoliberalism in my discussion of social capital. I have noted that whilst they have highlighted many significant elements of social capital, such as its measurement and the variability of definitions of it, critics have over-focused on the economic or 'neoliberal' connections with the concept. Whilst these features are important elements of many uses of social capital, as my analysis will show they are neither the only feature, nor ever-present when the concept is used. In the next chapter I will outline how I will use French pragmatism to explore the concept as opposed to a critical sociology perspective. 


\section{Chapter 3: Sensibilities of French Pragmatism}

Instead of 'uncovering' the economic and neoliberal undercurrents of social capital, and social capitalists' duplicity or ignorance of economic expansion as some other critics have, I approach social capital from the perspective of French pragmatic sociology, which includes (post-)actor-network theory and the work of Luc Boltanski. In this chapter I will discuss the sensibilities of post-ANT, and the elements of Boltanski's 'pragmatic sociology of critique' that together provide the framework for my analysis. In the first section of this chapter I will briefly outline the pragmatic approach to research. Then I will make and argument for my use of pragmatism to analyse textual data before discussing the concepts of 'translation' and 'immutable mobiles' which have been employed in the study of actor-networks. Moving on to Boltanski I will discuss how he has treated critiques, and make a case for why I consider communitarianism to include several corrective critiques of liberal economic policy. At the end of the chapter I will outline the data used, and specific methods employed in my study of social capital.

\section{Post-Actor-Network Theory and Boltanski: Two Branches of French Pragmatic Sociology}

French pragmatism (or neo-pragmatism (Bogusz, 2014)) emerged in the 1980s as a relatively coherent, empirically orientated approach to sociology in response to critical sociology, particularly that of Pierre Bourdieu (Bénatouil, 1999). It includes both actornetwork theory and its successors, and Boltanski's sociology of critique (Blok, 2013; Guggenheim \& Potthast, 2011). For authors in the pragmatic school, critical sociology is flawed because it develops generalised theories, and then applies them to a range of local contexts (Boltanski, 2011 ch. 2; Latour, 2004; 2005, pp. 28 - 29). In contrast, pragmatic sociology aims to attend to the local specificity and uncertainty of social interactions (Basaure, 2011, p. 362; Boltanski, 2011 ch. 2). It emphasises the need to recognise and incorporate the active and critical capacities of actors in everyday life into analyses, instead of imposing the external rationality of the sociologist (Bénatouil, 1999, p. 382; Boltanski, 2011, pp. 43 - 46; Gad \& Jensen, 2010). Furthermore, instead of applying a priori categories as explanations, pragmatic sociologists are concerned with exploring the work actors (human and non-human) perform in the production of realities. This involves the abandonment of a single reality, instead actors are seen to enact multiple and possibly 
contradictory realities, which they move between, in order to function in everyday life (Boltanski, 2011, p. 118; Law, 2005; Law \& Mol, 2002; Mol, 1999, 2002).

Guggenheim and Potthast drew on pragmatism's interest in symmetrical research to claim that the work of Latour and Boltanski are 'symmetrical twins', due to their approaches and the ways in which they have responded to one another (Guggenheim \& Potthast, 2011). Actor-network theory, with its focus on actors and a rejection of a priori categories, is undeniably a pragmatic approach to sociology. In On Critique Boltanski labelled his approach to sociology as the 'pragmatic sociology of critique' (Boltanski, 2011) and has regularly drawn on Latour throughout his oeuvre. However, his commitment to pragmatism has been questioned, with his work alternatively described as a combination between pragmatism and critical sociology.

Actor-network theorists and Boltanski both reject the treatment of actors as unaware or uncritical subjects, of social structures or ideologies. In addition Boltanski and Latour positioned their work in opposition to the deterministic nature of Bourdieuian sociology (Boltanski, 2011; Guggenheim \& Potthast, 2011; Latour, 2004). The recognition of what Boltanski referred to as the 'critical capacity of actors' further leads French pragmatic sociologists to reject the epistemic break between sociologists and lay actors. Rather than seeing the sociologist as 'uncovering' the Truth of social reality that is hidden to other actors by applying a priori sociological categories, they demand that sociologists should 'follow the actors', and account for their own explanations and understandings. As Latour put it, actor-network theory "always was [...] a very crude method to learn from the actors without imposing on them an a priori definition of their world-building capacities" (Latour, 1999, p. 20).

Some actor-network theorists have advocated abandoning a priori categories entirely. This was because the use of theoretically defined and fixed topologies of social categories results in predictable findings; research using a Foucaultian genealogical method would find systems of governmentality, Neo-Marxists find world systems and so on (Latour, 2005; Law, 2005, pp. 5 - 6). Such approaches artificially limit the categories that the researcher uses to interpret their data instead of letting actors explain their own worlds (Latour, 2005, p. 23). However, the success of actor-network theorists, including Latour, in abandoning them is dubious. Concepts such as 'translation', 'immutable mobiles' or even 'actor-networks' have all been taken from previous works and applied as explanations in new sites. Indeed Latour, without changing his position on a priori 
categories has begun to move toward a more delineated and directed approach to conducting research within actor-network theory (Best \& Walters, 2013; Latour, 2005). By the end of the 1990s it had become apparent that, despite intentions to the contrary, actor-network theory had become an alternative, fixed method that was universalising and involved the remapping of data to fit an a priori description (Gad \& Jensen, 2010; Law, 1999; Neyland, 2006; Whittle \& Spicer, 2008). Several researchers reconceptualised actornetwork theory as a 'post-ANT' sensibility' as opposed to a methodology. From a postANT perspective research should not follow a prescribed, fixed approach but rather consisted of "a set of empirical interferences in the world" primarily concerned with maintaining the complexity and heterogeneity of actors and attending to the reality that actors themselves create (Law \& Singleton, 2013, p. 489). This change in understanding was designed to return researchers to a situation where attempting to uncover or create some hidden central principle or methodology to the approach should be considered as misguided (Brown \& Capdevila, 1999, p. 1999).

The complete rejection of a priori categories, if possible, also raises issues beyond the representation of actors, with the role of the researcher becoming questionable. For Latour using social explanations in research, whilst not necessarily 'wrong', is cheating: consequently instead of deciding on the theoretical grouping and applying it to the data, ANT should focus on describing work done by actors (Latour, 2005, pp. 28 - 29). However, Law has opposed this, arguing that without some degree of prescription research risks being an apologist method that is aligned to the powerful (Law, 2009). In particular he noted that avoiding prescription resulted in a distinction between knowledge and production of power that was untenable. A purely descriptive position also fails to recognise that the production of knowledge by researchers is itself a performance that is unavoidably prescriptive (Law, 2009, p. 8). Latour's position risks actor-network theory and its successors falling into a naïve empiricism, assuming that its 'descriptions' are neutral or accurate representations of actor's worlds, with researchers simply refusing to recognise the inevitable prescriptive and explanatory elements of their research.

Boltanski's position on a priori categories is more complicated than Latour's. Whilst Boltanski positioned himself within the pragmatic tradition, his work is perhaps more of a conflation of critical and pragmatic sociology. A combination that has, at times produced tension in his work (Bogusz, 2014; Browne, 2014, p. 22; Quéré \& Terzi, 2014). Boltanski has argued that a combination of pragmatic and critical sociology is 
advantageous because, whilst pragmatism highlights uncertainty, it stumbles when it overestimates actors' abilities to manage this uncertainty in particular interactions, without 'registrars of reality' to draw upon (Bogusz, 2014; Boltanski, 2011, pp. 53 - 54). ${ }^{11}$ The notion of social institutions (social structures which reduce uncertainty by defining and stabilising realities through both discourse and action) was designed to correct this (Boltanski, 2011). Actors draw on multiple 'orders of worth' which, much like discourses stabilise realties through the appeal to a way of arranging and comprehending the objects and situations that actors encounter (Boltanski \& Thévenot, 1999a, p. 14). However, for Quéré and Terzi this highlights the non-pragmatic basis of Boltanski's work, as instead of interactions themselves being the site of meaning and reality production, they are reduced to sites of the testing of pre-existing meanings and interpretations (Quéré \& Terzi, 2014). Thus, Quéré and Terzi argued that Boltanski’s focus on semiotics as well as his adoption of both 'orders of worth' (Boltanski \& Thévenot, 1999a) and 'institutions' (Boltanski, 2011) as categories of action means that his work is not pragmatic. Instead they argued that Boltanski adopts a few features of pragmatism (such as uncertainty and the abandonment of the sociologist as an omniscient observer) but otherwise provides a mainstream 'critical' sociological approach (Quéré \& Terzi, 2014).

Regardless of the advantages in not over-stating actor's abilities to define their worlds, a combination of pragmatic and critical approaches has created a recurring tension within Boltanski's work. Boltanski has emphasised the importance of both keeping analysis as close to the interpretations of those being analysed, and to emphasise the importance of uncertainty in social relations and actions. From this perspective, critique (his core focus) is defined by actors instead of sociologists. However, at times he has provided external evaluations of whether something can be considered critique or not. For instance, in The New Spirit of Capitalism, Boltanski and Chiapello acknowledged that exclusion is often identified as a critique by those who use it, but largely dismiss this claim arguing that critique must address exploitation, thus exclusion cannot be considered critical (Boltanski \& Chiapello, 1999 [2005], pp. 354 - 355). By doing so they dismiss the actors' interpretation of their world in favour of a normative understanding of critique.

I do not have either the capability or space to provide a solution to the issues that arise with pragmatism's treatment of a priori categories in this thesis. I share with Boltanski a doubt over both the possibility and also desirability of purely pragmatic research, a doubt

11 Which Boltanski has claimed to be pragmatism's quasi-normative position 
that can be expanded to Latour's advocacy of a descriptive sociology. In the various datadriven chapters of this thesis I have adopted various a priori, or at least author given descriptors and analytical categories (such as the ancestors, precursors and founders in the next chapter, or my treatment of communitarianism as critique) and have applied them to my data.

The recognition that I will use a few a priori categories does not preclude my research being empirically, as opposed to conceptually driven. For both Boltanski and post-ANT researchers, research methods should be situated in, and directed by the topic being researched, instead of transplanting assumptions and methods from one situation to another. As Gad and Jensen phrased it:

"ANT has to work with the assumption that the analyst is likely to be wrong about his or her assumptions when encountering ontological work in practice. For good reasons, then it cannot equip the researcher with a failsafe method for doing ANT. Indeed, it just might be a mistake to follow the actor in some cases" (Gad \& Jensen, 2010, p. 73).

Recognising the problems with my own assumptions was a turning point in this research. I had expected to add my voice to the chorus of critics who constructed social capital as part of neoliberalism, particularly given the concept's use by Treasury. However, upon engaging with the data, I became unhappy with the generalisations and dismissals of Fine in particular, and began trying to comprehend social capital on the terms of those who used it. I also began exploring the complexity and polysemous nature of the concept as a foundation for my analysis. Consequently the categories of translation, (im)mutable mobiles and corrective critiques that I will outline in this chapter should be applied with caution and when they appear to align with the actors' interpretations of events. Contrary to Latour, I acknowledge that these are explanations. However, I make no claim to them being either the only possible explanation, or superior to the actors own accounts.

\section{Textual and Discourse Analysis in Pragmatic Sociology}

The use of texts, as opposed to the ethnographic studies of actions in situ is controversial in French pragmatism. My research is not ethnographic, but instead is a textual analysis. Consequently my work attends to semiotics but largely neglects materiality. Given that actor-network theory is often described as 'material semiotics', and is a sensibility to materiality, relationality and uncertainty (Law \& Singleton, 2013, p. 491), the suitability of the exploration of texts from a pragmatic position is an issue that needs discussion. 
Boltanski's empirical studies have all used textual data, ranging from philosophical, economic and sociological texts (Boltanski \& Thévenot, 1999a), management texts (Boltanski \& Chiapello, 1999 [2005]), or detective novels. This has led to claims that he is not a pragmatist, because he does not focus on ethnographic studies of the construction of meaning and interactions in situ (Bogusz, 2014; Quéré \& Terzi, 2014).

The opposition to using texts as primary sources of data has been evident in ANT, with many actor-network researchers arguing that ethnographies should be the primary subjects of analysis (Nimmo, 2011, p. 113). Latour has cautioned against overburdening texts with explanatory power because they are only the end product of knowledge production and individuals cannot be forced to read a text (Latour, 1986). Texts are also seen as simplifications that exclude and 'flatten' the complex and heterogeneous realities that they claim to represent. Law, for instance, argued that:

"[...] the coherences of textuality make powerful realities but they also lose something: the non-coherent, the non-textual. Realties enacted in other ways. And if we simply stick with the textual then we stop ourselves from 'reading', from knowing, from appreciating, those realities" (Law in Nimmo, 2011, p. 113)

One charge from Law was that texts are themselves simplified and exclude other realities, and the other was that they exclude materiality; one of the central sensibilities in postANT is that research should be symmetrical, with analyses of both material and semiotic factors (as well as both humans and non-humans) as part of research.

Despite this, there has been a stream of exclusively textual and discourse analyses that have adopted an ANT or post-ANT sensibility (Bowers \& Iwi, 1993; Latour, 1988; Law, 2002; Nimmo, 2008, 2010, 2011; Rip, 1986). These studies avoid providing singular, generalised explanations for the content of texts and also attend to the (partial) role that texts play in the enactment of realities. They also all demonstrated that a single term, or concept can be used in multiple, conflicting ways often by a single user or within a single text. Nimmo has argued that texts can be understood as complex and non-coherent forms of data (Nimmo, 2011). Latour also noted in The Pasteurisation of France that:

" $[t]$ hough there is no proper or figurative meaning, it is possible to appropriate a word, reduce its meanings and alliances, and link it firmly into the service of another" (Latour, 1988, p. 182). 
Even if texts themselves involve simplification, it would be an over-simplification to treat them as coherent and 'smooth' representations. Instead texts, and the signs they consist of, are themselves actors that may be internally contradictory and authors daw on multiple realities in producing them. Viewed from an actor-network perspective, or a pragmatic perspective more generally, text production remains open to analysis. They are heterogeneous and complex and are constructed from assemblages of other actors, instead of pre-existing 'given' ways of constructing the world. I will briefly discuss some of the ways that discourse and texts have been analysed from an ANT sensibility.

John Law analysed the construction of design documents in his study of the design of fighter aircraft (Law, 2002). He argued that design documents draw together heterogeneous resources and describe a complex reality but present such heterogeneity and complexity in a homogenised, simplified way that is again, in-part, determined by the purpose of the text. He demonstrated that certain facets of the design process, such as pilots, the intended enemy and conflicts between parties are excluded from design documents whilst at the same time being implicit in them (Law, 2002, pp. 126 - 127). Law also noted that the pilot's reactions during flight, the nausea, vomiting and nervousness are also absent from the design document. He argued that this is because they do not 'fit' the formality of design documents, a particular clean way of presenting the world with particular rules of what can and cannot be said. Law's work focused on the heterogeneous, variable and varying nature of design documents. Despite the attempt to present a formal and homogenous world, the contents of a design document can vary and single terms can be used in different ways. For example, gust response, 'G' appeared in many different ways within a single document - sometimes as a fixed requirement of the aircraft's design, at other times as a simplification of the formula for the relationship between aircraft weight, wind-design, velocity and so on (Law, 2002).

Whilst Law did not discuss discourses, his observation of the underlying restrictions aligned to how authors such as Foucault have approached discourses. Foucault's treatment of the term varied in his work with it (Foucault, 1972, p. 80), but for Foucault 'discourse' referred to existent statements that can in some way be individualised and can order objects in a particular way without establishing a fixed, canonical use of language (Foucault, 1972). Discourse must be treated only "as and when it occurs" as opposed to basing it on an assumed shared origin or given disciplinary label, it would also vary over time and between texts (Foucault, 1972, pp. 25 - 26). Thus, for Foucault, discourses 
should not be applied as a priori external explanations for the structure or shape of texts, but instead something that only becomes apparent in the texts themselves.

Bowers and Iwi applied some of the insights of ANT to the discursive construction of society through semi-structured interviews of English University students (Bowers \& Iwi, 1993). They argued that, as people draw on the concept of society in different ways, and to achieve different things, they are themselves enacting a local performance of society (Bowers \& Iwi, 1993, p. 387). The authors did not apply a pre-determined model of what the meaning, or possible constructions of society used by their interviewees were. They also attended to the heterogeneity and complexity of the discursive constructions of society in their interviews, without attempting to apply a priori sociological categories to explain them. Instead they argued that there were numerous, heterogeneous and often conflicting constructions of society given by their interviewees, and furthermore that within the space of one short interview, multiple interpretations of society could be performed by a single individual (Bowers \& Iwi, 1993, p. 368). Society could be something that the speaker positioned in opposition to their own perspectives, and could be an agent acting against, or having opinions on, a particular group within the same interview. The society that individuals constructed therefore depended on the purpose behind the evocation of society. Bowers and Iwi conclude that 'society' as a concept and a term is a flexible and valuable resource with no limit to the number of possible discursive constructions of it (Bowers \& Iwi, 1993, pp. 390 - 391).

Materiality is absent from Bower and Iwi's analysis. However their work demonstrated the advantages of treating concepts as complex and heterogeneous objects, and the insights gained in exploring how the concept is assembled in each instance. These advantages and insights can similarly be applied to social capital. The term shares 14 characters (including the space), and some attention to 'the social' but beyond this its meaning is determined from the context in which it is used, and the associations made between it and other concepts. Every instance of social capital will be surrounded an assemblage of words and meanings that affect the construction of the concept. More pertinently, the definition and meaning of social capital changes between different texts and literatures depending on the phenomena it is being used to address. To reiterate a point that I made earlier, this 'definitional chaos' is not a reason to dismiss the concept, rather it is something to be explored and be accounted for in research. It is also a reason 
why I see the critiques of the concept on the basis of its origins that I will discuss in the next chapter as limited.

\section{Translation, (Im)mutable Mobiles and Critiques}

So far in this chapter I have outlined and justified my use of French pragmatic sociology. Having done so, I will now outline some of the descriptive tools that I will use in exploring the social capital literature, before exploring my characterisation of communitarianism as a critique. In particular I will focus on three concepts, translation and (im)mutable mobiles from actor-network theory, and Boltanski's way of classifying critiques.

The 'sociology of translation' is one of many alternative names for actor-network theory (Best \& Walters, 2013; Brown \& Capdevila, 1999; Callon, 1986). For actor network theorists, translation is ubiquitous; every actor is in some way translated, thus the process is central to ANT and post-ANT research. Callon defined translation as a material and semiotic process that changed and stabilised actors and resulted in the creation of a new actor. There are different types of translation that are used by actor-network theorists. In Callon's study the scallops, fishermen, researcher and various actors were translated into scientific texts, and these texts claimed to represent them. Actors may also be materially translated, moved from one location to another (Callon, 1986). A semiotic object may also be translated through the 'enrolment' of textual and non-textual actors. This allows them to be employed as authoritative allies into a new text, which is particularly relevant for this thesis. A concept such as social capital, is translated between texts creating new (and different) versions of the concept, as well as simplifying earlier uses (by summarising theories or other empirical studies). This latter semiotic process is what I will refer to as translation throughout this thesis.

Callon identified 4 'moments' in the process of the translation in the work done by scientists researching scallops in St Brieuc Bay. Firstly, the researchers had to establish themselves as an obligatory passage point for other relationships in the network. Through their definitions of other actors, and the questions that they set out to answer, the three researchers were able to establish themselves as necessary to the survival and advancement of other actors. Their research was positioned as a requirement for the survival of scallops, advancement of scientific understanding, and the preservation of economic fishing interests. The second moment of translation involved the interessement (the imposition of a stable identity of other actors as well as the relationship between 
actors) of actors according to the researchers' reality. At the same time this interessement disrupted potentially competing associations and alternative ways of stabilising actors. Thirdly, the interessed actors were enrolled as allies to support the translating actors. For Callon's three researchers this involved experiments to get scallop larvae to anchor in St. Brieuc Bay: if the scallops can be made to anchor then they have allied themselves with the researchers' work and they have answered the questions the researchers asked. Finally, the gathered allies were mobilised by the researchers who as specialists or experts were then able to speak in the name of the scallops and fishermen to their colleagues at seminars or conferences. Through these 4 moments, the various actors have been translated into a stable (scientific) representation of the reality of scallops at St. Brieuc's bay (Callon, 1986). ${ }^{12}$ Translation does not mean that the actors are moved to a new context, rather it creates a new actor that claims to speak for a multitude of other actors that is neither a reduction of, nor reducible to, the reality it claims to represent and vice versa (Latour, 1988, pp. 169 - 170). In claiming to speak for a multitude of other actors, the new actor 'betrays' them particularly by representing them in a simplified way.

Scientific texts are (im)mutable mobiles, strong actors that are able to 'interess' more allies (such as other scientific texts, authoritative bodies, and the actors it claims to represent) to the point that it may become an obligatory passage point in the discussion of the actors it claims to represent, resulting in it replacing their voices. ${ }^{13}$ Immutable mobiles such as statistics, graphs or texts are further strengthened because they can be easily reproduced without substantial change and so are able to act over long distances (and for a longer time). For example, statistics such as life expectancy are not simply the reduction of population variables into simplified numbers, but rather a new actor that is both an immutable mobile, and an obligatory passage point in discussing that population feature. This new object speaks for the population that it claims to represent even though it 'betrays' it by simplifying it and portraying it in a particular way.

Stöcklová has argued that the idea of immutable mobiles has become so central, actornetwork theorists often use the concept implicitly, and do not attempt to explore the concept (Stöcklová, 2012). In ANT, immutable mobiles are objects that can be translated and moved over great distances whilst retaining their physical shape as well as their

12 However the alliances formed are only stable for a certain location, and at a particular time. Actors may dissent, the relationships change and established realities formed through translation will not be reconstructed elsewhere.

${ }^{13}$ Latour (1986) emphasised that this is part of a continuous test of strength, the new actants created are not inherently more powerful, and nor do they stay that way. The actants being represented by it - such as the scallops Callon discusses may betray the research done on them. 
relational and functional purpose, thus retaining the information they contain (Law \& Singleton, 2005). They are the 'paper tools' central to the construction and coordination of realities. They can take the form of texts (scientific or otherwise), graphs, tables, statistics, images, maps, money and so on. These are easily reproducible, and when reproduced, largely retain their content (Latour, 1986; 2005 ch. 12). Due to this durability and replicability, immutable mobiles are also able to act for long periods of time (should they survive) (Latour, 1987, pp. 227 - 228). Immutable mobiles are also able to represent massive amounts of data and enlist and speak for numerous allies all within a small, easily transferable amount of space (such as a computer document, graph or table). For Latour, they also play a role in connecting the local ('micro') to the macro. Situations involving immutable mobiles cannot be considered to be local because the immutable mobiles connect the situation to other localities, often over large spaces and times.

Immutability is, however, relative as opposed to absolute, and based primarily on the use of chains of references to other ideas. The immutability of concepts should not be taken for granted, because transportation and reproduction inevitably involves transformation. This led Stöcklová to question the lack of exploration of immutable mobiles by actornetwork theorists. She argued that, whilst actor-network theorists recognise that immutability is not absolute, in practice immutable mobiles are treated as too immutable by actor-network theorists. Furthermore, she argued that in many cases there is a degree of trade-off between immutability and mobility that is often ignored. Either an object remains immutable, in which case it is unlikely to be mobile, or it becomes mobile but also heterogeneous and mutable (Stöcklová, 2012, p. 290). Along similar lines, Law and Singleton also noted that attention to immutable mobiles has given too much immutability to objects. They suggested that if objects consist of fluid network relations, then objects are likely to be more mutable than was suggested in early ANT research. The idea of objects being mutable does not preclude them from also being stable (Law \& Singleton, 2005, p. 338). Rather, as with Stöcklová they will appear either immutable or mutable, depending on the approach taken and what is attended to. Following de Laet and Mol, they suggested that objects should instead be understood as mutable mobiles, which they defined as "a set of relations that gradually shifts and adapts itself rather than one that holds itself rigid" (Law \& Singleton, 2005, p. 339).

In addition to translation and (im)mutable mobiles, I will draw some insights from Boltanski's sociology of critique in my discussion of social capital in the political literature. 
Whilst ANT and post-ANT research has focused on scientific and technological knowledge production and controversy, Boltanski and various co-authors (Boltanski, 2011; Boltanski \& Chiapello, 1999 [2005]; Boltanski \& Thévenot, 1999a, 1999b) have explored different features of critique in order to understand the moral and institutional justifications drawn upon by human actors when critiquing and justifying actions. Boltanski has provided various theoretical tools to analyse critique (including both orders of worth and institutions), however I will focus on the descriptive classifications of critique that I will employ in my analysis of social capital.

Boltanski and Chiapello (Boltanski \& Chiapello, 1999 [2005]) and Boltanski (Boltanski, 2011, pp. 103 - 109) defined critique in relation to 'tests' of strength and legitimacy which were similar to Latour's trials of strength (Boltanski \& Thévenot, 1999a, p. 360; Latour, 1988, pp. 138 - 139). Tests of 'strength' pit two actors against one another and "reveal what they are capable of and, more profoundly, what they are made of' (Boltanski \& Chiapello, 1999 [2005], p. 31). ${ }^{14}$ Boltanski and his co-authors distinguish tests of legitimacy or moral worth from tests of strength; tests of strength may require acceptance that the test contributes to a particular 'order of worth"15, a particular understanding of the 'common good'. However, actors that do not accept that the test is promoting some form of common good, will consider it illegitimate (Boltanski \& Chiapello, 1999 [2005], p. 31; Guggenheim \& Potthast, 2011). ${ }^{16}$ The texts that I discuss include various tests of policy, including tests of what policy should be legitimate, which I will discuss in chapters 6, 7 and 8, as well as tests of academic legitimacy based on what models of definitions of social capital are legitimate in particular fields (particularly noticeable with critiques of communitarianism within the network approach that I will discuss in chapters 4 and 5).

\footnotetext{
14 Whereas for Latour trials of strength determine the reality of actors (which may be human or non-human). If an actor is resistant it is real.

15 This is one (substantial) area of Boltanski's work that I will not be directly applying to social capital. Boltanski and Thévenot noted that orders of worth share a common model in that they all appeal to some form of common good. In On Justification they list a series of orders of worth (economic, inspired, domestic, polity, civic and industrial) which they see as descriptive as opposed to explanatory categories. The social capital literature I explore could be fitted into one or more of these orders of worth. The civic order of worth, which is based on Rousseau's social contract and holds the notion that individuals possessing multiple wills which includes a desire to act in the interest of all, as opposed to their personal selfish interest could be applied to much of the literature (Boltanski \& Thévenot, 1999a, pp. 107 - 118 and 185 - 193). The 'industrial' order of worth, with the appeal to social structures could also be applied to some uses of social capital, as could the economic order of worth with its appeal to market value (Boltanski \& Thévenot, 1999a ch.2 and pp. 118 - 123). However, to apply these descriptive categories would generalise the social capital literature, and risk obscuring some of the variability of the concept. Instead I will draw primarily on Boltanski's various discussion of critiques in my analysis of social capital.

${ }_{16}$ More recently Boltanski gave another typology of three types of tests (truth, reality and existential), each with a different relationship with critique (the former two are generally employed against critique, with the last used by it) (Boltanski, 2011)
} 
For Boltanski and Chiapello, radical critiques are those which reject the legitimacy of tests and so see the tests themselves as unjust and failing to contribute to any acceptable order of worth. Consequently, such critiques seek to overthrow these tests and replace them with more just and legitimate ones. Many of the critiques that I have discussed above are radical critiques; they view the tests of actors within neoliberalism to be unjust and, from a position of exteriority, they argued for the need to replace neoliberalism (or capitalism) with a more fair set of tests. In contrast, corrective critiques accept the overall legitimacy of the tests they critique and wish to maintain most features of a 'test'. However, they also contain a desire to reform or expand the characteristics of the test (Boltanski \& Chiapello, 1999 [2005], p. 31). They may do so either by expanding the test to encompass other features or by modifying features to make the test fairer. Both of these types of corrective critiques can be seen at different times in the social capital literature. As I will discuss throughout this thesis, social capital is most often used to justify an, expansive critique. This critique is evident both in the histories of the concept, and in many political uses after the communitarian critique was incorporated into policy. The modification of features of policy tests has been less prevalent, but recurrent throughout the social capital literature. Where present it is articulated through the argument that social capital is damaged by the inequality caused by economic growth, and thus policy concerns should be changed to account for this.

This division between radical and corrective critiques is only one of the ways in which Boltanski has divided critique. Boltanski and Chiapello for instance distinguished between artistic and social critiques of capitalism (Boltanski \& Chiapello, 1999 [2005]). Boltanski has also distinguished between metacritique and critique. Metacritique refers to a particular form of critique that offers a universalised critique based on a particular theory (a 'metapragmatic register') that claims to unmask domination in a general way (Boltanski, 2011, p. 7). Boltanski further differentiates between critical (and metacritiques) and expertise driven sociology, based on their internality or externality to the framework of governance. Critics identify themselves as being external to the framework of governance, whereas experts identify themselves as internal to them. The sociology of expertise is aimed at either sketching out new social policy, or justifying existing social policy to those on the ground, without challenging the overall framework of governance.

Whilst starting from a position of exteriority, successful critiques are incorporated into the expertise of governance and become expertise in a new form of test (Boltanski \& 
Chiapello, 1999 [2005], p. 41). Boltanski and Chiapello argued that both the critique and the 'spirit of capitalism' are modified by this incorporation. They also argued that the incorporation of critique results in a substantive change in the way business operates, as opposed to merely a surface change to ideology or superstructure. They demonstrated an incorporation of critique in The New Spirit of Capitalism, which explored how post-war French management studies and government policy attempted to incorporate socialist and social democratic critiques. Such attempts lasted until the 1980s, when these critiques were largely abandoned. Instead the artistic critiques of the 1960s and 1970s, which were liberal, anti-state and pro-flexibility, were incorporated into a new mode, 'spirit', of capitalism (Boltanski \& Chiapello, 1999 [2005], p. 201).

The artistic critique was incorporated into a new spirit of capitalism in the late 1980s and 1990s. This form of capitalism was built on a model of a networked form of capitalism, or a 'connexionist city'. Consequently, as with the artistic critique of the 1960s and 1970s, it was opposed to hierarchical relationships, and instead aimed to manage work through the inclusion of individuals within networks. Individuals who were able to form substantial networks for personal gain, and could remain mobile, replaced both the entrepreneur and the cadre managers as the valorised 'great men' of capitalism. Boltanski and Chiapello's treatment of these 'great men' both overlapped with, and is partially based on, their analysis of Burt's use of social capital: 'great men' are those with substantial social capital (Boltanski \& Chiapello, 1999 [2005], p. 357). However, they argued that Burt did not acknowledge the need for mobile greats to 'deposit' an immobile actor, such as wage labourers, or in the case of mobile, multinational companies, a smaller local industry in a network to maintain their links. This immobile individual is exploited by the mobile great, they themselves are necessary for the accumulation of capital, but they cannot access it, since they are only connected to the mobile great (Boltanski \& Chiapello, 1999 [2005], pp. 357 - 364). I will discuss Burt's use of social capital further in chapter 5.

As a consequence of the connexionist nature of this new spirit of capitalism, exclusion partially replaced exploitation as the category of social negativity, with individuals needing to become connected to improve their situation. However, unlike exploitation, no group or individual was to blame for the exclusion of others; instead, exclusion resulted from a lack of mobility. Thus, for Boltanski, in the exclusion literature no one is at fault for causing exclusion (Boltanski \& Chiapello, 1999 [2005] cf. chapter 5 but particularly pp. 354 - 355). This lack of blame or connection to exploitation, coupled with the approach's 
methodological individualisation, made Boltanski and Chiapello hesitant to label it as a critical concept. Boltanski and Chiapello's treatment of exclusion highlights the tension that I commented on above. Instead of defining exclusion as a critique (or not) depending on how the actors themselves position it (either explicitly, or implicitly), they rejected the actors' analysis in favour of their own, externally imposed definition, of exclusion as uncritical.

I do not see social capital as a critique in itself, however. Instead, I argue that insight can be gained by describing many instances of social capital as elements of communitarian corrective critiques of liberal policy. As I noted above, this critique can have both expansionary and reformist tendencies. Throughout the rest of this chapter I will sketch an outline of communitarianism, and justify my treatment of it as a corrective critique.

\section{Communitarianism as a Corrective Critique}

I will frame my analysis of social capital in relation to the emergence of political and scholarly communitarianism in the late 1980s and 1990s. In contrast to Boltanski and Chiapello's treatment of exclusion, I treat communitarianism as a corrective critique of liberalism, because many authors who used social capital, including Putnam, positioned themselves alongside communitarians in providing a correction to liberalism or individualism.

During the 1980s and 1990s several communitarian philosophers and scholars critiqued the atomistic nature of Rawl's neo-Kantian liberalism and its elevation of individual rights and freedoms above the needs or interests of social groups (Bell, $1993 \mathrm{ch}$. 1; Honneth, 1991). Etzioni opposed the conceptualisation of individuals as rational, atomistic actors that characterises many strands of liberalism, instead, contending that "individuals do play a role, but within the context of their collectivities" (Etzioni, 1988, p. 181). Similarly Charles Taylor believed that there was an unrecognised need to recognise a moral and social element to individuals' behaviour (Bickerton, Brooks, \& Gagnon, 2006). He saw solidarity as an essential human good that could not be explained simply in reference to individuals' desire to belong (Smith \& Laitinen, 2009). Sage has recently offered a particularly forceful advocacy of the communitarian critique of liberalism, stating that:

"[a]s much as the communitarian thesis is a statement about the desirability of certain social goods, it is also a forceful critique about the perceived hegemony of the liberal 
worldview. At its simplest, the liberal worldview holds that society consists, or should strive to consist, of an association of free individuals, detached from imposed duties and obligations and free to form their own aspirations and interpretations of the good life" (Sage, 2012, p. 267).

As I have hinted at with Putnam, this critique of individualism was also applied to policy. Politically, communitarians were concerned with what they perceived to be the breakdown of social relations and communities in the western world as a result of liberal policies. Etzioni for instance, argued that communitarianism was a challenge to the laissez faire politics of Reagan and Thatcher, and was intended to promote a middle ground between individual and state (Etzioni, 1988, 2014). Taylor was (and remains) active on the left-wing of Canadian politics and has repeatedly opposed the individualising nature of liberal policy (Bickerton et al., 2006).

Foucaultians have argued that communitarianism emerged out of critiques of 'society' and a monolithic welfare state. During the $19^{\text {th }}$ and $20^{\text {th }}$ centuries, the construction of society as a totalised and monolithic representation of a population within a territory emerged as a domain outside the state, but still governed by it (Barry, Osborne, \& Rose, 1996, p. 8). Society was semi-autonomous and self-regulating, but required measured intervention from state organisations. However, during the 1980s and early 1990s, the monolithic and homogenous conception of the social that had been used throughout the $20^{\text {th }}$ century underwent a series of crises in both politics and the social sciences (Miller \& Rose, 2008, p. 87). This is often characterised as the result of neoliberal reforms in this period, particularly since the 'social' is often understood to have been antithetical to neoliberal policy. The position that neoliberalism was asocial is supported by arguments such as Hayek's that the social was "the weasel-word par excellence. Nobody knows what it actually means" or Thatcher's phrase "there is no such thing as society" that came to symbolise her market reforms (in Davies, 2015, p. 1). ${ }^{17}$ Opposition to the social was

\footnotetext{
17 As an aside, Hayek's argument against society was built on what Spies-Butcher described as his anti-modernism and more precisely on his subjectivist opposition to the importing of scientific methods into the social sciences. He decried this importing as 'scientism': "an attitude which is decidedly unscientific in the true sense of the word, since it involves a mechanical and uncritical application of habits of thought to fields different from those which they have been formed" (Hayek, 1942, p. 269). Science, Hayek argued had developed to the point where objective rules devoid of 'qualities' based on perceptions could be used to explain the world. The social sciences could not be so objective as all facts were subjective (rather objectivity was defined by shared belief and action (Hayek, 1942, p. 281)). Thus, Hayek argued that the social sciences must start from what 'men' [sic.] think and mean to do as the basis for fact construction in the social sciences (and that the revision and improvement of these thoughts should be purpose of social scientific work) (Hayek, 1942, pp. 283 - 286). Thus concepts which deal with 'collectivities' (society, economic system, capitalism, imperialism) were not facts but 'pseudo-entities' (Hayek, 1942). On the surface this is (uncomfortably!) close to some actor-network theory positions. However, as Boltanski and Thévenot noted both Hayek and other economists failed to recognise that their preferred terms of analyses (individuals, rationality etc.) fall victim to the same problems of appealing to a 'higher common principle' (Boltanski \& Thévenot, 1999a, p. 30).
} 
particularly strong within rational choice theory, where individuals were constructed as the only acceptable social actors (Spies-Butcher, 2005; Wagner, 2001a, p. 48). Dean has identified a strand of communitarianism within the politics of Margaret Thatcher and questioned whether it was the ontological state of society that was at stake for neoliberals or rather its conceptualisation in, and relationship to, national governance (Dean, 2010, p. 179). As I will discuss in chapter 6, the New Zealand Prime Minister Jim Bolger also adhered to a liberal communitarian philosophy alongside his economic liberalism, several Labour ministers also emphasised the importance of community-based social policy in response to diverse, active and involved subjects of governance.

The Third Way governments of the late 1990s and 2000s are most commonly associated with the political incorporation and application of communitarian principles. However, the Third Way is, much like social capital, an ill-defined and multiplicitous concept. McLennan characterised it as a temporary, ill-defined and shifting series of political ideas, as opposed to a definitive political proposition (McLennan, 2004, p. 484). White and Giaimo offered a critical, but somewhat sympathetic analysis of New Labour's Third Way. They accepted that it was part of a broader turn toward making social democracy more liberal and market friendly, but still suggested that this involved a capitulation to freemarket ideas (White \& Giaimo, 2001, p. 213). Levitas also acknowledged White's argument that there were significant divisions in the Third Way, particularly between egalitarians and meritocrats, and liberals and communitarians. She noted that the Third Way incorporated a mixture of political positions including new social democracy, communitarianism, social liberalism, and 'left-Thatcherism'. It could mean a middle ground between two alternatives of capitalism and socialism, a creation of a new alternative 'beyond left and right', or a rebirth of social democracy (Levitas, 2004). Overall though, Levitas characterised New Labour's Third Way as a:

“[...] 'soft' synthesis of market forces and a reliance on 'community' to mop up the damage done by market forces and replace, mediate or legitimate the policing functions of the state" (Levitas, 2004, p. 43).

Amin has further argued that the ethic of communitarianism advanced by both the Third Way, and the New Right of the 1980s and 1990s shared a "conformist civic particularlism $[\ldots]$ that expects collective action from communities in particular places and for highly instrumental ends" (Amin, 2005, p. 615). 
Despite its variability, the appeal to community was a common element running throughout the Third Way. Giddens argued that community building would aid in the construction and renewal of direct democracy in Western societies (Giddens, 1998). ${ }^{18}$ The New Zealand Fifth Labour government also regularly referred to community, even though there was never a shared vision as to what community meant. Gilling noted that in part this was because both the left and the right wings of the Party adopted the concept in support of their own political positions (Gilling, 2002, pp. 29 - 30). This community focus involved advancing policies to address (often ill-defined) notions of 'social inclusion', 'social development', and, of course, social capital.

The communitarian critiques of liberalism and economic policy that social capital has been embedded in, have often been predicated on the reconceptualization of the goals of policy along broadly utilitarian lines. The 'test' of whether a policy is just, and therefore legitimate, is whether it increases overall human wellbeing. This test was present in both political speeches and policy documents that I analysed (including the international development literature). It also pre-dated the use of social capital, for instance, the New Zealand Treasury in 1987 in Government Management ${ }^{19}$ stated a belief that wellbeing and not economic growth was the end-goal of policy. Instead of being the goal of policy, economic growth (through free-market reforms) was, the mechanism by which increases in wellbeing could be achieved (The Treasury, 1987). In Boltanski's terms, the use of wellbeing, or similar terms such as living standards, thus establishes the policy as just because it provides a common good.

There are two main corrective critiques of liberal and economic policy evident in the communitarian literature that used social capital. Firstly, some authors argued that liberal policy, with its focus on economic growth and conceptualisation of individuals as autonomous and free, had neglected the social or community influences on wellbeing. This is the expansionist critique that I referred to earlier. From such a perspective, current policy directions (particularly economic policy) do not require reform, but other considerations need to be added to them. This critique was readily incorporated into

\footnotetext{
${ }^{18} \mathrm{He}$ also discussed social capital in his work on the Third Way. For him social capital was desirable as an alternative mechanism for economic development (see Giddens, 2000 Chapter 2 for a detailed discusssion): "Community building emphasises support networks, self-help and the cultivation of social capital as means to generate economic renewal in low-income neighbourhoods. Fighting poverty requires an injection of economic resources, but applied to support local initiatives" (Giddens, 1998, p. 110).

19 Which was designed to advise the fourth Labour government on how to expand and deepen their free-market reforms. It was in many ways the height of Treasury's advocacy of the reforms, and I will return to it in chapter 7.
} 
policy and political documents, most notably during the Third Way which, as McLennan has noted, repeatedly asserted the mutually beneficial relationship between economic and social policy (McLennan, 2004, p. 486).

Other authors have argued that social capital was damaged by liberal and economicgrowth orientated policies, and used this association to support a reformist critique of policy. For these authors, liberal policies encourage individualism and competition, thus decreasing a sense of social togetherness and worth. Furthermore economic growth has increased inequalities which has damaged social capital and so has resulted in a decline (or at least non-increase) in human wellbeing. From this perspective, policy requires reforming in order to better account for the common good in order to be just. This critique was less evident in policy, and was near-absent from political speeches. However, it was a recurrent theme in activist and Māori ${ }^{20}$ presenters' uses of social capital in the Institute of Policy Studies seminars (see chapter 6), and has become a core part of 'wellbeing economics' (see chapter 9).

Throughout this thesis I will argue that many uses of social capital facilitated the incorporation of these critiques into governance. This is because social capital holds a promise for politicians and policy makers to make intelligible the complex and heterogeneous social of communitarianism. The concept is used to refer to a series of desirable resources that require building, which justifies the policy interest in communities and social relations. More than that it promises (although fails) to make these resources calculable and quantifiable, ideally within a single aggregate measure of social capital, which allows social features to be simplified and measured by government and nongovernment organisations.

\section{Quantification, Knowledge and the Practice of Governance}

Many authors, particularly those in government organisations have attempted to construct social capital as a simple, reified and quantifiable object and have offered measures of it. Given this tendency, I will supplement the work of French pragmatism with works exploring the relationship between knowledge and governance, and also the (perceived) necessity of simplification, as well as the advantages that quantification brings to governance. In this section, I will discuss how simplification and quantification have been

${ }^{20}$ The indigenous population of New Zealand. 
discussed in the sociology of science and also the role others have identified for them in governance.

Scott has argued that simplification is a necessary feature of modernist governance (Scott, 1998). This is because:

"[c]ertain forms of knowledge and control require a narrowing of vision. The great advantage of such tunnel vision is that it brings into sharp focus certain limited aspects of an otherwise far more complex and unwieldy reality. This very simplification, in turn, makes the phenomenon at the centre of the field of vision more legible and hence more susceptible to careful measurement and calculation" (Scott, 1998, p. 11).

Scott saw this as a universal feature of administration, because it is impossible to represent any social system without massive abstractions to simplify the world. Techniques of simplification adopted by the state include mapping, the development of statistics and, in the case of high-modernist planners, the organisation of cities into neat standardised blocks and zones. Such abstractions were necessary because local social lives are constantly fluctuating and social competence is often based on tacit knowledge that is difficult for outsiders to comprehend without transforming them into static, schematic models and structures. Thus, by simplifying, states make a constantly fluctuating and local social life that is difficult for outsiders to comprehend into a static, schematic model that allows outsiders (such as state officials) to easily administer a range of localities. However, this abstraction, and simplification, excludes most of the important features of the social life that it is supposed to represent, particularly the practical and particular knowledge of local situations (Scott adopts the Greek term metis to describe this knowledge ${ }^{21}$ ) in favour of universalised assessment criteria (Scott, 1998 ch. 9). This exclusion results in disastrous situations for both administrators themselves, who see their projects fail as a result of 'unforeseen circumstances' and for the social life in the localities being administered, whose mētis is damaged by plans and programmes.

\footnotetext{
${ }^{21}$ Scott's use of metis is close to some uses of social capital, and he does use the latter term occasionally in Seeing Like a State. This is likely due to the influence of the geographer Jane Jacobs, who Scott cites favourably as providing a powerful critique of modernist city planning (Scott, 1998, pp. 132 - 146). As I will discuss in chapter 4, Jacobs is often cited as a precursor to the social capital literature. Sadly her role is peripheral in this literature. Scott's discussion of Jacobs raises two points in the social capital literature: firstly, that in many ways the social capital literature could be seen as an attempt to account for 'mētis' in governance. Secondly how this concern if it is present, is lost in much of the literature as social capital becomes a quantified measure of social resources. I will return to this in the discussion.
} 
Scott primarily focused on the construction of maps and urban plans as representations of the world created from simplification. However, quantification of social features through the collection of statistics is another prominent form of simplification, and is of more relevance to social capital. As with simplification, the process of quantification is driven by the imperative to govern and comprehend large populations (Hacking, 1990; Porter, 1995, p. 44). The connection between statistics and governance is neither driven by ill-intent, nor should it be viewed as necessarily a negative development (Hacking, 1991, pp. 183 - 184; Porter, 1995). However, it does impact on the understanding and perception of populations and (more importantly) the perceptions of the problems that need addressing through the development of policies.

Statistics do not represent a pre-existing population in a more-or-less accurate way. Rather, as Hacking noted, the categories used to fit and enumerate people change regularly as a consequence of social and rhetorical changes. This relationship is reciprocal as, through the construction of these categories, statistics such as censuses create "new ways for people to be" (Hacking, 1986, p. 223). Statistics give authority and (the appearance of) mechanical objectivity to those who employ them, and they allow the construction of social facts that allows the state to construct the population in a way that facilitates governance. Hacking summarised the importance of statistics for both social scientists and the state:

\footnotetext{
"Statistics has helped determine the form of laws about society and the character of social facts. It has engendered concepts and classifications within the human sciences. Moreover the collection of statistics has created, at the least, a great bureaucratic machinery. It may think of itself as providing only information, but it is itself part of the technology of power in a modern state" (Hacking, 1991, p. 181).
}

Drawing on Foucault, Hacking saw the emergence of statistics to be entwined with emerging forms of governance. Although Hacking identified the desire for statistical analyses as early as the $16^{\text {th }}$ century (Hacking, $1990 \mathrm{ch}$. 3) he labelled 1820 as the year in which an 'avalanche' of statistics emerged. Throughout the rest of the $19^{\text {th }}$ century, statistics would develop into both a tool of governance and at the time, a way of demonstrating that human actions were governed by laws of nature. The latter of which it ironically killed because, contrary to predictions that human behaviour was governed by deterministic laws, statistical analysis found that "deviation from the mean' became the 'norm"' in understanding human populations (Hacking, 1991, p. 190). This shift was 
related to a broader shift in the perception of statistical probably, which went from being perceived as evidence of ignorance of deterministic laws, to being a law in itself (Hacking, 1990).

Porter added that the growth in statistics was driven by political pressures for decision making to appear rigorous, trustworthy and articulated, as opposed to apparently arbitrary and discrete decisions made by experts (Porter, 1995, p. 199). The importance of trust can also be expanded to the quantification in scholarly works. Porter argued that quantification is more common in 'weaker' and newer disciplines because it promotes confidence, both between authors within the emerging discipline, and from external authorities, granting the discipline greater cohesion and political influence (Porter, 1995, p. 225). A decision driven by statistical analyses is harder to challenge than those made through other 'arbitrary' means, and similarly statistical knowledge is 'harder' and more expensive to challenge. Finally, making statistics 'official' makes them even harder and 'real' (Porter, 1995, p. 42). Thus, for Porter, quantification was driven by the need for trustworthiness in produced knowledge, and the decisions made from it.

Speich coupled these arguments with an ANT sensibility (also applied to textual analyses) to argue that the Gross Domestic Product (GDP) has played a key role in the creation of development programmes. Speich argued that, rather than statistics such as the GDP being driven by particular development ideologies or discourses, $20^{\text {th }}$ century models of development had "based their assumptions on data gained through the procedures of national accounting" (Speich, 2008, p. 10). The GDP was developed in the 1930s, as a byproduct of Simon Kuznets' concern with income distribution and the relative importance of different economic sectors, and Kuznets did not intend it to be used as a comparative statistic (Speich, 2011, pp. 12 - 13). However, despite Kuznets' objections, it allowed development agencies to compare income, producing both a new view of the world as a place of enormous poverty, and the belief that issues of poverty could be solved through social engineering (Speich, 2011, p. 10). Because of this simple and powerful image of the world, after the Second World War the GDP became the basis for both national and global economic policy. Despite there being known problems with the GDP, as Arthur Smithies stated, there was an acceptance that:

"These figures [GDP and its derivatives] have been produced and people use them. They will continue to be produced, and people will continue to use them. If we start afresh, I would have a great deal of sympathy with what has been said about not using a single 
figure, and not even producing one. But the way the thing stands now is that in every government problem $[\ldots]$ national income figures are used ... And every international organisation that has been formed has used national-income statistics in one way or another" (Smithies in Speich, 2011, p. 18).

The abstractions of the GDP and similar national accounts produced a new reality of national level 'hard facts', which opened up the possibility of measured economic development (Speich, 2011, p. 24). The GDP, with a single, simple quantitative indicator, and assumptions in the ability of using it to compare different nation-states' wealth has made it a powerful object.

The strength of the GDP continues to be an issue for many national accountants because it does not 'see' enough to be a valid measure of human wellbeing. As I will discuss in more depth in chapter 8 , alternative measures have been developed, but these have had little impact on policy since they "do not yet fully cover human and environmental concerns, or distil them into an index as powerful as the GDP” (Frecker, 2005). Thus, in new frameworks such as the World Happiness Reports (which I will be discussing in chapter 8) the accurate measurement of happiness in the population level has been advanced as the first step in the development of policy aimed at improving happiness, as opposed to economic development (the second step is finding explanations for happiness on the individual, community and "whole populations" levels) (Helliwell, Layard, \& Sachs, 2012, p. 94). Furthermore, for measures such as these to be useful, they need to be simple and as with the GDP standardisable across nation-states.

The notion of making the subjects of governance calculable is central to governmentality studies. Miller, Kurunmäki and O'Leary argue that calculation is an ever present, if often obscured element of governance that constructs new objects through the linkages of other actors and agents (Miller, Kurunmäki, \& O'Leary, 2010). As Dean has noted, influences on government action go beyond the recognised theories, ideologies or philosophies of governance, and include immutable mobiles such as statistics, charts and handbooks that facilitate and direct governors (Dean, 2008, p. 83). Miller and Rose drew on actor network theory to note that one of the conditions for the emergence of a particular vocabulary requires "the possibility of implementing of a number of mechanisms of inscription, recording and calculation" - in other words, (im)mutable mobiles (Miller \& Rose, 2008, p. 36). 
Statistics and population facts are powerful objects, as (im)mutable mobiles they are able to speak for the populations that they represent. Single numbers, such as the GDP are particularly powerful as they are able to speak for a large area of reality as well as having the authority of being 'official'. As well as constructing populations, they allow governing bodies the ability to act on those constructions, at the exclusion of those elements deemed unimportant, or which are unmeasured. The importance of measurement has been noted in relation to the social capital literature, but only in passing. That social capital fits into contemporary governmentality was well argued by Coole (2009), but her focus was on the governance of a complex, diverse and mobile population as opposed to the process by which this construction of reality was shifted into measures of 'the social'.

\section{Summary}

In this chapter, I have briefly outlined the conceptual framework for this thesis, and have also discussed some of the critiques of the concept. I have built on my argument against the overly-reductive treatment of social capital in texts which have characterised it as part of neoliberalism (and dismissed it as such). Instead I suggested that I will incorporate the concept's heterogeneous nature into my analysis by drawing on the concept of translation and (im)mutable mobiles from actor-network theory in order to attend to how social capital has been constructed in different instances. I have, however, suggested that social capital has commonly been part of a communitarian corrective critique of liberal policy that has been incorporated into governance, and that social capital's appeal in policy can be understood as a way of making the social concerns of this critique calculable and therefore manageable. In the last section of this chapter I will briefly outline the data that I analysed in exploring the concept of social capital.

\section{Methods and Data}

I commented above that both actor-network theorists and Boltanski have opposed prestructured approaches to research. In analysing social capital I similarly applied a fluid approach that varied according to the data I was analysing. However, given my primary interests were in both the appeal and heterogeneity of social capital there were certain features that I attended to more than others. Each of the following chapters explores a particular case study of social capital for different reasons. Thus, the types of texts used varied between chapters. In all of the chapters, the texts chosen were given an initial reading to immerse myself in the literature. A more detailed reading of the texts then 
followed during which I coded the data and attended to particular themes that became apparent in the first reading.

Unlike the other data chapters Chapter 4, which discusses histories of social capital, did not have a clearly defined dataset. Rather, after the tendency for texts to provide histories of social capital became apparent to me, further texts which provided histories of social capital were added to the analysis during a broader reading of the literature. Each of the texts discussed were primarily about social capital, they either aimed to develop it theoretically, or attempted to apply it to particular areas of research (as opposed to peripherally referring to it). The analysis primarily attended to academic histories, but also included histories in policy documents. The coding for this chapter was basic. After an initial reading, cited authors within history sections (generally at the beginning of the text) were divided into three groups: ancestors, precursors, or founders. Ancestors were generally famous authors who were not identified as having used the term social capital and were not incorporated into the wider text. Rather they were enrolled into the literature by claims that their work attended to the same object. Precursors were authors who were identified as having used the term social capital, but had work done to distinguish them from the contemporary literature, either by stating the difference in their use of the term, or their lack of development of it. Finally founders were those authors who were constructed as having a great impact on the current discourse, and work was often done to exalt their contribution. I will cover this in more detail in chapter 4.

The data for chapter 5 consisted of journal articles from both public health and management studies. The articles were collected using Thomson-Reuter's Web of Science whole database (as opposed to the core collection). The top 10 cited articles per decade were chosen for analysis in each topic (10 from the 1990s, 10 from 2000s, and 10 from 2010s). The 60 articles explored are listed in Appendix 1. This selection was designed to ensure that contemporary publications ${ }^{22}$ were included in the analysis. Due to the time of data analysis (2014 - 2015) and the emergence of social capital in the mid-1990s, this resulted in a slight bias against articles published from $2000-2010{ }^{23}$

I coded the articles based on the type of article (empirical, theoretical, literature review, methodological), and in what 'level' social capital was constructed as existing in (national,

\footnotetext{
22 Which have less time to build up citation numbers.

${ }^{23}$ DeFillippi and Arthur was unavailable through the university, and was replaced by Kumar, van Dissel and Bielli (Kumar, van Dissel, \& Bielli, 1998), the eleventh most cited article.
} 
community, network, individual). I also recorded the definition of social capital (if given), and whether the authors constructed social capital in a way that was aligned to rationalchoice theory, that is if individuals were constructed as acting in self-interested, rational and predictable ways. I also recorded some elements of the methodology used. Finally I recorded the key findings of the article noting how these related to other articles in the dataset. The focus of the analysis was exploring the commonalities and differences between articles, and the two disciplines as opposed to judging their validity.

Whilst I had a degree of familiarity with public health, I had no prior engagement with the management studies literature. This added a few difficulties to my analysis, as decoding what was significant about the social capital literature, as opposed to the discipline as a whole was, at times difficult. For example, I initially attended to the tendency for management studies' texts to establish a series of hypotheses which would then be proven, or disproven by their statistical analysis. This proved however to be a common practice across management studies, and so the attention I gave to it was reeled in and limited to what the findings were taken to indicate about social capital.

The data for Chapters 6 and 7 are a combination of ministerial speeches and press releases, working papers and policy documents from New Zealand ministries and national accounting frameworks. New Zealand was selected because of an ease of access to both the ministerial data, and participants involved. I also had greater pre-existing knowledge and understanding of New Zealand politics and political history, further aiding the analysis. This was supplemented with other relevant texts such as the Institute of Policy Studies publications on social capital, and semi-structured interviews with three exministers: Jim Bolger, Steve Maharey and Winnie Laban. These ministers were chosen because they had extensively used the concept in ministerial speeches. Two others, Michael Cullen and Tariana Turia were unable to be reached for interviewing. Each interview was short, approximately half an hour long and focused on why the ministers had used social capital, and how they understood the concept. The participant consent form and question framework are included in appendix 2. Finally the autobiography of Jim Bolger published in 1998 dedicated an entire chapter to social capital and this has been used to supplement the discussion of his use of social capital. Initially I had intended on interviewing civil servants who had used social capital, but due to difficulties in both contacting the civil servants I wished, and in agreeing on the structure the interview would take, this was abandoned. Due to the limited responses the interviews were relegated to 
supplementary data, they helped to ensure that my analysis of political speeches was aligned to how the politicians themselves intended to use social capital.

The speeches and press releases studied were all given by government ministers, and were collected using a keyword search for "social capital" on the New Zealand Government's online archives (New Zealand Government, http:/www.beehive.govt.nz/) and are listed in full in Appendix 3. The dataset consisted of 105 texts: 91 speeches, 11 press releases and 3 'features' in which social capital was used. These documents covered six parliamentary terms; the last term of the $4^{\text {th }}$ National government $(1996-1999)$, the three terms of the $5^{\text {th }}$ Labour government $(1999-2008)$, and the first two terms of the $5^{\text {th }}$ National government (2008 - 2014). Social capital has been used in speeches by ministers from 5 political parties, including both of the major parties in New Zealand (Labour and National). Of the 105 speeches and press releases, 27 were from the $4^{\text {th }}$ National government, 69 were from the $5^{\text {th }}$ Labour government, and 9 were from the $5^{\text {th }}$ National government. Ministerial speeches from the Labour Party formed over half of the texts that used social capital: 66 texts were from Labour Party ministers, 32 texts were from National Party ministers (nearly all given by Jim Bolger), 5 speeches were from Tariana Turia when she was co-leader of the Māori Party, and three were from Jim Anderton, leader of The Alliance until 2002, and then the Progressive Party from 2002 - 2008. In addition to the 5 texts she gave as co-leader of the Māori Party, Turia gave two speeches that used social capital when she was a Labour Party minister. Compared with the associated concept of community, the proportion of speeches that have used social capital has been low (see figure 2). Only in 1997 (when Bolger first introduced the term) was social capital present in over $1 \%$ of the total number of speeches given by ministers.

The speeches were coded according to the topic of the speech, the definition of social capital given (if any) and, more commonly the inputs and outcomes, associated with social capital (initially phrased 'associated concepts'). Where available the audience and purpose of the speech was also recorded, as were any 'stock phrases' that the minister (or their speech writers) had previously used that related to social capital. Finally other features of interest, such as unusual or explicit statements or sentence constructions were also recorded.

Policy data for chapters 6 and 7 were collected from the policy and working papers published online at the Ministry of Social Development (MSD), The Treasury and 
Statistics New Zealand (StatsNZ). The Treasury documents were selected both because of their use of social capital in national accounting frameworks, which aided the analysis in chapter 8 , and because of the central role Treasury has played in New Zealand policy. The Ministry of Social Development was selected because Maharey's headed the department from 1999 until 2004, and the department regularly used the concept from 1999 until 2008. Finally StatsNZ was involved in aiding the measurement of social capital for other departments. Other national and local government departments have used social capital in various publications and on topics as diverse as community resilience, crime and health. As with political speeches the interest in social capital in policy fields in New Zealand originated in the late 1990s. Between 1997 and 2001 the Institute of Policy Studies published a series of collections edited by David Robinson on social capital in New Zealand in conjunction with various government organisations (Robinson, 1997b, 2002b). These were based on workshops and conferences on the topic during the same time and the papers covered a variety of topics.

A key word search was used to identify instances of social capital, social cohesion and social exclusion (due to the overlap of these concepts) in policy documents available on ministries' websites and documents which used social capital were then analysed. In total 40 MSD texts and 21 Treasury texts used social capital. 18 of the Treasury documents were working papers and three were Treasury papers (The Treasury, 2001c, 2011; Whitehead \& Annesley, 2005). ${ }^{24}$ The number of instances of social capital in each text (according to the word-search) was recorded, as was the paper's metadata (topic, type of paper, publication year etc.). For papers with five or fewer instances of social capital, only the sections with social capital in them were read closely to explore how the concept was used and defined. Texts with a more sustained use of social capital were read closely in order to understand how social capital fitted within the wider framework, as well as how it was treated on its own. This included recording the definition of social capital, how it was measured, what inputs and outcomes were associated with it.

Treasury's work on social capital primarily consisted of two Treasury paper frameworks: the Towards an Inclusive Economy framework in 2001 - 2002, and the Working Towards Higher Living Standards for All New Zealanders from 2011 onward. I will discuss all of the Treasury

\footnotetext{
${ }^{24}$ Treasury papers are authored by Treasury to represent their official position, whereas working papers whilst published by Treasury, and generally aligned with the Treasury papers (often as supplements), were not officially Treasury's position.
} 
documents except the Working Towards Higher Living Standards for All New Zealanders framework in chapter 7 . Whilst, there was a degree of continuity between the two frameworks (which Treasury itself acknowledges), Working Towards Higher Living Standards for All New Zealanders aligned better to the more crystallised national accounting frameworks of the late 2000s and 2010s. Because of this, these frameworks were discussed in chapter 8. I will also discuss the StatsNZ Framework for the Measurement of Social Capital in New Zealand (Spellerberg, 1997, 2001) and their Framework for Measuring Sustainable Development (Statistics New Zealand, 2008) in chapter 8.

The data for chapter 8 consisted of five national accounting frameworks, selected through purposive sampling. Each of the five frameworks were selected because they represented recent work on social capital within development frameworks and provided a slightly different use of social capital from different governing bodies. The frameworks that provided the focus of analysis were: The UNECE/OECD/Eurostat Joint working group's Measuring Sustainable Development framework (UNECE/OECD/Eurostat Working Group, 2008, 2013); the United Nation's World Happiness Report (Helliwell et al., 2012; Helliwell, Layard, \& Sachs, 2013, 2015); Treasury's THLS framework and the associated 'tool' (The Treasury, 2011); and the earlier OECD's Wellbeing of Nations (OECD, 2001) and later Four Interpretations of Social Capital: An Agenda for Measurement (Scrivens \& Smith, 2013). The OECD's earlier Wellbeing of Nations was also selected due to its impact on subsequent frameworks. The primary concern of chapter 8 is in understanding how social capital fitted into wider frameworks, thus the relationships between social capital and other 'capitals' (particularly economic capital) was given greater attention. This exploration of the relationships between the concepts was facilitated by the pictorial representations of the model in most of the frameworks (the World Happiness Reports was notably lacking one) which have been reproduced in the chapter itself.

\section{Conclusion}

This chapter has discussed the theoretical and methodological approach of my thesis. In it I have outlined the tools and concepts that I will use, situated them within post-ANT and Boltanski's work on critique, and have addressed some of the issues or challenges to my approach. I have also outlined and justified the choice of data used in the five data chapters. In the next chapter I will begin my discussion of social capital, by exploring the histories constructed by proponents and critics of the concept. 


\section{Chapter 4: Conflicting Histories of Social Capital}

In this chapter I will explore the histories of social capital that have been constructed by scholars. The massive and incoherent body of literature on social capital is a young one, having only emerged in the late 1980s. Despite its youth, there are several different historical narratives of the concept's forebears and the context of its emergence. This chapter will further explore the different ways that critics and proponents of social capital have constructed the concept through its history. My discussion of critics in particular overlaps with, and builds on my discussion in chapter 2. I also draw some concepts from Nikolas Rose to describe the different ways that authors have been enrolled in histories of social capital.

I have labelled the two groups of histories that I explored as 'proponent' and 'critical' histories. This division echoes Spies-Butcher's division between heterodox critics (which I term critics) and orthodox critics (which I label proponents). The two groups of histories have enacted disparate realities and consequently they assemble different explanations for the emergence of social capital's emergence. Proponent histories focus on constructing conceptual origins of the concept and do so in a way that universalises social capital's subject matter. For these authors social capital is the latest in a long line of communitarians, sociologists and classical theorists who had a shared concern in understanding the importance of social relations. Whilst socio-political context is mentioned in proponent histories, it is less prominent than the conceptual origins. In contrast, for critical perspectives the contemporary interest in social capital is the result of an expansion of economic interests (particularly neoclassical economics), fuelled by a need to bolster a neoliberal economic programme.

My discussion highlights the gap between critical and proponent constructions of social capital. This gap, coupled with overly focusing on the aforementioned economic history of social capital has limited many critical analyses. Critics have focused on the concept's economic origins, and the 'neoliberal' political context. Consequently they have downplayed the variation of the concept and largely excluded, if not dismissed, other noneconomic features that proponents perceive to be central to its appeal. Furthermore, some critics, most notably Fine, have been entirely dismissive of proponent histories, arguing that it is a fabrication to hide the concept's true origins, and dismisses it in favour of his own, critical history. 
These two groups do not cover all historical narratives of social capital; for instance, authors working from a 'network approach' of social capital trace its conceptual origins to social exchange theory and other network approaches, particularly that of Granovetter. Academic disciplines such as public health have also situated social capital's emergence within a context that is particular to the field. I will discuss the public health and management histories in the next chapter, as in this chapter I focus on texts that claim to provide histories of social capital as a whole.

\section{The Construction of Histories}

Historians do not describe events, but rather construct narratives which give history its explanatory power, and also help to justify the beliefs and positions of the historian (White, 1973 ch. 1). They select different themes and events before characterising and assembling these elements in particular ways to produce explanations, what Dean has termed the "active marshalling of historical resources" (Dean, 1994, p. 15). White saw critical histories as particularly problematic, not because of their choices of themes, but because they over emphasised particular features (such as class or gender) at the expense of others (Herman, 2011). Similar observations about the marshalling of resources have been made within actor-network theory. Scientists interess allies in order to legitimise and add weight to their claims. Authors who are able to interess the largest number of faithful allies are the strongest, and most likely to win academic controversies and establish their reality as factual (Latour, 1986, p. 5). These allies include other 'facts', statistics and accounts of events. Thus histories, whilst still constructed narratives are not solely socially constructed, but are rather produced from a combination of social and material features.

Nikolas Rose has argued that the function of historical narratives of scholarly disciplines is to establish a unity of the science by establishing a continuity of thinkers (both scientific and non-scientific) who have sought to understand particular objects of study and legitimacy by universalising the object of study (Rose, 1996). Rose drew on Canguilhem to argue that:

" $[\mathrm{t}]$ hese narratives establish the unity of the science by constructing a continuous tradition of thinkers who sought to grasp the phenomena that form its subject matter. Inescapably, from such a perspective, the object of a science [...] appears both ahistorical and asocial. It pre-exists the attempts to study it, it has always existed in some form, and all these thinkers of the past have circled around a reality that has remained the same" (Rose, 1996, p. 42). 
Thus according to disciplinary histories, the subject matter of the discipline is constant: only the approaches to the subject matter change, as they develop and become more scientific. For instance, within psychology the development of experimental methods, and modern psychological theory, separates current history from the pre-scientific 'past'. Rose also noted that, by constructing the subject matter as universal, historians decontextualize the subject matter and portray it in light of current interests and understandings. In other words, instead of positioning texts in relation to contemporary culture and discourses, they are repositioned in relation to current understandings within the science (Rose, 1996, p. 43).

In analysing the historical narrative of psychology, Rose borrowed a phrase from Ebbinghaus that it (and related disciplines) lay claim to a "long past but short history" (Rose, 1988, pp. 180 - 181). The long past consists of famous works, 'ancestors', that explored (according to the historians) the same object of study but from pre-scientific philosophical perspectives. These texts are understood as unscientific and many of them do not discuss the 'psyche' and are thus marginalised within the discipline. In contrast, works in the short history are seen to have employed the experimental method and thus are recognisably scientific in structure, findings, and are fully incorporated into the discipline. Farr also added 'founders' to these two descriptive categories. Founders are researchers who first developed and coded the discipline in a scientific way. However, in psychology at least, the works of the founders are often sources of embarrassment to modern scholars (Farr, R., 1991, p. 372). In my study of proponent histories I add 'precursors' to these categories. Precursors (unlike ancestors) are scholars who used the term 'social capital', but whose contribution is marginalised and detached from the contemporary discourse in favour of the work of the founders.

\section{Proponent Histories: The Long(er) Past of Social Capital}

Proponents of social capital enact realities where centuries of social scientists have addressed the same, universal subject matter, and social capital is the latest way of discussing this subject matter. Consequently proponent histories have typically traced the concept's origins back through classical sociology and enlightenment economics. Historians of social capital have enrolled these ancestors from a broad intellectual terrain that includes sociology, classical economics, enlightenment philosophy and communitarian thinkers. 
The authors enrolled as ancestors of social capital from this terrain has been broad enough that one historian, James Farr has even suggested that it is possible to argue that there was near universal use of the concept of social capital in the social sciences before the emergence of the term (Farr, J., 2004, p. 10). As with many authors, Farr's history universalised social capital by treating all previous work in the social sciences as dealing with the same object of study, but with different language. He suggested that it was possible to incorporate such a wide field because of both the breadth of the concept and because it was "to some extent merely new language for a very old debate in American intellectual circles” (Farr, J., 2004, p. 10).

Whilst there is a large list of ancestors of social capital, some have been more commonly evoked than others. The 'founding fathers' of sociology, Marx, Weber, Durkheim and Simmel, are the most commonly evoked ancestors. These early sociologists have been constructed as having a common object of interest which the social capital literature is exploring further. For instance, Begnasco suggested that the key questions of:

"[...] how can we replace primordial social capital? - returns to one of the original, variously expressed themes of sociology. Classic sociology posed the problem of what got lost in the passage from traditional to modern society" (Bagnasco, 2003, p. 361 emphasis in original).

Had now been taken up and updated by Putnam in Bowling Alone. Consequently Bagnasco equates the decline of social capital in America with $19^{\text {th }}$ century modernisation.

Portes suggested a different common issue:

"[d]espite its popularity, the term [social capital] does not embody anything really new to sociologists. That involvement and participation in groups can have positive consequences for the individual and the community is a staple notion [...]" (Portes, 1998, p. 2).

For Portes, and Portes and Sensenbrenner, different types of social capital reflects the work of a particular founding father of sociology, each of which explored the same phenomenon and developed a tradition spanning $20^{\text {th }}$ century sociology (Portes \& Sensenbrenner, 1993, pp. 1322 - 1327). For instance, Marx and Engels' work on class solidarity is reformulated as 'solidarity social capital', and is stated to be akin to Coleman's norms and values (Portes, 1998, pp. 7 - 8). They later implied that Marx and Engels themselves were in fact discussing a type of social capital claiming that " $[\mathrm{t}]$ he passages of the communist Manifesto where this type of social capital ['bounded solidarity'] makes its appearance are familiar" (Portes \& Sensenbrenner, 1993, p. 1324). They similarly 
interessed Weber's work as 'enforceable trust', Simmel's work as 'reciprocity transactions' and Durkheim's work as akin to the norms of 'generalised reciprocity', as all types of social capital that underpin the current literature (Portes, 1998, pp. 9 - 10; Portes \& Sensenbrenner, 1993). They further identified applications of these different types of social capital by $20^{\text {th }}$ century authors including Blau's social exchange theory (Simmel), Parson's structural functionalism (Durkheim), Tilly's work on immigrant communities (Marx and Engels), and ethnic entrepreneurships (Weber). Portes and Sensenbrenner later claimed to apply these different types of social capital to immigration in the USA, however, the famous theorists disappear. Only Marx \& Engels and Weber were cited after the history section, and then only once each to re-state the connections previously made above, as opposed to developing further insights.

Sociologists were not the only theorists enrolled into proponent histories. Michael Woolcock listed (amongst others) Marshall, Hicks, Mill, Hume, Muller, Bentham, Ricardo, Smith, Burke, Mead Marx, Simmel, Durkheim, Parsons, Weber and Merton as theorists working on the same subject as social capital (Woolcock, 1998). The names were listed, with at most a shallow outline of the theorist's contribution. For instance, he stated that:

"[a]s Swedberg has documented, the Durkheimian, Weberian, and Marxist traditions within classical sociology were all heavily influenced by the economic debates and issues of that period, and much of what we now refer to as "social capital" lay at the heart of these concerns" (Woolcock, 1998, p. 160). ${ }^{25}$

Later in his discussion, Woolcock briefly discussed utilitarian network, Durkheimian and Weberian approaches to social capital. As with Portes, his description of these approaches subsumed their work as being about a particular type of, or approach to, social capital: for instance Durkheim's work on "non-contractual elements of contracts" was a type of social capital at odds with utilitarianism (Woolcock, 1998, p. 156). In addition to the four traditions discussed above, Woolcock also added a fifth tradition of social capital research in utilitarianism, to which Farr has proposed a sixth tradition of the critical pragmatism of John Dewey (discussed below), and possibly even a seventh of $19^{\text {th }}$ century political economy (Farr, J., 2004). As with Portes, Woolcock quickly interessed most of sociology (and economics) as researching social capital, but without using the term, they again

25 The Swedberg article did not mention social capital and thus (presumably) is only intended to support the first half of the sentence. 
constructed these authors as sharing a subject matter with social capital. Interessing these authors also justifies the social capital literature's approach to this subject matter, by connecting it to well-regarded authorities within the social sciences.

Halpern traced this universal subject matter back further than either Portes or Woolcock, because "in so far as the social capital concept simply highlights the important role that community plays in individual wellbeing, it can be recognised in some of the most ancient texts known" (Halpern, 2005, pp. 3 - 4). He offered a shorter, but no less illustrious list including Smith, De Tocqueville, Durkheim and Aristotle as ancestors of social capital. Each of the first three was given a paragraph in Halpern's history in which he built tenuous links between their work in general and contemporary analyses of social capital (Halpern, 2005, pp. 4 - 6). For instance, Durkheim's connection to social capital was identified as his recognition that individuals' behaviour could not be explained without considering their social context. As with Portes, after their incorporation in this list these theorists are given a peripheral role in the rest of Halpern's book. Aristotle's influence on social capital was not mentioned at all beyond his presence in the list of forerunners. Smith is only mentioned once in relation to the impact of culture in game theory:

"A related finding is that people will often accept a lower payment in such games if this prevents risk being assumed by someone for whom they have sympathetic feelings. This web of sentiment was, of course, seen as central to the effective functioning of the economic and social world by the 'father of economics', Adam Smith" (Halpern, 2005, p. 66)

Durkheim was given a slightly more substantial discussion by Halpern, but his use was still sparse, and limited to universalising social capital's subject of interest.

Ancestors were often enrolled into the social capital discourse by labelling their interests as equivocal to social capital. This was particularly evident with classical economists and Scottish philosophers. Paxton identified De Tocqueville, Ferguson, Montesquieu, Habermas, Calhoun, Horkheimer, Arendt, and others alongside Putnam, Coleman \& Trow as part of a tradition addressing the "relationship between social capital and democracy" (Paxton, 2002, p. 255). Similarly, Paterson argued that philosophers of the Scottish enlightenment:

"[...] had a well-developed sense of mutual buman obligation that is quite close to the ideas on social capital that have become popular again in academic circles recently" (Paterson, 2000, p. 39 emphasis added). 
Unlike the sociologists discussed above, these authors did not associate these ancestors with a particular tradition of social capital. Instead, they were only linked by a common subject of interest.

The social capitalists who drew upon Putnam's communitarian approach often constructed Alexis de Tocqueville as the most significant ancestor of social capital. In Bowling Alone Putnam declared De Tocqueville to be the "patron saint of contemporary social capitalists" (Putnam, 2000, p. 292). Leonard and Onyx strengthened this connection, suggesting that:

"[...] social capital is formed when the individuals participate because they recognise that the co-operative activities of the group are ultimately to their benefit. De Tocqueville (1861) called this “self-interest rightly understood."” (Leonard \& Onyx, 2004, p. 2).

De Tocqueville was however only mentioned twice more in Leonard and Onyx's book, once to re-state the connection above (p. 29), and once to state the importance of voluntary organisations (p. 87). Similarly, MacGillivray and Walker identified the connection between Burke, Weber, De Tocqueville and contemporary social capital theory as the link between public and personal life (MacGillivray \& Walker, 2000).

The incorporation of these ancestors into histories of social capital legitimises contemporary research by placing it at the end of a long line of sociological research. As the quotes by Paterson, Woolcock and Bagensco and Farr highlight, there is an underlying assumption that social capital's subject of interest has been of interest to theorists far before the term itself emerged. An in-depth analysis of these theories is rarely required because their interessement and enrolment functions to legitimise social capital as dealing with long-term concerns within the social sciences, the classical theorist's work adds little to the research itself and they are sparsely mentioned (if at all) after the history section. The breadth of the theorists who are included in these theories highlights important elements of social capital, particularly the concepts' breadth, and its malleability. In each of the quotes above social capital is defined differently: sometimes as mutual obligation, other times as communities' impact on wellbeing or the importance of participation in groups. Furthermore, by acknowledging the work of previous theorists, however briefly, and in particular incorporating them as types of social capital, these scholars can also (preemptively) ward off critiques as to the similarity of the concept with prior work. 


\section{Proponent Histories: The Short(er) Past of Social Capital}

After listing illustrious names, historians of social capital typically list scholars who employed the term social capital before the emergence of the current social capital literature. Much like the ancestors, these precursors are generally given little, if any, more attention beyond being listed. However the first precursor, such as Hanifan, is occasionally given a substantial discussion to establish the similarities between their uses of social capital and contemporary uses of it (examples include Halpern, 2005, p. 6; Westlund, 2006, p. 1; Woolcock, 2010, p. 472). Other precursors, particularly Bourdieu and Loury are given a more liminal position in histories of social capital, occasionally constructed as precursors to the current literature, and occasionally as founders.

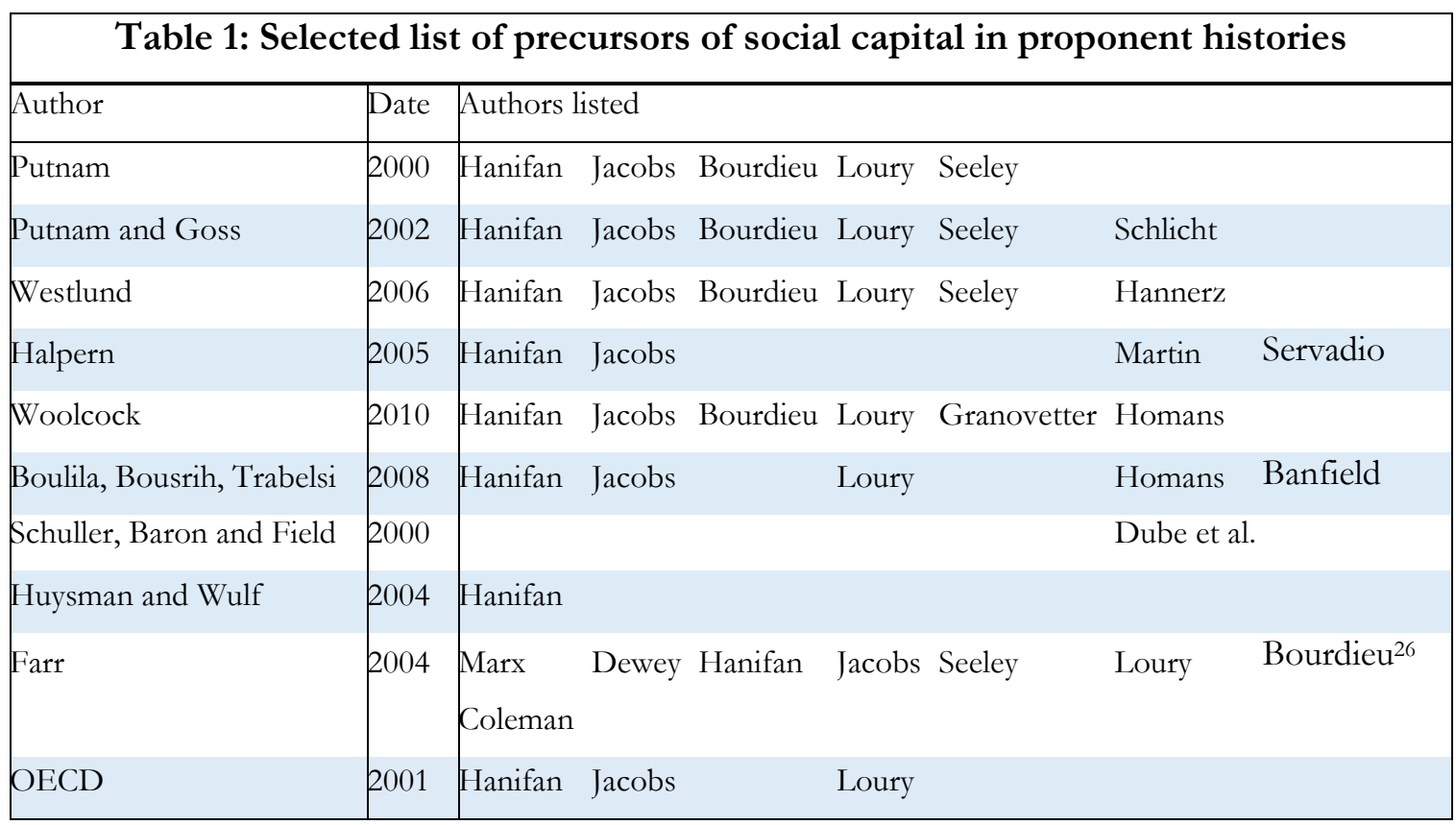

Putnam's history of social capital in Bowling Alone has had a significant impact on the mainstream short past of social capital. Putnam identified Hanifan as the original user of social capital and Jacobs, Bourdieu, Loury and Seeley as all 'reinventing' the concept before it was then 'settled' by Coleman (Putnam, 2000). Later in Putnam and Goss, economist Schlicht is added meaning that after Hanifan, "[d]uring the rest of the twentieth century the concept was independently reinvented at least six more times" (Putnam \& Goss, 2002, p. 5).

Putnam's list, with Hanifan as the first user of the term social capital, has been repeated (with some names missing) throughout the literature (see table 1). Several authors have also drawn on Putnam's argument that Hanifan's use of the term approximates the

${ }^{26}$ Farr associated all of these except Marx and Dewey as authors who Putnam credited for inventing the concept. 
contemporary discourse of social capital (Halpern, 2005; Putnam, 2000; Putnam \& Goss, 2002; Westlund, 2006). ${ }^{27}$ Halpern, for instance, argued that Hanifan's use of the concept closely resembles contemporary definitions because he used it to appeal to "hard-nosed businessmen who he felt would be more impressed by economic language than by 'softer' references to the importance of community" (Halpern, 2005, p. 6).

Whilst Hanifan is usually identified as the first to have used the term, some texts omit him from their histories, and thus identified other 'first uses of the term'. Jane Jacobs is occasionally identified as the first user of social capital in texts where Hanifan is not mentioned, particularly within management studies (a discipline with limited influence by Putnam - see chapter 5) (Nahapiet \& Ghoshal, 1998; Yli-Renko, Autio, \& Sapienza, 2001). Outside of management studies, Meadowcroft and Pennington also believed that the "phrase was originally coined by the urban anthropologist Jane Jacobs in her study The Death and Life of Great American Cities in 1961" (Meadowcroft \& Pennington, 2007, pp. 20 -21). They did not identify any other precursors, but gave Jacobs' use of the term a substantive discussion. Schuller, Baron and Field claimed that Dube, Howes and McQueen's work in 1957 "predates most of the more cited oeuvres" (Schuller, Baron, \& Field, 2000, p. 2).

In contrast to these $20^{\text {th }}$ century origins, Farr identified several uses of social capital prior to Hanifan, in particular John Dewey who he discussed in depth, but also Karl Marx who used it in some English translations of Das Kapital. Farr identified three uses of the term by Dewey, and whilst claiming a consistent usage notes that the term was not elaborated on, nor central to, Dewey's work (Farr, J., 2004). Farr argued that, whilst Dewey did not conceptually or theoretically develop the term, however his pragmatic philosophy and communitarian American socialism has formed the most "authoritative philosophy for the movements of civic education and the texts of social capital" (Farr, J., 2004, p. 14). Woolcock acknowledged the connection to Marx that Farr made (although not the connection to Dewey), but seemed doubtful of it, stating that:

27 In Hanifan, social capital was that which makes capital "count for most in the daily lives of people" (Hanifan, 1916). Hanifan also discussed social capital as something which people must do themselves, and not be told how to do: "The more people do for themselves the larger will community social capital becomes, and the great will be the dividends upon the social investment" (Hanifan, 1916). He only sparsely used social capital as a way of advocating for rural schools which he saw as centres of community. 
"[t]he idea of social capital enjoyed multiple [...] inventions over the course of the twentieth century, and even further back if one accepts Farr's contestation that Marx himself was the first to deploy the term" (Woolcock, 2010, p. 472).

However, Woolcock did not give a reason why he was sceptical of Farr's 'contestation'. ${ }^{28}$

As I noted above, Glenn Loury occupies a liminal space in social capital histories. He is generally placed near the end of the list of social capital precursors, but has occasionally been identified as a founder. Loury only mentioned social capital once (as noted by Portes), and did not develop the concept theoretically. ${ }^{29}$ Portes however, listed him as the 'second contemporary source' of social capital, after Bourdieu and before Coleman (Portes, 1998, pp. 4 - 5) - placing him among the founders. He also saw Loury as a link between contemporary uses of social capital, and the growing critiques of neoclassical economics in the 1970s and 1980s. Coleman also identified Loury as the first person who introduced the term social capital (Coleman, 1990, pp. 300 - 301). However, since Putnam listed him as one of his 6 'reinventors', he has commonly been treated as a precursor of social capital. Woolcock (2010) also listed Loury alongside Bourdieu, Jacobs, Homans and Seely as pre-Coleman 'reinventors' of social capital. Similarly, Loury was given a single mention in Westlund's history alongside Bourdieu, Hannerz, Jacobs and Hanifan as "another scholar who has defined social capital as an individual-level resource" (Westlund, 2006).

\section{Proponent Histories: Founders of Social Capital}

Precursors and ancestors of social capital are separated from current uses of social capital by the emergence of several 'founders'. No founder is included in all texts, including those that explore the emergence of the term, but three are more often used than others: Putnam, Bourdieu and Coleman. Others, such as Fukuyama, Granovetter, and Jacobs are also occasionally identified as founders.

\footnotetext{
28 This may be because Marx's use of the term referred to communally-possessed material capital, as opposed to resources in relations or similar (Marx, 1957). Marx's uses of the term in Capital were translations from the German gesamtkapital which could be more accurately described as the 'sum of capital' or 'total capital', further emphasising its different meaning to contemporary uses.

${ }^{29}$ Loury used the concept in his discussion of 'racial' inequalities from a rational choice perspective (Loury, 1977, pp. 153 - 154). At the end of his text he states that: "[i]t may thus be useful to employ a concept of "social capital" to represent the consequences of social position in facilitating acquisition of the standard human capital characteristics. While measurement problems abound, this idea does have the advantage of forcing the analyst to consider the extent to which individual earnings are accounted for by the social forces outside an individual's control" (Loury, 1977, p. 176). Thus as with Coleman this was a way of combining social context and structures with a rational choice model of human behaviour.
} 
Histories elevate the contribution of founders above that of precursors through statements of their influence or greatness. For instance:

"The birth of mainstream academic interest in the concept can be dated to the late 1980s, when attention was drawn to the concept by eminent sociologists in both Europe and the USA" (Halpern, 2005, p. 7).

"The seminal work of Coleman on education and especially Putnam on civic participation and democracy has provided the inspiration for most of the current work" (Woolcock, 2010, p. 472; Woolcock \& Narayan, 2000, p. 229).

“Time hasn't yet weathered our century in the same way. None the less, there seem to be, again, three candidates for gigantism. These are Bourdieu, Coleman, and Putnam” (MacGillivray \& Walker, 2000).

Some histories have included further work to establish the significance of these authors. For instance, Woolcock in discussing Making Democracy Work, stated that criticism had not stopped the book from:

“[...] accruing (as of this writing) $>15,000$ citations, making it by any measure a bona fide social science classic. (By way of comparison, Adam Smiths' The Wealth of Nations has garnered roughly 14,000 citations and Michel Foucault's Discipline and Punish: The Birth of the Clinic [sic.] > 16,000.)" (Woolcock, 2010, p. 474).

These statements further marginalise the precursors from other theorists - such as Fukuyama, Burt, Lin, Becker, or earlier such as Flap from the current discourse of social capital. Instead of simply being authors who used the term early on, Putnam, Bourdieu or Coleman are seen as providing definitive and developed definitions or influential applications of social capital. They are subsequently given greater attention both within the history, and are referred back to throughout most texts.

As with most features of the social capital literature, the relationship between the three most frequently identified founders (Putnam, Coleman and Bourdieu) has been constructed in various ways. Some texts have identified each one as founding different approaches to social capital. For instance, Huysen and Wulf identified Bourdieu with a Marxist approach to social capital they contrast to Putnam's communitarian approach (Coleman was not assigned a tradition and was instead listed alongside Burt and Portes as providing 'significant contributions' to the literature) (Huysman \& Wulf, 2004). Schuller, Baron and Field also treated the three separately from one another as founding different approaches (Schuller et al., 2000). In contrast, Halpern dealt with the founders 
chronologically: he treated Bourdieu and Coleman as contemporaries who were followed by Putnam before finishing his history with "another important figure" (indicating a lower esteem), Fukuyama (Halpern, 2005). Halpern's treatment of the founders was repeated by Westlund (Westlund, 2006).

Bourdieu's position in histories of social capital has been even more liminal that Loury's. At times he has been identified as a founder (Halpern, 2005; Huysman \& Wulf, 2004; MacGillivray \& Walker, 2000), at other times he has been marginalised as a precursor whose work is seen as having little impact on the discourse (Portes, 1998; Putnam, 2000). The policy documents that I will discuss in chapters 7 and 8 have generally omitted Bourdieu's work from the history of social capital. For instance, the World Bank only identified Coleman and Putnam's contribution (Grootaert \& Bastelaer, 2001). The OECD gave a list of historical uses of social capital that omitted Bourdieu's use of social capital, instead stating that he "used a closely related concept, "cultural capital"” (OECD, 2001, p. 40).

Portes suggested that Bourdieu's influence was curtailed because his work was in French, and the translation only appeared in a specialist field (Portes, 1998, p. 3). Fine, after stating that Bourdieu was "deservedly an inspirational figure", suggested that his marginalisation was due to a combination of Bourdieu's success with cultural capital (perhaps supported by the OECD quote above), combined with his own lack of that cultural capital and his Marxist leanings (Fine, 2001, pp. 53 - 55). Fine has also suggested that in the early 2000s there was a realisation within the literature that Bourdieu offered a superior theory of social capital, which resulted in calls to 'Bring Back in Bourdieu' to provide a context for mainstream economics (Fine, 2010, p. 68). Bourdieu himself also commented on his relative marginalisation in the social capital literature. In the introduction of The Social Structures of the Economy, he stated that the concept is "often associated today with the name of James Coleman, who was responsible for launching it on the highly protected market of American sociology" (Bourdieu, 2005, p. 2). As will become more apparent next chapter, Bourdieu has had a consistent impact on the network-approach to social capital in management studies. Somewhat ironically much of this work is on improving worker productivity and firm competitiveness, and approaches social capital from a rationalchoice perspective which contrasts with Bourdieu's Marxist politics.

Coleman's position as a founder has been more firmly established than that of Bourdieu. He is almost universally cited within the literature of social capital, most authors such as 
Halpern (2005), Farr (2004) and Portes (1998) treat him alongside Putnam and (if present) Bourdieu. Exceptions do exist however, for instance as I noted above Huysman and Wulf did not identify a tradition with him (unlike with Bourdieu and Putnam) (Huysman \& Wulf, 2004).

In many scholarly and political texts, Putnam was identified as key to the development, or at least popularisation of social capital. Halpern introduced him as the "one name [that] has become almost synonymous with social capital [...] is, of course, Harvard professor Robert Putnam" (Halpern, 2005, p. 7). However, the identification of Putnam as a founder is not entirely guaranteed, particularly within network-based approaches to social capital. In 1998 (before the publication of the book Bowling Alone, but after the initial article in 1995), Portes identified Bourdieu, Loury and Coleman as the founders of the discourse of social capital. He discussed Putnam at the end of his article and, whilst he stated that Putnam's work has "created something of a sensation", he was critical of Putnam's use of social capital (Portes, 1998, p. 19). Lin also reduced Putnam to a secondary role to Coleman, characterising Putnam as providing an empirical demonstration of Coleman's theory (Lin, 2001, pp. cf. 22 - 24 inc. footnote 22), or an expansion of it (Lin, 2001, p. 52) rather than a theoretical perspective in its own right. Lin's only engagement with Putnam was, as with Portes, a critique of his application of social capital (Lin, 2001, pp. 210 - 211). Similarly, Seibert, Kraimer and Liden identified Coleman, Granovetter, Burt and researchers from 'social resources theory' (Lin, De Graaf, Flap etc.) as purveyors of social capital theory with no mention of Putnam (Seibert, Kraimer, \& Liden, 2001). This marginalisation of Putnam is also repeated by Inkpen and 'Tsang (Inkpen \& 'Tsang, 2005). Gillies and Edwards' analysis of parenting and social capital also identifies Coleman and Bourdieu as the "two major theorists [who] have been formative in shaping this debate on social capital and families" with Putnam only mentioned once (Gillies \& Edwards, 2006). Outside of histories of the concept, Putnam's influence is notably less significant within network-based approaches, particularly within economics and management studies (Adler \& Kwon, 2002). However, as Halpern's citation numbers suggest, Putnam is often either accepted alongside Bourdieu and Coleman, or at times elevated above them (as Halpern did) as the key name associated with social capital. 


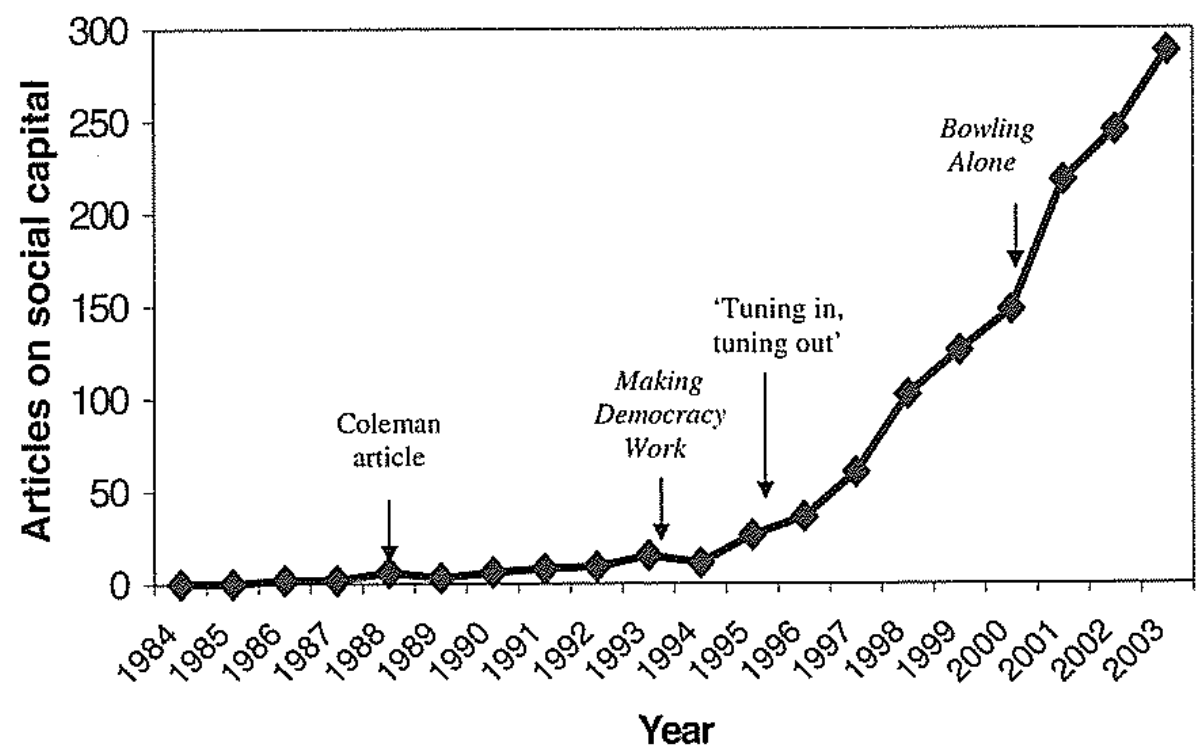

Figure 1.1 Academic articles on social capital, 1984-2003

Source: Figures for 1984-93 based on a combined search of Econlit, Psychlit, Crimlit and Medline; those for 1994-2003 based on Web of Science; that for 2003 projected from part-year total, assuming pro rata articles for remainder of year.

Figure 1: Graph of the expansion of references to social capital reproduced from Halpern (2005, p. 9). A similar graph can be found in in Woolcock (2010)

These founders are given a more substantial engagement than other authors in histories, and they will often be drawn on later in texts (unlike precursors), and proponent histories of social capital often end with them. However other histories included a discussion of the subsequent success of the concept. For instance, Halpern stated that " $[\mathrm{t}]$ he years since 1995 [the year of Putnam's initial Bowling Alone article] have seen an explosion in the use of the term 'social capital' (Halpern, 2005, p. 8). Halpern (Halpern, 2005 see figure 1) and Woolcock (Woolcock, 2010) both provided graphs of publications to support the claim of an explosion in use. Such graphs are (im)mutable mobiles that function as a further ally, justifying the claims of the centrality of the founders (as indicated by Halpern's notation of the key publications along the graph). They also further establish the lack of work on social capital before the founders' use of the term. Finally they continue to establish the concept as a central (and still growing) pillar of the social sciences. Neither Halpern nor Woolcock's graph measured the percentage or fraction of articles that use social capital. Thus they do not account for the (apparent) explosion of total journal article publications from the 1990s onwards (see appendix 4). Finally both discussed the varying fields in which social capital appeared after the founders' contributions, further emphasising the seminal nature of the founders by emphasising their impact across the 
literature. Woolcock, for instance, identifies "at least nine fields" in 2010 and seven fields in 1998 (Woolcock, 1998, 2010)..$^{30}$ Halpern's Social Capital was also dedicated to introducing the concept's application in different scholarly fields, whilst also attempting to make the discourse coherent (Halpern, 2005).

Histories of social capital construct a division between what I have termed precursors and founders of social capital. The use of founders in such histories creates (or attempts to create) obligatory passage points, research that must be cited within the context of social capital research. However, as this discussion has suggested, divisions have existed (and continue to exist) within social capital theory and to make such passage points obligatory is incredibly difficult, even in the case of well-known and popularist authors, such as Robert Putnam. Overall they construct a linear and uncomplicated narrative of social capital's emergence. There has been a long-time interest in the concept's subject matter, with a shorter-term intermittent use of the term. With the emergence of several influential texts in the late 1980s and 1990s, the concept itself became an increasingly popular way of analysing and explaining social relations in a way that incorporates and builds on the findings of various famous theorists who worked on the same subjects.

\section{The Socio-political Context of Social Capital}

So far I have discussed the interessment of various types of authors within histories of social capital, and have neglected mentioning context. This is because the socio-political context of social capital's emergence has been given less attention within proponent histories than narratives of the concept's conceptual history. For White, contextual histories isolate a particular area of the historical field (in this instance the social capital literature), and then trace it back into the circumambient natural and social space in which it occurs, and back through time to determine its origins. They form 'chains' of what the historian deems the significant events and threads in the historical field (White, 1973, pp. 18 - 19). The primary chain constructed in proponent contexts was of an emerging

\footnotetext{
${ }^{30}$ In 1998 these were 1. social theory and economic development 2. families and youth behaviour, 3. Schooling and education, 4. Community life in physical settings, and virtual settings (internet), 5 Work and Organisations, 6. Democracy and Governance, 7 General cases of collective action problems. In 2010 these were: 1. Families and behavioural problems, 2. Crime and violence, 3. Schooling and education, 4. Community life, "virtual" and civic, 5. Public health and environment issues, 6. Work and organizations, 7. General cases of collective action problems, such as the management of common-pool resources, 8. Economic development, 9. Democracy and governance
} 
recognition that policy required reforming in order to account for social relations as well as economic growth.

Proponents who discuss the context of social capital's emergence construct it as a combination of the political situation in the late $20^{\text {th }}$ century, and growing discontent with neoclassical economics and economic fundamentalism in policy. They suggest that social capital emerged in the 1980s and 1990s from a desire for some way of discussing the social that would not be dismissed by economists - with it providing a common language between economists and other social scientists. Halpern for instance, stated that: "[s]ocial capital counters the crude economic political fashion of the 1980s and 1990s especially characteristic of the USA, UK and New Zealand" (Halpern, 2005, pp. 1 - 2). This was necessary due to the dominance of economic concerns and discourses within late $20^{\text {th }}$ century liberalism. Woolcock further suggested that the desire for a 'social something' in policy was correlated with the end of the Cold War, an end that opened up a space for a discussion of the social in politics, without users being accused of being socialists (Woolcock, 2010), something that was particularly relevant in New Zealand (see chapter 6). However, earlier Woolcock connected social capital to an expansion of economic concerns which was driven by the success of human capital (Woolcock, 1998, p. 155) and Szreter and Woolcock claimed that the interest in social capital in public health was the result of the growing appeal of neoliberalism and communitarianism alongside the failure of individualism, and the disappointing outcomes of media campaigns to address smoking, depression and teen pregnancy (Szreter \& Woolcock, 2004).

The desire for a way to discuss the social has been oft repeated in policy and political uses texts that use the term (see Chapters 6 and 7 for examples of this in New Zealand). Bebbington, Guggenheim and Woolcock for instance gave a more specific context in their ethnography of the concept's use in the World Bank that aligns with this desire for a social. They characterised it and other concept's emergence as an outcome of three decades of "reform battles" around whether to broaden the definition and understanding of development (Bebbington, Guggenheim, \& Woolcock, 2006). These reform battles formed part of a broader attempt to reform the bank and the way that it operates. A similar narrative is evident in the New Zealand Treasury's incorporation of the 'capital approach' in its Towards Higher Living Standards framework and national account frameworks (discussed in Ch. 8). In a speech announcing the framework the Secretary for the Treasury John Whitehead argued that the Treasury of 2011 was very different from the conventional perception of the Treasury of the 1980s that was often seen as the 
primary driver of free market reforms of the $4^{\text {th }}$ Labour government. Social capital was, for Treasury the result of over a decade of changing thinking regarding the role of the social in their policy advice, and as a way of challenging what they perceived as misperceptions of their current position (Whitehead, 25 May 2011). Such histories support my association of social capital with communitarian corrective critiques.

\section{Critical Histories of Social Capital}

Authors critical of social capital have offered an alternative history of the concept that assembles a different group of actors to explain the emergence of social capital. For critics, discussions of the social in the 1990s resulted from failing neoliberal reform programmes and growing social problems coupled with a desire to expand economic explanations of behaviour into non-market social relations. As I noted in chapter 2, for critics, social capital was not the latest iteration of a long history of social science research, but the latest product of economists. For some such as Fine or Somers, it reflected the degradation of scholarship and was a 'Trojan Horse' in sociology, for others it was a neoliberal endproduct of changes within economics.

In earlier texts, Fine attributed the growth of social capital to the World Bank's adopting a 'post-Washington consensus'. He argued that the political situation of the late $20^{\text {th }}$ century resulted in a "scholarly third wayism" that "explains why, when a conceptual fad [such as social capital] gathers a foothold, it should gather cumulative momentum at the expense of considered scholarship" (Fine, 2001, p. 195). Thus the conceptual appeal of social capital was due to a number of factors including ${ }^{31}$ a degradation and popularisation of scholarship, general intellectual fashions, the retreat from post-modernism, an absence of 'proper' political economy and the distinction between society and economy (Fine, 2001 cf. ch. 11). More recently Fine has repositioned this argument. He still saw social capital as related to the post-Washington consensus (Fine, 2010, pp. 114 - 116), but adds that it was also the result of contradictions in early neoliberalism leading to a second phase, where state intervention was required to fix market imperfections (Fine, 2010, p. 10). For Fine, social capital was a reaction to the excesses of phase one neoliberalism, and so it "fits neatly into a growing reaction against both excessive statism and excessive neoliberalism" (Fine, 2010, p. 42).

\footnotetext{
${ }^{31}$ Fine lists 9 points in the conclusion of his book, however several of these are internal reasons for the success of social capital (such is its "gargantuan appetite") and thus I have not discussed them here.
} 
Fine also constructed social capital as the latest in a series of attempts to expand rational choice theory into the social sciences, with the most notable attempt being the social exchange theory of Homans and Blau. Earlier attempts at colonisation had failed due to the unpalatable nature of both an individual, and rational driven approach in the social sciences:

"Scarcely acknowledged as such in the social capital literature, this field of sociology [social exchange theory] prospered from the 1960s until it gave way to social capital theory. It was not simply superseded, however, for it proved to be the analytical precursor to its successor with marked continuities and some discontinuities between the two theories" (Fine, 2001, p. 65).32

Social exchange theory was, despite its success, unpalatable within the social sciences due to its explicit alignment with rational choice theory. Fine further argues that it had reached its own theoretical limits and thus "failed in its project to provide social theory with (individualistic) micro-foundations" (Fine, 2001, p. 71). Coleman, who published in the social exchange literature, learned from this setback. Thus in contrast social capital hid its connections and became more palatable, allowing rational choice theory to flourish within the social sciences. Fine credits Astone et al. (1999) with alerting him to the connection between social capital theory and social exchange theory, making a claim that he could not find references elsewhere. He considered this absence to support his hidden-history argument.

Fine argued that economic imperialism was facilitated by unwitting users of the concept within the social sciences who:

"[...] do not recognise the implications of the more recent revolution in and around economics that positively embraces the social by way of extension of the unchanged economic principles (or the economic approach as Becker dubs it). In this light, the role of social capital in social theory's response to a colonising economics is completely clarified. On the one hand $[\ldots]$ it can be understood as a form of peripheral colonisation, incorporating all social theory other than economics. On the other hand, it presents itself as the opposition to a colonising economics whereas, at most, it offers feeble resistance because it has no alternative economics of its own - at worst, it prepares social theory for the colonising advance of the economic approach" (Fine, 2001, p. 195 emphasis added).

${ }^{32}$ Fine repeated this claim several times in chapter 5 of Social Capital vs Social Theory (Fine, 2010). 
Somers has similarly characterised social capital as a Trojan horse for a reified neoliberalism that has shed itself from neoclassical economics:

"Whereas the neoclassical orthodoxy was to distain and dismiss the social, neoliberalism recognizes the greater advantage of hijacking it from its own domain and commandeering it into the reach of the market" (Somers, 2005, p. 8).

Both of these authors characterise social capital as an individualistic approach to human relations, but both of them also see it as a response to the need to acknowledge the social. Unlike for proponents, this was a way of more efficiently advancing the economic or neoliberal agenda into the social realm by bypassing resistance. The last sentence of the quote from Fine (emphasised above) indicates his recognition of proponent constructions of social capital as a critique of economic policy. However he largely dismisses this, seeing it as highlighting his argument of duped social theorists unwittingly aiding in the 'colonising advance of the economic approach'.

As Callon noted, that in order to enrol allies and stabilise, some actors must be excluded. Critical histories must similarly break up the assemblages constructed by proponents, by dismissing other, non-critical histories. Fine (2010) began his 'short history of social capital ${ }^{33}$ by arguing that the proponent short history ${ }^{34}$ is only possible because 'it' refuses to write two other histories:

"[...] one, as is already apparent, about how little social capital has been used in the past, and the other about when it was used, it was predominantly used in different ways than it has been recently. In particular, in the latter history, the main, if limited, use of social capital in the past was as an economic category" (Fine, 2010, p. 36).

Instead, he has offered an alternative history; in the $20^{\text {th }}$ century economics removed the social, leading to fertile ground for social capital to emerge. When it did it was through Bourdieu, which was uncomfortable for the 'orthodoxy'. Thus, with the growing neoliberal influence on American social theory, "social capital abandoned Bourdieu for the rational choice perspective most closely associated with James Coleman", resulting in Garry Becker emerging at the forefront of social capital research (Fine, 2010, p. 37). This academic 'hamburger's' victory over Bourdieu's 'French cuisine' however came at an inopportune time, as rational choice theory and excessive neoliberalism were on the wane

33 Following a discussion about history being written by the winners and how this does and does not apply to development economics, since development economics writes out its history, which is recovered by the 'vanquished'. 34 Fine did not distinguish between the conceptual and terminological history of social capital, instead stating that its origins are traced back through contributions. 
in the social sciences, allowing Putnam to offer a "definite but limited" break from rational choice theory to develop a more palatable version of the concept which hid its rational choice origins (Fine, 2010, p. 47). This required making the concept exclusively an explanatory factor in empirical work.

Fine dismissed all histories of social capital, stating that "the history of social capital is a fairy tale, pure invention" (Fine, 2010, p. 50). There were two reasons why it was a fairy tale, early uses of the concept differed from later ones, and early uses were few and far between. Since the concept has no intellectual history, historians of the concept should not go out and find its intellectual origins (which he critiqued Farr for doing), but instead explain the absence of the term. Fine explained this absence through the oxymoronic character of social capital: for "the vast majority of social theory", before the recent degradation of scholarly standards, it was impossible for the economy to be separated from its social context. Therefore capital cannot be a-social and, if there is no non-social capital, there cannot be a social capital. Only mainstream economics divided capital from its social context in the $20^{\text {th }}$ century, hence why it needed to develop 'social capital' (Fine, 2010, p. 51). He also offers a short, alternative history of social capital, in which he argues that pre-Coleman uses of the term (precursors) have tended to conceptualise social capital in the same way as Marx, as the aggregate of economic capital (Fine, 2010, p. 53), or as an anti-capitalised socialised ownership of capital (Fine, 2010, pp. 54 - 55).

Fine was critical of Farr's attempt to produce a conceptual history of social capital, in particular he critiqued Farr for presuming that social capital has a history. Farr may have offered a comprehensive attempt to trace the history but:

"[...] if much less than others, he has done so in a way that tends to presume that there are no deeper questions involved than who, when, and what in the use of the term. This is particularly inappropriate for, in the search for origins, what stands out, and yet tends to be overlooked, is that social capital his little or no conceptual history of weight $[\ldots]$ " (Fine, 2007a, p. 47).

Farr responded to Fine's accusations, noting that ${ }^{35}$ :

"Material circumstances or sweeping generalizations, especially those that span decades, are backdrops or conditions; they seldom explain with any specificity, or they explain too much. The economisation of social life and the encroaching hegemony of capitalist

\footnotetext{
${ }^{35} \mathrm{He}$ also responds to Fine's statement that social capital is a an oxymoron because there cannot be a non-social capital, stating that then what is of interest is why have people used a redundant term - including Marx and Dewey
} 
discourse in the West, for example, have been with us since the nineteenth century, not just last decade of the millennium" (Farr, J., 2007, p. 55).

Farr also noted that the term was commonly used in the $19^{\text {th }}$ century, and that many of these users were not capitalist apologists, and included socialists and reformers (Farr, J., 2007).

Spies-Butcher contextualised the emergence of social capital in Australia as a result of neoliberal reforms and the failure to account for civil society. This resulted in groups and individuals from across the political spectrum attempting to use social capital as a way of reintegrating civil society into the political debate, which is similar to my discussion in chapters 6 and 7. However, Spies-Butcher still saw the concept as informed by the antimodernism of economic neoliberalism, and explained the concept's emergence in relation to changes in economics. As I have discussed in chapter 2, Spies-Butcher (2005) offered a more nuanced analysis of social capital's conceptual history than Fine. However, the same chains of an economic origin and a socio-political context of neoliberal reforms are present. Spies-Butcher constructed a lineage of social capital back to Hayek's critique of the overly modernist approaches to economics. His narrative then moved through methodological branches of economics, particularly with the limitations in game theory that became apparent through the application of the Prisoner's Dilemma. For SpiesButcher, social capital emerged as the end product of a move away from some elements of rational choice theory, particularly the notion of single-equilibria models of decision making, and an honest attempt by some economists to engage with other social sciences. Thus, unlike Fine, Spies-Butcher perceived social capital as emerging from a change in thinking by some economists, and differentiated between the economic ancestors of social capital and neoclassicism. At the same time, he concludes that this was a small move, and one which supports a neoliberal policy and scholarly programme.

Smith and Kulynych offered an interesting combination of both contextual and conceptual origins. Unlike with proponent histories they traced the conceptual history traced social capital back through different economic approaches towards capital, from the terms origins in ancient Rome, through the classical economics of Smith and Marx and the emergence of human capital. However, at the same time they identified social capital as the product of economic imperialism driven by the current socio-political context (Smith \& Kulynych, 2002, pp. 162 - 163). Unlike with Fine, this is via the expansion of what can be termed capital - from material goods, to include 'human capital' 
and eventually 'social capital'. They argued that this growth intermingled with the political, intellectual and economic milieu of the late $20^{\text {th }}$ century USA (Smith \& Kulynych, 2002, pp. 160 -161). The concept was appealing to economists and others because it "obscures understanding of many key political issues" (Smith \& Kulynych, 2002, p. 161), particularly growing inequalities that have resulted from free market policy changes. Social capital also fits into prominent "a-political" understandings of politics that have attempted to valorise capitalism since the fall of the Soviet Bloc (Smith \& Kulynych, 2002, pp. 162 - 164). They also offered a short history of the term that aligns well to the proponents that I have discussed above - Hanifan, Jacobs, Bourdieu, Loury, Coleman and Putnam which retains a gap between precursors (Hanifan and Jacobs), and founders (the other 4).

This section has highlighted the disjunction between critical and proponent histories' construction of the conceptual origins of the concept. For critics, social capital's origins are in $20^{\text {th }}$ century economics and the classical sociologists, economists and philosophers that proponents identified are either absent or dismissed. The socio-political context is also given more attention than in critical histories, and is centred on a need to expand neoliberal reforms to incorporate or account for the social. This is not completely dissimilar to Woolcock's socio-political context, although critics have been generally sceptical of any significant change in either economics or policy. Instead, critics characterise the embracing of the social as either a protection of a failing neoliberal programme or an expansion of it.

\section{Conclusion}

As I mentioned in the introduction to this chapter, my purpose here has not been to provide an alternative history, nor to judge the accuracy of the narratives provided. Rather it has been to explore the different histories provided and offer some suggestions as to why these histories may exist, and to draw some relevant observations from this. Histories of social capital, whether critical or non-critical, enact different realities: they interess powerful allies into differing assemblages to explain the current interest in social capital in different ways. Proponent histories interess the work of famous social scientists as providing types of social capital, which universalises its subject matter and enrol them as powerful allies to legitimise the current interest in social capital. In these histories, social capital is the latest in a long line of social science concepts addressing the same issue. For critical historians however, social capital is an economic concept. Consequently they delegitimise the concept by assembling an undesirable (at least to the critics) collection of 
scholars and political rationalities which they claim social capitalists have ignored. These different histories result from the disparate realities enacted by proponents and critics. Proponents enact a reality of concern over declining levels of sociability, long-term and stable interest in social relations in the social sciences, and a progression of attempts to explore this interest. In contrast, critics enact a reality of economic imperialism, declining scholarly standards, and scholarly attempts to defend neoliberal or capitalist policy programmes.

Proponents have generally been far less concerned with the socio-political context than critics. In both cases social capital is constructed as having emerged from a shift in politics in the late $20^{\text {th }}$ century. For proponents this marked a substantial development in the way that policy is produced and societies are governed, with a move beyond an over-focus on economic growth and development. For critics the shift was less substantial and was essentially neoliberals recognising a hitherto overlooked part of policy and incorporating it in neoliberal terms.

Studying these histories also highlights some of the limitations of accounts of social capital. I will focus here on the critical accounts since I consider this thesis to be closer to these authors than the proponents. The concern of authors such as Fine has been to discredit the concept by constructing it as tainted by economic origins. Whilst the focus on economics reveals some important insights, it has resulted in the generalisation and exclusion of other features of the concept. The difference between these histories also highlights the distance between critics and proponents. In producing their different histories, critics have also often been dismissive of the claims of proponents. For instance, the absence of economic uses or history is taken to be a deception rather than indicative of variation in the concept or a development of it over time and across different disciplines and discourses. As Farr noted in his response to Fine, the alternative explanations offered are often too general, drawing on a-priori explanations rather than attending to the specificity of social capital's emergence. There has also been little engagement by critics with the authors who proponents identify as their inspirations or their given reasons for interest in the concept.

To reiterate, social capital is too heterogeneous a concept to simply characterise as a weapon of economic imperialism. Furthermore, it has often been viewed by those who use it as offering something new both politically and analytically, often in contrast to neoliberalism or economics. Further drawing on actor-network theory, Boltanski has 
noted the need for critiques to recognise the critical and analytical capabilities of the actors themselves, and recognise that they are active in constructing their worlds. Consequently, a more insightful framing of the concept as often being part of several corrective critiques which is closer to how the proponent historians themselves frame their work, as a communitarian and sociological challenge to the individualism and overly-economic focus of contemporary politics. I will return to this argument throughout this thesis, noting how different critiques can be more or less radical and also may be opposed different tests. 


\section{Chapter 5: Social Capital in Public Health and Management studies}

The key limitation of the critical work on social capital revolves around the treatment of the concept's heterogeneous nature. Most critics have recognised that the concept has varied meanings, but in practice have tended to focus on one element (economics), or argue that the 'definitional chaos' of the concept is a further reason to abandon it. In this chapter I will use two case study disciplines, public health and management studies, to continue to explore the constructions of social capital that have emerged from the enactment of different realities. Social capital was translated into public health and management studies in the 1990s in order to address problems particular to each discipline. This initial translation has guided most of the subsequent work and definitions of the concept, resulting in different social capitals. I argue that the variation in social capital is at least in part a consequence of the different reasons why social capital was translated into particular fields. I will also highlight some of the commonalities of social capital's use in the two disciplines, in particular the quantification and simplification of 'the social' that social capital represents. These points feed into subsequent analyses of social capital in politics and policy since many of the phenomena observable in scholarly uses of social capital are also evident in these other discourses.

The disciplines of public health and management studies were selected because they were two of the largest (and most clearly defined) disciplines to employ social capital. Furthermore, an initial exploration of the disciplines indicated that researchers working within them have adopted substantially different understandings of social capital. Public health researchers have largely adopted a communal or ecological understanding of social capital, whereas in management studies social capital referred to resources embedded in networks that individuals or businesses can draw upon for economic benefit. The management studies discourse fits the critical characterisations of social capital, with it being an economic and rational choice based concept as individuals are understood to rationally decide to invest in and draw on social capital for personal benefit. However, public health researchers do not give social capital a rational choice framing. Indeed, social capital is constructed as a response to individualistic and behavioural approaches to explaining health outcomes, and as a way of accounting for both inequality and social 
context, it is embedded in communities and provides the social context or ecology that impacts on individual health outcomes.

I mentioned that work on social capital is often divided into network and communitybased approaches in chapter $2 .^{36}$ The former approach focuses on the relationship between individuals (or occasionally groups such as firms), and the assets and values gained by membership in these networks. The latter approach aggregates social capital to a 'meso' or 'macro' level, and social capital becomes part of the environment or ecology in which individuals or groups operate. From the latter perspective, social capital's absence or presence within a community or state is taken to influence the outcomes of the community or state's members. As with many features of the social capital literature, this division has its origins in the 1990s, and was partially influenced by Putnam's construction of the concept. As I discussed in the introduction, Putnam constructed two different social capitals: firstly as a solution to Hume's 'tragedy of the commons' based on spontaneous socialisation, and secondly, in a more generic way, to refer to the role that American communities play. In both instances however, Putnam discussed social capital as embedded at the community or society level rather than it being possessed or usable by individuals.

Many authors working from the network orientated approach to social capital have objected to the communitarian approach to social capital. Network-based scholars such as Burt, Portes and Lin argued that Putnam's use of social capital redefined it as a morallyoriented public good, as opposed to a form of capital. They argued that defining it in this way robbed the concept of its individual base and attempted to base individuals within a structuralist framework which negated the concept's analytical usefulness. Lin critiqued Putnam's because:

“[d]ivorced from its roots in individual interactions and networking, social capital becomes merely another trendy term to employ or deploy in the broad context of improving or building social integration and solidarity" (Lin, 1999 p. 33).

Lin (1999) proposed three necessary features of a social capital theory:

1. Social capital represents the resources embedded in social relations.

\footnotetext{
36 The latter is also referred to as an 'ecological', 'environmental' or communitarian approach. I have decided on 'community based' to avoid confusion with the communitarian political philosophy. Community based approaches and communitarianism have a substantial overlap in the social capital literature particularly, as we will see politically. However I want to avoid the assumption that an acceptance of a community based understanding of social capital by scholars equates to an acceptance or belief in the political communitarianism I outlined in chapter 2.
} 
2. These resources must be more or less accessible by the individual and

3. Individuals can mobilise and use these resources.

These are necessary in order for social capital to remain a form of capital. A similar emphasis was evident in Burt's critique of Putnam in management studies (which I will discuss later in this chapter). For both Burt and Lin, social capital referred to the resources that individuals can mobilise in pursuit of personal gains. From such a perspective, the higher an individual's social capital, the more successful they will be in achieving their goals and the surrounding levels of social capital, the 'environment', should not be considered as a form of capital.

This debate was only brief, and largely one-sided, with many texts based on Putnam's work not acknowledging the existence of network approaches. By the mid-2000s most texts which dealt with multiple different approaches to social capital acknowledged the existence of both network and community-based approaches to social capital without rejecting one or the other. For instance, Halpern's schema of different types of social capital included both network and communal approaches. Discipline-specific texts, such as Kawachi et al. (2008) in public health, also distinguished between the 'social cohesion' school of social capital, and the social network school, and recognised the validity of both approaches. The former emphasises the importance of networks, resources, or social associations for social groups, whilst the latter emphasises the importance of social resources (as distinct from other aspects such as networks or associations) for individuals and, occasionally, social groups.

Despite the acceptance of multiple approaches to social capital, different disciplines developed different approaches to the concept. Social capital was translated into both management studies and public health at about the same time, and researchers in both disciplines referenced many of the same authors. Thus, the theory-based explanation for the concept's variation does provide some purchase but it cannot explain why different disciplines have developed very different social capitals. Rather, as this chapter illustrates, social capital was translated in response to discipline-specific issues, and into particular pre-existing approaches, it was thus assembled from different actors, which impacted on the way social capital is measured and conceptualised in the discipline. 


\section{Social Capital in Public Health}

In most public health texts social capital described the impacts of the social 'ecology' on individuals' health outcomes. For many authors it was a 'radical' concept that has challenged behaviourist and individualist explanations for health. Whilst it continues to be regularly used in the literature (see appendix 4), authors have begun to challenge the association between social capital and health outcomes, questioning both the treatment of social capital as a single object, and the correlation between community-level social capital and improved health outcomes. Thirty public health articles provided the data for this analysis. Thirteen of these article provided were based on original empirical data, seven were literature reviews (of which four were published post-2010), and ten were theoretical or mythological articles. Half of the public health articles in the dataset were published in Social Science and Medicine, but no other journal had more than two articles published in them.

The translation of social capital into public health was sparked by a series of epidemiological studies performed by a research team working at the Harvard School of Public Health in the 1990s. The team included Ichiro Kawachi, Bruce Kennedy, Kimberly Lochner and others (such as Richard Wilkinson) occasionally working with them. These researchers adopted a macro-level analysis of social capital to explore the possibility of social capital as a mediator between relative deprivation and health outcomes. They used USA state-level data to explore the relationship between social capital, income inequality/poverty and a variety of outcomes, including homicides and violent crime (Kennedy et al., 1998), age-adjusted mortality (Lochner, Kawachi, \& Kennedy, 1999) and self-rated health (Kawachi, Kennedy, \& Glass, 1999). For these authors, social capital was part of an attempt to bring greater recognition to the importance of social relations and structures in explaining health outcomes. Consequently, it was part of the emerging psycho-social explanations for health outcomes and thus was in opposition to individualistic 'behavioural' explanations and functioned as a 'mediator' for materialist explanations.

By the 1990s, there had been a degree of acceptance within public health that access to material resources impacted on health outcomes and mortality rates supported by substantial government reports, most famously the UK's Black Report (Black, Morris, Smith, \& Townsend, 1982). Other studies, such as the Whitehall II longitudinal study of British civil servants, found that life expectancy and health varied even within 
comparatively wealthy groups and so material explanations and absolute deprivation could only partly explain health inequalities (Brunner \& Marmot, 1999). Consequently, Wilkinson, Marmot and others argued that relative, as opposed to absolute, deprivation was the key to explaining unequal health outcomes. Attempts to explain why this was the case resulted in the emergence of psycho-social explanations for health outcomes. Elstad identified three core assumptions of the psycho-social perspective:

1. "the distribution of psychological stress is an important determinant of health inequalities in present day affluent societies"

2. "psychological stress is strongly influenced by the quality of social and interpersonal relations"

3. "the latter are determined to a large extent by the magnitude of society's inequalities" (Elstad, 2002)

Importantly (I will return to this later), for many of the scholars advancing psycho-social explanations, these are complementary to, as opposed to contradictory to, material explanations (Wilkinson, 1996 ch. 11). These psycho-social explanations also formed a critique of individualistic focused approaches to public health.

Social capital was constructed as a component of these psycho-social explanations. In particular, Elstad's second assumption was identified as a consequence of the third assumption, due to the impact inequalities had on social capital. Kawachi stated that:

"A growing literature points to the deleterious health consequences of income inequality [...] Although this effect has been attributed to the harmful social comparisons and psychological perceptions triggered by relative deprivation, at least part of the causal chain linking income inequality to poor health is likely to be mediated by the erosion of sociability, trust, and reciprocity" (Kawachi, 1999, p. 127).

Kawachi also agreed with Putnam's thesis of the decline of sociability in American society. However, he argued that growing socio-economic disparities, and not generational differences, were the primary reason for this decline in social capital (Kawachi, 1999).

Another component of social capital in public health was its measurability using national or US state-level survey responses. These surveys constructed social capital at a different level of aggregation to the community or ecological operation of social capital, an issue that I will return to later. However, both components were intended to highlight the significance of hitherto underexplored 'environmental' or 'ecological' determinants of health inequalities. They distinguished social capital from personal social networks or ties, 
instead constructing it as "a feature of the social structure, not of the individual actors within the social structure; it is an ecologic characteristic" (Lochner et al., 1999, p. 260). Kawachi and Berkman (2001) also stated that social capital research indicated that social ties cannot be reduced to the individual level and that the macro level (measured through survey data) was central in determining health outcomes. Therefore:

"[t]he notion that an individual's egocentric ties are contingent on structural characteristics (e.g., the density of civic associations or the extent of voluntarism in a community) is one of the key insights of social capital theory" (Kawachi \& Berkman, 2001, p. 463).

Thus, Kawachi and Berkman constructed social capital as operating at the national, community and individual levels, despite admitting that there is difficulty in establishing a causal connection between them (Kawachi \& Berkman, 2001, p. 465). However, at the same time Kawachi and Berkman acknowledged Lin's work, and suggested that a network and ecological approach could be combined in order to situate the individual in a multilayered model of social structures via the individual's egocentric ties.

Most other researchers in public health, have since adopted a construction of social capital as an ecological factor in explaining health outcomes. For instance, Veenstra stated that:

"[s]ocial capital theory adamantly adheres to the perspective that social capital is more than aggregated characteristics of individuals, but certainly the individuals living in social capital rich communities reflect that fact by their personal participation patterns and their personal attitudes towards one another" (Veenstra, 2000, pp. 620 - 621).

Rhodes, Singer, Bougois, Friedman and Strathdee (2005) identified social capital as one of several structural determinants to explain HIV rates among intravenous drug users. They drew on Making Democracy Work to define social capital as "measured in terms of the social, collective, economic and cultural resources available to a network, neighbourhood or community" (Rhodes et al., 2005, p. 1032). The identification of social capital as a neighbourhood level property was justified because:

"[t] he more socio-economically deprived an area, the poorer is the access to social capital, and provision of health services, and in addition, the poorest tend to live in inner-city areas lacking in social resources and marked by social disintegration" (Rhodes et al., 2005, p. 1032).

Furthermore, they argued that social capital was significant because it was associated with macro-level political-economic forces. Rapid macro-level change, such as new policies, 
wars or upheavals may result in declining social capital, and in turn negatively impact on health outcomes. More recently Mohnen, Groenewegen, Völker and Flap emphasised that their study was exploring social capital as a macro-level ecological feature of the community as opposed to micro-level relational or individual resources. They measured social capital through self-reported association with the community adjusted for individual characteristics such as age, sex [sic.], income, home ownership etc. which were believed to have a potential impact on an individual's perception of social capital. They found that there was a correlation between neighbourhood social capital, and individual's health outcomes (Mohnen, Groenewegen, Völker, \& Flap, 2011, p. 666).

Other researchers applied this community-based understanding of social capital in different ways. For instance, Cattell (2001) focused on the historical and social context of social capital's emergence. Cattell accepted that social capital was a structural feature which connected poverty to ill health, but argued that the mechanisms by which it acts had been glossed over. She argued that the context of the neighbourhood, its history, stability, work opportunities, and opportunity for participation were all key determinants in developing social capital. The determinants of social capital included material elements, such as the design of communal housing to encourage cooperation and communal behaviour, echoing how Jacobs' had used the concept (Cattell, 2001, p. 1512). As with Kawachi and Berkman, Cattell also incorporated elements of the network approach in her construction of social capital, arguing that there are multiple different types of network groups (e.g. homogenous, socially exclusive, heterogeneous, solidarity based groups) each which affects individual's health differently (Cattell, 2001, p. 1502). She also suggested that the relationship between social capital and health outcomes may be complex because deprived areas may have high social capital, and so it is unclear which networks are best for protecting health. She suggested that if inequality is detrimental to health, then homogeneity may also be crucial to promoting better health outcomes, but this may further add to the exclusion of residents who cannot (or do not) conform, therefore lowering their health outcomes.

Given the macro-level and ecological construction of social capital within public health, Durkheim's position as an ancestor of social capital was particularly strong in the literature. Kawachi, Kennedy and Glass (1999), associated social capital with a Durkheimian research programme (Kawachi, Kennedy, \& Glass, 1999, p. 1187), a connection re-stated by Szreter and Woolcock (2004, p. 650). Giordano and Lindstrom claimed that Durkheim's work on suicide was the first research program to link social 
cohesion and individual health (2010, p. 700). Kawachi and Berkman also identified Durkheim as an ancestor, but they briefly discuss Brown and Harris's use of Durkheim to distinguish between social regulation (which may increase mental health problems) and cohesion (which protects against depression and other health problems) (Kawachi \& Berkman, 2001, p. 463). They use this distinction to argue that caution should be exercised in promoting tighter-knit, high social capital communities to address mental health issues.

The ecological factors, and inequality that were used in its construction, meant that social capital has been perceived as a critical, or even radical concept within public health. Johnathan Lomas characterised the concept as being on the 'radical end' of social health promotion and stressed that it was a way of bringing back the social system into public health, and challenging individualistic, behavioural notions of health promotion (1998, p. 1182). Lomas saw three elements to the social structure that related to health: the physical (material) structure, the social structure (such as mechanisms for redistribution, places to meet and opportunities for interaction), and social cohesion (the product of the adequacy of the former two) (Lomas, 1998, p. 1182). Contemporary interventions in public health had failed to address these determinants in favour of individual-orientated, and victimblaming interventions. This was, according to Lomas, a result of different value positions by different researchers (Lomas, 1998, pp. 1184 - 1186).

Fran Baum's editorial in Journal of Epidemiology and Community Health echoed the challenge to individualist and behavioural explanations in public health. For Baum, social capital was part of a growing recognition of the complex environmental determinants of population health, as well as a reaction "to the overwhelming dominance of economic considerations in public policy debates" (Baum, 1999, p. 195). ${ }^{37}$ She did, however, warn of the dangers of an 'uncritical' adoption of social capital as presenting a romantic view of community as well as the murkiness of the concepts application. She also briefly highlighted the political significance and contested nature of the concept:

"Those on the right of the political spectrum see social capital as an opportunity to argue for a withdrawal of the state from welfare and social provisions. Those more towards the left argue that state support is crucial to the accumulation of social capital” (Baum, 1999, p. 195). 37 Wilkinson had made a similar argument about social capital being a response to the overly economic focus of policy
and research (Wilkinson, 1996) 
However, Baum argued that social capital offered a "great opportunity for health promoters to flex their theoretical muscles in coming to grips with the social elements of health determinants and health promotion" (Baum, 1999, p. 195).

Later Kawachi et al. critiqued political uses of the concept in the Third Way. They argued that Third Way politicians had peddled the concept as a cheap solution to social problems that abrogate the state of its responsibilities to its citizens. In response, they emphasised the need to acknowledge power relations, and that social capital investment requires more than the voluntary labour of citizens and "requires real money and resources, and hence involvement in both the state and the private sector that are committed to such a strategy" (Kawachi et al., 2008, pp. 19 - 20). Whilst they maintained the partnership ethos of the Third Way as a valid mechanism to build social capital (see chapter 7), they were of the belief that state investment was more important because the private sector would underinvest in social capital. They also claimed that many of these political issues are not necessarily part of scholarly uses of the concept, meaning that scholars were more ready to identify issues and difficulties in building it. Social capital was understood by all of these authors as being aligned to progressive, or radical politics that challenge liberal and mainstream policy conventions.

In contrast to this construction as a radical concept, critics of social capital within public health have argued that the attention to social capital was damaging to progressive policy reforms and detracted from arguments over the importance of inequalities on health outcomes. Hawe and Shiell for instance, argued that the concept was too broad, adds little to the existing literature, and may damage other policy pushes due to its lack of depth. Social capital also excluded many issues and pre-existing initiatives such as community development, empowerment and capacity-building that "lean towards the political and material aspects of social capital" but in contrast "a great deal of social capital rhetoric pertains only to its relational aspects" (Hawe \& Shiell, 2000, p. 880). They also identified the concept's appeal to both communitarians and libertarians as an issue, and highlighted its use by the World Bank as further reasons for concern. Consequently they constructed social capital based on Coleman and Putnam as little more than a spray-on solution to the social problems that emerged in the 1970s and 1980s. ${ }^{38}$

\footnotetext{
${ }^{38}$ Hawe and Shiell also questioned the usefulness of the metaphor of 'capital' due to the concept's basis in trust and obligation. Social capital may have costs involved in its acquisition, and it is durable, but they argue that it is hard to determine ownership, it does not deteriorate with use, and it has intrinsic benefits alongside the instrumental ones commonly associated with capitals (Hawe \& Shiell, 2000, p. 874).
} 
Coburn constructed social capital as a meso-level approach, and argued that that its appeal resulted from income inequalities being deemed out of the reach of reform activities (Coburn, 2000). He claimed that meso-level concepts as deficient in explaining health inequalities. Instead he constructed an assemblage where neoliberalism caused both the growing inequality and decline in social cohesion that negatively affected health, which social capital researchers had ignored in favour of community-level explanations (Coburn, 2000, p. 138). Wilkinson responded to Coburn's critiques, constructing a different assemblage where relative deprivation, not 'neoliberalism'39 caused growing health inequalities and that "widening income differences seem likely to be damaging, almost whatever their source", re-legitimising social capital as an explanation for health outcomes (Wilkinson, 2000, p. 998). Wilkinson also denied Coburn's accusations of the depoliticisation of health inequalities in the social capital literature, arguing that the impacts of Thatcher and Reagan's reforms on health inequalities were never in doubt. Later Coburn expanded his critique to include income inequality or socio-economic statusbased approaches alongside meso-level approaches as ignoring the common cause of neoliberalism. Coburn argued that income inequality was a proxy for various health conditions "operating through individual and collective, material and psycho-social pathways, rather than [...] being a single main cause of poorer health" and instead constructed growing class differences as the underlying cause of poor health (Coburn, 2004, p. 43).

The ecological or structural construction of social capital was the most common one in public health, but it was not universally applied. Harpham, Grant and Thomas acknowledged this. They retained an ecological focus of the concept but also noted that:

“[...] while there is no 'set' definition of the concept in use, this paper understands social capital to refer to the degree of connectedness and the quality and quantity of social relations in a given population" (Harpham, Grant, \& Thomas, 2002, p. 106).

They split social capital into structural and cognitive elements, and addressed both. The former consisted of associational links and activity, the latter consists of trust, perceptions of support, reciprocity and sharing. Gilson, a health economist equated trust with social capital, and explored it in relation to health promotion (Gilson, 2003). She argued that there are two different poles of trust: trust as strategic (self-interested behaviour), and trust as moralistic behaviour, with the different poles being unequally distributed in

39 Wilkinson repeatedly put neoliberalism in quotation marks 
society. Gilson perceived both forms of trust as significant in encouraging healthy behaviours, at both the individual level through the relationship between health provider and patient, as well as their structural impacts through greater state legitimacy (Gilson, 2003).

The construction of social capital as a structural determinant of health outcomes was less stable in articles which discussed policy approaches to building social capital. For instance, Gillies argued that social capital was a necessary concept for health economists because it allowed them to better analyse the costs and benefits of health interventions on the community, particularly in relation to partnership or 'alliance' approaches to health promotion (Gillies, 1998). For Gillies the relationships between adults within a community was the basis of social capital, and whilst she did identify social capital as a way of addressing the structural determinants of health, she distinguished structural concepts from meso-level concepts. Social capital was 'meso-level concept' that offered inexpensive ways of:

"[...] offsetting the most abrasive effects of health inequalities in society. However, we must not forget that the provenance of many of the inequalities in health [...] lie in structural issues such as poverty, relative poverty, homelessness, unemployment and the like. Healthy public policy to address such issues must clearly continue to be pursued vigorously" (Gillies, 1998, p. 115).

Gillis was particularly focused on using community partnerships to promote health, and a community, as opposed to population level understanding of social capital. Her work highlighted the overlap between network and community understandings of social capital in many public health texts.

Thomas Bossert shared Gillies' concern for evaluating the effectiveness of the decentralisation of government decision making on health outcomes. He constructed social capital as the consequences of membership in associations, based on a belief in spontaneous socialisation. Using this construction, he was in favour of government decentralisation because it would allow communities to build social capital, which would "strengthen their capability to choose innovations and implement health programs effectively" (Bossert, 1998, p. 1525). Therefore, the role of government should be to provide incentives and sanctions to promote particular behaviours at the local level (Bossert, 1998). Both Gillies' (who worked for the UK's National Health Service at the time) and Bossert's use of social capital aligned to Third Way and political communitarian 
uses of social capital, with building social capital being perceived as a way to address social problems, whilst keeping costs low, and decentralising government decision making.

Szreter and Woolcock (2004) offered an unusual construction of social capital in public health. ${ }^{40}$ Whilst they recognised the greater structural focus of public health research, they identified the 'centre of gravity' in social capital research in general at the micro-end, of relationships and networks. As with most of Woolcock's work on social capital, they attempted to expand the concept's origins and interests across most of the social sciences, identifying many different definitions of the concept, and treating them as all valid. They recognised that the interest in social capital within public health was an attempt to account for inequality briefly, and outlined the importance of relative inequality as opposed to absolute inequality (Szreter \& Woolcock, 2004, p. 654). However, Szreter and Woolcock claimed that the advantage of social capital lay in its ability to combine the different public health foci of support networks, economic inequality and access to material resources as a unified explanation for health outcomes, and so incorporated a large swath of public health work into the social capital literature.

Szreter and Woolock attempted to apply social capital to explain health outcomes in $19^{\text {th }}$ century Britain. They began by arguing that the poor laws and a strong military-fiscal regime made $19^{\text {th }}$ century Britain the most cohesive society in the world. However, throughout the century there was a shift towards laissez faire attitudes and growing divisions in class interests, coupled with the 'New Poor Law' of 1834 and the growth of demands in the name of market efficiency. This resulted in a collapse in social cohesion and, in particular, a collapse in 'bridging' social capital between classes as different classbased ideologies developed (Szreter \& Woolcock, 2004, p. 658). They argue that this collapse in social capital resulted in poor health outcomes for the British urban working class in the second half of the $19^{\text {th }}$ century.

Regardless of the approach, social capital was always constructed as one factor amongst many in determining health outcomes within public health. However, many of the early studies excluded other factors from their analyses, and focused solely on the correlation between social capital and a chosen health outcome. More recent articles have identified this as a problem and have begun to resituate social capital as a single explanation among many. For instance, Huang et al. identified social capital as the theoretical underpinning

${ }^{40}$ Neither were public health researchers, Woolcock is a public policy lecturer who works for the World Bank, and Simon Szreter is a historian. 
for the adaption of public health to the challenge of climate change. The lack of social capital was one of six constraints to adaption alongside future uncertainties, financial challenges (particularly inequality), technological limitations, institutional restriction and individual cognition (Huang et al., 2011, pp. 184 - 186). Renalds, Smith and Hale's literature review identified social capital as one feature of 'built environments' that may have an impact on health, retaining the earlier concern over exploring ecological as opposed to individual determinants of health outcomes. As with Cattell, they constructed social capital as the outcome of the physical environment, with certain architectural designs improving sociability (Renalds, Smith, \& Hale, 2010).

The emphasis on multidimensional approaches to social capital in public health has been fuelled by growing methodological critiques of the concept. Particularly important has been the question as to whether social capital referred to multiple distinct phenomena that impacted on health in different ways, or a single phenomenon with a clear causal relationship. Even in early texts, social capital was divided into trust and associational membership, and each was measured differently. Self-reported levels of generalised trust and perceived reciprocity were measured using the General Social Survey ${ }^{41}$, and membership in voluntary associations, again using the General Social Surveys. These were stated to relate to the core constructs of social capital that Coleman and Putnam had identified (trust and civic engagement) (Kennedy et al., 1998, p. 8), however social capital was in practice generally treated as a single object.

Various literature reviews have since questioned the statistical correlation between social capital and health outcomes, destabilising social capital's strongest alliance in public health. Early in the literature, Veenstra found the relationship between social engagements in voluntary associations, that Putnam and others had used as a measure of social capital, and health outcomes was not strong. Instead, Veenstra argued that only the 'old standbys' of education and income were strongly related to health outcomes, making them superior explanations to social capital (Veenstra, 2000). More recently, Meijer, Röhl, Bloomfield and Grittner (2012), studied 40 texts on the correlation between community and mortality rates. Even though they concluded that, in addition to economic capital and cultural capital, social capital or: 41 "Generally speaking, would you say most people can be trusted?" and "Would you say that most of the time people
try to be helpful, or are they mostly looking out for themselves?" 
"[...] ALSES [Area-level socioeconomic status] has an effect on individual mortality because inhabitants in neighborhoods [sic.] affect each other's' health behaviour through exchanges of norms, values and social sanctions" (Meijer et al., 2012, p. 1209).

They found that the results were mixed, with roughly half of studies finding a correlation, and half not. Unlike Veenstra, they constructed this as the result of a lack of nuance. They were of the opinion that further research was required in order to "disentangle the relative contributions of the social and the physical environments on individual health and to identify mediating processes between ALSES [area-level socio-economic status] and mortality" (Meijer et al., 2012, p. 1210). Giodarno and Lindstrom noted a similar problem, with mixed results of social capital's impact on public health. They argued that this was potentially due to the different disciplinary foci all "vying for plausible explanations of the same phenomenon [social capital]", coupled with a conceptual failure to treat trust and participation as two distinct phenomena (Giordano \& Lindstrom, 2010, pp. 700 - 701).

The recognition that measures of social capital have failed to capture the multifaceted nature of social capital is a long running one within the public health literature. Lochner et al. (1999) argued that social capital was a complex construct, so the simple survey proxies and secondary data used by Kawachi et al. were insufficient in analysing it (Lochner et al., 1999, p. 108). Instead, surveys designed to measure social capital were required in order to fully capture the concept's complexity. These would be required to distinguish social capital from its causes and consequences, and would have to go beyond the aggregate of individual measures that are generally used in public health. This would include culturally sensitive measures, collective efficacy with an overall theme that "community characteristics ought to be distinguished from individual level characteristics, and measured as the community level" (Lochner et al., 1999, p. 267). Harpham et al. made similar observations and, as with Lochner et al., were supportive of developing more nuanced ecological measures (Harpham et al., 2002, p. 110). De Silva et al. also emphasised the importance of more sensitive measures of social capital, and the importance of incorporating context into analyses (De Silva, McKenzie, Harpham, \& Huttly, 2005, p. 629). Much like Kawachi et al., Suzuki, Takao, Subramanian, Komatsu, Doi and Kawachi (2010) distinguished between network social capital and ecological/community/macro-level social capital. They also argued (much like De Silva et al.) that the two approaches tackle different phenomena and so require different measurements even if they are not mutually exclusive (Suzuki et al., 2010). 
The argument that social capital conflates many different phenomena has become increasingly common observation in several areas of the literature and the public health literature has become increasingly fragmented over time. In response to the weakening relationship between social capital, as a single object, and health outcomes, recent empirical studies have begun to attend to the multifaceted nature of social capital. Ball, Cleland, Timperio, Salmon, Giles-Corti, and Crawford (2010) drew on survey data to explore the impact of social capital on women's physical activity rates in Melbourne, Australia. They divided social capital between individual, and community measures. Social participation rates and perceived (self-reported) connectedness with the community were individual characteristics because "these constructs both primarily tapped individuals" own behaviour, rather than characteristics of their community" (Ball et al., 2010, p. 809). Whereas:

"[a]t the community level social capital was operationalized as interpersonal trust, norms of reciprocity, and social cohesion within neighbourhoods, since these three themes tapped into perceived characteristics of the neighbourhoods [...]" (Ball et al., 2010, p. 809).

Regardless of level, all facets of social capital were measured through survey questions, as were levels of physical action. As with De Silva et al., the authors found that individual level measures of social capital were strongly associated with physical activity rates, but that with the exception of interpersonal trust (which used the General Social Survey question), community level measures of social capital were not correlated with physical activity rates. However, instead of questioning the validity of social capital, they suggested that their findings may have been the result of measuring physical activity responses at the individual, as opposed to community level (Ball et al., 2010, p. 810). Furthermore, the authors still advised that public health initiatives should be aimed at fostering both individual and community level interactions, as well as emphasising that this must not be at the expense of economic policies to address inequalities (Ball et al., 2010, p. 813).

De Silva, McKenzie, Harpham and Huttly reviewed empirical articles on social capital in public health and divided ways of measuring social capital into individual and ecological approaches (De Silva et al., 2005, p. 619). They found that the correlation between social capital and mental health outcomes was mixed. Individual level studies showed a consistent inverse relationship between levels of social capital and mental health outcomes, both when it was measured as individual's cognition (such as with levels of 
trust) or through behaviour (such as membership in associations). However, ecological studies showed mixed results often with no correlation. ${ }^{42}$ They concluded that their findings:

"[...] may underline the assertion that individual and ecological social capital do not measure the same thing, and supports arguments that it may be confusing to consider them as similar" (De Silva et al., 2005, p. 624).

To repeat a claim by many within the field, the public health literature on social capital neither defines nor measures the concept in a unified way. However, most authors have assembled a collection of statistical artefacts, with both psycho-social theoretical explanations, and social theory to construct an ecological, structural social capital. This has its origins in the reason for the concept's translation into public health - as a contribution to the emerging psycho-social explanations in the 1990s. From the psychosocial perspective, the public health literature focused too much on individual and behavioural causes of health inequalities, and the existing alternative - materialist explanation - did not fit the findings of inequalities among wealthy populations. Social capital allows the recognition of the impact of the social ecology in particular inequality on health outcomes.

The association between social capital and health outcomes (the most important alliance for social capital in the discipline), has been challenged, with questions raised of the methodologies used, and in the strength of the correlation between it and health outcomes. These critiques have, in part, been responded to by a more complex and divided construction of social capital, particularly between cognitive and structural social capital, and between macro and micro level social capital measures. They have not (as of yet) resulted in a decline in the concept's use in public health (see appendix 4), despite some articles challenging the 'core' argument of social capital in public health - that ecological level social factors impact on health outcomes.

The public health literature highlighted the significance of social capital as a quantifiable short-hand term for the social. It also highlighted the lack of context in constructions of social capital. Many of the empirical studies applied social capital to a different social

\footnotetext{
42 The following factors were significantly related to health: socialisation with workmates, willingness to turn to a workmate in times of trouble, attendance at religious services. But the first two were no longer significant once human capital was accounted for. Psycho-social constructs such as trust and community identification were not significant, neither were voluntary and community factors.
} 
context - state differences, exercise regimes in Australia, health outcomes in the south of the UK - with little account for the specificities of these areas. Despite the variations in method, definition and subject matter, all of empirical works in this dataset employed a quantitative methodology and generally relied on survey data to measure social capital. The American General Social Survey was commonly used - particularly its questions on perceived trustworthiness and reciprocity, and this was adopted in studies on social capital in other nation-states such as Australia, the UK and Japan. As Maynard and Schaeffer have noted, such survey research objectifies the subjective, standardising responses as demographic characteristics and making the population calculable (Maynard \& Schaeffer, 2000). Concurrently social capital itself was reified, with the assumption that certain survey questions measure social capital, or part of it.

An analysis of the public health literature suggests that caution should be exercised in making arguments about the economic elements of social capital. Most authors in public health did not include any form of rational choice, or economic theory into their assemblages of social capital. This is not simply (as Fine has claimed) a refusal to acknowledge embarrassing origins. Rather, the emphasis on a Durkheimian social ecology in social capital conceptualisation was because it was translated into the literature to support alternatives to individualistic or behavioural explanations for health outcomes. Features that critics have often decried as absent from social capital, such as power and inequality, have been central to social capital in public health. Elaborating on the relationship between inequality and health outcomes was a reason for social capital being translated into public health, and there was no 'bring back in' phase where researchers attempted to incorporate issues of power, class, ethnicity or gender into their research (Fine, 2010 ch. 3). The way that authors such as Baum, Lomas, Kawachi et al. positioned social capital also fits the description of a corrective critique. More particular it was occasionally part of a reformist corrective critique of public health, a discipline that straddles both scholarship and policy. However, this was not a significant part of the public health literature. However, as the management studies literature highlights, this should not be generalised to the social capital literature as a whole. In other disciplines social capital is strongly rooted in rational-choice explanations for human behaviour. 


\section{Social Capital in Management Studies}

In management studies, much like in public health, social capital was identified as fitting into a pre-existing literature and was again constructed as challenging "individualist, essentialist and atomistic explanations" and instead was promoting more "relational, contextual and systemic understandings" of behaviour (Borgatti \& Forster, 2003, p. 991). This fit was neat enough that Borgatti and Forster claimed that social capital added nothing beyond a renaming of pre-existing network concepts, making these arguments more powerful and influential by collating them into a single literature. There were a larger amount of empirical studies (21/30) within the management studies dataset than in public health. This also meant that there were fewer theoretical papers (6/30), and literature reviews $(3 / 30)$. The articles were published in a greater variety of journals than the public health articles. The Academy of Management Review and Journal published a combined seven articles, whereas the Strategic Management Journal published four, and MIS Quarterly published three articles, all other journals published one or two of the thirty articles.

As with public health, social capital was translated into management studies discourse in the 1990s. When compared to public health, the use of social capital in management studies has not varied substantially in methodology, object of study or conceptualisation of the concept, and there have been no substantial challenges to social capital's key alliances. In the management studies literature, social capital was constructed as the resources provided to either an individual or firm (the one substantial variation) from their relationships within a network. Social capital was important because it facilitated the transfer of knowledge between network nodes (individuals or firms, depending on the conceptual level of the network), thus improving either firm competitiveness or employee productivity. Methodologically, nearly all of the studies examined were based on quantified surveys of either firm managers or employees (Reagans and McEvily provide an interesting alternative). The community based approach was entirely absent from the management studies literature, and few authors cited either Coleman or Putnam positively (Nahapiet and Ghoshal providing the most notable counter-example). Instead Granovetter and Burt were the two prominent founding authors.

Management studies authors constructed a substantially different history of social capital than the ones that I discussed in chapter 2. Putnam was rarely mentioned in the management studies literature. Rather, Loury, Bourdieu, and Burt are placed alongside Coleman as the central founders of social capital theory (Cooke \& Wills, 1999). These 
influences were evident early in the literature. For instance, Belliveau, O'Reilly and Wade (1995) did not mention either Putnam or Coleman, and instead drew on Burt's work, whilst acknowledging the influence of Lin, Flap, De Graaf, Bourdieu, and others on the literature. When Putnam's work was discussed, it was in a highly critical fashion - such as Lin and Burt's discussion that I mentioned at the start of this chapter. Cooke and Wills argued that Putnam's work gave a static understanding of social capital, failing to account for variation over time and the process of construction of relationships. Rather, the network-based work of Ganovetter, Portes, Woolcock and Flora et al. has allowed the concept to move beyond a static concept of social capital to a dynamic one (Cooke \& Wills, 1999, p. 232). Zheng constructed Putnam as being interested in connecting networks and the efficiency of society (Zheng, 2010). Borgatti and Forster did not critique Putnam, but instead re-cast him as a network theorist, summarising his findings as " $[\mathrm{t}]$ he ties created by such associations such as organized bowling leagues are thought to knit a society together, ultimately contributing to a society's ability to prosper" which they argued was virtually identical to Granovetter's network theory (Borgatti \& Forster, 2003, p. 994). ${ }^{43}$

Although he did not use the concept of social capital, Granovetter (1973) was a key figure in the management studies literature. He advanced a network theory of sociology as a way of bridging the micro-macro gap. Without drawing on empirical data (instead claiming that intuition would suffice), Granovetter argued that weak ties, 'bridges' between networks of strong ties (determined on a "rough intuitive basis") are important in allowing the flow of knowledge and the integration of individuals into communities. The distinction between strong 'bonds' and weak 'bridges' has, through bonding and bridging, become a ubiquitous element of the social capital literature, even when Granovetter's influence is otherwise limited. Granovetter was strongly embedded in rational choice and social exchange theory, but he also attempted (through their network ties) to embed rational individuals inside larger social structures (such as communities) (Granovetter, 1973). Granovetter's influence on management theorist's use of social capital was most evident in the work of Ronald Burt. I mentioned in chapter 2 that Boltanski and Chiapello saw Burt's work as exemplifying the emerging 'connexionist' spirit of capitalism. This was because his work conceptualised relations in a networked way and constructed 'great men' as those who were able to best position themselves within these networks.

${ }^{43}$ Which is not to dispute their connection. However it is a more receptive approach to Putnam's work than most within management studies, most of whom do not even acknowledge Putnam's work. 
Burt's combined Granovetter's theory with an interpretation of Coleman and Bourdieu's understandings of social capital to construct his own social capital that facilitated the flow of knowledge over 'structural holes' (Burt, 1997, 2005). For Burt, structural holes exist in all networks because individuals lack incentives to broker (Burt, $2005 \mathrm{ch}$. 1). The construction of non-redundant relationships over these holes - 'bridges' - gave those who formed them (entrepreneurs and managers) greater social capital which they can then exploit for their own benefit by facilitating knowledge transfer across the hole. He further argued that the high returns from non-redundant relationships meant that individuals who were able to position themselves next to 'structural holes' between two densely connected networks can more efficiently exploit the transfer of information between the two. Being strategically positioned in 'structural holes' allows well-placed individuals to 'play' similar individuals, divided by the structural hole, against one another for further gain (Burt, 1997, p. 345), which Burt would later identify as an example of tertius gaudens ${ }^{44}$ (Burt, 2005, p. 17). A network where everyone knows everyone else destroys social capital because ideas and knowledge become homogenous in the group, therefore no one can benefit by bridging structural holes. Social capital was thus an individual property granted by network position, as oppose to a property of a network. As in Bourdieu, an individual's relationships gave them access to social resources (of varying quantities) for personal benefit. Thus, for Burt: "[s]ocial capital predicts that returns to intelligence, education, and seniority depend in some part on a person's location in the social structure of a market or hierarchy" (Burt, 1997, p. 339).

Burt was explicit about the influence of rational choice theory and social exchange theory on his work. Individuals are self-interested and play against each other to maximise the personal benefits which can be gained from their social capital. Burt's construction of social capital was used to justify the salaries and high standings of 'top managers', he found that managers are better brokers of ideas between different groups, and cited the favourable reception of top-managers' ideas by other top managers to support this (Burt, 2005 ch. 2). All of these features were repeated in the literature. For instance, Leana and van Buren, also emphasised that social capital is a property that individuals can exploit, in a similar way to Burt. This justified the concept's identification as a form of capital, because it involves investment for personal reword. Since it is capital, it is also an asset

44 "The third who benefits". Essentially an outsider who can insert themselves in a structural hole and play individuals off against each other can gain personal benefit from their position - a concept he attributed to Merton and Simmel. 
that may be beneficial for firms, and so needs to be managed appropriately to allow individuals to realise its full value (Leana \& van Buren, 1999, p. 539).

Whilst management studies' social capital was based in rational choice theory in many texts, social capital was seen as modifying the methodological individualism of management studies, by providing a 'contextual factor' that influenced individual action. Unlike in public health, this context was constructed of the network surrounding the individual relationship. In these approaches social capital was detached from the individual and was instead embedded within the network surrounding individuals (Kankanhalli, Tan, \& Wei, 2005; Nahapiet \& Ghoshal, 1998, p. 243). An individual's position within a network gives them greater or lesser access to the network's social capital. Nahapiet and Ghoshal's work on social capital provided an early and influential example of this construction. Drawing on Bourdieu and Putnam, they identified social capital as the trust and norms within networks. Granovetter's 'structural' and 'relational' embeddedness were reconceptualised as two of the three 'dimensions' that Nahapiet and Ghoshal identified in social capital: structural and relational social capital. Structural social capital referred to the actor's (either firm or individual) position within a network and interactions which provide advantages for the actor. Relational social capital referred to assets, such as trust and trustworthiness of individuals, embedded in networks. Finally, they identified cognitive social capital as pertaining to the shared norms and codes within networks (Nahapiet \& Ghoshal, 1998; Tsai \& Ghoshal, 1998). Tsai and Ghoshal applied this model to firms' value creation behaviour, arguing that structural and cognitive social capital create network social capital (i.e. trust) which in turn encouraged resource exchange and leads to value creation (Tsai \& Ghoshal, 1998, p. 466). Cooke and Wills also identified social capital as something that was not individually owned. They operationalised Granovetter's model of embeddedness by applying Woolcock's distinction of linkage, integration and synergy and identified embeddedness as one of the key elements of a dynamic understanding of social capital (Cooke \& Wills, 1999). They argued that linkage (connection to others outside of the community) was absolutely essential for small and medium businesses seeking to innovate (Cooke \& Wills, 1999, p. 223). Most other management studies 'social capitalists' adopted this construction of social capital, with the only significant variation being whether it operated at the individual or firm level.

The interest in social capital in management studies was due to its perceived instrumentality in improving economic outcomes and many of the studies were orientated 
toward providing practical advice in ways for firms and managers to either build more social capital, or to exploit it more effectively (Fang, Duffy, \& Shaw, 2011; Kankanhalli et al., 2005; Reagans \& McEvily, 2003). For instance, Brüderl \& Preisendörfer argued that social networks (particularly strong ties) played a key role in allowing entrepreneurs to overcome 'shortfalls' in human or financial capital and thus increased new business success (Brüderl \& Preisendörfer, 1998). More frequently, however, social capital was seen as key to the transfer of knowledge (human capital). The importance of social capital in knowledge transfer was identified as operating at both the individual and firm level (Nahapiet \& Ghoshal, 1998, p. 245), and both firms and individuals were identified as acting in the same way. Gold et al. began their research by stating that " $[\mathrm{t}] \mathrm{o}$ compete effectively, firms must leverage their existing knowledge and create new knowledge that favourably positions them in their chosen markets", and they saw social capital as a key, but under explored element of this transfer (Gold, Malhotra, \& Segars, 2001, p. 186). ${ }^{45}$ Kankanhalli, Tan and Wei identified social and technological factors as requiring simultaneous attention as key determinants in both the access, and exploitation of information, for either individual or firm gain (Kankanhalli et al., 2005). As in much of the management studies literature, there was a strong cost-benefit analysis to Kankanhalli et al.'s use of social capital: trust facilitates actions and knowledge transfer because it lowers the risk of opportunity costs for individuals (Kankanhalli et al., 2005).

Individuals' social capital was important in maximising firm's profitability and efficiency. Fang, Duffy and Shaw (2011) built on Burt and Granovetter to develop a model of social capital's impact on new employee socialisation within firms. They argued that the number of weak ties a new employee forged within a firm impacted on the employee's ability to clearly understand, and master their role and position within the new organisational infrastructure. Consequently, higher levels of social capital resulted in a better understanding of work, and thus better outcomes for both firm (higher levels of productivity and employee loyalty), and the individual (higher salaries, greater job satisfaction and promotions). As with much of the management studies literature, this was couched in practical terms - they wished to evaluate (theoretically) different socialisation strategies in order to determine which ones best produce social capital. Consequently, they offered a series of propositions to maximise social capital usage in socialising newcomers into a firm.

45 Kankanhalli et al. opened their study with: "The strategic management of organizational knowledge is a key factor that can help organisations to sustain competitive advantage in volatile environments" (Kankanhalli et al., 2005). 
In Fang et al., social capital was constructed as the product of organisational tactics as well as the newcomer's personality. They interessed organisational tactics and newcomer proactivity into social capital, arguing that they were linked with one another because they produced social capital for newcomers (Fang et al., 2011, p. 144). Levels of social capital in a firm was higher if there are active socialization structures in place, and the individual would be better placed to 'mobilise' this social capital if they have a proactive and highself monitoring and self-evaluating personality (Fang et al., 2011, pp. 140 - 141). Furthermore, since social capital was the resources within networks, the persons involved in the network (e.g. managers) may impact on the amount of social capital contained within a network. Whilst it was individualised, Fang et al.'s construction of social capital was more generalised and decontextualized than social capital in public health; the socialisation process that works best in one firm and with one employee was assumed to be best for others.

In a similar way to Fang et al., Reagans and McEvily used survey data to evaluate the (perceived) ease of knowledge transfer and codability in a firm. They complemented this with a sociometric and egocentric survey to assess network strength among 102 employees of an American research and development firm (Reagans \& McEvily, 2003). ${ }^{46}$ As with Burt, they noted the importance of structural holes, and presumed that, unless a strong tie crosses a hole, individuals would lack enough shared knowledge to facilitate further knowledge transfers (Reagans \& McEvily, 2003, p. 263). They divided knowledge into two categories - codified (formal) knowledge, and tacit (informal) knowledge, and argued that both the strength of ties, and the density of networks, made knowledge transfer easier, particularly with tacit, uncodified knowledge (Reagans \& McEvily, 2003, p. 260). However, given the (presumed) time and effort required to establish strong ties they advised that it would be inefficient for firms to foster strong ties to transfer codified knowledge. Instead, time should be more efficiently spent transferring tacit knowledge through strong ties, or establishing denser networks of weak ties to facilitate the transfer of codified knowledge. Thus, the complete closure of holes, and between individuals with

\footnotetext{
46 The sociometric survey asked each respondent to assess the closeness of their relationship with each other individual in the survey, and whether they had shared knowledge with that person. The egocentric survey asked individuals to respond to questions in order to generate names, and then describe the nature of their relationship with the named individual. The strength of each connection between individuals was also self-reported based on an evaluation of emotional closeness and frequency of contact, as well as if they consider the contact a friend or a source of advice. This resulted in a measure of network density based on the number of shared third party contacts between any particular individuals.
} 
different knowledge, should not be promoted, in order to allow a more efficient transfer of knowledge and completion of projects.

Whilst there have been few challenges to social capital in Management Studies, some authors have identified potential negative effects of improperly managed social capital on employees' performance. Oldroyd and Morris argued that the improper management of social capital negatively affects the productivity of 'star employees'. Non-star employees are likely to try and build ties with star employees in order to get the start to assist in the non-star's work. This leads to stars having an over-abundance of social capital, resulting in both greater levels of redundant information flows, as well as information overload for the star employee - negatively impacting on their performance (Oldroyd \& Morris, 2012). Furthermore, the star's greater social capital and knowledge is also likely to result in other employees requesting information from the star (again facilitated by their social capital), which further erodes the star's ability to complete their assigned tasks (Oldroyd \& Morris, 2012, p. 403). Again, this interest was practice-driven, Oldroyd and Morris argued that human resource managers need to develop strategies to manage the star's information transfer and prevent overloads. This could be achieved in various ways including improving the star's cognitive processing capacity and long-term memory, allowing them to have "diverse workplace experiences", and improving the star's motivation. Managers could also reduce the information load on stars by discouraging 'greedy' information requests, and providing support staff for the star to filter incoming information requests, and to narrow the star's networks (thus lowering their social capital).

The importance of social capital in facilitating knowledge transfer more efficient was not limited to the individual level, but was also seen as central to the transfer of knowledge between firms. Cooke and Wills (1999), Walker, Kogut and Shan (1997), and Yli-Renko et al. (2001) identified firm social capital as central to explaining the success of high-tech start-up companies. All of them predicted that poorly connected firms would be unable to access the same level of resources and would therefore be 'culled' from the industry (Walker et al., 1997, p. 110; Yli-Renko et al., 2001). Yli-Renko argued that this is because firms can be depicted as "repositories of knowledge and competencies", and social capital regulates the ability for the firm to exploit and acquire knowledge from other sources (YliRenko et al., 2001, p. 588).

Whilst firms were constructed as self-interested maximisers of resources, social capital theory was seen as offering a different model of the firm. Firms were seen as cooperative 
as well as competitive entities. For instance, Walker et al., measured social capital by the number of formal relationships firms had with other 'partner' firms, by using a database of 114 start-up biotechnology firms who had formed cooperative agreements. They distinguished social capital theory (that firms will choose to build new and durable relationships with others to constrain behaviour) from structural hole theory (that firms will choose to exploit a lack of constraining relations for personal gain), and found that social capital theory more accurately predicted the preferred strategy among start-up firms (Walker et al., 1997, p. 118). They suggested that cooperation may be due to a mutual dependence and firm's requirements for extensive long-term relationships, as opposed to the shorter duration associations of market transactions (Walker et al., 1997, p. 118). Thus, social capital was constructed as constraining partner firms, encouraging more cooperative behaviour and preventing competitive, opportunistic behaviour by others. The authors also argued that this could explain why inter-firm relationships were often of a long duration, instead of being short and exploitative (Walker et al., 1997, pp. 120 - 121). As in public health there has been some empirical challenges to the alliance constructed between social capital and its outcomes, particularly in studies of firm social capital. YliRenko et al. hypothesised that greater level of knowledge gained from social capital would result in young technology firms producing higher numbers of new products, their products being more distinctive, and having lower sales costs (Yli-Renko et al., 2001). As with Walker et al., their study was primarily based on surveys filled in by managers at startup tech firms. These surveys were supplemented by other data, such as the number of patents filed as a proxy for technological distinctiveness (which they acknowledge is a poor proxy but continued to use it), and sales and marketing data (Yli-Renko et al., 2001, p. 597). They found that, whilst some elements of social capital were positively related to knowledge acquisition, others, such as reported relationship quality, were negatively related (Yli-Renko et al., 2001, pp. 607 - 608). However, whilst they suggested that their findings were important because "it provides empirical support for proposition in recent research that different social assets may have different effects on relationship outcomes" they did not develop this into any challenge to, or critique of social capital research (YliRenko et al., 2001, pp. 609 - 610).

Whilst start-up and technology firms were the focus of many studies, other authors applied social capital to other firm types, to raise further questions about social capital. Carey, Lawson and Krause (2011) applied a standard survey of managers to UK-based manufacturing organisations. As with Yli-Renko et al., their focus was on the relationship 
between organisations and their suppliers, and also found mixed results. They divided social capital into cognitive (shared vision, ambition and values), structural (social interactions) which, when combined, fed into the norms-based 'relational' social capital. They found that 'relational' social capital facilitated the translation of different types of social capital into increased productivity, product quality and product development for purchasing firms (Carey et al., 2011, p. 285). However, unlike Yli-Renko, Carey et al. argued that different types of social capital have different impacts, and thus they conclude that greater attention should be paid to these components, instead of treating social capital as a unified object like most management studies texts had done.

As well as the need to distinguish between types of social capital, the benefits of social capital as a whole was challenged by Rowley, Behrens and Krackhardt (2000). Rowley et al. studied established steel and superconductor companies, and found no evidence that social capital was beneficial for steel firms, furthermore, in the case of highly interconnected industry networks, more ties (i.e. higher social capital) was damaging for performance (Rowley et al., 2000, p. 383). Thus, they argued that the advantage offered by ties is contextually dependent on how interconnected a network is. This inserted another actor (network connectivity) between social capital and firm performance that disrupted the relationship between the two, and detached structural social capital from relational social capital. Their work also highlighted a particular feature of the management studies literature - that social capital refers to being better connected, not necessarily being more connected. Rowley et al. argued that the more connections firms had with one another the greater the amount of redundant information for the firm. Furthermore as information is likely known by most or all others this would provide no competitive advantage for the firm (Rowley et al., 2000). This distinction was clear in Burt's work as well, where many ties in a closed network do not allow individuals to generate advantage over their peers, but a single tie to another network may give them great advantage.

Villena, Revilla and Choi (2011) have recently argued that social capital has a 'dark side' which leads to a loss of objectivity, opportunistic behaviour and poor (non-profitable) decision making. As with Carey et al. they divided social capital into different types, and argued that too much structural or relational social capital negatively affects performance. High levels of relational social capital resulted in excessive levels of trust, and thus increased opportunism by other parties. Furthermore, high levels of structural social capital resulted in too many strong relations and thus too much information to process, 
negatively impacting on performance. In contrast, higher levels of cognitive social capital (shared values and aspirations) did not at any stage result in diminished performance (Villena et al., 2011, p. 571).

When compared to public health, there was far less variation conceptually, methodologically, or in the methods employed to measure social capital, in the management studies literature. One significant variation has been the 'level' of the concept, with it operating at the individual and firm levels. However, in practice the two are treated as behaving in the same rationally-choosing, self-interested, and egocentric ways, mediated by the need to maintain social capital. The lack of variation is particularly evident in study designs and topics. Nearly all authors adopted similar survey-based analysis and almost all focused on the relationship between social capital and knowledge transfer. Barring the occasional recognition of the need for minor changes to the assemblage of actors that construct social capital (such as Rowley et al.) there does not appear to have been the same level of emerging doubt over the validity of social capital as there has been in public health.

The one notable alternative construction of social capital can be found in one of the earliest articles in the dataset. Belliveau, O'Reilly and Wade (1995) explored the ability of social capital to explain variations in CEO bonuses and compensation and conceptualised it:

"[...] in terms of both social similarity between a CEO and his or her compensation chair [of the board of directors] and the absolute and relative status of the CEO and the compensation chair" (Belliveau et al., 1995, p. 1569).

They argued that economic performance only explained $20-30 \%$ of the variation of CEO compensation, and proposed that both psychological and social influences played a more significant part. They constructed social capital from a combination of Burt's early work, and Bourdieu, resulting in social capital being the social similarity between two individuals (such as membership in the same organisations, or a shared identity) and an individual's status (membership in elite institutional associations). Social capital thus "takes into account the social context in which compensation decisions are made" (Belliveau et al., 1995, p. 1573). Their analysis was based on information gathered from 'Who's Who', Forbes 500, and Business Week's annual surveys to estimate firm performance and the levels of social capital possessed by CEOs and the company board's chairperson. Social capital was measured by the degree of overlapping background 
between CEO, and chair, and shared previous Forbes 500 board memberships. Social capital status was a measure of the number of board memberships in Forbes 500 boards, trusteeships, membership in social clubs, and undergrad degrees at Yale, Harvard, or Princeton (Belliveau et al., 1995, pp. 1576 - 1577). They found that there was no correlation between social similarity and compensation, but there was a significant positive correlation between the relatively higher status of CEOs compared to board chairs and compensation. They also found no correlation between CEO social status relative to other CEOs and compensation (Belliveau et al., 1995, pp. 1579 - 1582). Thus they concluded that more attention should be paid to the relative levels of social capital between decision makers (i.e. chairs) and those being remunerated instead of absolute status levels. They also constructed social capital as challenging traditional economic assumption that human capital, or performance, had significant effect on CEO remuneration (Belliveau et al., 1995, p. 1587).

A more recent atypical construction of social capital was evident in Stephan and Uhlaner (2010). They built on Fukuyama's exploration of the impact of culture on entrepreneurship, and drew on Fukuyama's construction of social capital as a culturally descriptive norm (or culture) to promote cooperation, in contrast to a performance based culture, which is more individualistic and future-oriented. The authors used the global Entrepreneurship Monitor Adult Population Survey to measure rates, and perception of entrepreneurs in 40 countries. They found that social capital, as opposed to a performance-based culture, "is the aspect of culture that drives both the overall level and the quality of national entrepreneurship" and thus improves economic performance (Stephan \& Lorraine, 2010, p. 1357). They positioned their findings in a changing interpretation of entrepreneurship as a socially contextualised, as opposed to individualistic endeavour.

Whilst public health researchers assembled social capital from a reality of aggregate statistical populations, inequalities, and ecological actors impacting on health outcomes, the management scholars assembled it from a reality of networked, rational economic actors, at either the firm or individual level. These actors were standardised, except in their access to, and exploitation of, different forms of capital for personal gain. Social capital fitted into this assemblage as a way of describing the function of social relationships in the flow of knowledge (economic capital). It was a type of capital because individuals had to pay costs to accumulate it. Once accumulated, it would grant advantage to competitive actors, primarily firms if they were able to exploit it. Management studies 
use of social capital lacked context and attention to other variables, even when compared to (still decontextualized) construction of social capital in public health. Each study provided a few 'hypotheses', and establishes the correlation (or rarely a lack of) between two different variables (social capital and either an input or outcome) and then draws generalised conclusions, with little, if any, consideration of other factors. When context is provided, it is simplified to redundancy. Stephan and Uhlaner for example, placed social capital as part of a cultural context for entrepreneurship, but they identified only two categories of culture across 40 countries and only a limited exploration of the legal and institutional influences on entrepreneurship. Virtually no social phenomena beyond social capital itself, whether specific (individual or group perspectives, personalities and so on), or general (social categories such as gender, ethnicity, or inequalities), were present in these studies. Belleveau et al.'s Bourdieuian analysis of social capital was the one example where the history of the studied individuals was even mentioned, and they also unusually, recognised status and inequality.

Unlike in the public health literature, there is little evidence of critique in the management studies construction of social capital. Rather to follow Boltanski (2011), the work is expertise-driven, aimed at improving management instead of changing it or improving the fairness of 'tests'. Management studies authors enacted a reality where individuals' and firms' value could be reduced to their levels of social and human capital. Variation between actors was only of concern to the extent that it impacted on performance, with no consideration of the personnel being managed. For instance, the possibility that 'star' employees may get job satisfaction from helping others even if they become 'overloaded' is ignored, as is the possibility that these employees may be antisocial, and so do not accrue greater levels of social capital.

\section{Conclusion: Constructing Social Capital to Address Problems}

In this chapter I have argued that public health and management studies researchers have used very different constructions of social capital, both conceptually, and in terms of measurement. The measurement of what is labelled social capital was different, in management studies social capital is measured through the number of relationships, and the redundancy of those relationships. Whereas in public health it was individual reported trust, membership in associations and similar measures, potentially aggregated out to either the network or society-level. Conceptually, social capital varied, from the 'resource capital' of management studies, to the ecological, or structural determinant of health 
outcomes in public health. Researchers in the two disciplines have also constructed different histories emphasising different founders, and situating social capital inside discipline specific pre-existing literatures.

This variation was, in part, due to realities that public health and management studies authors were enacting. The two disciplines enacted different realities which had their own actors and problems/issues that needed to be addressed. Social capital was constructed from assemblages of pre-existing actors in a way to address identified issues. Public health authors enacted a reality of structural inequalities in health outcomes, determined by inequalities in other (structural) features of society. It was a reality populated by aggregated survey statistics (not) correlating with one another, in assumed causal linkages. However for the authors who used social capital, too much attention was given to behavioural and material explanations of health outcomes, and a neglect of ecological or structural explanations for health inequalities. Social capital was translated into the public health literature as a way of describing the importance of elements such as income inequality, and community features. These ecological features have remained central to social capital's application and construction in public health. It is thus a 'structural' level explanation, and all of the empirical studies explored have used survey data to attempt to establish the correlation between the various phenomena labelled as social capital, and various health outcomes. Thus I have tentatively suggested that it could be understood as part of a corrective critique.

In contrast, social capital's use in management studies was part of an enactment of a reality of networked, and rational economic actors who performed to different levels because they possessed, or had access to different amounts of capital. For management scholars, social capital offered a simple way of discussing the impact of network density on firm and employee performance. It facilitated the flow of knowledge (human capital) between firms and employees, lowering risks for firms and improving employee performance. Consequently, it was something that required managing - either by building, or by ensuring that an optimal level was attained - with little concern as to the impact or fairness of that management on employees. Despite its micro-level approach, the management studies approach to social capital existed in a world of standardised individuals. Personal preferences, interests, personality, and personality traits were all absent from discussions of social capital (unless levels of human and social capital constitute personality traits). Inequalities were rarely discussed and, when they were, they were constructed as a justifiable and unproblematic result of different access to, and exploitation, of capital. 
As well as demonstrating the variability of the concept, the two disciplines demonstrated some of the commonalities of social capital. Social capital was translated into both disciplines by prominent empirical sets of work which remain commonly cited and largely defined future applications of the concept. Alternative constructions of social capital were present but in neither case appear to have replaced the construction that was initially translated into the literature. Management studies and public health scholars have both characterised social capital as important because of its positive outcomes, and much of the research in both disciplines is in establishing the validity of this connection. In public health, social capital is an important consideration because of its (disputed) impact on health outcomes. In management studies it is important in determining economic outcomes - either for the individual or the corporation.

Fine has insightfully observed that social capital over-simplifies the phenomena it purports to represent, and the outcomes attributed to social capital depend on which phenomena are excluded or included in any particular analysis (Fine, 2010, pp. 32 - 27). Per his idiom however, he saw this as characteristic of the 'McDonaldisation' of the social sciences that added nothing to the subject being studied beyond the advancement of the careers of a few 'hackademics' at the expense of the degradation of the social sciences in general. Whilst social capital clearly over-simplifies the social in its application in both management studies and public health, I disagree with Fine's argument that social capital added nothing. In both of the disciplines I have explored here, it has added an additional dimension of concern to the research, and a new way of addressing existing issues. In public health social capital added a way of discussing sociological factors in an ecological way - how communally orientated is your neighbourhood, and how connected to it are you - that were seen as impacting on health outcomes. This was a challenge to the prevailing behavioural explanations for individual's health outcomes, and also a way of addressing inequalities beyond simple material or income inequalities. The simplicity of the concept is part of its appeal, not because the researchers employing it were so degraded as to be incapable of comprehending a complex social, but because through its simplicity it appeared to allow for the exploration of particular associations that had been neglected in these disciplines.

Due to its simplicity, social capital enables the comprehension and measurement of a mess of complex, shifting phenomena. It also holds, or held, the promise of quantifying and measuring the important elements of the social under a single concept. What was considered important is different in public health and management studies, with the 
former concerned with sociability to improve mental and physical health outcomes, the latter is concerned with the ability to efficiently transfer knowledge required to maximise productivity and profitability. As the next two chapters will show, these features of simplification and quantification were central to the concept's appeal outside of academia. As Scott has made clear, simplification has problems - it often excludes key phenomena resulting in outcomes that are undesirable for both governors and the governed (Scott, 1998). It also creates problems for scholars. As is particularly clear in public health, social capital's simplicity results in it often being used to describe multiple different phenomena which often contradict each other. This has resulted in social capital being divided into smaller phenomena or 'types' of social capital which have been recognised as potentially contradictory in public health, but not (often) in management studies. As chapter 8 will discuss, the recognition of these limitations has also become increasingly recognised in national accounting frameworks. For instance, Hammer and argued that the concept declined in the World Bank because researchers increasingly required more nuanced and particular concepts, rather than an umbrella term for the social (Hammer \& Pritchett, 2006). 


\section{Chapter 6: Communitarian Liberalism and Critique: Social Capital in 1990s New Zealand}

In this and the following chapter, I will discuss the changing place and understanding of social capital in New Zealand policy and political discourses. In chapter 8, I will also expand this analysis out to include international national accounting frameworks which have adopted the 'capital approach' in expanding measures of progress beyond the GDP. Most of the academic work on social capital has been expertise based and particularly with Putnam's later use of the concept, often more accessible than many social science concepts. This work readily lent itself to being translated into political discourses aided during the 1990s by Robert Putnam's politically-orientated advocacy of the concept (Woolcock, 2010). Consequently, during the 1990s politicians in the UK, USA, Australia and New Zealand began to employ the concept in speeches, and a diverse selection of government ministries and NGOs began exploring its relevance to policy development. I will argue that exploring social capital illuminates the multiplicity of political philosophies in New Zealand at this time - with social capital being part of a communitarian stream in the Labour Party and to a lesser extent in the National Party led by Jim Bolger. I will also continue to explore the heterogeneous constructions of social capital. This discussion covers the three New Zealand governments since 1990, the fourth National government (1990 - 1999), the fifth Labour government (1999 - 2008), and the fifth National government (2008 - present).

This chapter will discuss the emergence of social capital in New Zealand during the 1990s. I will first explore the seminars on social capital organised by the Institute of Policy Studies. These seminars highlight the concept's variability, as well as its appeal to some critics of free-market reforms. In the second part, I will explore Bolger's advocacy of the concept, and how he constructed social capital in a way that was aligned to a liberal communitarian rationality and to justify the devolution of government decision making to communities.

The fourth National government came to power after winning the 1990 election promising to return decency to both politics and society, after the deep, and undemocratic market reforms of the 1980s, resulted in a Labour Party that was both internally fractured and externally unpopular. The Labour leadership, particularly Roger Douglas, David 
Cargill and Richard Prebble had pushed their reforms through quickly to avoid parliamentary debate and to ensure that opposition would come after the fact. This contributed to the government's unpopularity and instability which became particularly pronounced in the lead up to the 1990 election, when Labour had three leaders in a few months. Bolger's National Party won the 1990 election, and subsequently governed alone for two terms until 1996. After the first mixed-membership-proportional (MMP) election in 1996, National formed a coalition government with the populist New Zealand First Party, led by ex-National Party cabinet minister Winston Peters, and the small libertarian ACT (Association of Citizens and Tax Payers) Party.

Bolger's government continued and expanded many of the free-market reforms and government cuts of the Labour government. This included reforming areas such as labour laws and (most controversially) the healthcare system. Bolger led the government until the end of 1998, when he was toppled by the right-wing of the Party, and replaced by Jenny Shipley. Whilst his government pursued a free-market and deregulatory policy program, Bolger had built his 1990 election campaign on the promise to restore the "decent society". The decent society indicated an interest in establishing a new form of social policy that also incorporated a brand of paternalistic liberal communitarianism. Hughes characterised the decent society as building "a cooperative community supported by a range of basic but universal rights and ties of kinship in place of intrusive state intervention" (Hughes, 2013, p. 58). The interest in community was later evident in the National Party's 1993 election manifesto 'The Path to 2010'. According to Bolger, 'The Path to 2010' was to provide a stable, long-term plan to address issues of social cohesion "rather than just stagger from election to election" (Bolger, 1998, p. 261). In it, Bolger stated a concern for the need to address growing social problems in New Zealand through various lenses - including social cohesion, the decent society and social capital - but in each case he advocated for government withdrawal in order to allow diverse and active local communities greater control and responsibility for their members. Bolger's communitarian tendency was situated in a wider shift in the way populations were conceptualised in government that I discussed in chapter 3. During the second half of the $20^{\text {th }}$ century the construction of 'the social' as a monolithic population underwent a crisis in liberal politics. At the same time 'community', as a series of diverse populations became an increasingly significant domain in policy and political discourses. 
The translation of social capital into the New Zealand political context occurred at a time when the expansionist corrective critique of communitarianism was incorporated into policy. The incorporation of this critique meant that economic policy was no longer perceived as sufficient for policies to build wellbeing. Social capital provided a way of conceptualising the influences that social relations had on wellbeing. Within political texts, social capital was constructed as both compulsory for successful communities and 'buildable' through quality governance. The concepts' breadth, and overwhelmingly positive valence in political discourses further added to this appeal. A simple equation of more social capital with higher living standards is as powerful as the already existing rhetoric of 'economic growth' increasing living standards. As with my discussion of scholarly uses of the concept, this argument should not be generalised to all uses of social capital. In politics, as in academia, the concept is heterogeneous, and has been constructed differently by different authors, in part in response to the policy issue being addressed. Whilst there was a degree of continuity between Bolger's use of the concept and early uses by Labour ministers, there were also differences, particularly in the role of the state, which I will return to in the next chapter.

I mentioned in chapter 2, that political uses in New Zealand were influenced by Robert Putnam. In Bowling Alone, and the earlier articles on the same topic (Putnam, 1995), Putnam offered both explanations for, and solutions to what he saw as a decline in social capital in western societies. Putnam visited New Zealand twice in the late 1990s at the request of a group of scholars and policy people interested in social capital and spoke at a series of meetings organised by the Institute of Policy Studies (Robinson, 1997a, p. 1). This visit, and growing interest in the concept in Australia, sparked an emergence of policy-orientated academic work on the concept of social capital in New Zealand.

Whilst Putnam would have a substantial influence on social capital in New Zealand, the initial introduction of social capital in New Zealand was driven by the advocacy of the then Prime Minister Jim Bolger, who wished for a way to address social issues in New Zealand. Bolger would introduce the concept to the wider political discourse in a series of speeches during 1997, beginning with his five 'Millennium Agenda' speeches which drew heavily on Francis Fukuyama's work on trust. For Bolger there was a pre-existing lack of social capital in New Zealand which, due to social capital's overwhelmingly positive valence required building, primarily through the withdrawal of central government from policy making. At the same time several ministries, including StatsNZ, 
began exploring ways to operationalise the concept, either by measuring it, or developing policy to 'build' it.

\section{Critique, Community and Productivity: Social Capital in the Institute of Policy Studies Workshops}

The Institute of Policy Studies (IPS) began working on social capital in 1996 in response to Jim Bolger's requests for conceptual tools to build community oriented social policy. The IPS began discussions of the concept in New Zealand policy circles, inviting a range of politicians, civil servants, organisers of non-government organisations (NGOs) and others taking part in a series of workshops they organised in Wellington (Good, 2000). Two of these workshops were held in 1996, with an additional one in 1997 and a fourth in 1998. Papers from three of the workshops were published in three edited collections Social Capital and Policy Development (SCPD) (Robinson, 1997b), Social Capital in Action (Robinson, 1999) and Building Social Capital (Robinson, 2002b).

The purpose of the 1996 workshop was to "clarify how the ideas associated with the term 'social capital' could contribute to current policy development in New Zealand" (Robinson, 1997b). The 1998 and 2000 workshops would move discussions away from conceptualising the concept toward case studies of community projects for building social capital (Robinson, 1999, p. 4; 2002b). All papers in the workshops adopted the same definition of social capital established in the first workshop, that:

"The term 'social capital' refers to the social networks that help society to function effectively, the voluntary associations (including community groups, sports and cultural clubs, and residents' associations) that provide linkages between people in the community and enable them to be more effective in business, politics and a wide range of social activities. Social capital refers to the 'connectedness' between citizens. To develop social capital communities require high levels of trust, a range of voluntary associations, and opportunities to meet and discuss community concerns" (Robinson, 1997a).

The definition aimed to reflect the variability of the concept, as well as the tendency to define social capital by both its inputs, and outcomes (which may also be the same thing). As with most uses of social capital, this definition lacked contextualisation, with no reference made to any specifics of the New Zealand context. It also highlighted that social 
capital was not defined by any economic connections, rather it was a way of conceptualising social relations in a way that was distinct from economics. However, whilst they shared this definition, the various presenters constructed social capital in different ways. Many of them also contextualised the concept to Aotearoa/New Zealand, particularly with the discussion of Māori social capital.

Many of the presenters at the 1997 workshop were civil-servants, or policy-orientated academics. However there were also two economic consultants (George Barker from the Law and Economics Consulting Group, and Ifor Williams from TradeNZ), and two members of non-profit NGOs (Ted Douglas of the Maori Congress, and Mike Riddell of the NZ Council of Christian Social Services). The 1998 workshop included a combination of heads of non-profit NGOs (Barrett, Trout, Puketapu), and analysts/academics (Cody, Robinson, Witten-Hannah), with Paul Curry (Department of Internal Affairs) providing a commentary on the proceedings. The workshop in 2000 lacked presentations by either civil servants or economists. Instead the topics of debate were orientated toward analysis of case studies (Robinson, 2002b; Williams \& Robinson, 2002) or social theory (Cody, 2002; Robinson \& Robinson, 2002).

With the exception of the two economists, presenters discussed social capital in relation to civil society and community, with economic growth being at most a peripheral concern. Whilst Putnam's Making Democracy Work was drawn on by several presenters, it was cited because it highlighted the significance of civil society (and social capital) for social progress, rather than its theoretical basis in game theory or spontaneous sociability. Other elements of the concept - such as its relation to economic growth (and the neoliberal reforms), as well as why the concept was important were contested in the workshops with some presenters arguing that social capital and the associated social cohesion had intrinsic value, and others seeing the concepts as only relevant if it could demonstrate instrumental value in different areas such as economic growth, crime rates or healthcare. This connection to community and civil society, and the perceived instrumental value of social resources would be central to the concept's political purchase in New Zealand for the next decade.

The focus of a number of presenters, particularly those speaking about, or from a Māori perspective, was on the need to recognise the damage that previous policy had done to social capital and Māori communities. In these presentations, social capital was 
constructed as have been damaged by economic reforms. Ted Douglas of the Māori Congress argued that what he termed the economic and social adjustment programmes of the 1980s and 1990s, "run counter to programmes designed to encourage social cohesion, civic engagement and social capital" (Douglas, 1997, p. 5). He was also concerned with the long-term effects on Māori social capital from the assimilationist, and individualist, Pākehā ${ }^{47}$ government policies which emerged from the reforms. These policies contributed to inequality, unemployment and exclusion and unless these were attended to:

"[...] by the increasingly illusionary partnership between Maori and Pakeha, then the considerable store of social capital in Maori communities will be undermined and frittered away and the ability of the rest of society to make progress will be severely compromised" (Douglas, 1997, p. 12).

Presentations in later workshops constructed Māori social capital in a similar way. Williams and Robinson provided an ethnography of the impact of Māori social capital on the ability for the Opotiki community ${ }^{48}$ to address social problems and provide social services. As with Douglas, social capital provided a way for Māori to address problems that emerged from various assimilationist policies, the economic reforms of the 1980s and 1990s, and most recently the 'Closing the Gaps' of the $5^{\text {th }}$ Labour government (Williams \& Robinson, 2002, p. 17). Williams and Robinson also expanded on the theoretical understanding of how Māori social capital was distinct from Pākehā. They suggested that Māori social capital was an expression of their cultural capital in practice, thus it was embedded in the seamless boundaries between iwi and whānau, unlike Pākehā social capital which is embedded in community and formal associations. The informal nature of Māori social capital was also seen as important because of the potential damage that could be done to it by attempts to formalise relationships and associations (Williams \& Robinson, 2002). This differences in social capital contributed to the problems in engagements between Māori and Pākehā because:

"[i] $\mathrm{f}$ Maori are locked out of the often informal discussions that take place in non-Maori social settings and only have the opportunity to engage in formal structured meetings, then it is unlikely that they will be able to make full use of their social capital resources in these discussions" (Williams \& Robinson, 2002, p. 28).

\footnotetext{
${ }^{47}$ The Māori term for the European (or non-indigenous) New Zealanders.

48 A small rural community in the North Island of New Zealand with a majority Māori population.
} 
The construction of a Māori social capital as distinct from Pākehā social capital, and the importance of social connections within Māori, have been taken up by Māori politicians and advocates. Most of these constructions also positioned economic growth and state intervention as detrimental to Māori social capital. This contributed to critiques of both market fundamentalism and state-based policies designed to 'include' Māori but which are not 'by Māori, for Māori'.

Puketapu was particularly critical of government intervention in Māori life. In his presentation to the second IPS workshop, Puketapu contrasted government people who "cannot think like you [Māori] because they are already tied to the whims or the decisions of politicians" with Māori communities taking ownership of their own futures and decision making through the use of the social and cultural capital of the people (Puketapu, 1999, p. 17). Although he used social capital in his presentation, he expanded the critique of the free-market reforms to the concept of social capital itself, stating that the two words do not go together. Consequently, he stated that for the purpose of his presentation social capital was "about people" (Puketapu, 1999, p. 16). By positioning social capital in opposition to both government and economy, Puketapu echoed the tripartite division between state, civil society and economy common in the communitarian literature. Puketapu used social capital to represent civil society which he, much like Etzioni, positioned in opposition to both an overly strong state and the exaltation of the virtues of the free market.

Barrett's presentation also shared the critique of government policy aimed at Māori (in this instance to increase immunisation rates among Māori), but on the grounds that government involvement prevents the community development key to building social capital (Barrett, 1999, p. 101). This was particularly valid for Māori because "Maori work naturally in a community-based model, so a community delivery system should continue and be encouraged - we as a community are good at it" (Barrett, 1999, p. 100). She identified the jealousy instilled in individuals by capitalism as a further factor limiting the ability for community projects to build social capital because the individualistic ethos of capitalism undermined cooperative, communal projects. Consequently Barrett advocated for the devolution of relevant policy making power to the Maori Women's Welfare League, because unlike the government, NGOs were aligned to the community. 
Presentations addressing Māori social capital were not the only ones where social capital was constructed as damaged by economic fundamentalism. Although Riddell stated that he wished to avoid delving into debates about the necessity of the free-market reforms, he argued that the selfishness, individualism, inequality and side-lining of human dignity that emerged from the reforms were antithetical to Christian thought (Riddell, 1997, pp. 22 - 23). He further believed that the concept of social capital offered a way out of the economic fundamentalism that had driven New Zealand policy concluding that:

"[i]t is ironic that social capital should enter public discourse through the Trojan horse ${ }^{49}$ of economic policy considerations. It seems that discussions of issues of value are only possible when legitimised by their bearing on economic consideration $[\ldots]$ The current discussion will be unproductive if its scope is only limited to factors which advance the prosperity of the nation. It must encompass questions such as the nature and purpose of civil society, the value of freedom in democracy, the significance of collective responsibility and the negotiated policy goals of government" (Riddell, 1997, pp. 24 - 25).

The presentations that I have discussed so far, exemplified the communitarian corrective critiques of policy based on the need to build social capital. Each contained an expansionist critique, arguing that policy concerns needed to be expanded beyond economic fundamentalism, in particular to account for Māori interests. They also contained a reformist critique of the economic fundamentalism of New Zealand policy. Whilst each author labelled the market fundamentalism of New Zealand policy in a different way (economic fundamentalism, capitalism, assimilationist economic reforms) they all constructed it as something that was problematic because it damaged social capital. This drew on pre-existing critiques. Riddell in particular situated his presentation in this debate, citing the work of critics of neoliberalism, such as Kelsey (Kelsey, 1995) and Randerson (Randerson, 1992), as providing evidence of the social damage resulting from the free market reforms. These constructions of social capital were also similar to that of Eva Cox in Australia who also identified social capital as something that was damaged by freemarket reforms (Cox, 2002). However, given the distrust of the state by the Māori presenters, social capital was often placed in opposition to both the logic of the market and the state.

${ }^{49}$ Using the metaphor earlier, and in the opposite direction to Fine, and Somers. 
A more instrumental understanding of social capital was offered by the civil servants and academics who presented at the workshops. For civil servants, social capital could be an important concern if it could demonstrate to have an impact on their particular department's area of interest. For example, Peter Crampton's treatment of the concept also had an instrumental focus in relation to health outcomes (Crampton, 1997). Crampton's presentation was largely a review of the public health literature, and aligned with what I identified in the last chapter as the common construction of the concept in public health: he saw social capital as "chiefly a characteristic of societies rather than individuals" (Crampton, 1997, p. 65) and as a mechanism linking growing inequalities with health outcomes (Crampton, 1997, p. 75). Other areas of interest included crime Joblin, 1997), social cohesion and economic benefit (Blakeley \& Suggate, 1997; Reid, 1997) and conservation of the natural environment (O'Brien, 1997).

Several presentations in the second workshop (Social Capital in Action (Robinson, 1999)) focused on the relationship between NGOs and government, including several from the perspective of NGOs. All of these presentations emphasised the importance of partnerships to ensure that NGOs had government support, but also remained independent from the state. This would allow NGOs to both provide services and build social capital in the communities in which they worked. I mentioned how Barrett's presentation focused on the importance of giving greater control to non-government 'community' organisations. Witten-Hannah explored social capital's role in community development, and also emphasised the need to move toward "smaller, locally controlled and more personalised support and decision making systems" to move toward a less expert-focused and more empowering governance (Witten-Hannah, 1999, p. 25). She believed that her case study of the Waitakere City Council's 'West Coast Plan' provided evidence to support partnership-based devolutionary policy, provided that this was based on a 'shared vision of the future'. She further argued that social capital could potentially benefit, and benefit from, a devolutionary approach to policy. However, the connections made by Witten-Hannah were highly abstract: social capital's impacts included an influence on the "levels of understanding between participants", improving the ability of groups to represent their members, and be empowered. Partnership-based policy was beneficial for social capital because it: provided a catalyst to bring people together, fostered a sense of pride and attachment to their place for individuals and groups, and built relationships between government and community (Witten-Hannah, 1999, pp. 41 42). Her policy model fitted well with the deliberative democracy advocated by Third Way 
thinkers at the time, and aligned with some of the policy programmes that the $5^{\text {th }}$ Labour government would subsequently adopt (see chapter 7). She also contested some of the implications of the Māori non-profit presenters, stating a concern that parallel policies for different ethnic groups would not encourage them to work toward shared goals and so would lead to tension and disharmony (Witten-Hannah, 1999, p. 40).

Trout discussed the NGO Plunket's ${ }^{50}$ role and focused on the impact of community cohesion and child health outcomes and the impact of the changing relationship between government and Plunket on the latter's performance. She interessed data from Runyan et al.'s (1998) application of a social capital index to the LONGSCAN (Longitudinal Studies of Child Abuse and Neglect $)^{51}$ study to construct New Zealand's levels of social capital as dangerously low, and to highlight the role Plunket takes in providing home support for children, ${ }^{52}$ in order to advocate for greater funding for Plunket. She identified both benefits and problems for Plunket from the changes toward a 'funder-provider' model in 1994. She identified benefits of faster review systems and operational process from the changes but also problems resulting from a lack of funding and training for Plunket staff.

Two presenters in the first workshop (Barker and Williams) constructed social capital from assemblages of economic actors. As with management theorists, they constructed social capital as a resource for individuals that required investment and gave returns. Barker, although sceptical of the concept's relevance, discussed social capital within a rational-choice framework. Barker separated social capital out from community, arguing that social cohesion and economic growth emerged spontaneously from individuals' pursuit of their self-interests (Barker, 1997, p. 140). For Barker individuals' pursuit of their interests was limited by their income, but investing in or having access to other forms of capital allowed individuals to expand these limits (Barker, 1997). Social capital was potentially one such form of capital, however any impact would only be through social capitals' exchangeability with other forms of capital and not any intrinsic value. He

\footnotetext{
${ }^{50}$ A charity that provides free health services to children under 5 in New Zealand.

51 A study coordinated by the University of Northern California since 1991 that has explored the causes and long-term impacts of abuse and neglect on children aged $0-14$.

52 Runyan et al.'s study on the impact of family social capital is part of a larger literature using the concept in paediatrics that I do not discuss in detail here. They identified five measures of social capital in their study. High social capital families were ones with two parents in the same household, no more than two children in the household, possessing social support for the mother, and strong neighbourhood support (both measured through a survey of mothers) and with a mother having strong church involvement (Runyan et al., 1998, p. 14). Their study is one of the clearest examples of a strong moralistic conception of social capital, with at least three measures being based on moral expectations of good parenting. It also treated social capital as a multidimensional concept that required a 'constellation' of measurements to be properly addressed.
} 
concluded that social capital, needed a 'coherent framework' that 'implies an emphasis on the dynamics of economic and social exchange and investment decision making." Such a framework was required if the concept was to be useful for policy development (Barker, 1997, p. 148)..$^{53}$

Williams drew less on behavioural economics than Barker, and instead focused on social capital's role in producing 'high performance clusters' of business. His presentation did not discuss social capital in any particular depth but, for Williams, New Zealand was a low-trust economy which limited New Zealand businesses' abilities to collaborate with other firms and form high performance clusters. Consequently entrepreneurs (such as TradeNZ) were required to facilitate greater levels of trust in New Zealand and build "business connections and aligning the diverse range of separate elements that are necessary to build the wealth creating capability of their community" (Williams, 1997), with the end goal of improving New Zealand's export performance to stimulate economic growth. As with Barker, Williams' presentation was closely aligned to the management studies literature in both concerns and in the way social capital was conceptualised. However, Williams was less focused on establishing a behavioural basis for social capital, and instead focused on the relationship between trust and economic growth.

This brief analysis illustrates that the early work on social capital in New Zealand was seen as a way to promote civil society and, with the exception of Barker, lacked any basis in spontaneous sociability or game theory. It also demonstrates that social capital was at the same time an immutable and mutable mobile. The activist presenters, particularly when discussing Māori, used a concept that had been translated from the United States to enact a reality where decades of assimilationist policies and capitalist/neoliberal economics had threatened the social capital at the heart of Māori culture. Thus, for these presenters, the need to build social capital ran counter to current economic policy, and policy required reforming in order to recognise the importance of social capital to prevent further damage to it. At the same time a small town in New Zealand was constructed as sharing parallel concerns (a decline in social capital) with the United States, demonstrating that the concept was not entirely mutable. Other presenters, such as Williams or Barker, enacted a reality where social capital was complementary to current economic policy. Williams and Barker's assemblages also differed from one another; Williams assembled a similar group

${ }^{53} \mathrm{He}$ also stated that "Our interest in social capital is only instrumental" in the pursuit of economic growth and social cohesion 
of networked business actors to the management studies scholars I discussed in the previous chapter. Barker in contrast focused on the behavioural and exchange aspects of economic thought, constructing social capital as an uncertain actor that, if it existed, resulted from the rational, self-interests of individuals. Overall though, the demand to reform economic policy was particularly strong in the IPS presentations, particularly when compared to the ways that government ministers would use the concept.

\section{"All that is good in Society": The Social Capital of Jim Bolger}

As I mentioned above, Bolger was an early advocate of social capital in New Zealand, and consequently he was interviewed as part of this project. Bolger was also the first New Zealand politician to extensively employ social capital in political speeches. Whilst other ministers (notably the then Minister for Crown Health Enterprises, Bill English) occasionally used social capital, Bolger was by far the most enthusiastic proponent of the concept during the $4^{\text {th }}$ National government, an enthusiasm that echoed his long-term interest in community and social cohesion. Bolger introduced social capital in a series of speeches to the National Party's regional conferences entitled 'The Millennium Agenda'. He used social capital in 15 other speeches, in the 7 months between the first of these speeches and him stepping down as Prime Minister on the $8^{\text {th }}$ of December. The speeches were on a range of topics and to a diverse collection of audiences, from the New Zealand Royal Air Force to the Royal College of Psychiatrists and the Auckland Chamber of Commerce, as well as dedicating a chapter of his autobiography to his uses of it (Bolger, 1998).

Bolger's use of social capital was not particularly theoretically developed. He did not provide a definition of the concept when he introduced it in the 'Millennium Agenda' speeches. However, two months after the 'Millennium Agenda' speeches he defined social capital as "all that is good in society" (02/08/1997). A definition he repeated in a slightly modified form in his autobiography. ${ }^{54}$ This 'good' was never elaborated on, but it did not need to be: for Bolger social capital was the reason why the government needed to devolve decision making to communities. Consequently, the specific benefits of social capital were less important than it being something New Zealand needed to 'build' more of, which allowed policies that built it to contribute to the common good.

54 "the sum total of all that's good in society." (Bolger, 1998, p. 259) 
Perhaps because of the definition he assigned to it, Bolger's use of the concept focused on outlining ways of building social capital, with little attention to the potential outcomes of higher social capital. Whilst his development of social capital was limited, Bolger was clear that building social capital required devolving decision making to the community and trusting communities to address their own, local problems. He repeatedly stated the importance of devolution of power to the community:

"The central thrust [of his speeches on social capital] is to provide greater opportunities for people to be involved in issues that directly affect them - like education, health and safer communities. The way to achieve this is to devolve power" (Bolger, 08/08/1997).

"Social capital is about the community successfully achieving progress towards solving society's ills" (Bolger, 02/08/1997).

"The goal of Government in the first decade of the $21^{\text {st }}$ century, must be to continue to successfully manage economic issues, define our national identity in a way we are comfortable with and most importantly build up the social capital of New Zealand by trusting and encouraging the community to take greater responsibility" (Bolger, 25/09/1997).

For Bolger, devolutionary policy had not been attempted before because it was a "step away from our [Central Government] traditional comfort zone” (Bolger, 02/08/1997), either due to a lack of trust in communities' abilities to manage their own affairs, or in the case of Labour, the ongoing influence of interest groups and unions. ${ }^{55}$ For Bolger, the challenge of building social capital fitted "like a glove to the core values of the National Party; it reaches back to the way civic society operated before the arrival of Big Government" (Bolger, 17/05/1997). In his interview Bolger clarified why devolution was necessary. He stated that, whilst government ministries may have the best of intentions but that they were always less able to react as quickly to than local communities. Central government had an impossible task because:

"[...] even with the most committed staff they are expected to understand the nuance of different individuals in different communities across the length and breadth of New

55 For Bolger interest groups were distinct from, and often in opposition to the community. The reference to Labour and unions in particular was likely intended as a political attack, as this speech was given to a National Party conference. Bolger stated that his social policy: "It is totally opposed by the groups wedded to Big Government - the teacher unions and the Labour and Alliance Parties. That lovely cohort of yesterday's thinkers are fearful of losing control. Put simply they don't trust the community. My message is the opposite - we must trust the community" (17/05/1997). 
Zealand, but essentially deliver the same results to them all $[\ldots]$ that seems to me to be blind faith rather than a reasonably thought through policy approach.”

In contrast, the smaller size of local bodies made them more efficient and focused than central government departments, in particular they could modify their concerns to local circumstances. He conceded that the benefits of devolution were:

“[...] hard to measure but if we're providing support in a more [...] tailored fashion, one would hope to reduce the abuse in societies, the crime in society, you have a more cohesive society because they have a bigger say in their community."

He also repeatedly cited Francis Fukuyama's work on trust and social capital as evidence for the damage that states do to social capital, since state involvement would stop individuals from trusting one another (instead they would defer to the state). If the government was to withdraw and allow communities to make decisions and manage their own affairs, then these communities would come together and improve the speed and quality of decision making. Bolger's emphasis on devolutionary policy showed a strong liberal rationality to it, with it sharing many of the characteristics of what Spies-Butcher termed 'civic liberalism' in Australia.

Bolger repeatedly drew direct parallels between his use of social capital, and the freemarket reforms his Party had been advancing, including identifying social capital as having economic benefits (in particular Bolger 24/05/1997). He contrasted his approach with both 'big government' and 'old fashioned socialism':

"My concept of 'social capital' draws not on old fashioned, discredited socialism, but on my conviction of the strength, goodness and common sense of communities. It is the exact opposite of old fashioned socialism which trusted no one and ran everything through large over-regulated departments" (Bolger, 02/08/1997).

"How do we build up 'social capital' as well as 'economic capital'? But - and this is a big 'but' - the modern world demands solutions that do not smack of the discredited socialism of the past, because they know that didn't work" (Bolger, 17/05/1997).

Bolger was clear that neoclassical economics had 'carried the day' against socialism with neoclassical economics vindicated by the collapse of the Soviet Union. Consequently the National Party's economic policies did not require change and their: 
“[...] overall objective is the same one we had when the government took office in 1990: a more competitive economy, generating greater economic growth, more opportunities and a greater sense of being in control of our lives and our country" (Bolger, 25/09/1997).

Bolger's interest in social capital was purely an expansion of policy interests, rather than a desire to reform existing economic policy in order to make it more conducive to building social capital. However, whilst the economic future of New Zealand had been secured, "[s]mugness is a temptation we would do well to resist because, while we are far better endowed in terms of economic capital, we are not yet rich in social capital" (Bolger, 24/05/1997). Unlike many IPS presenters, Bolger did not see any need to reform existing economic policies, instead he only perceived a need to expand concerns (and policy directions) in order to account for social, as well as economic capital.

Whilst he primarily advocated the withdrawal of the state, Bolger occassionally adopted the language of partnerhips between the government and non-government organisations because such:

"[p]artnerships are at the very heart of building social capital. [...] The ultimate aim of these partnerships must be to improve social cohesion; they must work towards encouraging greater individual responsibility, efficiency and fairness in the delivery of social services, and development of a civil society" (Bolger, 30/09/1997).

The language of partnerhips would later be characteristic of the $5^{\text {th }}$ Labour government's use of community and social capital. In his interview Bolger made clear that the state had a role in funding community organisations. However, he then immediately repeated that, even so, communities must be responsible for their own decision making in order to recognise the diversity of communities, and to improve service provision.

Whilst devolution was the primary mechanism for building social capital Bolger also stated that the "effort to empower individuals and provide opportunities for them to succeed in a dynamic market environment helps to build social cohesion", which again fed back to building social capital (Bolger, 30/09/1997). Education was another mechanism to build social capital (a reversal of the relationship between social capital and knowledge in management studies). For Bolger, building social capital through education required more than government investment but also "involves individuals, families, communities and firms committing themselves to participation in education and training" 
(Bolger, 06/06/1997). He saw Catholic schools as representative of this approach, because they were embedded in communities, and provided services beyond formal education. Schools' roles were to educate students in community and cultural values (alongside families and the community) as well as improving educational outcomes.

In his interview, Bolger stated that the direct resourcing of schools was the only fully implemented policy designed to build social capital. During the 1990s the National government instigated a series of reforms in the school sector to promote competition between schools (Nash \& Harker, 2005) and to devolve control over spending to elected boards of trustees. The policy built on the $4^{\text {th }}$ Labour government's 1988 'Tomorrows Schools' which similarly aimed to give schools greater responsibility and powers of selfmanagement. Both governments attempted to move toward the 'bulk funding' of schools: the state was to provide the funding for schools, would set a centralised curriculum and in the case of mismanagement temporarily remove the board and take direct control of the school's finances. Beyond these requirements, the boards of trustees would have total control over how they spent the funding that the state provided (Butterworth \& Butterworth, 1998, pp. 237 - 238). ${ }^{56}$ For Bolger, the direct resourcing of schools was desirable because boards of trustees were elected by the community, empowering them through direct resourcing would also empower their communities (Bolger, 06/06/1997). Furthermore, as per Bolger's logic, locally-elected Boards of Trustees would be more able to quickly respond to changing demands and needs of the school. Whilst Bolger claimed that this policy was a success, it faced substantial criticism. For instance, Nash and Harker argued that reforms also resulted in a growing inequality and unevenness in school provision across the country and displayed little in the way of savings or improved educational outcomes (Nash \& Harker, 2005).

Bolger's interest in devolution in order to build social capital, and misgivings about the ability of central government were echoed by Bill English's (the Minister for Health) use of the term. English presented at the last IPS workshop and in his presentation he argued that the construction of social spaces by government were 'highly likely' to be on government terms. Consequently:

\footnotetext{
56 After strong opposition from teachers, unions and the New Zealand Educational Institute, Labour's policy was reined back and became an opt-in voluntary one that only 11\% of schools had joined by 1998 (Butterworth \& Butterworth, 1998, p. 237).
} 
"[a] current issue is whether government can create social spaces that reflect the values of others, and which would therefore be on the community's terms. This is of particular importance in relation to Maori. The lack of general recognition of the issue of contested norms and values and the absence of effective means of evaluation means that the question remains unanswered" (English, 2002, p. 83).

English equated the issue of diversity to greater recognition of Māori interests. However, unlike the other IPS presenters, he did not connect lower levels of social capital with free market reforms. Instead he constructed Māori social capital as only damaged by centralising government policies that had failed to attend to Māori concerns and values. He also argued that civil society predates government and therefore this meant that it could survive and thrive without state intervention. Despite this construction, he did not advocate for complete withdrawal; the government had a role in supporting communities but this required doing so without damaging the legitimacy of the decisions made by communities (English, 2002).

English also employed social capital when discussing mental health care, and again it was used to advocate for greater government devolution. By the time Bolger and English had become interested in social capital, the government's attempt at instigating competition in the delivery of mental health services had come under increased criticism, particularly with the publication of the 1996 Mason Report on the state of mental health care in New Zealand (Brunton, 2005). Alongside other recommendations, the report recommended that the focus of mental health care be redirected toward rehabilitating patients in the community and also recognising the bicultural nature of New Zealand society (Brunton, 2005; Dew \& Kirkman, 2002, pp. 176 - 177). English argued that social capital was more important for mental healthcare than physical healthcare because although:

"Caring for people with mental illness does have a strong clinical element, but it's also got a strong social and cultural element, which isn't susceptible to highly centralised control or understanding [...] A great deal of mental illness, its diagnosis and treatment, is culturally determined. Often what's important is the social process around the care as much as the care itself”' (English, 03/09/1997).

In two speeches addressing the Mason Report, English identified four features that "tie in well with the idea of social capital": 
- Organise services and funding for mental health care around the patient and community: "We've organised our communities and our patients around the institutions and the funding, and that has to change."

- Improve healthcare with no extra funding "[...] by building better relationships between the carers, and their clients", between hospitals, GPs, pharmacists, psychiatrists, carers and whanau."

- Look for local solutions to local problems: "We also know that local solutions work better because they'll reflect local tradition, local history, local culture, and local relationships."

Decisions about funding and care should be made "as close to the need as possible" by decentralising government services (English, 03/09/1997).

English framed his discussion on this broadening of mental health care in order to recognise the importance of social and cultural features. Clinical psychiatry and centralised state-based psychiatric care are both things to move away from, in order to attend to the importance of social capital in mental health care.

Christine Fletcher, the Minister for Women's, Youth and Cultural Affairs referred to social capital once (Fletcher, 19/04/1997), two weeks before Bolger introduced it in his 'Millennium Agenda' speeches. As with both Bolger and English, she constructed state withdrawal as central in building social capital. In discussing the 'delivery co-ordination for families at risk' Fletcher stated that:

"[a]ny Government desiring change in this area must take the public with them, particularly women's organisations by demonstrating overwhelmingly that their motivation is a genuine attempt at improving the social capital of our country for families rather than fiscally driven from a narrow welfare perspective" (Fletcher, 19/04/1997).

Social capital was also placed in direct opposition to 'fiscally driven policy' that relied on welfare to improve the lives of women and children in New Zealand. Fletcher aligned the public and women's NGOs with social capital 'improvement' in opposition to the financial politics of the government. She also argued that there was no guarantee that child welfare policy which failed to account for social capital would improve outcomes for the family, or reduce state costs (Fletcher, 19/04/1997). The state's role would again be withdrawn to educating families and researching the factors that influence life outcomes, as opposed to direct intervention through welfare support. 
In his critique of social capital, Fitzsimons' argued that Bolger's social capital aimed to responsibilise individuals, which redirected the blame for social failure from the state to individuals themselves (Fitzsimons, 2000, p. 2). He further equated social capital with Jenny Shipley's 'Code of Social Responsibility' that the Party adopted after Bolger stepped down. However, Bolger was clear that for him the two policies were opposites. The 'Code of Social Responsibility' was about the government forcing individuals to be responsible for their community and forcing those outside of the mainstream to conform. In contrast social capital:

"[...] acknowledges that society is getting more diverse, that there will be different answers to the same question in different communities, and the only way to have a truly cohesive society is for the community to have greater responsibility in assisting those who for whatever reason fall by the wayside" (Bolger, 1998, p. 267).

The two policies were based on opposing logics: Shipley was advocating the need to make individuals responsible for their communities, whereas Bolger was advocating communities being responsible for individuals. In an interview he reiterated that his "concept was that society accepted a responsibility. Which is the social side of providing support for those who needed it." This distinction again highlights the communitarianism (and perhaps with an element of paternalistic conservatism) that coexisted with Bolger's liberal economic policy. Whilst he undoubtedly believed in small government, and a freemarket economy, Bolger also repeatedly advocated for 'civil society', represented by community as opposed to individual self-interest or responsibility.

Perhaps because of this attention to community and social responsibility, social capital received a mixed reaction within the National Party. Bolger recalled that whilst:

"[m]any applauded me for opening up a new area of political thought which explored an issue that had, until then, been put in the 'too hard' basket. Others were totally bemused and wondered if somehow or other the prime minister had picked up the wrong speech notes. A third group saw it as some latter-day socialist plot that I was advocating" (Bolger, 1998, p. 265).

He also attributed the poor reaction to a conservative mind set within the Party that opposed new ways of thinking, and was set on an individualistic and economistic policy mind-set. In the face of this opposition, Bolger saw himself as using the authority of the office of the Prime Minister to bring an important academic concept to the general 
consciousness and using it to tackle social problems. Bolger perceived this opposition as being limited to the National Party, believing that social capital was well-received outside of the National Party, noting that the copies of the Millennium Agenda speeches (whilst not televised) were the most requested of all of his speeches (Bolger, 1998, p. 258).

Whilst Putnam had the largest influence on the IPS researchers, Bolger's interest in social capital was strongly influenced by the work of Francis Fukuyama. Throughout his speeches on social capital, Bolger referenced the art of association (including entitling one of his Millennium Agenda speeches The Art of Association) a phrase he attributed to Fukuyama. ${ }^{57}$ For Fukuyama, a society's level of economic development was dependant on the ability of particular social forms to produce social capital. Societies with strong states would not develop high levels of social capital because the population would defer to the (inefficient) state instead of developing relationships of trust that 'mid-range' social forms such as businesses, churches, unions and voluntary associations would produce (Fukuyama, 1995, p. 27). Fukuyama was explicit in his belief in spontaneous sociability (Fukuyama, 1995, p. 54), and acceptance of free-market economics, but (much like Bolger), was also concerned with the dangers of excessing individualism and a lack of sociability (Fukuyama, 1995, p. 28). However, whilst Fukuyama attended to the levels of trust between individuals (which he saw as damaged by the state's interference), Bolger's focus was primarily on the government's trust, or lack of trust, in communities' abilities to manage their own affairs.

I started this section by arguing that Bolger's construction of social capital was theoretically limited, being 'all that is good in society'. I also noted that Bolger paid little attention to the outcomes of social capital, and I have suggested that this may have resulted from his extremely broad definition of social capital which included any positive outcome related to the community or civil society which meant that the discussion of specific outcomes was unnecessary. Instead I have suggested that Bolger's interest in social capital was constructed to align with a desire to address social problems by devolving decision making to communities, and making them responsible for their members. Consequently discussing exactly what constituted social capital, or what benefits it provided were unimportant.

\footnotetext{
${ }^{57}$ De Tocqueville originally used the phrase, although Fukuyama also employed it in Trust.
} 


\section{Conclusion}

This chapter has explored the early uses of social capital in New Zealand and has expanded my analysis of the heterogeneous constructions of the concept into New Zealand policy. The constructions of social capital in New Zealand were in many ways similar to how it was constructed in Australia, with it being employed both by critics of the economic fundamentalism of the 1980s and 1990s, as well as by the governments they were critiquing. The critics in the IPS workshops, performed a reality where informal Māori communities were both threatened by, and resistant to, decades of assimilationist and individualist policy. These community ties were also threatened by (but again resisted) growing economic inequality in New Zealand. Social capital was a way of highlighting issues for Māori and challenging the social damage of the reforms of the 1980s and 1990s, and emphasising the importance of maintaining (and building) communities. Bolger offered a different construction of social capital. He saw it as akin to, but distinct from, the economic policies of the 1980s and 1990s. As with many of the IPS presenters he constructed social capital as a way of 'empowering' communities, but this was through devolution of government responsibility to organisations such as boards of trustees. Social capital was never constructed in opposition to economic growth by Bolger, instead it was opposed to both individualism (reflected in Shipley's Code of Responsibility) and 'old fashioned socialism'.

The different realities enacted by different, and the particular social capital constructed by these various authors meant that social capital was, at different times, part of both a reformist and expansionist critique of policy. Social capital was used to support both a reformist and expansionary corrective critique by many of IPS presenters. Many of the IPS papers based their use of social capital on a communitarian critique of free-market individualism. For these authors, capitalism in general, and the reforms of the 1980s and 1990s in particular, were damaging to communities' social capital because they promoted individualism, greed and competition and caused increasing inequality. These feature of capitalism needed reforming in order to recognise and protect the value of communities. Social capital further contributed to this critique by constructing the social resources embedded within the community of equal importance to economic capital. Individualism and increased inequality damaged social capital which, given the intrinsic and instrumental value of social capital, was undesirable. Social capital was often placed in opposition to the state, as well as market individualism, primarily by Māori authors. State policy also 
required reform in order to more fairly account for Māori values and to protect Māori social capital. As I will discuss in the next chapter, the incorporation of these critiques would, in-part, result in the emergence of the Third Way policies of the early 2000s. However, the construction of social capital by Bolger and other National ministers did not contain the reformist critique of the IPS authors, instead only the expansionist critique was incorporated into government. When mentioned, the relationship between social capital and economic growth was constructed as a complementary one, and Ministers did not identify economic action as damaging social capital. Bolger's alignment of social capital with economic growth, coupled with his emphasis on government devolution, showed the alignment between free-market liberal policy and social capital after the latter was incorporated into government discourse.

Bolger's communitarian policy has often been interpreted as an attempt to 'protect' neoliberalism and allow it to continue. Certainly the social capital policies that Bolger advocated fitted with the liberal policy direction of the 1980s and 1990s, but Bolger repeatedly constructed this as a parallel but distinct policy programme. The sustained and unpopular nature of his social capital (and decent society) policies within National, coupled with Bolger's own construction of social capital suggests that building social capital was not solely about economic growth. It was, as Bolger noted also not about responsibilising individuals, rather social capital was part of a communitarian position that was aligned with an economic liberalism, which was distinct from individualism. It placed responsibility on the notion of 'community', instead of the individual and was based on a belief of greater efficiency and responsiveness offered by decentralisation. To draw on Boltanski and Chiapello, this can be seen as an attempt to modify the spirit of New Zealand policy in response to communitarian critiques by incorporating the expansionist critique, but without incorporating the reformist critique.

Bolger's advocacy of the concept would turn out to be short lived and had a limited impact on the National Party, as he himself acknowledged. Few other ministers adopted the concept, Bolger did however, play a key role in the translation of social capital into the New Zealand political discourse. Many of the features of Bolger's social capital would be repeated by Labour ministers. In particular, the complementary relationship between social and economic capital as well as their (at least rhetorical) equal importance would continue to be central to the $5^{\text {th }}$ Labour government. 


\section{Chapter 7: Social Capital in the $21^{\text {st }}$ Century, Labour and the Third Way}

In the last chapter I explored the political uses of social capital in New Zealand, with a focus on the IPS workshops and Jim Bolger's speeches. I began discussing the translation of social capital into New Zealand, and how National's construction of the concept was aligned to existing policy areas, particularly devolution of power away from the state. In this chapter I will move my discussion into the 2000s, and explore the various ways that social capital was constructed by ministers during the $5^{\text {th }}$ Labour government, and was also incorporated into policy documents during this time. I will also begin to discuss the attempts by government departments to develop measurements of social capital which formed a central, if overlooked part of the concept's appeal. Since National were reelected in 2008, there have only been 8 speeches mentioning social capital, and none of these have explored the concept in any depth. Consequently, I will address these alongside the Labour minister's speeches.

Labour's constructions of social capital shared many features with Bolger's constructions. Social capital retained both a positive valence as well as an ill-defined instrumentality for Labour ministers. Thus higher levels of social capital were equated with various positive outcomes which included, but was not just limited to economic growth. Nearly all of Labour's social capitals retained an alignment between social capital and economic growth, and also a central role for communities. Thus, the interest in social capital by Labour ministers was in expanding policy concerns rather than reforming existing economic policy, much as it had been when Bolger had used it. As my discussion of Laban will touch on, the evocation of the economic benefits of social capital were often as a way of using the concept to 'sell' the voluntary and community sector, rather than a result of it being a way of kick-starting neoliberalism or similar. ${ }^{58}$ However, Labour ministers were less adamant of the need to devolve power to communities, and identified the state as having a more central role in building social capital. During the Labour government the concept was also more thoroughly integrated into policy, and measuring levels of social capital also become a concern, with several ministries attempting to provide frameworks for measurement. However, whilst Labour ministers initially enthusiastically adopted

${ }^{58}$ In this way her interest in social capital echoes Putnam's interpretation of Hanifan, who used the concept to appeal to 'hard-nosed businessmen'. 
social capital, and associated it with a variety of policies and desirable outcomes, uses of the concept declined and narrowed in Labour's last term in government, becoming nearexclusively associated with the community and voluntary sector.

As with other centre-left parties during the 1990s and 2000s, the $5^{\text {th }}$ Labour government was influenced by the 'Third Way' politics of Anthony Giddens. I noted in chapter 2, that the Third Way has been characterised as an ill-defined and shifting series of political ideas as opposed to a set of definitive political propositions (Levitas, 2004; McLennan, 2004, p. 484), but that one common feature of Third Way politicians was a concern with the community. Third Way politicians advocated partnerships between the state, businesses and voluntary NGOs, as the cornerstone of social policy aimed at including communities in decision making.

\section{Changing uses of Social Capital during the Fifth Labour Government}

As with other Third Way concepts, such as social development or community, there was no shared definition or construction of social capital by the Labour government. Labour ministers and government departments constructed far more social capitals than either the scholars that I discussed in chapter 5 or Bolger. Whilst Bolger was the only National Party minister to extensively use social capital, multiple different Labour Party and coalition ministers employed the term, and the range of politicians using social capital, in relation to a range of fields likely contributed to the lack of common definition or usage. However, the assemblages of actors that social capital was constructed from also changed during the Fifth Labour government. In particular there was a notable shift both in who used social capital, the policy areas that it was related to during Labour's last term in government (2005 - 2008). Early in the Labour government ministers associated social capital, particularly the benefits from it, with a range of policy areas. However, after 2005, the concept became narrowly associated with the community and voluntary sector. This coincided with a decline in the concept's use in political speeches, which has continued into the current Fifth National government and has largely been echoed in overall declines in uses of community (see figure 2). 


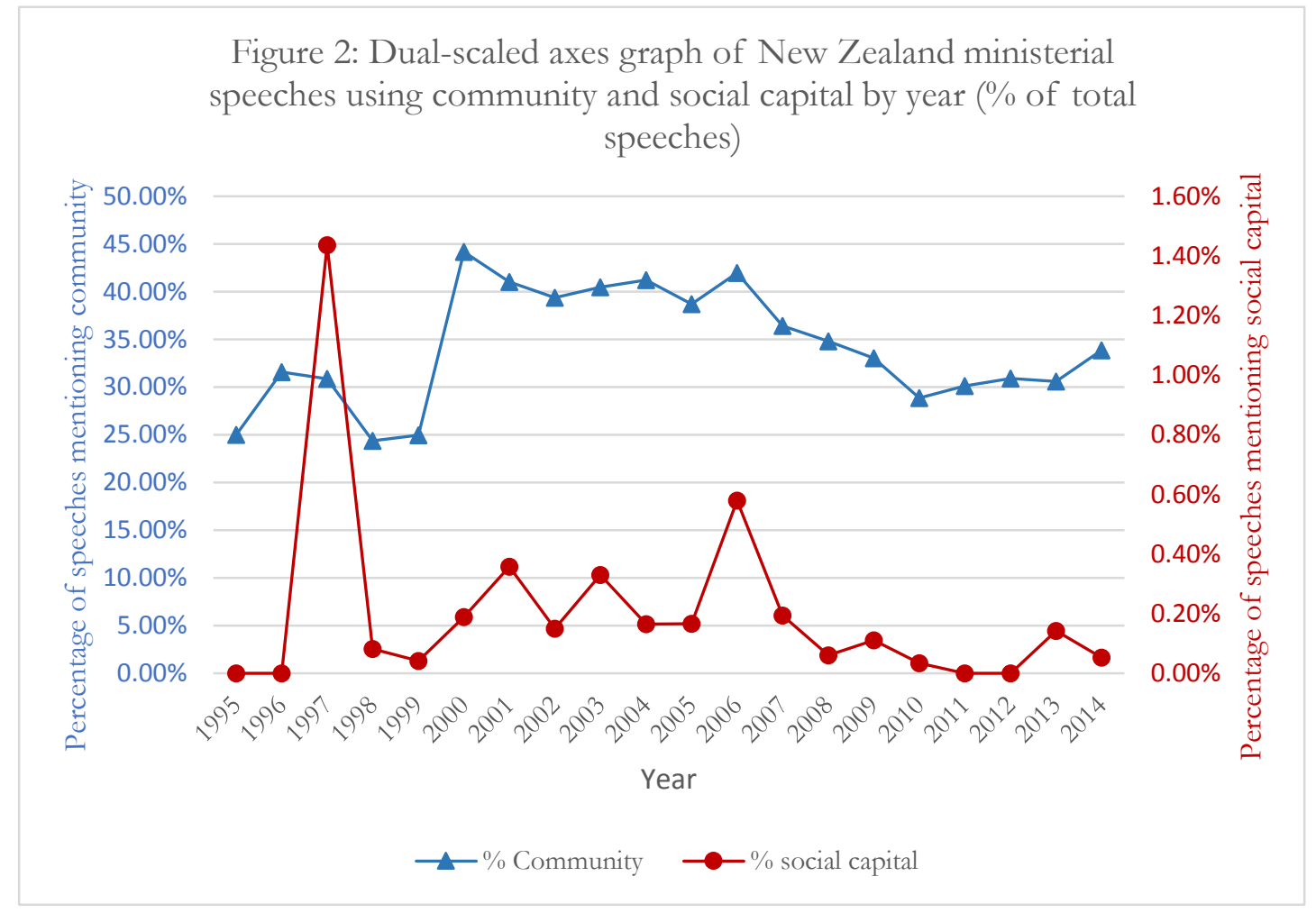

Labour ministers associated communities and voluntary work with social capital from 1999. However, in total only 10 of the 40 speeches that used social capital between 1999 and 2005 primarily focused on volunteering, community work or philanthropy. Other speeches associated social capital with a wide range of beneficial outcomes, and constructed it as being as important as economic policy. During this time social capital was employed in speeches on education (Dalziel, 09/03/2000, 07/09/2000, 04/09/2003, Maharey 26/09/2000), Māori enterprise (Turia, 25/09/2001), social development (Maharey, 21/02/2002), socially responsible investment (Cullen, 21/05/2002), fiscal accountability (Cullen 29/06/2004), healthcare (King, 08/08/2001, 25/05/2005, Cullen, 07/05/2005), assisting migrants to enter the workforce (Maharey, 01/12/2003), drug policy (Anderton, 16/03/2004), and farming projects (O'Connor, 23/11/2004). In contrast, after 2005, 20 of 28 speeches and press releases that used social capital focused on volunteering, community work or philanthropy and none of the speeches associated social capital with education, economic growth or health. This shift in focus was accompanied by a change in both the ministers who were using the concept and in the definitions they gave it.

Steve Maharey, the Minister for Social Development was the most prolific user of social capital during the first two terms of the Labour government. In his interview, Maharey 
stated that he became aware of the concept when working as a sociologist during the 1980s and 1990s. He later found it a useful way to discuss social policy because it allowed ministers to recognise the importance of social issues, and the diversity of populations, without evoking an unpopular return to welfare state-driven policies. However, despite its apparent usefulness, Maharey ceased using social capital after 2005. He suggested in his interview that this was unlikely to indicate a change in policy direction, rather he thought that it would have been an unconscious change, and also noted that:

“[...] the ministerial speeches, $[\ldots]$ the ones that you probably get about $80 \%$ of those are written by the officials and I wouldn't have delivered them [...] So there, there may well be a difference between what I said and what was written in that script because it might be that the officials have stop, they've stopped using that concept."

He also suggested that his change in portfolio may have been a further reason for this connection, as he became the Minister of Education and Minister for Research, Science and Technology in 2005. Positons that he suggested were less conducive to discussions of social policy issues.

Regardless of why Maharey stopped using social capital, the timing coincided with other ministers dropping the term. Between 1999 and 2005 seven other ministers including the Deputy Prime Minister Michael Cullen (Jim Anderton also used social capital, but only after he left the post of Deputy Prime Minister in 2002) employed social capital multiple times in their speeches. However, after 2005, Winnie Laban, minister for The Community and Voluntary Sector, was the only Labour minister to make repeated reference of social capital after 2005. Other ministers, including Nanaia Mahuta, Jim Anderton, Mark Bunton and David Benson-Pope, used the term, but did so rarely, and only in passing.

In addition to this abrupt change, Labour ministers' construction of social capital slowly changed to become more community focused. For instance, Maharey's early definitions defined social capital as a reified something embedded in social relationships:

"Without going into all the views that have been put forward, a synthesis of several approaches sees social capital as networks of social relationships characterised by norms of trust and reciprocity which operate at the individual, family, community and national level" (Maharey, 07/09/2001, repeated in Cullen, 20/11/2001). 
"Loosely defined it is the connections between individuals and their social networks and the forms of reciprocity and trustworthiness that arise from them" (Maharey, 26/09/2000).

Such definitions were ambiguous on the positive nature of social capital (however in each of the speeches social capital was subsequently identified as a positive object or value that must be 'built'), and social capital was seen as operating at multiple levels from the individual to the national. In later definitions however, Maharey disembedded social capital from relationships, and equated it with the benefits gained from relationships:

"Social capital means the benefits that our communities get from good social relationships and from strong community networks" (Maharey, 01/12/2003, 21/04/2005).

“The value derived from social connectedness" (Maharey, 26/06/2003).

He also removed any interpretation of social capital as value-neutral or having negative effects, instead imbuing it with a positive valence. Consequently, higher social capital would always be more desirable than lower social capital. This change was only evident in speeches; as I will discuss later, some ministries and policy groups, including Maharey's Ministry of Social Development, continued to mention possible negative effects of certain types of social capital throughout the Labour government. The association of social capital with the benefits of connectedness or networks reinforced the positive valence that politicians had otherwise attributed to social capital. Much as with Bolger's 'all that is good in society' this likely added to social capital's political appeal, as it created a simple correlation between levels of social capital, and levels of wellbeing.

Maharey was not the only minister to employ a value-neutral definition of social capital. Michael Cullen, the Deputy Prime Minister and Minister of Finance, adapted one of Maharey's definitions, to define:

"[...] the social capital of a nation $[\ldots]$ as the networks of social relationships characterised by trust and reciprocity and which operate at the individual, family, community and national level" (Cullen, 20/11/2001).

However, most other ministers either did not provide a definition of social capital, or gave it a positive valance. For instance, Turia stated that: 
"[t]he benefits of social cohesion are sometimes called social capital. I have mentioned some of these already: higher levels of trust and social participation, and better access for everyone to opportunities and resources" (Turia, 27/09/2003).

Similarly, after 2006, Laban regularly employed a stock definition of social capital as "the glue that binds our communities together" (Laban, 22/05/2006). For Laban, social capital was 'jargon' that referred to relationship building:

"If we use the popular jargon, this relationship building and 'connecting up' of people can be referred to as 'social capital' - or the glue that holds our communities together" (Laban, 22/04/2006). ${ }^{59}$

In this second quote, Laban equates social captial with the process of building relations, as opposed to being embedded, or emerging from them. This phrase would later be adopted by Turia during the $5^{\text {th }}$ National government ${ }^{60}$ :

"It is also about acknowledging that a strong community and voluntary sector can foster social cohesion and social capital - the glue that holds our communities together" (Turia, 11/03/2010).

Other $5^{\text {th }}$ National government ministers continued the tendency of constructing social capital as the beneficial outcomes of social relations. As I mentioned earlier, such valuepositive definitions recaptured the simple equation that Bolger had used: higher social capital equals better outcomes for communties. From such as perspecitve, policies which build social capital would be beneficial, as opposed to the more complex relationship to policy from a value-neutral definition.

I noted above that, in Maharey's early definitions, including the one re-used by Cullen, social capital operated at multiple levels. This also changed during the Labour government as, social capital was increasingly constructed as operating at the community level. For example:

"Clearly, a safe community is one in which every member is safe and secure. A safe community is also one that respects the rights of everyone living in that community. A safe community is one where everyone can access the services they need. A safe

\footnotetext{
59 The phrase 'the glue that binds us together' had previously been used by the World Bank.

${ }^{60}$ Tariana Turia left the Labour Party in 2004 to form the Māori Party that joined a coalition government with National from $2008-2014$.
} 
community has high levels of trust and support among its members. It has high social capital." (Bunton, 02/06/2006).

"Social capital consists of the networks of trust, support, and goodwill in a community. It consists of the contributions people make to the community's wellbeing, contributions that go beyond immediate self-interest" (Mahuta, 25/05/2006).

Entwined with this change in level, building social capital became narrowly associated with voluntary work. And, as I mentioned above, after 2005, voluntary work was the only mechanism discussed as building social capital, as Laban used social capital to 'sell' the benefits of volunteering. For instance she stated that:

"Volunteering has a profound effect on New Zealand and it is important to acknowledge the enormous economic and social contribution that the voluntary sector makes - social capital is the glue that binds our communities together" (Laban, 12/03/2006).

And in a speech to Youthline she stated that:

"Ensuring your services are widely available, accessibile, and meaningful for all New Zealanders will greatly enrich the social capital that Youthline, along with every voluntary worker and organisation, is helping to build every day" (Laban, 30/06/2006).

In other speeches she identified voluntary services such as Youthline (Laban, 30/05/2006), Aged Concern (Laban, 9/12/2006), the Presbyterian Church (Laban, $1 / 08 / 2006)$ and volunteering in general as building social capital. In her interview she added volunteer sports coaches, arguing that without them sport would collapse due to the decline in social capital from their work.

The narrow association of social capital with community and voluntary work, coupled with declining interest in the concept, continued into the $5^{\text {th }}$ National government $(2008$ - present). In the six years since National were elected only 8 speeches or press releases have mentioned social capital. Six of these were by the co-leader of the Māori Party, and ex-Labour minister, Tariana Turia. Jo Goodhew, Minister of the Community and Voluntary Sector used the concept once in both 2013 and 2014, and Minister for Civil Defence Nikki Kaye used it in a speech in 2013 to state that "[i]nitiatives that build linkages and connectedness between people help to increase social capital - a vital ingredient of a resilient community" (Kaye, 22/05/2013). Goodhew, much like Laban 
identified social capital as a reason why voluntary work was important and needed celebrating:

"Celebrating what volunteers do, alongside the people who guide and assist them, builds the wider social capital that enriches our communities" (Goodhew, 21/06/2013).

As with Kaye, Goodhew drew on the emerging interest in social capital in the community resilience literature, to provide another reason why voluntary work was important (Goodhew, 26/03/2013). By building social capital, volunteering made communites more resiliant to disasters or challenges, and allowed them to recover more rapidly.

During Labour's 9 years in power, social capital shifted from being a concept used in a variety of speeches, that was associated with many, broad inputs and outputs to something that was produced by voluntary work and had benefits for communities. This trend, coupled with a decline in uses overall, may indicate that the concept's political appeal declined in this time. The decline may have also been the result of a shift within the Labour Party post-2005, as their 'strategic' social development policies, that social capital was part of, such as the Inclusive Economy or Bridging the Gaps were abandoned. Garlick suggested that a social policy 'strategy fatigue' emerged after the mixed results of initial bursts of large-scale social development programmes, resulting in Ministry of Social Development, and the government more generally, refocusing on day-to-day management as opposed to macro-level policy changes (Garlick, 2012).

\section{The Role of Government in Labour's Social Capital}

Whilst Labour ministers' constructions of social capital were similar to Bolger's in several respects, they strongly emphasise the relationship between the state and social capital. Bolger's use of social capital was largely antagonistic to the state and rested on a belief in the spontaneous socialisation of communities. The position of Labour ministers was again varied, ranging from arguments for the 'right' sort of involvement, to clearer advocacy for state involvement in building social capital. Generally though, Labour ministers saw government involvement, as necessary to create the conditions for building social capital, even if they were often unclear as to what involvement was required. 
Of all Labour ministers, Michael Cullen most strongly emphasised the necessity of government investment and involvement in the production of social capital. In one speech he warned that:

“[...] when governments lose touch with social responsibility the impact is sometimes slower to arrive. This is because communities are often reasonably resilient and able to weather a temporary under-investment in social capital. The impact begins to show over time, however $[\ldots]$ Hence if we reduce our investment in human and social capital we can expect in time to see people lose their sense of belonging and participating in society" (Cullen, 29/07/2004).

For Cullen, the state needed to reconceptualise growth in broader terms than GDP, and should be concerned with distribution, environmental damage and social capital in order to ensure these were not neglected (Cullen, 21/05/2002). Government needed to invest in 'socially responsible' ways, which meant they should be concerned with the 'triple bottom lines' of environmental, economic and social capital.

Maharey constructed the relationship between social capital and the government differently. He saw government involvement as necessary, but was clear that it was insufficient because:

“[...] while government plays an integral role in building social wellbeing for New Zealanders, achieving it is not a solo act. Building a thriving, prosperous, inclusive nation is a task that extends well beyond the steps of parliament" (Maharey, 1/11/2000).

Furthermore, too much government involvement in the affairs of a community could damage a community's social capital, meaning that the 'right type' of involvement was needed. The government needed to empower families to allow them to build their own social capital:

"Internationally, there are different views on the extent to which government can positively affect the development of social capital. One view is that overly large government can crowd out community activity, and diminish people's sense of group identity and trust. [The] other is that a minimal state leaves less fortunate families and communities to flounder.

In other words, whereas the right kind of support can facilitate economic and social development, the wrong kind (that is too much government intervention or inappropriate 
interventions) disempower individuals and families and creates dependencies" (Maharey, 07/09/2001).

Later in the same speech, Maharey clarified that the Labour government's intent was to be an "active partner in building a relationship based on honesty, trust, recognition of diversity, integrity, compassion and caring" with communities, but that the government could not do it alone.

In his interview, Maharey offered another reason for limiting the state. Instead of an overly large state damaging social capital, state based policies were unavailable as an option due to public opposition of the welfare state. He stated a belief that:

"I think it [the welfare state] was a better way of doing things, and for me it was [...] but I'm not sure you would excite everybody by saying that we're going to rebirth the 1950s."

The unavailability of these welfare state approaches meant that other mechanisms for government involvement in social policy needed to be found. This is something that Maharey saw as still relevant because:

“[...] for the centre left it's almost inevitable that they're going to have to come back to something like this [social capital] because um, they could try to rebirth an entire state [...] which I guess is what Labour was doing, what MANA [a minor parliamentary Party to the left of Labour] was doing, those sorts of Party platforms were looking highly statist again and obviously no one wants them, or [not] enough people want them um so they're, they're I think they're stuck with the need to kind of say, well, there really isn't the stomach, never mind the money to return to you know big pension schemes you know, public health for everyone you know free tertiary education, whatever might have grown out of the welfare consensus has become both unaffordable and probably undesirable in people's eyes, they want something else."

Later in the interview he argued that migrant groups may also have left countries where they had poor experiences with the state which added to their distrust of the welfare state. He suggested that this opposition was particularly pronounced among Māori and migrant communities who found the welfare state as monolithic and assimilationist, an issue that I covered in chapter 6 , and will return to later in this chapter. 


\section{Social Capital and Economic Growth}

As with Bolger, Labour ministers saw social capital as a parallel and complementary to economic growth. As I mentioned above, Cullen argued that social and economic capital were equally important. For Cullen, recognising this equality formed the core of Labour's Inclusive Economy policy, the flagship policy during their first few years in government. The Labour Party wanted:

"[a]n economy that is inclusive rather than exclusive, where big business and social capital are equally important" (Cullen, 11/02/2000).

Because:

"Social responsibility and fiscal accountability [...] Each is necessary, but not a sufficient, condition for growth, and here I mean growth in its wider sense, encompassing GDP growth and also growth in social capital, quality of life and community cohesion" (Cullen, 29/07/2004).

Ecological concerns formed a third element to this relationship:

"I would also want to extend the point about developing a better relationship with environmental assets to cover social capital as well. This is often as hard to define and measure as environmental values, but no less important. It is interesting to note how the language of socially responsible investment echoes that of the social democratic tradition in politics. Triple bottom lines and balanced scorecards are conceptually very close to the conviction that the purpose of government is to foster growth that is measured in terms not only of gross domestic product or even its distribution within the community, but also in terms of community development and cohesion, the protection of the natural environment, and the promotion of the institutions of democracy and civil society as ends in themselves" (Cullen, 25/05/2002, emphasis added).

For Cullen, economic and social policy had historically been incorrectly conceptualised as adversarial demands, instead they were dependent on each other in an "unhappy union" (29/07/2004) with neither being sufficient to improve wellbeing by itself. As will become apparent, it also fitted well with changing policy concerns during this time, including the changes in thinking in the New Zealand Treasury. More notably, Cullen's tripartite division also echoed the 'sustainable development' literature that I will discuss in the next 
chapter and, with the addition of 'human capital' this division formed the basis of the capital approach to national accounting.

The reciprocal relationship between social capital and economic growth meant that social capital had economic benefits (and that economic growth had social benefits). The economic benefits of social capital were part of the concept's instrumental appeal. Maharey strongly emphasised the economic benefits of social capital when promoting the concept. He stated a belief that " $[\mathrm{r}]$ esearch indicates that the richer a community is in social capital, the greater the likelihood of economic growth" (Maharey, 21/02/2002). Although he identified non-economic benefits of building social capital (ill-defined improvements in civil society and democracy (Maharey, 07/09/2001)), he often treated these as an afterthought. Social capital was capital because social relations:

"[...] have, and add, value, specifically improving the productivity of individuals and groups. Of course as well as productivity they add self-esteem and identity as well" (Maharey, 26/09/2000).

He drew on Putnam's Making Democracy Work and Fukuyama's Trust to support claims that social capital had economic benefits (e.g. Maharey, 14/08/2001), and saw this appeal as a key reason as to why the concept required building.

Maharey was not alone in promoting social capital through its economic benefits. Turia defined social capital as the benefits from social cohesion, which included:

"[...] higher levels of trust and social participation, and better access for everyone to opportunities and resources. These, in turn, generate economic activity" (Turia, 27/09/2003).

But she later in the same speech indicated that these economic benefits were only part of the instrumental value of social capital:

"The intent of those activities [to build social capital/cohesion] supported by government is to assist the reintegration of excluded persons in the five following areas: housing, employment, health, education and living standards and safety" (Turia, 27/09/2003).

Whilst Maharey, Turia and others identified social capital as having economic benefits, this was often to politically 'sell' the concept, rather than because social capital was a defence of neoliberalism. Laban was interested in the concept due to a lack of attention 
to the contribution of volunteering in policy that was driven by market concerns. Individuals volunteer and build social capital because they care for others, as opposed to wage labourers who work for economic benefits. However, whilst she believed that:

"[v]olunteerism has always been the lifeblood of New Zealand and my culture, because we're very communal. I also felt that it was a whole sector that wasn't valued as much as the economic sector or the paid sector. And you know, that it needed to be acknowledged."

Laban repeatedly discussed of the possibility of attaching a 'dollar value' to social capital in terms of hypothetical wages for volunteers. However, this was not necessarily due to a desire to apply market logics to non-market relations, but instead as a way of recognising and quantifying the contribution of volunteers, in interactions where a dollar value was equated with the contribution to the common good.

There was a notable tendency for ministers and ministries to associate social capital with more than just economic benefits. This suggests that the key appeal of social capital was in its instrumental value in general, as opposed to its economic benefits in particular. Social capital's non-economic benefits, and the negative outcomes from a lack of social capital, were given more attention than its economic benefits. Ministers associated a lack of social capital with various 'undesirable' outcomes, such as high levels of diabetes, deprivation and drug use. For instance, Anderton argued that "[d] rug use and deprivation are closely linked and problems are most acute in communities with little community infrastructure or social capital" (Anderton, 16/03/2004). Cullen associated the concept with the protection of the natural environment, the institutions of democracy and civil society from irresponsible investment (Cullen, 21/05/2002). Or Turia's assemblage of 5 areas in which social capital could reintegrate the excluded that I quoted on the previous page. The importance of non-economic benefits was also clear in Laban's use of the concept.

The equation of higher levels of social capital leading to higher levels of wellbeing meant that social capital itself was also constructed as a goal of policy. For example, in May 2005 both Annette King (then the Minister of Health) and Michael Cullen gave speeches to promote the 'Let's Beat Diabetes' plan that used social captial in near-identical ways (King's speech was slightly longer than Cullen's). They stressed the importance of community-based approaches because: 
"[s]uch commitment may end up having an even larger impact than perhaps we can imagine at this point. Influencing the root causes of diabetes and cardiovascular disease through strong community action will affect more than just people's health. It will build social capital, durable relationships, and improve the overall wellbeing of all our communities" (Cullen, 07/05/2005).

Whilst he constructed social capital as something that would be built, and was desirable, he did not elaborate either on mechanisms by which the plan would build social capital, or on the specific benefits of social capital. Rather, much like with Bolger, and to a lesser extent Laban, social capital was something that had benefits, thus a policy that builds social capital, contributes to the common good.

\section{Social Capital in Treasury's Towards an Inclusive Economy}

The construction of building social capital and growing the economy as equally important step in increasing wellbeing was also evident in policy documents, most clearly in New Zealand Treasury's 2001 Towards an Inclusive Economy (TIE) framework (The Treasury, 2001a, 2001b, 2001c). The TIE framework formalised the reciprocal relationship between social and economic resources, with both constructed as resources for improving human wellbeing (see figure 3). The framework represented a slight shift in Treasury's thinking as they expanded their policy concerns beyond purely economics. This shift was partially the result of Treasury's broadening influence during the 1980s and 1990s: as their power and influence over government expanded Treasury had begun to comment on policy areas outside of its traditional domain including social and welfare policy (Goldfinch, 2000). As I mentioned in chapter 3, in Government Management Treasury had stated that wellbeing, and not economic growth, was the end goal of policy. However, economic growth through free market reform was the means by which to attain higher levels of wellbeing in Government Management.

Government Management was published in 1987 and provides an interesting counterpoint to TIE because it was released at the height of Labour's free-market reforms and arguably was a quintessential 'neoliberal' text. Thus comparing it with TIE, highlights the changes in Treasury's thinking during this time. Treasury stated in Government Management that individuals were not atomised, but rather, using language that would be reminiscent of that later used by Labour ministers, the: 
"[...] drive to support one another is part of the glue which binds society together and the Government must always be careful to preserve this natural social cohesion" (The Treasury, 1987, p. 401). ${ }^{61}$

However, Treasury made clear that social policy and cohesion were peripheral sources of wellbeing. Rather, the individual, as a rational-chooser, was the "person best able to attend to his or her own welfare" through the production of goods and services in the workforce (The Treasury, 1987, p. 400). Treasury was also sceptical as to the possibility of group action or group rationality (The Treasury, 1987, p. 432), believing that all policy should begin with the assumption that individuals were self-interested, even if a few may act altruistically (The Treasury, 1987, pp. 433 - 434). The belief that individuals were selfinterested was used to justify their advocacy of minimal government intervention because the government should avoid aiming to gain social benefits from policy since these were simply 'spillovers' or positive externalities from the self-interested actions of individuals (The Treasury, 1987, p. 449). Due to the social benefits being 'spillovers', the government could not provide greater welfare than any other entity, particularly the marketplace (The Treasury, 1987, p. 402). Consequently the government should promote policies that were conducive to market growth, and allow social benefits to emerge from market activity.

By the time the TIE framework was published, Treasury no longer considered macroeconomic policy to be the only mechanism by which governments could improve wellbeing. Instead, as in Cullen's speeches (who headed the Treasury when TIE was developed and published), 'productive capability' and 'social capability'62 existed in a reciprocal relationship with one another, and both were of equal importance to human wellbeing (see Figure 3 for Treasury's representation of this relationship). Treasury believed that the two capabilities were complementary and had a 'feedback loop' between them. Consequently, if policy designers neglected one of them, they risked creating a negative feedback loop that would damage wellbeing.

61 Treasury further stated that whilst their position "emphasises individuals it does not offer any support to individualistic policies, or assert that individuals can be understood as autonomous beings remote from their society" (The Treasury, 1987, p. 407).

${ }^{62}$ In Towards an Inclusive Economy Treasury state their preference for social capability over social capital because of the definitional and methodological vagueness of the latter. However they draw exclusively from the social capital literature. Later documents (such as Working Towards Higher Living Standards for All New Zealanders) also stated that social capability was equitable with social capital in the TIE framework. 
The social features that Treasury identified and classified as social capital/capabilities had direct benefits to the wellbeing of individuals. For Treasury:

"[t]here can be no doubt that individual well-being derives form a number of factors in addition to income. People's participation in social networks, community life, political choices and civil society are also key means through which they achieve well-being" (The Treasury, 2001c, p. 13).

Bridging social capital was particularly desirable because it "may also help address neighbourhood effects, by exposing deprived individuals to more positive interactions and encouraging beneficial spillovers" (The Treasury, 2001c, p. 52). Unlike in political speeches, Treasury did not see higher levels of social capital as unequivocally beneficial. Treasury warned against the risk of close-knit groups with high bonding social capital who do not share the wider values of society (such as gangs or traditional families), as these could lead to a decline in the more valuable bridging social capital. Environmental effects of low social capital could also be damaging because, although individuals choose where they live, there may be 'negative spillovers' in areas with low-wellbeing that may trap individuals, which in turn reduced their opportunities to improve their wellbeing (The Treasury, 2001a).

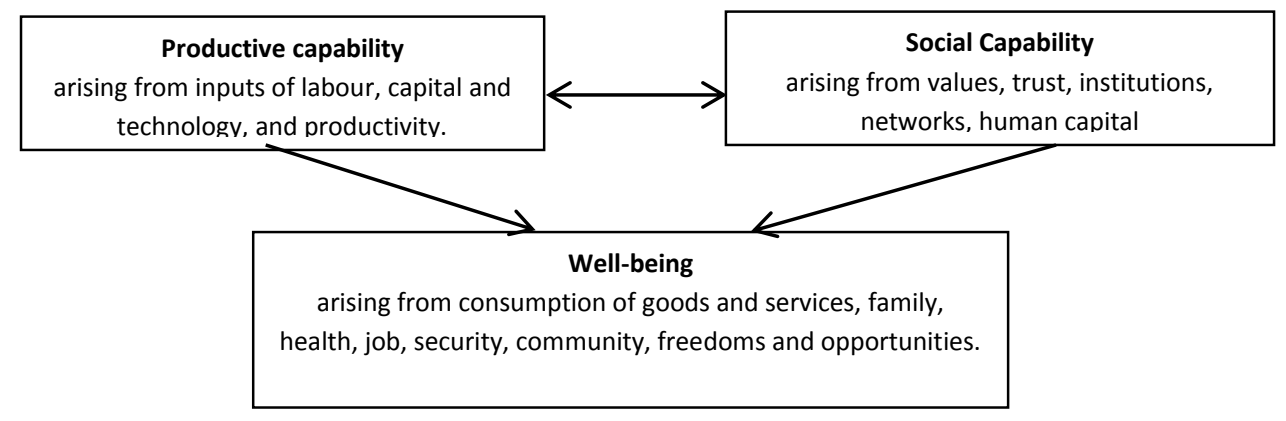

Figure 3: Treasury's diagram depicting the "three main sets of relationships on which an inclusive economy depends" (The Treasury, 2001c, pp. 15 - 16).

The changes to Treasury's thinking between Government Management and TIE should not be over stated, however, particularly as Treasury retained both a belief in free-market economics, and based their work on behavioural economics, still perceiving individuals to be rationally choosing. The inclusion of social features in TIE did not predicate a change in Treasury's advice on economic policy, and unlike in the public health literature, or later in the OECD's Wellbeing of Nations (which I will discuss in chapter 8) it did not lead to, or emerge from a concern over inequality. Instead, social capital/capability was primarily used to justify current economic policy. For instance, a concern over 
maintaining levels of social capital was used to argue against redistributive policies because redistribution did not account for the non-economic determinants of wellbeing, meaning that: "[i]ncome transfers do not by themselves guarantee that those affected by adverse events are back on a trajectory of evolving positive well-being" (The Treasury, 2001c, p. 27). Redistributive policies could also lower wellbeing, as tax-payers will resent tax-based income redistribution, and this resentment would reduce social cohesion. Treasury's preferred solution was instead to increase the human capital of the less well-off in order to "recognise that growth depends on entrepreneurship, and accept high incomes justly earned" (The Treasury, 2001c, p. 29).

The construction of a reciprocal relationship between social capital and economic growth meant that Treasury rarely identified any issues emerging from economic policy. They identified one negative impact of economic growth (the uneven distribution of benefits). This was not a concern because it negatively impacted on wellbeing, rather, growing inequalities were naturalised, and an unavoidable outcome of 'growth':

"Growth often creates winners and losers as resources shift from declining to expanding sectors, skill categories or regions. This means that the fruits of growth can turn out to be unevenly distributed, with particular individuals and groups suffering relative or absolute losses alongside others who experience rapidly improving fortunes. This can cause social tension and divisions. Unless governments manage these changes well, this can lead to opposition to further changes and policy reversals" (The Treasury, 2001c, p. 21).

Treasury made no suggestion that governments should step in to reduce inequalities or help the 'losers' from economic growth. Instead their concern was that the population may begin to oppose government economic policy if governments failed to properly manage the tensions emerging from these inequalities. Treasury later reiterated this in passing, stating that growth could potentially create "strains on the social fabric" due to an increased mobility of capital and skilled labour, which again required government management to prevent opposition (The Treasury, 2001c, p. 22).

Treasury's rejection of redistributive policies provided a clear example of a government ministry employing social capital/capabilities to justify and defend free market policies. As such, Treasury's use of social capital aligned with critical perspectives on social capital. It also highlighted the absence of a reformist critique in government uses of social capital 
during this time, with only the expansionist critique of policy being incorporated into government concerns. The expansion of policy, and the notion of multiple, comparable but discrete areas of policy all feeding into wellbeing would be expanded further a decade later in Treasury's Toward Higher Living Standards framework (The Treasury, 2011), that I will discuss next chapter.

\section{Social Capital in the Ministry of Social Development}

Social capital was a central concept in Labour's new Ministry of Social Development (MSD) ${ }^{63}$, and its importance was highlighted by the concept's inclusion in four statements of intent (Ministry of Social Development, 2004b, 2005, 2006, 2007). In contrast to Treasury, the MSD rarely connected social capital with economic benefits, instead they allied it with the strategic policy of 'social development', and several more specific policy areas including child development and older person independence. Different MSD documents translated social capital into various assemblages of actors, and consequently constructed it in different ways. In higher-level strategic documents however, social capital was constructed as an ecological factor in the community, most clearly seen in the MSD's attempts to measure social capital in the first two Social Reports (Ministry of Social Development, 2001b, 2003). The statements of intent constructed social capital as an important resource both for communities and in helping individuals to be civic minded and engaged with their communities (Ministry of Social Development, 2004b, 2005, 2006, 2007). ${ }^{64}$ In contrast, more focused and policy specific documents generally adopted a network understanding of social capital, with actors 'investing' in relations which improved their outcomes.

The MSD's Social Reports were intended to provide a 'snapshot' of the current level of social development of New Zealand, and to allow the government to measure the nation's social progress. In them the ministry provided a range of statistics on social issues annually between 2001 and 2010, and much like the TIE, connected these to an overall level of human wellbeing (Ministry of Social Development, 2001b, 2004a, 2010). In the Social

\footnotetext{
${ }^{63}$ Formed in 2001 from the Ministry of Social Policy and The Department of Work and Income.

${ }^{64}$ The Ministry's use of social capital peaked from 2003 - 2006 with regular publications not only employed the term in passing but also explored the potential ways of incorporating the concept into policy. Only a single paper since 2008 has used social capital - the 2009 paper Ageing in the Community: In a Place I call my Own (Ministry of Social Development, 2009) and this uses an individual, Bourdieu influenced understanding of social capital. A word search suggests that social capital was not replaced by a similar concept (such as social exclusion and social cohesion).
} 
Reports, the MSD measured social capital as membership in various voluntary associations, much as Putnam had done in Bowling Alone. Higher levels of social capital would help create an inclusive society and an inclusive national identity. Similar community-level understandings of social capital were also evident in documents dealing with social development, where lack of social capital was constructed as causing social exclusion (Ministry of Social Development, 2001a). As with Bolger they suggested devolving decision making to communities in order to allow them to manage their own affairs (Ministry of Social Development, 2001a). In a co-publication with the Department of the Prime Minister and Cabinet the MSD also claimed that urban renewal was a key determinant in fostering a community culture in order to build social capital (Department of Prime Minister and Cabinet, 2003).

Although some MSD documents adopted communitarian and ecological constructions of social capital, many MSD documents adopted a network-based approach to the concept. This was particularly evident in documents dealing with specific policy areas, such as child development, family resilience, migrant inclusion or older persons' policy. Families have access to different levels of social capital, based on the relationships that they either as a unit, or the individual parents form with the wider community (Kalil, 2003, p. 19). In Early Childhood Centres and Family Resilience social capital was defined as the:

“[...] process by which families participate and access social, family and non-family networks and develop resources as a result of those reciprocal relationships" (Duncan, Bowden, \& Smith, 2005, p. 2).

It was something that families should invest in, because " $[t]$ he theory of social capital suggests that parents can enhance their children's opportunities for success by investing in social relations" (Aimer, 2003, p. 22). As well as improving child outcomes, familial investment in social capital was also important because it provided resources to make them resilient to the 'experience' of poverty (Duncan et al., 2005, p. 7). In New Zealand Families Today, mobility was identified as negatively affecting families' abilities to form strong social networks, and families' access to telecommunications are identified as family-level elements of social capital. Familial structure was constructed as important in determining levels of social capital that children can draw upon. In these documents social capital constituted of resources for the family based on their investments. A family which has invested in social relationships can use the social capital from those relationships to 
improve the opportunities for their children. When social capital was constructed as a family resource, it was also associated with strong normative expectations. For instance, two of the three 'key indicators' of social capital in Young People Not in Education, Training or Employment were 'growing up in a single parent family' and a level of family conflict (Hill, 2003). However, this connection was also (in part) the result of the way that the existing measurements from the longitudinal Dunedin Health and Development Study, which Hill was reporting on, as opposed to a change resulting from the incorporation of social capital in the study.

The Ministry's work on aged care assembled social capital from older person's networks of associations, and resilient, independent older persons. Personal social capital was constructed as an individual resource that would allow older persons to live independently. For instance:

"Even when serious disability or illness occurs, these personal resources and social capital increase choices and enhance the likelihood that an individual can access services, be supported informally, and stay living independently" (Dwyer \& Gray, 2000, p. 58).

Two later documents that used social capital in relation to older persons (Davey, 2006; Ministry of Social Development, 2009) were both based on interviews with aged home owners. In 'Ageing in place' (Davey, 2006) a single mention of social capital defined it as the relationships that older persons had with trades people that allowed them to be resourceful and independent. Social capital (embedded in the relationships between older persons and others) could be drawn upon by the older person in order to satisfy their needs. In Ageing in the Community the authors stated that their network-based approach "was generally informed by the social capital approach developed by Bourdieu" and used a network-based understanding of social capital(Ministry of Social Development, 2009, p. 5). ${ }^{65}$ In Ageing in the Community, a social 'unit' (such as a family, child or older person) can draw upon its invested social capital to improve their outcomes, and live independently even in times of financial stress (Ministry of Social Development, 2009).

The division between network and communitarian approaches was not clear cut, however. Earlier documents regarding child development adopted an ecological

\footnotetext{
${ }^{65}$ However despite this general informing, social capital is not elaborated on or employed elsewhere in the document (neither is Bourdieu or any other form of analysis).
} 
understanding of social capital. For instance, the 2000 literature review Familial Caregivers' Physical Abuse and Neglect of Children (Saville-Smith, 2000) equated social capital to the social ecology:

"The few studies undertaken suggest that significant amounts of the variations in reported rates of child maltreatment found between neighbourhoods can be explained by reference to the socio-economic profile of the neighbourhood [...] Research suggests that these variations in child abuse and neglect reflects differences in the 'social ecology' or 'social capital' of neighbourhoods"' (Saville-Smith, 2000, p. 25).

Social capital was used in a similar way in New Zealand's Agenda for Children (Ministry of Social Development, 2002). In these documents social capital was more akin to the ecological construction that was common in public health, as opposed to the investment in relationships model that characterises network-based approaches.

The notion of investment, either in order to get higher returns from child development, or through independent living, indicated an economic influence in the MSD's thinking. The promotion of independent living also highlighted the liberal undercurrent of their ageing policy, particularly as it expected older persons to be self-responsible for building and maintaining their stocks of social capital, for instance through maintaining good relations with tradespersons or those with similar skills in order to be "supported informally", as opposed to being supported through formal government assistance (Davey, 2006; Dwyer \& Gray, 2000). Similarly parents and disabled people were expected to actively invest in social networks to be successful participants in society:

"The theory of social capital suggests that parents can enhance their children's opportunities for success by investing in social relations. People with disabilities can strengthen their participation in society by building on social networks" (Aimer, 2003, p. 20).

As with the other Labour policy documents and ministerial speeches, the MSD never constructed social capital as something damaged by economic growth. Unlike Treasury they also did not construct it as an expansion of policy concerns into new areas (possibly due to the Ministry's mandate already focusing on social life as opposed to economic development). The one area of policy that was seen as requiring modification in response to social capital, was the need for governments to incorporate diverse communities with differing values into New Zealand society. 


\section{An Inclusive Society: Diversity and Social Capital}

Boltanski and Chiapello argued that a key concern in the new, 'connexionist' form of capitalism was ensuring that individuals were not excluded from society. A similar point has been noted by analysts (and critics) of the Third Way. The New Zealand Labour Party's use of social capital displayed a concern with including a variety of ethnic groups, and Māori in particular, into New Zealand society. The Inclusive Society and the Closing the Gaps policies exemplified this concern, with Labour attempting to reduce inequalities between Māori and non-Māori whilst, according to Humpage, pursuing an assimilationist approach to Māori culture (Humpage, 2006).

Connexionist capitalism and the Third Way political programme both opposed monolithic constructions of society and a one-size fits all welfare state, instead they enacted a society that was constituted of diverse populations with different norms, values and demands for governance. In New Zealand this was related to a growing acceptance of ethnic and cultural diversity in political rhetoric. This diversity required management to ensure that diverse communities and ethnic groups would be included in 'wider society'. Given this, and its use in UK policy (Cheong et al., 2007), it should be no surprise that social capital fitted into Labour's concern with inclusivity. However, the relationship between social capital and diversity was complex. In some texts social capital was constructed as a necessity for the functioning of multicultural societies but cultural diversity could also damage social capital. Furthermore, social capital was again connected to Māori self-governance by Labour ministers, particularly Turia, and some authors of policy documents.

Concerns about social inclusion and cohesion were often framed in relation to New Zealand as a multi-cultural society with differing values existing in different communities. As with much of New Zealand's Third Way policy, this echoed developments in the UK and Australia. In the UK this was a conservative, moralistic communitarianism with a strong (but mixed) one-nation message (Driver, 1997). The 'inclusive society' of Labour was based on a belief that all individuals (regardless of background) should be able to fully participate both socially and economically. As with Bolger, the need to account for diverse means and demands mean that social development required devolving power to communities. For instance, the MSD believe that diverse groups required 'harnessing' in order to reduce social exclusion and this: 
“[...] will often mean focusing on building community capacity, ensuring there are local solutions for local problems, and recognizing the role of social capital in sustaining good economic and social outcomes" (Ministry of Social Development, 2001a, p. 13).

The Ministry also stated that individuals who felt included in society and their community would build social capital, and this would in turn allow society to function effectively (Ministry of Social Development, 2001b).

Due to this need to include diverse populations, social capital was constructed as particularly important for a multicultural society. However, the relationship between social capital and diversity varied between texts. Most commonly, the social capital between social groups, bridging social capital, was key to ensure that different communities and ethnic groups would be able to function effectively without state direction. Some documents developed a stronger association between the two, constructing diversity as an important source of social capital:

"Culture and heritage are sources of social capital and can help address the social problems that are seen most acutely in Auckland. People who are confident in their cultural identity are more likely to accept diversity and to contribute to the city's social cohesion" (Department of Prime Minister and Cabinet, 2003, p. 20).

And in Population and Sustainable Development the government stated that:

"The issues that arise from a more diverse ethnic mix in New Zealand relate most strongly to social and cultural capital. Social capital is a resource that exists because of and arises out of these interactions" (Ministry of Social Development, Ministry of Economic Development, \& Department of Labour, 2003, p. 43).

In particular mix-ethnicity people were good for social capital, as they provided a longterm bridge between ethnic groups. Much like social capital and economic growth, social capital and diversity possessed a reciprocal relationship with one another.

Concurrently, social capital was constructed as the shared norms, values, preferences and institutions within a society, suggesting some element of inclusions policy was required to build social capital. Increased diversity increased need for higher levels of social capital in society in order to include all ethnic groups. Ministers echoed these sentiments of inclusiveness in their speeches: 
"[g]overnment interventions will need to vary according to the specific needs of the broad range of groups that make up our society. We will only develop and build the social capital within our society if all our communities can tap into our social structures and participate fully in society" (Burton, 28/02/2006).

Anderton claimed that:

" $[t]$ he richer ethnic mix that is emerging in New Zealand highlights the need for the development and maintenance of our workforce and communities - or what is sometimes called "social capital" - so that everyone can participate fully in our society" (Anderton, 08/09/2002).

Three years earlier Maharey had also identified the importance of social capital for migrant communities in seeking employment (1/12/2003). He claimed that the Auckland Metropolitan Migrant and Refugee Strategy was designed to increase social capital for migrant 'job seekers' who were understood as lacking social networks and the qualifications to get jobs. This was necessary for migrants to have the same opportunities as "all New Zealanders" and so to be integrated into New Zealand society. Social capital was thus also a requirement for the inclusion and peaceful co-existence of diverse ethnic groups in New Zealand.

As well as requiring social capital to function to prevent exclusion or conflict, and the interactions between groups constructing social capital, a multicultural society was identified as a potential threat to levels of social capital if the divides between groups were not adequately bridged - such as in Treasury's TIE framework. This was discussed later by the MSD in relation to The Social Capital Benchmark Survey which suggested:

“[...] that ethnic diversity tends to reduce social solidarity and social capital (social networks and norms of trust) in a society and to increase social isolation, at least in the short-term post-immigration, until new or more encompassing identities are formed. A Canadian researcher, Helliwell (2003) has challenged these findings. Helliwell found that the links between social capital and diversity depend on the institutional context specifically whether immigration policy is assimilation-focused (eg US and France) or integration-focused (eg Canada)" (Strategic Social Policy Group, 2008, p. 48).

In both the TIE and The Social Capital Benchmark Survey, diversity required management in order to protect social capital. These competing demands meant that integrationist 
policies which allowed migrants to retain their cultural customs were superior to assimilationist ones, which focused on inclusion to the expense of diversity.

Humpage has argued that the social exclusion/inclusion discourse within New Zealand was focused on Māori during the $5^{\text {th }}$ Labour government (Humpage, 2006). ${ }^{66}$ Much like in the IPS papers, Māori social capital was constructed as distinct from Pākehā social capital, and was also connected to demands for Māori autonomy. Turia rejected the notion that iwi needed to adopt an "individualistic western paradigm" for conducting business. Instead Māori enterprises not only contributed to Māori economic capital, but to the social capital of whānau (extended families), hapu (sub-tribal divisions) and iwi (tribes) (Turia, 25/09/2001). She argued that Māori enterprises had four bottom lines, an economic one, an environmental one, a social one and a cultural one, each of which was connected to different forms of capital (economic, environmental, social and cultural) that iwi-based business provided to Māori because of their collective and cultural nature (Turia, 25/09/2001). For Turia, social capital consisted of the benefits of a cohesive society and included "higher levels of trust and social participation, and better access for everyone to opportunities and resources" (Turia, 27/09/2003). In the same two speeches Turia emphasised the importance of Māori required recognition as separate decision makers in a partnership with the state.

In StatsNZ's Framework for Measuring Social Capital, Spellerberg adopted Williams and Robinson's analysis of Māori social capital as something distinct from Pākehā social capital. She began by stating that accounting for Māori social capital was necessary in order to fully understand social capital in New Zealand and then identified nine emphases of Māori social capital:

- The lack of a divide between family and community in Māori social capital

- The importance of understanding social place within a social system such as iwi

- The importance of informal associations

- The primacy of relationships and less significance of the instrumentality of relationships

- The connection between social and cultural capital

- The importance of bridging social capital between iwi

- The importance of a cultural sense of belonging

${ }^{66}$ She also highlighted the tension between the notion of being included and the desire for Māori autonomy. The discourse of social inclusion/exclusion failed to account for the importance of Māori cultural identity and autonomy, instead advancing a belief that all New Zealanders wanted to be 'included' and thus continued to advocate assimilationist policies. 
- The importance of social capital in defending and expanding existing iwi

- Recognising the impact of governmental reforms on Māori social capital (Spellerberg, 2001, pp. 12 - 15).

Beyond this summary, StatsNZ has not discuss Māori social capital in any detail. The Framework for Measuring Social Capital offered a substantial list of potential measures of social capital none of which correspond to the distinct features of Māori social capital. Instead they drew them from international measures and frameworks which lacked a contextual specificity to New Zealand. Three years later, the MSD's Inclusive Society: Next Steps attempted to measure the difference between Māori and Pākehā levels of social capital. This was done through three proxies: the availability of phones and internet in Māori, Pacifica and Pākehā households; the percentage of Māori, Pacifica and Pākehā people who have undertaken voluntary work in the past week and 'trust in others' which lacked a specific indicator (Strategic Social Policy Group, 2004). ${ }^{67}$ That these same measures were also applied to non-Māori suggests that Māori social capital differed in quantity, but not substance for the MSD.

Māori were entirely absent from Treasury's Towards an Inclusive Economy documents. Consequently Treasury did not address cultural differences between Pākehā and Māori, and did not address the possibility of a distinct Māori social capital. In a later document Treasury did suggest that Māori social capital was distinct from Pākehā social capital, with social capital being more important for Māori business (Whitehead \& Annesley, 2005), but did not explore this difference. Later, in Working Towards Higher Living Standards for All New Zealanders (The Treasury, 2011) Treasury acknowledged the possibility of differences in social capital between Māori and Pākehā, and stated that:

“[...] an analysis of social capital in a Māori society is likely to identify an important role for culture in establishing a sense of identity and belonging, along with other features such as the primary importance of extended family relationships" (The Treasury, 2011, p. 25 emphasis added).

They also identified whānau as a source of bonding social capital, although they also reiterated the importance of bridging over bonding social capital (The Treasury, 2011, p. 24). This was without a discussion of the importance of whānau to Māori social capital or

${ }^{67}$ Which is unusual, given that trust is by far the most commonly measured element of social capital, and the General Social Survey question on trust is the most commonly used proxy for social capital - see chapters 5 and 8 ). 
culture. Beyond these few issues, Treasury did not discuss or consider the different cultural context that others saw Māori social capital operating in. Nor did they cite work done by other researchers in this area, and did not develop Māori social capital as a distinct type of social capital in any detail.

One of the critiques of social capital has been its universalisation, and lack of recognition of social and cultural contexts. The case of Māori social capital in particular, and diversity in general, suggests that there was space for cultural variation in the way authors constructed social capital. The research by the various presenters in the IPS seminar series emphasised the distinctiveness of Māori social capital and this has been occasionally acknowledged by both ministers and government departments. However, few documents during the $5^{\text {th }}$ Labour government acknowledged this difference and even the few which did offered a shallow overview at best, with little evidence of an attempt to modify their use of social capital to accommodate a distinct Māori social capital. Social capital was also constructed as both benefitting from and threatened by growing cultural and ethnic diversity. Both shared norms, values and institutions and an acceptance of a diversity of norms, values and cultures were advocated to build social capital.

\section{Quantification of the Social}

Throughout this and the previous chapter, I have mentioned the instrumentality, or 'use value' of social capital, and suggested that this is central to understanding why the concept was so enthusiastically adopted by both Labour and National. For the rest of this chapter I will begin to discuss another key element of social capital in policy: the assumption that it was quantifiable and measurable. This would again be a recurrent theme in political speeches, policy documents and, as I will discuss in the next chapter, national accounting frameworks.

The quantification of social capital was more evident in government documents published during the $5^{\text {th }}$ Labour government, than in political speeches. Statistics New Zealand's (StatsNZ) Framework for the Measurement of Social Capital in New Zealand was an early attempt to explore ways to measure social capital in New Zealand (Spellerberg, 1997, 2001). The framework itself did not measure social capital, but rather connected a conceptual model of social capital to a series of potential proxy measures and suggested pre-existing datasets which may be adapted to provide these proxy measures. Spellerberg identified 3 different 
areas of proxy measures (demographics, attitudes, and social participation) that could be used to measure social capital in New Zealand (Spellerberg, 2001).

The MSD attempted to provide a measure of social capital in the early (2001 and 2003) editions of The Social Report but this was discontinued in 2004. The Social Report used the proxy measures of group membership, access to telecommunications in the home and the regularity of contact with family and friends for social capital (Ministry of Social Development, 2001b, 2003). . The data collected by the MSP and MSD on these measures were correlated with various demographic factors such as age, ethnicity, income, family structure and so on. Ten 'categories of associations' were also identified as proxy measures of social capital. These categories of association were close to Putnam's varying measures of social capital, such as group membership, informal sociability, voluntary and philanthropic work. Whilst offering these proxy measures the MSD warned readers that:

"The measurement of social capital is at a very early stage of development. Current indicators do not necessarily capture informal, as well as formal, relationship. Nor do they adequately measure the quality of those relationships. These are areas for future development" (Ministry of Social Development, 2001b, p. 88).

These developments do not appear to have occurred, and later editions of the Social Report moved away from describing the phenomena measured as social capital, eventually entirely dropping references to social capital. As I noted above, the use of social capital by the MSD varied between community and network approaches to social capital. This meant that they used different data, such as interviews, as proxy measures of social capital. Despite these attempts at developing measures, social capital has largely remained at the theoretical level, either as a concept of interest or one which broadly guides particular studies.

Whilst they may not have offered measures of social capital in their speeches, politicians drew on international rankings of social capital, and constructed these as proxies for social progress. For instance, Turia discussed New Zealand's first place ranking on the Legatum Institutes' social capital index (Turia, 11/11/2009), identifying a collective concern for communities, hapu and iwi as the cause for this ranking. The Legatum index, much like the national accounting frameworks I will discuss in the next chapter, quantified social capital and used it as a measure of nation states' social progress (Legatum Institute, 2015). The construction of social capital as referring to a quantity was also evident in the repeated 
uses of verbs such as 'building' or adjectives such as 'levels' of social capital by ministers (Bolger's quote on page 129 is a good example of this). Other frequently used verbs such as 'declining', 'fostering' and 'investing' also construct social capital as an amount that can be increased or decreased. Bolger made 29 references to building social capital in 20 speeches, and Maharey used it 17 times in 21 speeches. In 2002 David Robinson noted this tendency and suggested that it would be better instead to ask how to discuss 'activating' or 'making use' of social capital, rather than building social capital (Robinson, 2002a, p. 2). However the construction of social capital as a level, added to its appeal for policy makers. Social capital constructs social resources as being calculable and tangible (to a degree), and correlates them to social progress: build more social capital, and a society becomes more socially developed.

\section{Conclusion}

In the previous two chapters I have provided a systematic discussion of social capital's use by ministers in speeches from 1997 to 2014, noting how the concept's use has both declined and become increasingly narrowly associated with the community and voluntary sector. I have also highlighted how ministers have generally treated social capital as something with an overwhelmingly positive valence that provides instrumental value in achieving a large number of different (and often ill-defined) goals. This exploration has been complemented with an analysis of the use of social capital in policy papers. Despite the breadth of the work that I have explored, there are areas that I have neglected - such as how the concept has been used by non-government organisations (although some of the IPS presentations gave an indication of this) and its more recent use in community resilience (such as by the Wellington Regional Emergency Management Office (Wellington Region Emergency Management Office, 2012)). ${ }^{68}$

Labour ministers and policy makers constructed more social capitals than Bolger. Different Labour ministers and policy documents have defined social capital differently, and related it to different policy outcomes, and benefits. As I noted at the start of this chapter, ministers' constructions of social capital also changed over time, from it being

\footnotetext{
68 There has been a recent take-off of scholarly interest in social capital's role in community resilience to disasters (Aldrich \& Meyer, 2015; Norris, Stevens, Pfefferbaum, Wyche, \& Pfefferbaum, 2008; Wickes, Zahnow, Taylor, \& Piquero, 2015). A brief reading of this literature suggests there is some overlap, and substantial similarities with the public health use of social capital as a resource. In this literatures social capital allows communities to 'bounce back' after disasters. The higher a community's level of social capital, the better able it is to respond to natural disasters and rebuild afterward.
} 
widely used in relation to a range of policy areas, to it becoming exclusively associated with the community and voluntary sector. These various constructions of social capital also meant that it was related to other objects in various and complex ways. For instance, depending on how it was constructed, social capital could be damaged by government intervention, or could require it. Policy documents also constructed social capital in different ways, depending on the assemblages of actors used to define and construct the concept. In TIE Treasury constructed social capital as a national level resource, that was necessary for maintaining a stable macro-economic environment, and was produced by nationally shared norms, associations and supportive institutions. Various documents within the MSD assembled social capital from groups of actors that depended on the issue they were addressing: in the Social Reports, social capital was constructed of aggregate level statistics, particularly membership in associations. In the MSD's social development documents social capital was based on national-level aggregate statistics, and was also constructed as being necessary for shared norms for the purpose of 'inclusion'. In contrast, in documents attending to older persons or families, social capital was something that various types of actors (families, older persons, parents) could invest in, for individual, or family benefits (independence or successful, employed children).

The New Zealand political constructions of social capital also highlighted the often illdefined relationship between cultural diversity and social capital. For authors social capital could be something that was damaged by diversity, could be a necessary resource to manage diversity, or could be a resource produced by greater diversity. For both Maharey and many of the IPS presenters social capital allowed social policy to account for diverse populations, as opposed to the monolithic construction, and assimilationist policies that characterised the welfare state. This was also evident in both the MSD and Treasury policy uses of social capital, however for both of these documents improperly, or un-managed diversity was a threat to social capital. In the New Zealand context the unique issue of social policies addressing Māori social policy created a contextualised understanding of social capital in some situations. As my discussion of the IPS workshops in the previous chapter highlighted, there were high levels of distrust of Pākehā institutions among Māori. I also noted that many of the IPS presenters who offered a reformist critique of policy did so in relation to Māori social capital. Turia was the only Labour minister to construct 'capitalism' in opposition to social capital, and she did so in relation to Māori social capital. However, more often ministers and the authors of policy documents constructed Māori 
social capital as either identical to Pākehā social capital or as something damaged by assimilationist government policies.

I have suggested that part of the appeal of social capital can be understood by exploring its contribution to the incorporation of a corrective communitarian critique into policy. Many political speeches and policy documents framed social capital within a distinction between the economy and society, with social and the economic resources being constructed as equally important in improving human wellbeing. Social capital often referred to the resources that the social provided to improving wellbeing, and, consequently was constructed as having an overwhelmingly positive impact. Politicians in particular used it to 'sell' the importance of particular policy ideas or areas by claiming that they build social capital and thus improved human wellbeing. Bolger's devolutionary policies or the importance of voluntary work for Laban were examples of this. In this way, social capital was used to argue that social policy areas contributed to the common good of New Zealand. I have suggested that, in addition to this instrumentality, social capital has been seen by some authors as allowing social resources to be measured. As my discussion of national accounting will demonstrate, the promise of social capital providing an aggregate, and powerful measure has been seen by some authors as a required step for the social to be given equal treatment with the economy in policy circles.

Unlike many of the IPS presenters, ministers constructed the relationship between economic and social capital as a reciprocal one. Building social capital would improve the economy, and economic growth would make building social capital easier. Because of this reciprocal relationship, no politician or policy document claimed that building social capital required economic policy to be reformed. I have argued that critics of social capital have over emphasised the economic in their discussion of social capital. Whilst I acknowledge the lack of a challenge to economic policy from most political constructions of social capital, the treatment of the social as a distinct, but equally important domain to the economic in policy, coupled with the use of social capital to sell social policy should not be subsumed under economic considerations. Many critics have downplayed the variation of realities enacted by politicians using social capital, instead they have tended to treat New Zealand politics as sharing a neoliberal 'core', and have seen political concerns over social policy as attempts to support this core. As I noted in chapter 2, this tendency has resulted in critics treating Fifth Labour government policy as a continuation or embedding of the neoliberalism of the 1980s and 1990s. The interest in social policy by Labour ministers has been sceptically dismissed as a defence of neoliberalism - 
whether a phoney social to embed market relations into the social in order to bolster economic growth (Craig \& Cotterell, 2007), or to reactivate the 'trickle-down' effect to increase support for neoliberalism (Fitzsimons, 2000, p. 2). However I have argued that, whilst social capital was not used by politicians to reform existing policy, it was used to expand policy concerns into other areas which they saw as important determinants of human wellbeing. As I noted above, social capital was used to politically 'sell' the importance of social resources, whether they are seen as operating at the individual, community or national level into areas where the importance of social resources are perceived to have been neglected.

During the National and Labour governments the expansionist communitarian critique of liberalism was incorporated into policy concerns. The various constructions of social capital played an important role in this incorporation by allowing social relations to have predictable outcomes that could in theory be calculated and measured, and which would have wide-ranging benefits. Whilst the political purchase of social capital substantially declined in New Zealand in the last term of the Fifth Labour government, the concept continues to be used in other policy spheres, and by international organisations including national accounting. In the next chapter I will discuss some of these constructions of social capital in national accounting frameworks. In these accounts the quantification of social capital became more significant, as the concept was used as a representation of society alongside human, economic and natural 'capitals'. As with the New Zealand uses, national accounting frameworks have demonstrated the tendency for government and international development organisations to construct the social and economic capital as reciprocal to one another. However, I will also discuss some recent challenges to this alignment from within the UN's World Happiness Report. This chapter will also bring my discussion to the present day. 


\section{Chapter 8: After the Third Way, Social Capital in National Accounts}

This chapter expands on my discussion of social capital in policy by exploring the construction and measurement of social capital in national accounting frameworks. As I hinted at in the previous chapter, this discussion will pay more attention to the attempts to quantify and measure social capital. In this chapter I will first offer a brief history of national accounting frameworks, and their expansion in the late $20^{\text {th }}$ century. This will involve a quick commentary on some of the other 'capitals' used in these frameworks and how these have incorporated both a social critique and an environmental critique. I will then analyse social capital in five national accounting frameworks: the OECD's $W$ ell-being of Nations and Measurement of Social Capital, the UNECE et al.'s Measuring Sustainable Development, New Zealand Treasury's Working Towards Higher Living Standards for All New Zealanders, and the UN's World Happiness Report. My analysis builds on arguments that I have been making throughout this thesis: firstly that the construction of social capital depends on the rationality enacted in the literature that it is translated into, and secondly that the core appeals of the concept lie in the assumptions that it is quantifiable and has broad instrumentality that can be linked to notions of social development or progress. Social capital in these frameworks has a more obvious 'economic' element to it than with some of the other discourses I have explored, both in the attempt to quantify social capital, and in the emphasis of the economic impacts of social capital. I will also pay significant attention to the use of social capital in the UN's World Happiness Reports, in particular the chapter in the 2015 report by Geoffrey Sachs (Helliwell et al., 2015 ch. 8) which I believe opens up interesting possibilities of social capital re-emerging as a reformist corrective critique to models of neoclassical growth.

The new measures of national accounting more clearly illuminate the changing nature of what could be described as a 'spirit of policy' that was evident in the New Zealand political uses I discussed in the previous two chapters. Economic growth, whilst still accepted as a key policy goal in all of these documents, was not constructed as an end-goal in itself. Instead, increasing level of the often ill-defined utilitarian concept of 'human wellbeing' was now the end-goal of policy development. Wellbeing was constructed as being a broad and holistic conceptualisation of states of being. Consequently, policies aimed at economic growth are no longer seen as sufficient and (as the UN's World Happiness 
Report indicates) are increasingly seen as detrimental to wellbeing in many cases. National accountants seek to measure wellbeing, and its determinants, and social capital was employed as a broad, quantifiable and scalable measure of the social in these accounts. As with much of the expansion of the concept, social capital was translated into development economics in the 1990s and, by the end of the decade, its importance was explored in relation to national accounting. Fine has argued that sociologists in the World Bank became interested in social capital during this time as a way of getting the Bank's economists to take their concerns seriously.

There has been relatively little analytical work on social capital in national accounting frameworks. Ben Fine's critique of the concept within the World Bank provided one (limited) analysis (Fine, 2001, 2010), and the ethnographic discussions in Bebbington, Woolcock, Guggenheim and Olsen (2006) offered additional insights into the concept's appeal and use within the World Bank. For Fine "[s]ocial capital has primarily played a legitimising role for the [World] Bank in rhetoric and scholarship with very limited impact upon policy" (Fine, 2010, p. 111). For Fine social capital was intended to legitimise a new 'Post-Washington Consensus' which replaced the more excessively neoliberal 'Washington Consensus'. However, when the concept was fleshed out it became problematic and challenging for economists and so was abandoned (cf. Fine, 2010 ch. 6). Fine's analysis offered one useful insight, that there has been a difficult relationship between economics and social capital. This was evident in the often forced alignment between the two (that was also evident in the speeches and policy documents that I discussed in the previous chapter). Fine dismissed any impact social capital on the World Bank (Fine, 2001; Fine \& Green, 2000). He argued that the concept would not lead to a revaluation of economic policy, instead it "simply fills out anything not already taken care of in terms of standard economic analysis" (Fine, 2001, p. 158). It also gave economists control over social issues as they use social capital and its well-meaning sociological proponents to 'colonise' the social sciences. In his updated analysis, Fine added that social capital, after making a negligible impact on the Bank was dropped because elements such as power, gender, ethnicity were 'brought back in' leading to economists losing interest in it (Fine, 2010, p. 124 also cf. ch. 6). He also claimed that World Bank social capitalists accepted his critiques, and that these resulted in the concept's decline in the bank but that 
they excused "their stance on the strategic grounds of civilising less intellectually rounded economists at the Bank" (Fine, 2010, p. 19). ${ }^{69}$

In contrast to Fine's analysis, the World Bank economists, Hammer and Pritchett described the Bank's interest in the concept as emerging from both the challenges to game theory that Spies-Butcher discussed, and practical problems identified in the 1991 Wapenhans Report. The Wapenhans Report deemed rates of failure of the Bank's development projects as unacceptable and identified a disconnect between Bank project plans and the "social realities on the ground" as contributing to these failures and thus demanded greater attention to social analyses (Hammer \& Pritchett, 2006, pp. 68 - 70). They argued that many of the economists in the World Bank had a rocky relationship with social capital, particularly as economists attempted to generalise the concept, and began to find limitations with the ability to use it as an aggregate measure, and as a type of 'capital' (Hammer \& Pritchett, 2006, p. 71). Hammer and Pritchett further argued that social capital proved to be a useful, but overly broad concept. As such they believed that the decline in interest by World Bank economists was because economic analyses of social phenomena has moved to 'a new level' that required more nuanced concepts (Hammer \& Pritchett, 2006, p. 86). ${ }^{70}$ Other World Bank 'social capitalists' ${ }^{71}$ were more optimistic of the future of the concept. Woolcock and Narayan in the same volume as Hammer and Pritchett discussed the ongoing and growing interest in the concept, arguing that social capital was in its early stages of analysis, and represented an ongoing concern with social relations in development studies (Woolcock \& Narayan, 2006). A recent article by Woolcock similarly challenged claims of the decline of social capital, characterising the concept as having been 'routinized' as a common frame of reference for the social nature of humans in interdisciplinary discussions (Woolcock, 2010, p. 471).

Regardless as to whether social capital has disappeared from the World Bank (and, whether the reasons Fine claimed are right), the concept certainly continues to be used by other international development organisations - particularly the OECD, the EU and the UN. A large part of this has been because social capital has been translated into national

\footnotetext{
${ }^{69} \mathrm{He}$ also reiterates his arguments that it was more likely "the economists that were doing the levering and welcoming social capital, as a way of legitimising their unreconstructed economics and its extension to the non-economic" (Fine, 2010, p. 113).

70 Hammer and Pritchett's argument however does seem to support an argument for the absorption of 'social' phenomena into economic analyses. Whether this is 'colonisation' as Fine argues, or more of an incorporation that Spies-Butcher argues is debatable.

71 To use Fine's term
} 
accounting frameworks, and measures of 'social progress'. This incorporation of social capital has been part of the expansion of national accounts to include broader and more varied measures that has been occurring since the 1970s in which happiness (subjective wellbeing), knowledge (often human capital), the environment (often natural capital) and the social (often as social capital) have been incorporated into accounts in an attempt to provide a holistic approach to national progress or development.

\section{GDP and Beyond: The Rise of Alternative National Accounting Frameworks}

National accounting frameworks are intertwined with development programmes and the international organisations that produce both. Escobar has noted that from the 1950s through to the 1970s, there was a belief that, through the application of (economic) capital, science, and technology, all nations would be able to take on the features of "advanced" or "developed" nations. For both capitalist developers, and anti-capitalists, development was therefore a certainty. Consequently the preoccupation was on how to address particular social and economic problems to result in development (Escobar, 1995, pp. 1 - 5). Central to these development programmes was the image of a world divided between more or less developed nations, and central to the creation of that image were national accounts.

In chapter 3, I discussed Speich's treatment of the GDP, and that the GDP had become popular and powerful, despite the known limitations of the measure. These limitations, coupled with its influence, resulted in an expansion of critiques and alternative measures of development throughout the latter part of the $20^{\text {th }}$ century from a variety of positions and groups. These critiques included both a 'social slant', that opposed the notion that economic growth equalled social progress, and environmental slant which opposed the environmental destruction resulting from economic growth (Gadrey \& Jany-Catrice, 2006). These critiques resulted in an expansion of areas of interest in national accounts (such as the environment), as well as the indexes and methods available for accountants. In 2006 Woolcock and Narayan argued that:

\footnotetext{
"While it is too soon to announce the arrival of a new development "paradigm," it is not unreasonable to claim that there is a remarkable, if often unacknowledged, consensus emerging about the importance of social relations in development" (Woolcock \& Narayan, 2006, p. 53).
} 
This incorporation of social relations, often under the rubric of social capital, has been part of a more general expansion of national accounting frameworks into new fields based on a belief that including these features will create more 'holistic' measures of human wellbeing. This expansion created a more fragmented and complex reality for national accountants, with the world varying in levels of multiple different resources and features of wellbeing. National accountants who combined these (and other) measures of the world believe that for things to be taken seriously in policy development they need to be accurately measured (Gadrey \& Jany-Catrice, 2006). The economist John Helliwell for instance, has stated his belief that wellbeing will only become a policy concern if researchers are able to accumulate sufficient data on it using a small set of measures (Helliwell, 2006, p. C44). There are many different approaches to these new national accounts. Four of the five frameworks that I explore in this chapter used the 'capital approach' to sustainable development. The last framework - the World Happiness Reportdrew on happiness economics with a less mechanistic framework, but still retained elements of the capital approach.

All of these frameworks appeal to the notion of sustainable development, which they trace to the Brundland Report (World Commission on Environment and Development, 1987). According to the Brundland Report, the goal of sustainable development was a non-declining level of wellbeing over time. This included goods consumption but also a concern for preserving natural resources. The measurement of sustainable development was formalised in the 1992 Rio Earth Summit's Agenda 21. Agenda 21 identified three pillars of sustainable development: the environment, the economy and society. The agenda also raised concerns over income distribution and inequality of sustainable development, with non-increasing inequality being a key definer of sustainable society in some sustainable development frameworks (see for instance Swiss Federal Statistics Office, 2012 where social cohesion is equated with inequality particularly p. 20). Evans, Strezov and Evans have claimed that:

"[s]ustainable development cannot be measured by the traditional economic model of increasing per capital income or gross domestic product (GDP) as this can mask situations where the poor are getting poorer despite increasing average GDP" (Evans, Strezov, \& Evans, 2015, p. 291). 
Subsequent national accounting measures of sustainable development share this common consideration of environment, economy and society, and belief that development should be sustainable in these three areas.

Gadrey and Jany-Catrice located the immediate origins of what would become the 'capital approach' in Osberg and Sharpe's measure of 'Sustainable Well-being' developed in the late 1990s. This capital approach was adopted by the OECD in their Wellbeing of Nations: The Role of Human and Social Capital, before it became an integral part of several prominent measures. From the perspective of the capital approach, the determinants of human wellbeing can be captured by five 'capitals' - financial capital, produced capital (often combined into 'economic capital'), natural capital, human capital, and social capital. A detailed discussion of each form of capital is both beyond, and unnecessary for this thesis. Instead I will limit myself to a brief outline of each one in national accounting in order to orientate the reader to the reality being enacted in these new national accounting frameworks, before proceeding with my analysis of social capital in the frameworks I will be discussing.

In the capital approach, economic capital was divided between liquid (financial capital) and material (physical capital) assets. It was the original 'capital' and the primary object of concern for both economics, and national accounts such as the GDP, and referred to resources invested in (at a cost) for financial gain. It was the most concretised and discussed form of capital within the 'capital approach'. In the national accounting frameworks this basis was entwined with neoclassical economic assumptions about how to create a favourable macro-economic environment to increase levels of economic capital. For instance, the New Zealand Treasury's framework warned against risks and high national debt (i.e. low stocks of financial wealth) because it "may increase vulnerabilities to future credit shocks, which can undermine incomes and require costly government responses" (The Treasury, 2011, p. 19).

Human capital was the first new form of capital translated into development economics. Unlike later forms of capital, human capital did not emerge from external critiques, but from developments within the economics discipline itself. In the 1940s - 1960s there was a near-exclusive focus on 'physical capital' investment by international development agencies, with a belief that an increase in capital investment would result in an increase in GDP and would therefore the nation would 'develop'. However by the 1980s, the failure of grand strategies for development resulted in them giving way to a second generation 
dedicated to the application of neoclassical economic principles as a guideline for development (Meier, 2001, p. 17). Investments in physical capital were no longer sufficient for development because knowledge and skills were required to exploit physical capital investments. Consequently, individuals' skills, knowledge, training and health became objects of concern for development economics and this also resulted in the incorporation of human capital into development economics. Human capital was often constructed as a private good that gives returns on investments to individuals (in the form of higher wages, better employment etc.). Human and social capital are treated as closer to each other than other elements of national accounting frameworks, with both being described as 'intangible capital'. An example of this can be seen with the OECD's Wellbeing of Nations which treats the two of them as 'Human and social capabilities' which is distinct from both natural and produced capital (see figure 4). However, in more recent documents the two have been treated as distinct types of capital.

Natural capital was bound up with the emergence of ecological economics in the late $20^{\text {th }}$ century as growing environmental critiques impacts on national accounting frameworks. In 1972 the United Nations held a conference in Stockholm on the human environment in response to earlier growing concerns about the environmental impact of development (Egelston, 2013 ch. 4). A decade later they formed the World Commission on Environment and Development (the Bruntland commission) which in 1987 published Our Common Future ('The Brundtland Report'). The 'Bruntland Report' introduced the concept of sustainable development, and defined it as:

"[...] a process of change in which the exploitation of resources, the direction of investments, the orientation of technological development; and institutional change are all in harmony and enhance both current and future potential to meet human needs and aspirations" (World Commission on Environment and Development, 1987, p. 17).

Limitless economic growth and consumption were no longer possible as the need to conserve resources for future generations becoming a policy concern. At the same time 'ecological economics' was (re-)emerging as a scholarly discipline, focused on ways of accounting for natural resources. Natural capital included both physical, exploitable and exhaustible resources (such as timber or mineral deposits), intangible "core" capital stocks - such as clean air, water and natural phenomena of indeterminate value (such as sunrises, or natural beauty). Core capital stocks were non-substitutable forms of capital and maintaining them is seen as an absolute necessity for continued human survival. As with 
human capital and financial/physical capital, natural capital is associated with improved economic productivity, and there have been attempts to monetise it using market values, despite the non-tangible qualities of some elements of natural capital.

In the $21^{\text {st }}$ century, 'Happiness economics' or wellbeing economics has emerged as another concern for national accountants. Happiness economics emerged from a renewed interest in the subjective measurement of happiness in psychology (Linley, Joseph, Harrington, \& Wood, 2006; Seligman \& Csikszentmihalyi, 2000), sociology (Veenhoven, 2004, 2009) and economics (Helliwell, 2006; Layard, 2006). Much of this literature also overlapped with the social capital literature. For instance, Ruut Veenhoven has argued that there are 4 types of wellbeing, two of which were external, and could be represented by social capital, and two are internal (psychological capital). Psychological capital included the abilities of an individual, but also the length and happiness of their life, and proposes a 'happy life years' measure by multiplying happiness (on a scale of 0-1) with life expectancy (Veenhoven, 2009, p. 11). ${ }^{72}$ Bhutan's 1972 adoption of 'Gross National Happiness' is regularly cited as a key development in this literature, as are both Aristotle's eudemoni ${ }^{73}$ and the utilitarianism of Bentham and others. Amartya Sen also developed a utilitarian argument for 'living well' by improving the capabilities of individuals to improve their wellbeing also contributed to this emerging discourse (Deneulin \& McGregor, 2010; Sen, 2001). For these authors, subjective wellbeing has been incorrectly treated as an unreliable and subjective measure of either utility or wellbeing. ${ }^{74}$

Wellbeing economics, much like the sustainable development approach adopted a utilitarian ontology, in which happiness is the universal and ultimate goal of human lives (Frey, 2008 ch. 1), consequently a nation's aggregate of self-reported happiness is seen as a more valid measure of societal progress than GDP. Happiness economics has also been

\footnotetext{
${ }^{72}$ Veenhoven was also an avid critic of the welfare state arguing that it redistributes wellbeing, not increasing it, and that too much welfare may harm wellbeing (Veenhoven, 2000). Thus highlighting this as a curious national-level utilitarian measure of wellbeing in happiness economic. Treasury have explicitly highlighted the utilitarian underpinnings of their Toward Higher Living Standards framework, although they identify it as going beyond the Benthamite utilitarianism to incorporate Sen's capability approaches

${ }^{73}$ Aristotle is a particularly clear case of the interessement (imposition of a stable identity), and enrolment of powerful ancestors without detailed incorporation of their work.

${ }^{74}$ Davies has critiqued wellbeing arguing that it: "provides the policy paradigm by which mind and body can be assessed as economic resources, with varying levels of health and productivity. In place of the binary split between the productive and the sick, it offers gradations of economic, biological and psychological wellness" (Davies, 2011, p. 65). This, he argued is a policy concern because depressed workers are inefficient and links this to neoliberalism requires high levels of enthusiasm and hope but destroys these through insecurity, unattainable individual ideals and powerlessness of the population (Davies, 2011). However, more recently he has suggested that there is a new form of the social emerging within wellbeing economics (and the social capital literature) that challenges neoliberalism (Davies, 2015). Whilst he raised concerns over origins of this new social's origins within corporate management, he also suggested that there is the potential for this new social to critique (and change) polities that have rendered "productive and healthy relations impossible" (Davies, 2015, p. 16).
} 
suggested as a possible challenge to traditional models of economic growth, particularly because of the 'Easterlin Paradox' (Clark, Frijters, \& Shields, 2008; Layard, 2006). In 1974 Richard Easterlin found that aggregate levels of self-reported happiness in the post-war United States had remained static, despite rapidly increasing GDP (Clark, 2012; Easterlin, 1974). Thus the 'paradox' was that at a certain level of GDP, economic growth no longer increases aggregate happiness. However, happiness continued to be correlated with wealth relative to other members of a society - the wealthier you are compared to your 'neighbours' the happier you are (on average). To draw on Boltanski and Chiapello, governance must be justified by an appeal to the common good (Boltanski \& Chiapello, 1999 [2005], p. 27), and economic growth did not increase wellbeing it did not benefit the common good. Thus findings of those such as Easterlin have challenged the notion of economic growth as the primary mechanism for attaining higher levels of wellbeing. These various features and areas of concern have been integrated into national accounting frameworks in different ways.

\section{The OECD's The Well-being of Nations and Measurement of Social Capital Project}

In 2001 the OECD published an in-depth analysis of the potential impact of human and social capital on economic and social development. Social and human capital were constructed as distinct parts of human and social capabilities (terms drawn from Amartya Sen), alongside political and legal systems. They fed into human wellbeing, economic wellbeing and GDP and existed in a direct, reciprocal relationship with both natural capital and produced capital (OECD, 2001, p. 13 see figure 4). In the Well-being of Nations the OECD gave what has become the most frequently cited definition of social capital in national accounting frameworks, that it "refers to the norms and networks facilitating cooperation either with, or between groups" which are impacted on by political institutions and legal frameworks. Social capital was distinct from social cohesion, "the shared values and commitment to a community" (OECD, 2001, p. 12). The OECD's concern with social and human capital was instrumental: neither capital was desirable for 
its own sake, but both were constructed as resources that aid in economic and social development (OECD, 2001, p. 9).

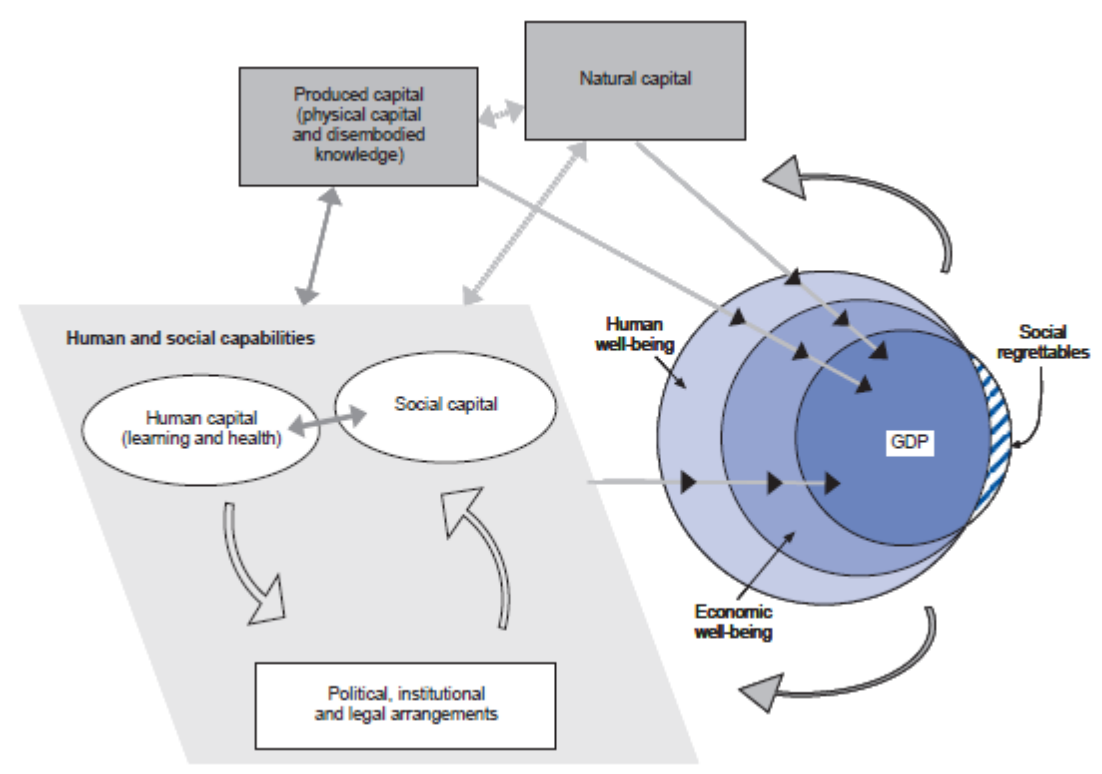

Figure 4: The OECD's Wellbeing of Nations framework (OECD, 2001, p. 13).

As in the Third Way, this expanded interest did not result in a reform to the OECD's economic policies. Rather, social capital was important because of the necessity of institutions in providing a stable macro-economic environment for growth (OECD, 2001, pp. 13 - 14). Much like Treasury, the OECD retained a belief in the 'rising tide' analogy of economic growth, and downplayed the negative effects of economic development. The OECD concluded with their belief that:

"[e]nsuring continued economic growth and improving the well-being of all are major challenges for OECD societies. In a fast-changing global economy, the value of social and human capabilities in meeting these challenges is as important as ever" (OECD, 2001, p. 71$)$.

The 'global economy' remained naturalised, economic growth was a goal of policy alongside wellbeing. Human and social capital were supplementary areas of concern to this pre-existing economic development framework.

Despite this alignment, the incorporation of social capital created a potential tension around the relationship between social capabilities and economic growth, a tension that the OECD recognised and addressed. They acknowledged the possibility of economic 
growth damaging social capital, but quickly neutered any contradiction between them stating that:

"[t]his report finds no evidence to show that increased prosperity has necessarily depleted social capital reserves, but it does suggest a link between some aspects of economic progress and increased stress or loosening of social ties. However new conditions of production and work also give new opportunities which, when seized, may contribute to significant advances in wellbeing" (OECD, 2001, p. 10).

The OECD dismissed the extent of the damage caused to social capital from economic growth, by stating that they have found no evidence for it. They then raised doubts as the strength of the connection between economic growth and damages to social capital by limiting the connections to some aspects of economic growth that are suggested to weaken ties (thus these are not necessary for economic growth to occur). Finally they shifted back to the benefits of economic growth, thus even if these negative impacts may occur (which is not necessarily the case) they were counter-balanced by the new opportunities afforded by economic growth. As with both the subsequent frameworks, economic growth was a primary (but not exclusive) aspect of wellbeing, so long as it was of 'high quality' (OECD, 2001, p. 10). Later in the document the OECD gave a detailed discussion on what "lies behind changes in levels of trust and civic participation" (i.e. declining social capital) and did not suggest that economic changes could be the cause. They briefly discussed the impact of inequality on social capital, but the relationship was constructed as uncertain, with most of the focus being on social capital's impact on equality than vice versa.

The OECD did not attempt to measure social capital in Wellbeing of Nations. They stated that this was due to the lack of available proxy measures coupled with the infancy of existing approaches to measuring the concept. This was particularly problematic because "[m]uch of what is relevant to social capital is tacit and relational, defying easy measurement or codification" (OECD, 2001, p. 43). They also warned of the danger in conflating proxy measures with the 'underlying concept' of social capital, so for the OECD social capital was a reified object, as opposed to a shorthand for other features. The few proxy measures they discussed were Putnam's use of associational membership, the World Bank's 'ground up' surveys, and Fukuyama's measure of crime and family breakdown. They also identified the World Values Survey's trust question ("Generally speaking would you say that most people can be trusted, or that you can't be too careful dealing with people?") as offering a proxy measure of social dysfunction which is implied (but not out-right stated) in turn be a potential proxy measure for social capital. 
The OECD suggested some pilot ideas for future evaluation: supporting families, supporting voluntary initiatives, supporting direct democracy, promoting IT communication and decentralising healthcare to communities. The framework also included an eclectic group of measures of trends in the 'social and economic environments'. As these were not separated into sub-groups it is difficult to ascertain with any confidence which relate to measures of social, human or economic capital. The OECD wished for any potential or future measures to be transferable between social contexts, thus allowing comparisons between national level surveys. They concluded that there was a need to clarify the concept and develop measures of both individual access and social access and developing policies to improve understanding of how to build it (OECD, 2001, p. 70).

The OECD continued to work on the concept of social capital after publishing the Wellbeing of Nations. In addition to the Measuring Sustainable Development framework (below), they established an agenda for measuring social capital in Four Interpretations of Social Capital: An Agenda for Measurement (Scrivens \& Smith, 2013). A key part of this agenda was to standardise social capital measures, again to permit international comparisons. In this later framework, the OECD offered a series of proxy measures for social capital. These measures varied from time-use-surveys, surveys on the composition of individual's social networks, the nature, regularity and causes of social interactions, and access to both monetary and non-monetary help. As part of the same project they also attempted to construct a database of questions to measure social capital, which as of 2013 had reached 1281 questions (OECD, 2013). These were not scalable, and the OECD made no attempt to provide a unified measure of social capital in this agenda.

The number of proposed proxy measures reflected a development in the OECD thinking with a growing belief that social capital cannot be considered a single concept. Scrivens and Smith recently developed a schema of four 'interpretations' of social capital for the OECD: personal relationships, social network support, civic engagement and trust/cooperative norms (Scrivens \& Smith, 2013, pp. 21 - 41). These are seen as being closely linked (thus justifying their inclusion under social capital) however, they are also "distinct enough to merit being treated as individual concepts in their own right" (Scrivens \& Smith, 2013, p. 55). Whilst Scrivens and Smith did not suggest abandoning social capital as a concept, they argued that unless more complex analyses of different phenomena "related to all things social" are performed, knowledge on the relationship between society and human wellbeing is unlikely to advance. Similar divisions were evident in other 
national accounting frameworks, and have also become topics of discussion in the scholarly literature. For instance, as I noted in chapter 4, Giordano and Lindstrom critiqued the concept's use in public health for conflating multiple different social phenomena and thus obscuring the impact of social interactions on health outcomes (Giordano \& Lindstrom, 2010).

The alignment between social capital and economics was significant in the OECD's work, but it was not the only important consideration. In both Wellbeing of Nations and Four Interpretations of Social Capital the OECD emphasised the need to measure social capital to represent the impact of a distinct social domain on wellbeing. Four Interpretations of Social Capital also hinted at the issues that have emerged in developing a single conceptual and empirical object to account for as much of social life as possible. The analysis of social (and human) capital in Wellbeing of Nations has been highly influential in subsequent work published by development organisations, with a similar understanding of the concept inserted into a wider 'capital approach'.

\section{UNECE/OECD/EuroStat's Measuring Sustainable Development}

The task of unifying measures of social capital was enthusiastically adopted by the joint UNECE, OECD and Eurostat working group on sustainable development. The group was established in 2006 to develop international measures of sustainable development (UNECE/OECD/Eurostat Working Group, 2015). It published a report on Measuring Sustainable Development in 2008, and a follow-up report on the recommended measurements of sustainable development in 2013. The report divided the resources humans consume to increase their wellbeing into the five different forms of capital: financial, physical, human, social and natural - with financial and physical capital treated together as 'economic capital' in the 2013 report. Each capital represented a 'stock' of resources, which has associated 'flows' that impacted on the stock and also impacted on other forms of capital. The report provided a short discussion of what social capital entails, and used the OECD definition, but their main focus was on establishing the theorists who had used the concept, rather than how it was used. They chose social capital, as opposed to another concept because it was "closely connected with economic theory and is therefore more amenable to economic modelling and to developing satellite accounts" (UNECE/OECD/Eurostat Working Group, 2013, p. 10). The purpose of using capital stocks and flows was designed to simplify the measurement of sustainable development. Each form of capital could (in theory) be quantified by a single measure 
that is scalable with other forms of capital. The 2013 report also discussed subjective measures of wellbeing as a 'theme' to measure current human wellbeing within a nationstate.

Unlike the OECD in Wellbeing of Nations, the working group actively began a programme to develop a simple measure of social capital. The group aimed to develop a small set of indicators (ideally from existing surveys) which would be weakly sustainable (they would be interchangeable and replaceable by increases in other indicators). Sustainable development was defined as non-declining, or increasing consumption of various different forms of capital. This included consumption via market mechanisms, but also included non-marketable resources such as sunrises or social relationships. A society was sustainable so long as the aggregate level of all capital stocks was not declining, even if one or more type of capital was. As in The Well-being of Nations the working group aimed to harmonise the various approaches and measures of capital, to allow comparisons to be made between them. The group perceived a need to permit comparisons between different states to assess the levels of sustainability at an international level.

Despite stating their interest in non-marketable resources, the group suggested monetary value as the shared measure for all five types of capital. Monetary value was identified as offering a "robust, if not yet complete" picture of wealth, furthermore market value was stated to be "close to theoretically ideal accounting prices". So the value of a traded good was assumed to be a close approximation to the impact of that good on wellbeing. However, there were also certain critical capital assets which, regardless of monetary value, could not be substituted by other forms of capital, such as air or safe water, and the recognition that natural, human and social capital may contribute to wellbeing outside of the marketplace (UNECE/OECD/Eurostat Working Group, 2008, pp. 61 - 64). The working group recognised that their approach could be a limitation of the framework, because it would appear too economic for some users (UNECE/OECD/Eurostat Working Group, 2008, p. 74).

A combination of monetisation and additional measures for critical capital stocks of capital, established a streamlined, if highly problematic framework for measuring the first four forms of capital stocks (financial, physical, human and natural). The non-market value of human capital was to be measured through the percentage of the population with high school degrees, and the health-adjusted life expectancy of the population. Natural capital stocks could similarly be substituted with market value because: 
"[m]any of the same features of the environment that are critical to [economic] development are also those from which humans would derive non-market well-being" (UNECE/OECD/Eurostat Working Group, 2008, p. 63).

However, social capital proved particularly problematic for the framework. The group argued that monetary value could, in principle, be applied "to social capital, though there are no market prices at all for this sort of capital or for the services it provides" but they could provide no measures of this contribution (UNECE/OECD/Eurostat Working Group, 2008, p. 59). Additionally they believed that, in principle, "it seems reasonable to suggest that social capital makes a contribution to non-market well-being", again they could not provide a measure of this contribution. They were similarly unable to offer a potential measure of the 'flows' associated with social capital ${ }^{75}$ - although this was because of the lack of parallels between the proxy stock indicators and potential proxy flow indicators (besides changes in group membership) (UNECE/OECD/Eurostat Working Group, 2008, p. 66). The up-shot of this was that social capital stock and flow indicators were 'placeholders' barring the proxy measures of trust/adherence to norms, and 'collective action'. These problems continued to be evident in the proposed set of sustainable development indicators which included no potential measures of social capital, although the risk of poverty was suggested to be in principle be an explanatory variable (UNECE/OECD/Eurostat Working Group, 2008, p. 78).

The group restated the problems and limitations of monetising social capital in the 2013 document. However, despite this they also re-stated their belief that economic, natural, human and social capital could be measured in physical and monetary terms (UNECE/OECD/Eurostat Working Group, 2013, p. 10) and a 'placeholder' measure of a monetised social capital was inserted into the batteries of measurements. In addition they included a small battery of proxy measures of social capital, under two 'themes' of social capital: trust and institutions. The World Value Survey question provided a measure of generalised trust, supplemented by the regularity of contact with family and friends, and participation in voluntary work as measures of trust. Institutions were measured by voter turnout, the percentage of women in parliament and the contribution of the state to international institutions. However, the group noted that trust was the only dimension of social capital that was used widely and developed enough to allow for international

\footnotetext{
75 In economics capital flows refers to the investment of monetary assets in capital. However when applied to the other forms of capital in both this and the Treasury framework 'flows' were poorly defined. They largely referred to features that impact on particular capital stocks but also referred to the outputs of the interactions between different capital stocks such as income, employment, freedom, security, amenities.
} 
comparisons. Consequently 12 years after the Wellbeing of Nations, the group believed that measures of social capital were still insufficient. The proxy measures they offered also had no scaled measure (such as monetary value) limiting the ability of the group to compare them with stocks of other forms of capital. Some, such as generalised trust, were scored from $0-10$, others such as women's representation in parliament, are fractions or percentages. Additionally statistics such as women's representation in parliament or the contribution to international organisations whilst important, did not fit the definition of social capital as a resource offered by the working group.

Measuring Sustainable Development offered an explicit attempt to monetise social capital, but the reason given for the decision was in part pragmatic. Since economic production was already measured in monetary values, measuring others in the same way would allow them to be quickly scalable and comparable. A small number of proxy measures would allow for the equal treatment of all different forms of capital in a holistic measure of the determinants of wellbeing. These frameworks also starkly demonstrated the difficulty in either monetising or aggregating social resources into a single value.

\section{New Zealand Treasury's Working Towards Higher Living Standards for All New Zealanders (and StatsNZ's Framework for Measuring Sustainable Development)}

The New Zealand Treasury released their Working Towards Higher Living Standards for All New Zealanders (THLS) framework in 2011 which they identified as an expansion of earlier thinking in the TIE framework (Whitehead, 25 May 2011). The THLS framework was based on the Measuring Sustainable Development framework, but combined Financial and Physical capital to create four types of capital (economic, human, social and natural). These four types of capital were seen as inter-related and, when combined, determined the living standards of New Zealanders (Treasury equated living standards with wellbeing). Treasury supplemented the capital approach with Amartya Sen's capabilities approach, as well as emerging insights from happiness economics and wellbeing studies. The former provided theoretical support for the model whereas the latter was seen as a cross-check in measuring the impact of higher levels of social capital on living standards (see figure 5). As with most New Zealand policy documents, the THLS framework drew heavily on work from other government and extra-government organisations particularly the World Bank and OECD. It was also produced in conjunction with 
StatsNZ, who attempted to develop measures for the framework (Statistics New Zealand, 2008). A year after the initial framework was released Treasury released a supplementary tool at the International Wellbeing Conference in Wellington (Karacaoglu, 2012). The tool was intended to directly assist in the development of policy in Treasury's day-to-day work as opposed to the higher-level and more theoretical framework.

Treasury gave two reasons for producing the framework. They believed that changes in understandings of wellbeing in the international literature meant they needed to use broader, more comprehensive measures of societal progress/standards of living in New Zealand (Gleisner, Llewellyn-Fowler, \& McAlister, 2011; Gleisner, 2012; The Treasury, 2011; Whitehead, 25 May 2011)(Karacaoglu, 2012). They also wished to change the way they were perceived by New Zealanders. Treasury viewed its interests to be broader than fiscal matters and considered itself to have oversight over the state sector. However, they believed that the population perceived them solely as interested in financial matters. John Whitehead emphasised that the THLS framework was designed to dispel what Treasury saw as myths surrounding its role. Whitehead stated that:

" $[t]$ he reality is that the framework represents, in a number of ways, what Treasury has been advising over the last 10 years or even longer. This is not a sudden lurch into new territory, however, it does seek to establish a broader intellectual basis for our work - one that provides a guide for how we should be thinking about the complex and multidimensional nature of living standards" (Whitehead, 25 May 2011).

He argued that the Treasury of 2011 was substantially different from the conventional perception of the Treasury as unchanged since the 1980s when it advanced the free market reforms of the $4^{\text {th }}$ Labour government (Goldfinch, 2000; Goldfinch \& Roper, 1993; Kelsey, 1995). ${ }^{76}$

As with the OECD's later publications, Treasury framed their discussion of social capital around a series of sub-divisions. These were two 'stocks'; trust and strong institutions and three 'flows'; shared social values, rights and freedoms. Public institutions facilitated this trust and cooperation by providing security and providing "the framework in which the society and the economy function" (The Treasury, 2011, p. 24). Trust was further divided

\footnotetext{
${ }^{76}$ Whilst Treasury claims to have an interest in non-economic 'social' factors, this interest has been somewhat limited. Of the six working papers Treasury published in 2011 only three mentioned living standards and in one of these living standards were only mentioned twice, once in the mission statement which headed some of Treasury's working papers, and once in relation to the impact of export performance on living standards. In 2012, only a single working paper (again of six) mentioned Living Standards. This is a continuation of the isolated use of social capital by Treasury I noted in the previous chapter.
} 
into 'bridging' and 'bonding' capital. Bonding capital is defined as the "strong ties that emphasise a shared identity within a group such as whanau [Māori extended families]" (The Treasury, 2011, p. 24). Whereas bridging capital described the weaker ties between communities and groups. Treasury repeated their belief that bridging capital was more desirable because it builds cohesion between different ethnic groups. As in the TIE framework, bonding social capital was less desirable because it may cause a decline in bridging social capital (The Treasury, 2011, p. 25).

Treasury also repeatedly mentioned the need to encourage 'shared social values' and lowering antisocial behaviour in order to increase levels of social capital. They noted that cultural norms differ between groups within a society and that 'culture' plays an important role in Māori (the indigenous New Zealand population) society "in establishing a sense of identity and belonging, along with other features such as the primary importance of extended family relationships" (The Treasury, 2015). However, Treasury believed themselves to be neutral and impartial and as such did not discuss what shared social values are, or should be present in New Zealand. Neither did they explore the consequences of imposing 'shared' values on a diverse population such as in New Zealand.

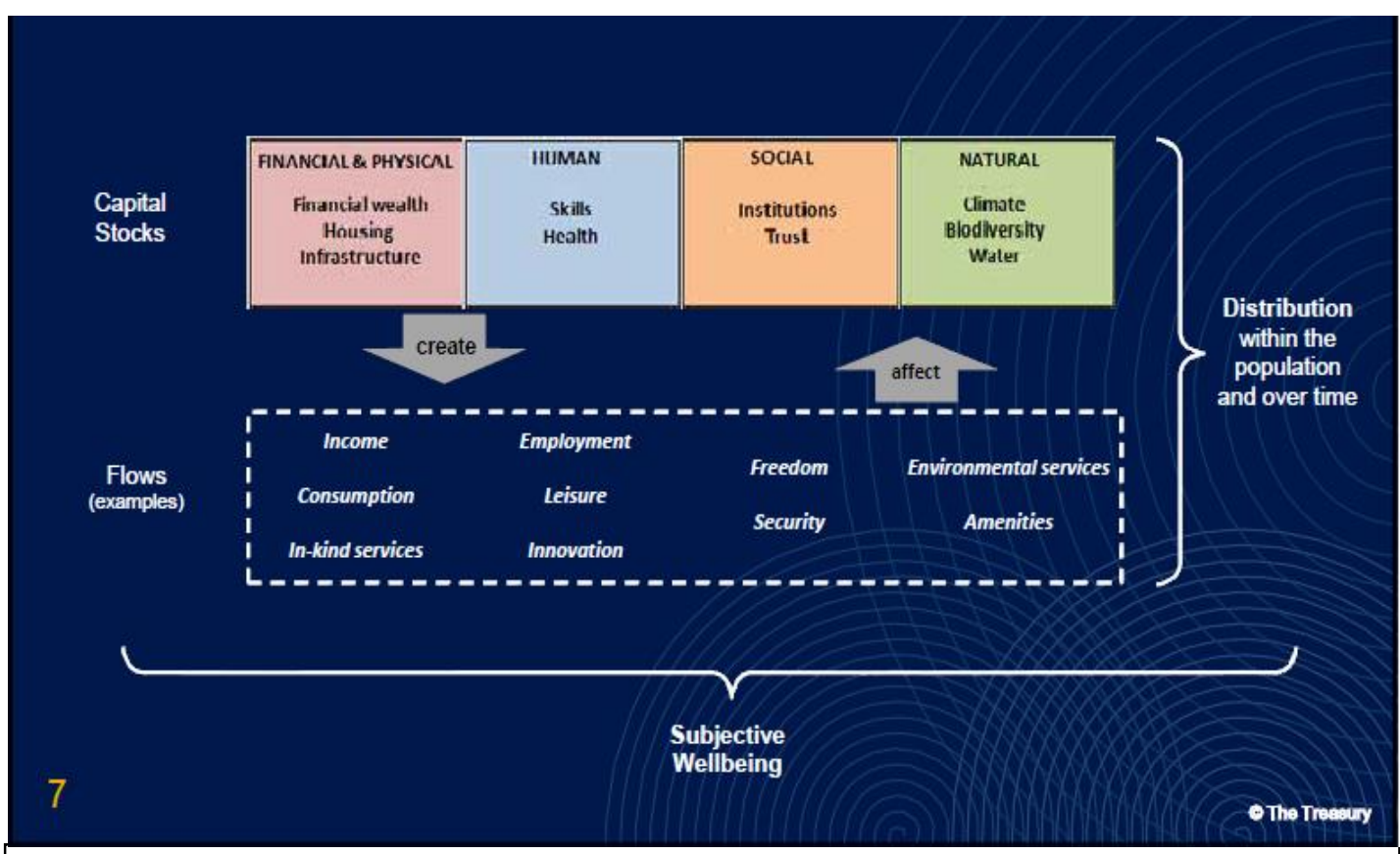

Figure 5: Treasury's Higher Living Standards framework in Whitehead (Whitehead, 25 May 2011) and the Conference Paper (Karacaoglu, 2012). A similar graphic is used in the Treasury paper (2011: 3), but it omitted the 'Subjective Wellbeing' and 'Distribution within the population and over time' brackets. 
As with most of the literature, social capital was constructed as important due to its instrumentality, and Treasury emphasised a number of positive outcomes from higher levels of social capital. In practice however, these benefits were connected to subdivisions of social capital (such as trust), as opposed to the concept overall. For instance, increased trust and shared values would encourage individuals to work toward common goals which would improve their living standards, and institutions were important because:

"[...] a transparent system of government gains the trust of the population, which reinforces the responsibility of institutions to the public. Aspects of social capital also have benefits for the economy, particularly in terms of decreasing transaction costs $[\ldots]$ if people know others will honour contracts and can trust people they do not know well" (The Treasury, 2011, pp. 24 - 25).

Similarly, culture was important because influenced the context that the economy operated in. Human and property rights were also important types of social capital, with both requiring legal protection.

Unlike the UNECE/OECD/Eurostat working group, Treasury did not attempt to develop a single, unified measure of social capital and neither Treasury nor StatsNZ attempted to monetise the different forms of capital. Instead Treasury provided a battery of 8 indicators designed to measure social capital. These were designed to allow comparisons with other OECD countries and to be broken down by gender, ethnicity, household type, ages and income where possible (The Treasury, 2011, p. 32). The indicators were:

Generalised trust

Perception of corruption in government

Reported as trusting others by ethnicity

Reported as trusting others by income bracket

Percentage of population reporting crime over past 12 months

Percentage of population feeling unsafe on streets after dark

Percentage of population reporting victimisation over past 12 months by ethnicity

Percentage of population reporting victimisation over past 12 months, by age (The Treasury, 2011, pp. 41 - 44).

These proxy measures were required because capital stocks were abstract concepts that could not easily measured directly. To aid in this proxy measurement the 'flows' of trust 
and institutions were seen as corresponding to already available metrics. In addition to the stocks and flows, Treasury referenced a broad but ill-defined range of 'factors' which influenced living standards, with the stocks and flows approach being intended to account for these factors (The Treasury, 2011, p. 30) even if they did not directly equate to individual capital stocks. The list of 'factors' was very broad including: rights, capabilities, income, crime, accidents, terrorism, bio-security hazards, natural disasters, health, the rule of law, tolerance, security, equality, employment, education, freedom (economic, political and personal), wealth, human relationships, and a clean environment.

With the 2012 release of the Tool, Treasury took the THLS framework in a new direction. In 2013 Treasury produced five 'short guides', based on the five 'aspects' of the tool (see figure 6) that were intended to incorporate the framework into policy advice. 'Growing Social Capital' was rephrased to 'Social Infrastructure' in the short guides but retained the same analysis and key points. Social Infrastructure shared the centrality of 'trust' as a proxy measure with social capital. The guide also briefly mentioned 'bonding' and 'bridging dimensions' of social infrastructure, but unlike in the Treasury Paper these were not identified as types of capital. As with earlier Treasury discussions on social capital there was no attempt to outline how social infrastructure levels can be measured. However, social infrastructure was identified as increasing social cohesion, and strengthen families and communities in order to reduce the burden on the government. Much like social capital it had economic benefits including increased market attractiveness, greater efficiency through reduced costs, reduced health and welfare expenditures and so on. Property rights were also discussed under both rubrics, however human rights were present in the social capital discussion but absent from the Social Infrastructure short guide. From the documents it is unclear why Treasury included both Social Infrastructure and Social Capital in the tool, and why what are almost identical factors are labelled 'Growing Social Capital' in the conference paper and 'Social Infrastructure' in the short guides. As with the stocks and flows of the framework, the five factors of the tool are interrelated. These relationships could either be synergistic, where increases to one factor also results in increases in others, or create tensions, where increases to one factor results in decreases to others. When tensions exist they created the need for trade-offs. For instance, Treasury claimed that redistribution creates perverse incentives, high deadweight costs and reduces the wellbeing of others. Treasury also identified tensions within 
'Sustainability for the Future' between current and future living standards and raising GDP and lowering income inequality within their discussion on 'Economic Growth'.

Increasing Equity was a 'factor' present in both the conference paper and the short guides. In the THLS paper, Treasury used the Gini coefficient as well as the ratio of disposable income and wealth between the top $10 \%$ of earners, and bottom $10 \%$ as measures of inequality. However, Treasury was clear that their role was to avoid normative approaches toward distribution, instead adopting a 'positive' approach to stating what income inequality $i$, as opposed to a subjective discussion of what level of inequality would be fair. In the 2012 conference presentation that launched the Tool Treasury stated that:

"[w]hile research has shown that income inequality has little impact on subjective wellbeing in most countries, it also shows that in our type of society, the average sense of well-being is lower if people do not think the system is being "fair". This suggests that policy which addresses the needs of those in difficulty, reducing their barriers to participation, it will improve the overall living standards over and above the direct impacts of the policy" (Karacaoglu, 2012).

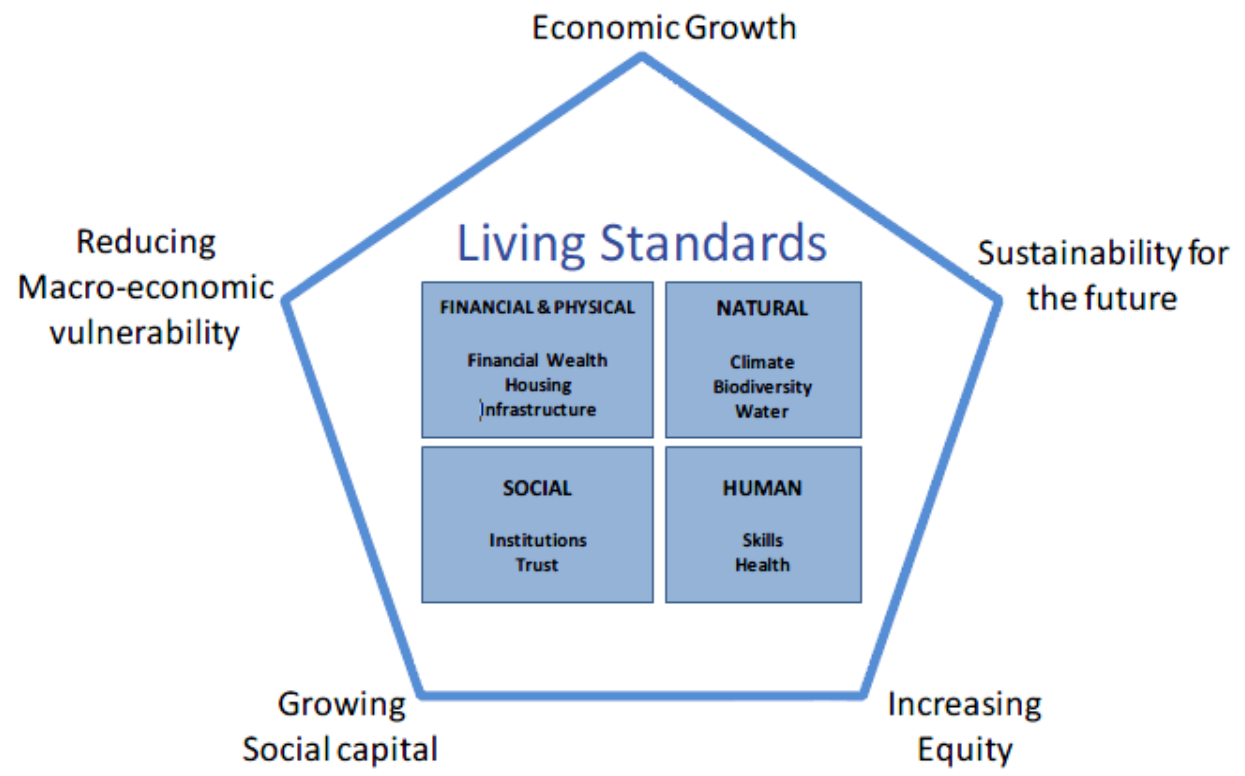

Figure 6: Treasury's Higher Living Standards tool from the conference paper (2012: 1). A simplified version is available online and in each of the 2013 draft analysis guides.

It is notable that Treasury cited the United Nations' World Happiness Report as evidence for their claim that inequality has little effect on subjective wellbeing, because the section of the report they cited stated that: 
"Nevertheless empirical work on the effects of inequality on life satisfaction has yielded very mixed results. Many studies have failed to find any effect. The most positive results are in an interesting time-series study using both the U.S. General Social Survey and Eurobarometer. This finds that in both the U.S. and Europe increases in inequality have (other things equal) produced reductions in happiness. The effect has been stronger in Europe than in the U.S.” (Helliwell et al., 2012, p. 71).

A single comment of mixed results in the World Happiness Report was reworked as indicating a negligible impact. As I will discuss in the next section redistribution and equality were both central to the World Happiness Reports. In the more expansive coverage of equity in the short guide Treasury defined a 'New Zealand' approach toward equity, believing that this approach "has been defined by our commitment to equal rights, a safety net that protects the vulnerable, and the opportunity to participate in society" (Treasury, 2012).

Three years before Treasury produced the THLS framework, StatsNZ's produced a Framework for Measuring Sustainable Development that was formally based on the capital approach to sustainable development (Statistics New Zealand, 2008, p. 2). However, in practice the forms of capital were somewhat peripheral in the measures of progress. Instead StatsNZ divided their areas of concern alongside sustainable development lines: 'environmental responsibility', 'economic efficiency' and 'social cohesion'. Each of these correlated to a series of 'principles' and potential indicators. Contrary to the paper's title, these indicators were not measures, but broad objectives that policy should aim for in order to promote sustainability. For instance, the principle of "Social Participation" was given the measure of "Social participation is promoted" (Statistics New Zealand, 2008, p. 9). StatsNZ did attempt to provide a measure of New Zealand's progress using sustainable development. StatsNZ offered 15 topic areas (each with a battery of measures), such as 'economic resilience', or 'social connection and governance'. Social capital was only a basis for one of these topic areas - Living conditions - alongside economic and environmental capital (Health was identified as being affected by social, economic and structural factors particularly housing quality and income, although StatsNZ did not identify this as a capital stock or flow). Social capital could be connected to the topic of 'social connection and governance' given that the topic's six associated indicators were:

Formal unpaid work outside the home

Rate of death from assault 
Impact of fear of crime on quality of life

Voter turnout at general and local elections

Representation of women in parliament and local government

Trust in government institutions (Statistics New Zealand, 2009, pp. 118 - 123).

Most of which correspond to capital stocks and flows identified by Treasury in their THLS framework - effective public institutions, trust, security from harm (The Treasury, 2011, pp. 24 - 25). However, StatsNZ themselves did not discuss this connection.

Treasury and StatsNZ's use of social capital displayed many of the features and issues that were evident in other frameworks, particularly the difficulties of defining and measuring social capital. Treasury's use of social capital also highlighted the limited contextualisation of social capital in national accounting, as they paid little attention to the New Zealand context, particularly Māori cultural issues. Treasury avoided suggesting any particular policies in the THLS framework, likely a result of their perception of themselves as neutral and unbiased purveyors of information that facilitates government decision making. However, they remained committed to an orthodox economic perspective at the base of an expanded 'holistic' measure of wellbeing.

\section{Social Capital in the United Nations' World Happiness Reports}

The frameworks that I have discussed so far displayed similar tendencies regarding the assumed quantification of social capital and the alignment between social and economic development, as well as formal frameworks that were designed to account for the cause of human wellbeing. The UN's recently developed World Happiness Report, whilst drawing on measures of sustainable development offered an interesting alternative incorporation of social capital into the goals of development and offered reformist corrective critiques of economic development. With the other reports, the three volumes of the World Happiness Report have focused on subjective wellbeing as a goal of human policy, but they have not constructed the relationship between different capitals as reciprocally beneficial. Instead, they constructed economic growth as damaging to social capital and so economic growth lowered, or at least had failed to increase, wellbeing. The World Happiness Report laid its foundations in the Easterlin Paradox, the findings of the economist Richard Easterlin that although levels of GDP has continuously increased in the USA and Europe, aggregate levels of self-reported happiness remained static. 
The United Nations' Sustainable Development Solutions Network published three volumes of the World Happiness Report. Each report was compiled by a group of economists and psychologists. The reports emerged from the Rio+20 conference, which invited member states to measure the happiness of their population in preparation of a new set of sustainable development goals to be adopted in September $2015{ }^{77}$ Four goals were identified: end extreme poverty, achieve environmental sustainability, be socially inclusive and have good governance (Helliwell et al., 2012, pp. 7 - 8). The World Happiness Report was intended to allow nations to measure their progress toward these goals based on the levels of self-reported happiness in the population. The Reports were primarily concerned with measuring self-reported happiness and wellbeing in order to allow these to be taken more seriously in policy discussions.

There have been three reports published in 2012, 2013 and 2015. ${ }^{78}$ The 2013 report focused on measurements and explanations of subjective wellbeing and establishing the importance of happiness and mental health (Helliwell et al., 2013, pp. 3 - 4). The 2012 report was concerned with establishing the framework, and reporting current data on world happiness. The 2015 report included "a variety of chapters providing deeper analysis of specific issues" beyond happiness, which included social capital (Helliwell et al., 2015, p. 5), particularly Jeffrey Sachs last chapter in the 2015 report. Social capital was discussed in the 2012 report, and central to certain chapters of the 2015 report, but was absent from the 2013 report.

In the World Happiness Reports the sources of individual happiness "include the set of social interactions through which individuals are interconnected. The quantity and quality of social relations in a community is sometimes referred to as social capital" (Helliwell et al., 2012, p. 69). The authors also used a network construction of social capital, and justified why social capital was capital: a. networks are accumulated over time, and b. these networks yield benefits "such as informal mutual assistance or simply the pleasure of being socially integrated and participating in intense social interactions" (Helliwell et al., 2012, p. 69). ${ }^{79}$ More significantly, from the World Happiness Report's definition, social capital

\footnotetext{
77 Rio +20 conference also acknowledged that there had been at best mixed progress in attaining the original goals of Rio 1992 (United Nations, 2012).

78 An 'update' was published in March 2016 that ranked countries' happiness, unfortunately this was published too late to include in this thesis. A brief reading suggests that social capital was not present in the document, however they do suggest six factors determining wellbeing, which includes social support, trust, freedom to make decisions and generosity. Features that have been commonly cited in the social capital literature.

79 The authors of Treasury's THLS framework drew on the significance afforded to social capital in the World Happiness Report to state that it was among the most important areas in the tool because "issues such as social support, corruption levels, and the level of freedom had the most impact on an individual's sense of wellbeing" (Gleisner, 2012, p. 229).
} 
was not something rationally accrued for personal benefit, but rather something that accrues unconsciously in conductive environments. Social capital also had intrinsic value, as opposed to being of interest solely due to its instrumentality.

The 2015 report offered two additional definitions of social capital (from different authors) both of which differed from that in the 2012 report. The first was given by Becchetti, Bruni and Zamagni, they drew similarities between the "public faith" (a genuine love of the common good) of Genovesi to define social capital as "a fabric of faith and civil virtue" that permitted and sustained human development (Becchetti, Bruni, \& Zamagni, 2015, p. 135). This definition inferred a strong normative and affective element to social capital, with it being central to human wellbeing and economic growth. ${ }^{80}$ Becchetti et al. advocated social capital as a central part of a 'civic economy'. This civil economy would correct to three tendencies in economics; namely the reduction of humans to homo economicus, the reduction of organisations to profit-making corporations, and the reduction of 'value' to GDP (Becchetti et al., 2015).

Sachs constructed social capital in a less affective way, noting that it was a "meaningful, albeit broad concept that describes the extent of trust, social support networks, and prosociality in a society" (Sachs, 2015, p. 153), before later offering a practical definition as of it as the "social conditions that promote pro-sociability" (Sachs, 2015, p. 157). Sachs identified four measures of social capital - trust, social support systems, individual generosity and honesty in governance each of which were positively correlated with levels of subjective wellbeing establish that the levels of it vary between nations. A similar universalising model of social networks is evident across the World Happiness Report, and support an argument that, although social capital may offer a critique of economic fundamentalism (and in the case of the World Happiness Report, economic growth itself), it remains a highly modernist construct with an assumed quantifiability.

Unlike in previous national accounting frameworks, and in New Zealand political speeches, the World Happiness Reports constructed economic growth as damaging social capital, and advocated for a reform of policy to mitigate or negate this. In the 2012 report the authors stated that:

"[...] we face a set of real choices. Should the world pursue GNP to the point of environmental ruin, even when incremental gains in GNP are not increasing much (or at

\footnotetext{
80 An instance of the report's authors falling back on the habit of identifying economic growth as a goal of policy. As an aside, there is also a tendency at times for the authors to directly equate economic growth with subjective wellbeing, despite the problems they have identified with such as connection.
} 
all) the happiness of affluent societies? Should we crave ever higher personal incomes at the cost of community and social trust?" (Helliwell et al., 2012, p. 6)

The answer to these (largely rhetorical) questions was no: whilst economic growth may be desirable if all other things were equal, all other things were not equal. Furthermore, even in 'the economy' other factors such as job security and equality are more important to individuals than increased income (Helliwell et al., 2012, p. 66). Acknowledging this in policy also required a change in the way individuals were constructed:

"We increasingly understand that we need a very different model of humanity, one in which we are a complicated interplay of emotions and rational thought, unconscious and conscious decision-making, "fast" and "slow" thinking. Many of our decisions are led by emotions and instincts, and only later rationalized by conscious thought. Our decisions are easily "primed" by associations, imagery, social context, and advertising. We are inconsistent or "irrational" in sequential choices, failing to meet basic standards of rational consistency. And we are largely unaware of our own mental apparatus, so we easily fall into traps and mistakes" (Helliwell et al., 2012, p. 5).

According to the World Happiness Report, the rational choice model that drove $20^{\text {th }}$ century policy was at odds with 'sages' such as Buddha and Aristotle, psychologists, and advertisers, all of whom identify contextual and non-income factors as important for individuals. Whilst these changes are significant, the World Happiness Report aimed to correct policy test, and not replace them entirely. The economy and 'the business cycle' were naturalised, and accepted as important to wellbeing whilst acknowledging the need to attend to the negative effects of them, including declining social capital. Declining social capital, manifesting as a loss of trust and sense of community were 'disorders of affluence' that could explain the Easterlin Paradox, and so social capital was one of the key determinants of happiness and wellbeing, and was given greater attention than the other forms of capital. Much like in the public health literature, increased inequality was particularly concerning since it reduced trust and cohesion, which in turn caused declines in social capital. This decline in social capital counteracted any increase in self-reported happiness that may have occurred as a result of higher levels of material wealth.

In the last chapter of the 2015 World Happiness Report, Jeffrey Sachs built on the brief mentions by Becchetti et al. to produce a developed critique of economic growth in social capital. Sachs drew heavily on the developments in game theory which were the inspiration for early work on social capital to offer a corrective critique of current development and social policy. Social capital, argued Sachs had both an instrumental value 
(improved economic and social performance), and an intrinsic value (the human yearning for love friendship and community). It also had a key (and non-substitutable) role in solving social dilemmas which occurred when "an individual faces the choice of incurring a personal cost for greater benefit" (Sachs, 2015, p. 153). Sachs re-opened the connection between the failings of game theory and the emergence of social capital with this discussion of 'social dilemmas'. Game theory failed because it assumed that individuals would act egotistically when faced by dilemmas, however empirically they did not. Consequently the egotistical and self-interested models of human behaviour of $20^{\text {th }}$ century economics were flawed.

Sachs offered nine reasons why individuals do not act egotistically, including the existence of human altruism and compassion, ethics, sanctions, a desire to cooperate with another cooperative individual and social norms, personality traits and so on. He saw these elements as providing the origins of social capital. From this foundation Sachs built on the World Happiness Report's conception of inequality lowering social capital (and therefore subjective wellbeing) to critique notions of individualism and freedom inherent in 'Anglo-Saxon political theory' and instead promoted a more social political theory. This would involve building a stronger welfare state, rediscovered social morality, universal access to education, training in compassion for policy makers and economists, and deliberative democracy plus any other policies that could, in general promote 'pro-social behaviour'.

On top of his theoretical critique of economics (via game theory, and a decline of economic rationalism), Sachs argued against the training of economists because it promoted in anti-social behaviour. Instead economics should be trained in "social dilemmas and the potential gains of cooperation" in order to produce an environment of cooperation. A similar, but distinct argument was made in the need to establish a prosocial code of ethics in banking, coupled with greater state regulation against anti-social behaviour to counter the attitude of "pure egoism in the pursuit of profits" that dominated policy (Sachs, 2015, p. 162). The same rationale applied to public sector corruption - promote pro-sociable behaviour and regulate against anti-social behaviour to prevent egotistical behaviour.

Sachs argued that social capital theory meant that social policy also need to be changed in order to promote equality and pro-social behaviour in the general population. He drew on the work of Bo Rothstein to argue that there was a reciprocal relationship between 
social capital and stronger welfare. Higher levels of trust would make individuals more supportive of redistributive policies and in turn a stronger welfare state would foster trust and reduce stigmatisation of welfare clients. Deliberative democracy to encourage greater debate of policy would also have a mutually reciprocal relationship with social capital connecting individuals and benefitting from the greater engagement from those connections. Finally, the ability to accurately report pro-social (instead of anti-social) behaviour would both encourage more pro-sociability and correct "falsely pessimistic view of social mores" leading to people trusting each other more - again building social capital (Sachs, 2015, p. 163).

Regardless of the either the suitability or possibility of Sachs' proposed reforms, they constituted a strong reformist corrective critique of social and economic policy based on the concept of social capital from within an international government organisation. The World Happiness Reports went beyond the need to expansion of policy concerns (largely taking that as a given), into the need to reform economic policy due to its negative impacts on social capital and wellbeing. Social capital was de-coupled from the unhappy marriage that Third Way politicians and earlier national accountants created with economic growth. Instead, the World Happiness Report focused primarily on the negative impact of economic growth on happiness, and identified a decline in social capital as one mechanism by which this impact occurs.

\section{Conclusion}

As with the GDP, the new, alternative national accounting frameworks enact realities. New national accounts enact a reality where human wellbeing is objectively measurable, and is 'holistically' determined by a range of different distinct, but related, spheres of policy concerns. In the capital approach, these spheres were represented by the various capital stocks and flows. Much as it had done in New Zealand political speeches, social capital fitted into this assemblage as an often ill-defined aggregate of social resources. It was, in theory, measurable and scalable with the other four forms of capital, and existed in a reciprocal relationship to them. It also impacted on wellbeing, both directly and indirectly, although often in ill-defined ways.

As with my discussion of management studies, this chapter has discussed some of the more strongly economic influenced constructions of social capital; with both national accounting scholars and development organisations approaching the world from the 
perspective of building capital resources for individuals to use in pursuit of higher wellbeing. The economic basis of social capital was also evident with the (unsuccessful) attempts to monetise social capital in some sustainable development frameworks. However, I have again argued against over-emphasising the economic aspects of social capital and have opposed the notion that the concept should be part of an economic colonisation of the social sciences. The economisation of the social was neither the purpose for using social capital, nor the only element of these accounts. Instead, the interest in social capital in national accounting frameworks emerged from wellbeing, as opposed to economic growth, being the goal of policy leading to more holistic measures of progress. These frameworks represent the ongoing (slow) expansion of policy concerns that was evident in both Bolger and Labour's uses of social capital. They incorporated a series of different corrective critiques of policy - the communitarian critique in social capital, the more recent utilitarian critique in wellbeing and happiness economics and the environmentalist critique the latter two which I have glossed over in this chapter. This incorporation of corrective critiques has had an impact on the way in which human wellbeing has been conceptualised with policies and development no longer seen as sufficient if they only attend to economic issues.

From the perspective of these new national accounts, policy makers are required to account for economic, human, social and natural capital, because they are all determinants of a common policy goal of increasing human wellbeing. This expansion has created additional work to maintain the alignment between economy and society when the frameworks have had to address conflicts between policies to build social capital. In most of the frameworks conflicts were side-lined as potential issues, and generally economic growth trumped improving social capital or natural capital. The notion of weak sustainability, where different forms of capital were treated as interchangeable, fulfilled a similar function. The frameworks again demonstrated that only the expansionist communitarian critiques were incorporated in most cases. However, the World Happiness Reports embraced the reformist corrective critique, seeing economic growth as contradictory to social capital if it lead to increased inequality.

Social capital was seen as allowing the social to be quantified in a way that can provide a simple measure of social progress, akin to the GDP. The early OECD work, and the work by the UNECE/OECD/Eurostat group both aimed at developing a single, aggregate measure of social capital that would be comparable (and scalable) to the GDP. More recent frameworks have focused on a small series of proxy measures of social capital often 
connected to various sub-divisions that have been identified in the concept. Despite the inability to create a single measure, there is a continuing goal to develop a small set of standardised measures of the concept of social capital to comparisons to be made both over time and between states.

The use of statistics provided a scientific 'hardness' to discussions of social development. As Speich noted of the GDP, statistics are difficult (im)mutable mobiles to challenge, particularly official statistics collected in large datasets. There are advantages for government departments and non-government organisations in being able to state that levels of social capital have risen/declined as opposed to stating that society is doing well/poorly. This may be most obvious within national accounting frameworks, but the modernist nature of the social constructed by social capital is also evident in political and policy uses in New Zealand. The division between economic and social capital was clear in Bolger's speeches and during the Labour government. Its overwhelmingly positive valence in all of these discourses, and the language of 'building' social capital suggest a desire to fit it in a framework of social progress. 'Building' social capital suggested a quantifiable social resource with a predictable instrumentality. As I noted at the start of this chapter, national accountants believe that, for politicians and policy makers to take the social seriously, a single powerful aggregate measure of social resources needs to be developed, and social capital offered one potential way to develop this measure. However, much as in the public health literature, the ability to develop a single measure of social capital has recently been questioned, and none of the national accounting frameworks that I discussed were able to provide one.

The capital approach in national accounting also highlighted social capital's connection to a modernist world view. Ben Spies-Butcher argued that social capital represented an attempted move away from the hyper-modernism of rational choice theory in economics by some economists. His argument was based on firstly the partial abandonment of the autonomous, rational individual making decisions in isolation from their context and secondly the notion of a single, attainable equilibrium in rational choice theory (see chapter 2). Whilst I agree with Spies-Butcher (particularly in his discussion of economics) this chapter suggest that this was a limited move.

Sustainable development frameworks accept the modernist division between nature and society, and also the separation of economics from society (Latour, 1993). In the capital approach this is represented by the different forms of capital, which were constructed as 
distinct, purified domains, with their own 'stocks' and 'flows', but which also have reciprocal relations between them. The notion of quantification and development itself also fits with modernist thinking, with a goal of 'advancing' all societies in similar (western) ways. Various development goals ('sustainable' or otherwise) published by the United Nations and other organisations continue to believe this is possible, but with a wider range of ingredients required. Capital, science and technology would all fall under the purview of 'economic capital' in the capital approach. Each new area of concern that has emerged (human skills, conservation of nature and 'the social') has been attached to these development programmes as distinct, purified domains of interest. 


\section{Chapter 9: Discussion}

In this thesis I have explored the concept of social capital using some of the tools and sensibilities of the French pragmatic school of sociology. Consequently, I have attended to (and accepted) the heterogeneity and the variability of its application in different fields, and have drawn on Boltanski and Chiapello's work on critique as a framing device in order to gain insight into why social capital was incorporated into political discourses. I also attempted to represent the actors who have used social capital as critical and reflexive individuals, as opposed to being unaware, devious, or unwilling to accept some elements of the concept.

In chapters 4 and 5, I discussed academic uses of social capital. These chapters highlighted the variability of both the histories of social capital, and how the demands of different disciplines resulted in the concept being constructed in different ways. The variability of social capital has been recognised both by proponents of the concept, and critics. However, for the former, variation indicates a lack of clarity, and so is a problem that requires overcoming - either by developing a framework of different social capitals, such as with Halpern (or to a lesser extent Woolcock), or by establishing new definitions that incorporate some elements of the concept, whilst excluding others. Critical approaches, whilst occasionally acknowledging the heterogeneous, or at least variable, nature of the concept identify it as evidence of a 'lack'. Variation is seen by critics to indicate the vacuous nature of the concept, and to support arguments that connect it to either neoliberalism or market fundamentalism.

The second half of my thesis addressed the political and policy uses of the concept, with a focus on the New Zealand context. I noted that, much like in Australia, social capital in New Zealand had a strong communitarian connection, with a variable relationship with economic growth. Some authors who use social capital identify economic growth as increasing inequality and so damaging social capital, and others (particularly in the $5^{\text {th }}$ Labour government) construct social capital and economic growth as having a reciprocal relationship. I argued that many constructions of social capital aligned with liberal policy, and had a reciprocal relationship with economic growth but argued against attending to this feature at the exclusion of others. Consequently I noted that the communitarian and quantification elements should be given similar importance in explaining its emergence in political discourses. 
In this chapter I will bring together and summarise the three main arguments that I have made throughout this thesis, firstly the multiple constructions of social capital, and why it should not be generalised to a single object. Then the common use of social capital within communitarian corrective critiques of liberalism, and finally what I have suggested social capital offers to policy, namely the promise of making social life quantifiable and measurable. After this discussion I will address some of the limitations of my research, and suggest a few areas for further study. I will end the thesis on a personal note, by briefly discussing my own critiques of social capital and communitarianism

\section{Multiple Realities, Multiple Social Capitals}

Throughout this thesis I have echoed an oft-mentioned feature of social capital: that the concept has been given multiple, varied meanings. However, this is not simply the adoption of disparate definitions of the concept, but reflects the different assemblages of actors used to construct social capital, and also the issues it was intended to address. Authors construct social capital in a way that aligns with the realities they are enacting, and so different constructions of social capital can also contradict each other.

The clearest example of the enactment of different realities, resulting in different social capitals, was in my comparison between public health and management studies that I discussed in chapter 5. Management scholars sought to explain the economic performance of active, networked employees and firms, with the end-goal of providing advice on improving that performance. They enacted a reality of more or less well performing economic actors whose success is determined by their access to, and use of various types of capital. Social capital was, obviously, one such form of capital. In this networked management reality, social capital granted economic actors access to knowledge (human capital) useful in improving their economic performance. In contrast, public health theorists enacted a reality of unequal health outcomes that are related to social inequalities. Instead of networked economic actors pursuing personal gain, they enacted a reality of aggregated populations with varying levels of social capital. Their construction of social capital was not the networked concept of management studies, it was not something that individuals invest in, but rather a statistical representation, correlated with inequalities in both incomes and health outcomes. The proponent historians that I discussed in chapter 4 enacted a different reality where social capital was a new way of describing an old subject-matter, a continuation of many concerns in the 
social sciences. Critical historians in contrast enact a reality of economic and neoliberal expansion, of a social science under-siege, with social capital as a Trojan Horse inside the walls.

This heterogeneity was also evident in the political literature, although with a less stark contrast. Policy writers and government academics enacted various realities populated with isolated older persons, (un)successful youths in (dis)connected families, unequal nation-states, and various understandings of human wellbeing. In each reality social capital was a different object: sometimes it was the networks and resources of older persons, other times it was the need for integrated (two-parent) families, at other times it was part of a reformation or expansion of strategic policy concerns in order to better achieve the end-goal of improving human wellbeing. In those documents that associated social capital with economics, the relationship between the two varied. For Treasury, social capital was a way of representing social resources built by, and key to, improving economic growth and improving wellbeing. Social capital itself was trust that facilitated economic cooperation, and was constructed from the various rights and institutions required for a functioning economy and society. In the UN's World Happiness Report however, social capital was part of a reality where inequalities caused by economic growth damaged social capital, and therefore, wellbeing. Thus declining levels of social capital were a concern because human wellbeing is not only determined by economics, instead humans require a plethora of resources and interactions to be 'well'.

Politicians fitted social capital into a reality of media and public scrutiny, a reality that was also dominated by economic rhetoric. For Bolger and Maharey in particular, social capital was something distinct from economics, but also distinct from 'old fashioned socialism' or unpopular welfare statism. These two politicians in particular enacted a reality of $\mathrm{New}$ Zealand being constructed of diverse communities, with demands and needs too variable for central government to adequately attend to. Instead of being governed by a centralised state, communities needed empowering, and social capital was a way of advocating for that empowerment. Laban, in contrast, enacted a reality where hard-working volunteers kept their communities together through the 'glue' of social capital, but whose contribution lacked recognition compared to that of paid labourers. Social capital again offered her a way of 'selling' the importance of volunteers, with voluntary work providing this intangible but key resource. The need to sell policies meant that social capital was always constructed as overwhelmingly positive, to build social capital was to improve New Zealand. Any potential negative aspects of social capital, gangs, Mafias, closed and isolated 
communities, were entirely excluded from the political social capital. Instead of having the 'wrong' social capital, they were (if mentioned) a symptom of a lack of social capital.

Turia also enacted a reality where community-focused Māori have survived two centuries of assimilationist and individualistic government policy and capitalist economics. This was the reality enacted by the IPS activist presenters. Social capital has been neglected by government policy, and has been battered by growing inequality and the promotion of selfish individualism and competition. The cultural features that produced Māori social capital were constructed as different from those that produced Pākehā social capital. Protecting the uniqueness of Māori social capital was thus opposed to the assimilationist policies of the New Zealand government. In his interview, Maharey similarly enacted this reality, aligning it with the need to accommodate diverse communities demanding selfgovernance, but losing much of the uniqueness of the Māori cultural context. This differed from the discussions of New Zealand commentators such as Craig, Cotterall, Porter, Humpage and so on, who have tended to classify the political interest in social relations as a defence of neoliberalism, or as part of a second 'roll out' phase of neoliberalism, as opposed to the result of multiple rationalities, demands and interests acting on politicians. As Turia and Maharey (among others) indicate, these realities were not mutually exclusive, and many of them overlapped.

I also have argued that, since social capital's heterogeneity was the result of it being constructed in order to fit a particular reality and support the goals of its actors, social capital is not characterised by definitional chaos as Fine argued, but rather reflects the realities enacted by authors who use the term. For the rest of this chapter I will discuss some of the common features of the social capital literature. I argue that the appeal of social capital lay in its ability to make social relations comprehensible and manageable in discourses where 'the social' had previously only been a peripheral concern, which was a necessary part of the incorporation of communitarian critiques into governance. Social capital made social relations politically appealing by constructing them as having instrumental value, and at times intrinsic value in improving wellbeing. Finally I will offer a brief, normative critique of social capital, and suggest some areas for further research. To reiterate a point I have returned to throughout this thesis: given the heterogeneous nature of the concept, none of the points I will discuss here are universal in the literature. Instead, they are, frequently invoked features of social capital that I believe contributed to the concept's appeal in various discourses. 


\section{Incorporating the Social and Reforming Economic Policy}

Whilst authors who have used social capital have enacted multiple realities, and thus constructed the concept in different ways, one recurrent theme has been the connection between social capital and communitarian corrective critiques of policy. As I discussed in chapter 2, communitarians opposed what they perceived as an overly economic focus in policy during the 1970s and 1980s reforms. They also opposed a monolithic construction of society, which they equated with the $20^{\text {th }}$ century welfare state. Thus, Etzioni characterised his work as an attempt to find the 'middle ground' between statism and individualism (Etzioni, 2014), a sentiment that was also clearly evident in Gidden's Third Way, with its acceptance of the free-market, but with an interest in expanding policy concerns beyond it (Giddens, 1998). Communitarians rejected homo economicus with a view that economic rationalism was a threat to civil society (Pusen, 1996). Such a position was clearly articulated (if poorly supported empirically) by Putnam in Bowling Alone, and this opposition is central to many uses of social capital in politics. Thus I have suggested that communitarianism provided a pair of corrective critiques of policy. The first was an expansionist critique of the overly economic focus of policy tests. From this perspective in order for tests to be 'fair', they needed to recognise the impact of communal and social living on both human wellbeing and economic growth. The second critique was reformist, it shared the need to recognise the social with the expansionist critique, in this reality economic growth may increase inequality and thus damage wellbeing. Thus economic policies required modification in order to ensure that they did not increase inequality and thus damage social capital. In both cases the critique appealed to a pre-existing 'common good' of human wellbeing/living standards, but they wished to change the policy mechanisms used to attain that common good.

The expansionary corrective critique of communitarianism argued that policy tests needed to attend to social phenomena, and social capital provided a means to do so, whilst accepting, or at least not challenging, current economic policy. This was most evident in national accounts, where the various forms of capital were constructed as isolated spheres, in reciprocal relations with one another. A similar, but less mechanical example of this was also evident in the New Zealand political and policy discourses; for both the National and Labour Parties, social capital represented something that was as important as economic growth (at least rhetorically) in improving human wellbeing. A similar, expansionist, desire was also was evident in both public health and management studies 
literatures. In the case of public health, this was primarily driven by the need to recognise ecological determinants of health outcomes, as opposed to an overly individualistic focus. In contrast, social capital in management studies signalled a recognition of the importance of personal and corporate associations in determining the success of various economic actors.

The expansionist critique, with its lack of challenge to existing policy, easily fitted into governance. This was evident in its adoption by Bolger, Labour and a range of inter-state governmental organisations such as the OECD, World Bank and UN. In all of these cases, social capital was constructed as existing in a reciprocal relationship with economic growth. Whilst conflicts between building social capital and 'growing the economy' were occasionally acknowledged, these were marginalised and often neutralised. However, the expansionist critique was not aimed at improving economic outcomes in particular, but instead at policy concerns in general. From this perspective, the simple incorporation of social capital, or other community-based concepts, would be sufficient to improve human wellbeing without reforming the economy. Labour and National ministers differed on the policies required to build social capital. Bolger was strongly in favour of the devolution of power, viewing this as successful in stimulating economic growth, and transferrable to social capital as well. Labour ministers, particularly Cullen often viewed the government's role in building social capital as essential and saw a withdrawal of government involvement as damaging to communities' social capital. To further draw on Boltanski and Chiapello (Boltanski \& Chiapello, 1999 [2005], pp. 40 - 42), the incorporation of social capital alongside economic and other forms of capital indicated that the communitarian critique was to a degree successful as it was incorporated into policy concerns. However this incorporation was partial, and view that social capital was potentially damaged by economic growth was largely absent from political and policy discourses.

In contrast to the expansionist critique, the reformist critique questioned the ability for economic growth to improve human wellbeing, particularly when it resulted in increased inequality and declining social capital, due to the promotion of individualism and competition. This critique was evident in many of the IPS workshops, as well as Eva Cox's use of social capital, and was a recurring theme in the public health literature. It was rarely incorporated into mainstream political discourse, with only a few instances of its incorporation, such as the UN's recent World Happiness Reports, and also occasionally in the concept's use by Labour ministers (such as Turia). 
Jeffery Sachs' recent use of social capital in the UN's World Happiness Report complicates an argument that the expansionist critique was incorporated, whilst the reformist one was not. Sachs constructed social capital as something that was negatively correlated with levels of income inequality and as having a direct impact on happiness - and thus was similar to some of the public health texts. He also promoted a prescriptive programme of policy reform to address levels of inequality, corporate greed, individualism and competition. Sach's critique (and the World Happiness Report in general) was a development of the long-term recognition in policy in which human utility (happiness, wellbeing, living standards etc.) replaced economic growth as being perceived as the end-goal of policy, but without claims of different capitals being mutually reinforcing. The change from other national accounting frameworks was an acknowledgement that current economic policy damaged utility and required correction. The reformist critique was also evident in the public health uses of social capital. In public health, increasing inequality was seen as reducing levels of social capital, which in turns leads to lower health outcomes. As I discussed in chapter 4, this was due to relative deprivation increasing stressors and isolation, as opposed to absolute deprivation reducing material access to health.

In brief, whilst there is certainly a political alignment between many uses of social capital, and pre-existing liberal economic policies, this should not be taken as either the only reason for the political interest in social capital, nor should social capital be reduced to economic imperialism or a defence of an economic program. The concept was more frequently used as a way of discussing the impacts of social features on wellbeing and, whilst these impacts included economic benefits it also included many non-economic benefits as well. The uses of social capital which placed it in opposition to 'neoliberalism' should also not be sidelined. Instead, they highlight the complexity of interest in the concept, as well as the appeal to human wellbeing in politics.

\section{Quantification and Calculation}

As well as being constructed from various assemblages, different social capitals also act in different ways. I mentioned some of these above when discussing the various problems social capital was used to address. However as I have touched on throughout this thesis, social capital is regularly constructed as quantifiable, and in a simple way. It was often used in governance as a way of making social relations and resources comprehensible, and ideally measurable, whilst retaining a theoretical simplicity and strength. The interest in 
the concept was because of its instrumentality, with social capital constructed as important because of the 'use value' of social relations in improving human wellbeing. This was often constructed as simple correlation between higher social capital and higher wellbeing. The scholarly interest was similarly instrumental, and as with political uses, the outcomes associated with it varied; including employment opportunities (in management studies), population health outcomes (in public health), a variety of social and economic outcomes (political science), or human wellbeing (in national accounts).

In many texts, social capital was understood as being a measurable quantity, a measurability that was also evident with the prevailing use of 'building' social capital in political discourses. Whilst social capital was occasionally labelled an 'intangible' capital, the concept itself was often reified, a feature that spilled over into the belief in its measurability and quantifiability. Stating the importance of quantification in modernism is hardly a contentious issue in the social sciences. Porter argued that quantification is particularly important for the state in the pursuit of standardised, and apparently impartial policy. Standardisation and quantification imply impartiality, and this was the result of a complex relationship between political demands, the needs of bureaucracy and an antiintellectualism among the general population (Porter, 1995).

Perhaps the best known scholarly attempt to provide a quantified measure of social capital was Putnam's Bowling Alone, however, Putnam was far from the only one to attempt to measure it. Nearly all of the empirical works that I explored in Chapter 4 were quantitative and attempted to provide either a single measure of social capital, or multiple measures for different types of social capital. Politically, the clearest example of the reification and quantification of social capital was in the national accounting literature. Porter noted that as early as the $19^{\text {th }}$ century, statisticians recognised that a few 'powerful' numbers - such as life expectancy - were more desirable than many complex ones (Porter, 1995, p. 82). This logic remains clearly evident in the national accounting literature, with a single (or small number) of aggregate measures of social capital being preferred to a long battery of possibly contradictory statistics. A single, or small number of measures would allow social capital to have comparable impact to, and scalability with, the GDP, which would in turn facilitate the measurement of societies' social development/success, much as GDP allowed them to measure their economic development. In the logic of national accounting, such a single measure would allow 'the social' to be considered as important as the economic, in policy circles. Thus it would be possible to advance policies to 
promote social development in addition to economic growth, with the end-goal of improving human wellbeing. Much of the early policy work in New Zealand similarly made repeated attempts to provide quantities of social capital - from the MSD's Putnaminspired Social Reports to StatsNZ's theoretical framework. Many of these projects (international and national) were unable to actually provide measures of social capital, but there was both a stated intent to measure, and an emphasis on the importance of measuring it for policy reasons. The preference of a single, simple, broad and measureable way of representing the social was also evident in the New Zealand political discourse. Whilst politicians did not attempt to provide a framework for quantifying or measuring social capital in their speeches, the concept was still constructed as representing a distinct domain of comparable importance to the economic - social capital as a parallel to economic capital.

The appeal to quantification in the social capital literature gives authority to those using the concept and makes discussions of the social appear scientifically 'objective' or 'valid'. This may have been particularly important in political and policy discourses. Statistics, particularly official statistics collected in large datasets, are difficult (im)mutable mobiles to challenge. There are advantages for government departments and non-government organisations in being able to state that levels of social capital have risen/declined as opposed to stating that society is doing well/poorly. A lack of measurements risks such statements appearing partial and based on moral judgements as opposed to the apparent impartiality in levels of social capital. Similarly there are also advantages for scholars in quantification. Porter has argued that quantification emerged in both bureaucratic circles and in 'weaker' sciences such as medicine and economics, as a defence against claims of partiality and a lack of trust in the discipline by others (Porter, 1995). For those importing ideas from the social sciences, which are traditionally viewed as 'weaker' sciences, the ability to quantify may add authority to their claims of correlation or causation between social features and other outcomes.

Despite intentions, there has yet to be an agreed measure of social capital, or even an agreed set of proxy measures. The General Social Survey question on generalised trust has come the closest to a common measure, but this is usually seen to be only a partial measure of social capital and usually represented as one of the 'stocks' or subsets of social capital. The development of battery measures has also been hindered by various proposed components displaying little or no correlation to one another. As I mentioned in relation 
to public health, this has resulted in some authors calling for the breaking up of the social capital concept into multiple different concepts. The need to divide social capital into a range of concepts has also been evident in some of the national accounting frameworks, particularly in the OECD's Measuring Sustainable Development. It may also have been the reason for the concept's decline in the World Bank (Hammer \& Pritchett, 2006). However, outside of the World Bank the concept continues to be used, and attempts to measure it continue.

The quantification and simplification of the social, whilst an improvement on the economic focus of policy, also creates a problematic construction of the social. Despite the attempts to make measures as decontextualized and universal as possible, they continue to be imbued with strong liberal and European norms as to what a 'good' society would be. A single, decontextualized measure of the social would be unable to even approximate the complexities and variations of social relations and life. Even batteries of proxy measures cannot even approximate the impact of social life on wellbeing. The use of social capital by politicians displays similar tendencies, with the construction of social capital as something that is broad, with a positive valence and must be 'built'. This becomes particularly problematic when social capital measures are the basis of comparisons between different nation-states or as ways of assessing progress. As Scott has noted, previous attempts to account for what is 'important' have resulted in disaster as it excludes a massive amount of key elements deemed 'unimportant' (Scott, 1998).

Regardless of its success, this quantification promised by social capital facilitated the incorporation of social resources into contemporary governance. Areas that were hitherto considered either unimportant or incomprehensible for policymakers became important, and through social capital, comprehensible. Consequently the 'social', or at least a particular construction of the social, can be taken seriously as topics of governance. However, as I have noted (in chapters 6 and 7), this often involves negating the elements of the communitarian critique that cannot be easily aligned with current policy concerns, particularly the critique of economic growth on the grounds of the damage it does to social capital or related concepts (social cohesion or community for instance). 


\section{Limitations and Directions for Further Research}

The key limitations, or more accurately contradictions, in this thesis are in my application of pragmatism. I have followed Boltanski and others in identifying my work as pragmatic, and in chapters 2 and 3 I provided a discussion as to why I think this was justified. However, in the same chapters I discussed issues of textual analysis and a priori categories, both of which hinted at possible arguments that my thesis is not pragmatic.

The first issue, that of analysing texts as opposed to 'actions', I covered in some depth in chapter 2. To reiterate my points there, texts should be considered as valid objects of analyses from a pragmatic sensibility because they are internally heterogeneous, potentially contradictory and also (as the concept of (im)mutable mobiles aptly demonstrates) act. I have however neglected the process of producing texts in my thesis.

The application of a priori categories, and contextual explanations is a more interesting, and difficult issue. Boltanski has been unequivocal in stating his belief that pure pragmatism is limited because of its outright rejection of categories for analysis; a point that, coupled with his own application of categories, has resulted in his work being rejected as non-pragmatic (Quéré \& Terzi, 2014). Similar critiques can of course be levelled at this thesis; I have 'applied' concepts such as translation, corrective critique, long pasts and short histories that are borrowed from other researchers, as opposed to the actors themselves. My use of communitarianism as a framing/context also runs contrary to a strong pragmatic programme. I have suggested that many political uses of social capital were entwined with communitarian corrective critiques of some features of liberal policy. At the same time my application of these concepts has not been intended to reveal a 'truth' unknown to the authors I have discussed, neither do I believe my arguments to be more valid than those of actors themselves. Instead I have attempted to 'follow the actor of social capital and understand how it has been assembled in difference instances. My use of pragmatism has been designed as descriptive tools to facilitate my discussion. I have also, as much as possible, avoided simplifying, overruling or denigrating the positions of the texts I have studied.

Given the size and variability of the concept of social capital, I have only covered a small part of the social capital literature as a whole, and there are other areas that could warrant further study to develop a more complete picture of social capital. For instance, I have not attended to the use of social capital by non-government voluntary organisations or charities, although these groups have used the concept in their documentation (Powell, 
Cullen, Butler, \& Marshall, 2005). There are also many academic fields that I did not discuss, particularly social capital's recent translation into the community resilience literature (Aldrich \& Meyer, 2015; Norris et al., 2008; Wickes et al., 2015). Both of these literatures could offer avenues for further study. In order to focus the thesis I have also near-exclusively attended to social capital at the expense of a comparison with other concepts such as social cohesion, inclusion or exclusion. I have also given little attention to other forms of capital, and the 'capital approach' to constructing the world, with its goal of improving human wellbeing is deserving of an analysis in its own right.

I have also touched on the nature of wellbeing in government policy, and this is an area that warrants further analysis as a way of appealing to the 'common good' in policy. Wellbeing in governance was my initial thesis topic, however it proved to be a nebulous and ill-defined topic that I struggled to grasp in my first large research project. I hope to return to it and contribute to the emerging literature on wellbeing in governance (for example Davies, 2011 or for a New Zealand focus, vol. 30 issue 3 of New Zealand Sociology).

\section{A Critique of Social Capital}

The focus of this thesis has been on trying to understand the concept of social capital, and explore why it is seen as useful as opposed to repeating the critiques of it. However, this does not imply that I do not have normative critiques of social capital. Politically, the desirability of the communitarianism that social capital has been part of is debatable, at least from a left-wing perspective. Social capital is, as I have repeatedly argued, a heterogeneous concept, and it has been associated with a range of political programmes, from Bolger's desire to deregulate in order to build social capital, through the Third Way's ill-defined middle-ground to Sachs' social-democratic and welfarist policies. The more 'radical' uses of the concept echo some of the characteristics of $20^{\text {th }}$ century social democracy and Keynesianism, particularly the belief that capitalism (for lack of a better term) can be reformed and made to work for the common good.

These represent a positive change from economic-driven contemporary policy but are fairly weak. The programme that Sachs provided in the World Happiness Report is slightly more radical than the one Putnam offered in Bowling Alone, with a slightly greater emphasis on regulation, a devaluing of individualism and increased acceptance of the welfare state. The capitulation to free-market capitalism in the Third Way and related projects was also 
evident in most of the political uses of social capital, and is increasingly challenged by the parliamentary left. The concept's connection to progress or development should also be reasons for concern, particularly given the often moralistic nature of measures of social capital. Thus, whilst I consider communitarianism to be a critique of liberalism, personally I find little appeal in the critique, or in related concepts such as social capital.

I am more ambivalent as to the usefulness of the concept in academia. Of all of Fine's critiques, I find his argument that social capital represents the decline or 'McDonaldisation' of scholarly standards the least convincing. As I noted in chapters 4 and 5, scholars who have used social capital acknowledge that the concept does not open up a new field of study, but reorients existing discussions. Additionally the simplicity and elegance of social capital has helped facilitate discussions of social relations in areas where these have been neglected. Still, the use of a single concept for a range of social phenomena makes it a blunt instrument, which has created problems that have been recognised in both the public health and national accounting literature. Furthermore, the simplicity and translatability that contributed to social capital's appeal are problematic from a post-ANT sensibility. The concept epitomises what Latour referred to as 'sociology of the social' (Latour, 2005, p. 12); it is a decontextualized explanatory concept that obscures the contextual determinants of social interaction in favour of an a priori explanation. As I noted in chapter 3, it is not desirable to entirely avoid using such concepts, however, at the same time the universalised nature of social capital means that it is a catch-all explanation akin to class, gender, ethnicity, governmentality or neoliberalism.

Whilst it is beyond the scope of this thesis to do the topic justice, social capital may highlight a disconnect between the qualitative, complex and critical work in the social sciences and the current expectations and requirements of governance. A quantitative, aggregate measure of the social being is, as I have argued more appealing in government due to its apparent scientific hardness as well as its simplicity. I suggested in the last few chapters that these features of social capital also suggest that, even if the concept represented a move away from 'high modernism' in economics (Spies-Butcher, 2005), it is still a modernist social concept. However, much like social capital and neoliberalism, 'modernity' is heterogeneous, and so whether social capital is modernist or not depends on what construction of social capital and modernity is used. In We have Never been Modern, Latour outlined what he labels the 'modernist constitution' that has dominated Western thought for roughly the past 400 years (Blok \& Jensen, 2011, p. 60; Latour, 1993). He 
argued that modernism is a particular ontological position built around the dual processes of purification and hybridisation and the separation of nature, society and God. Moderns have increasingly isolated nature and society from one another, creating purified domains of interest. This was clearly evident in the national accounting frameworks, with the division of multiple different forms of capital, but it was also present in the Third Way distinction between economy and society. There was also an evident belief in linear progress in political speeches and policy documents which was also exemplified in the national accounting literature, another feature that characterises modernist concepts.

In the introduction I stated that the aim of this thesis was to contribute to the critical debates on social capital, but I also justified my attention to critical histories in chapter 4 on similar grounds. By drawing on the pragmatic sensibilities of Boltanski, Latour and others, I have aimed to offer an alternative understanding of social capital and its appeal in politics. I positioned this understanding in opposition to explanations which drew on an overly broad understanding of neoliberalism. However, as this section has made clear, this was not from some defence of the concept, but rather an attempt to add a greater understanding of the concept's appeal and variability. My analysis of social capital was intended to allow the 'actors speak for themselves' as much as possible, to understand the reasons why various authors had used social capital, and what insights they felt they gained from it.

\section{Conclusion}

I have argued that social capital's success, particularly in politics was a result of its promise to measure the impact of social relations on various outcomes, particularly wellbeing. This made an important contribution to the incorporation of communitarian critiques into policy, because it made it possible to expand policy concerns into the 'communities', therefore making them governable. When used by governments, social capital can be seen as facilitating the partial incorporation of communitarian corrective critiques into policy. These critiques had, and continue, to advocate for a more socially-orientated policy milieu. The expansionist critique required the expansion of the test of what policy constitutes to include social relations, as well as economic concerns. At other times users of social capital constructed economic concerns as contradictory to building social capital - the reformist critique. For these authors, the expansion of concerns was insufficient. Instead, economic policy itself required reform and a downgrading of importance. Whilst the expansionist 
critique was readily incorporated into policy (most clearly with the 'Third Way') the reformist critique has been largely absent from either New Zealand political speeches or international development frameworks.

The expansion of concerns to account for social relations and resources was similarly evident in both of the scholarly disciplines that I explored, although in different ways. In both management studies and public health social capital was seen as a way of moving away from individualistic explanations for human outcomes. In management studies, social capital moved the construction of individuals away from the atomistic models of rational-choice theory to being situated in social networks, but retained the rational selfinterested individual. In public health social capital provide a way of explaining the correlation between income inequality and health outcomes in situations where preexisting materialistic explanations were insufficient. I noted how in public health the social capital literature was positioned as a critique of policy, and seen as a 'radical' concept. However, I also noted that it fitted the description of a reformist critique, with a desire to change the way that determinants of individual's health were perceived away from individualistic or behavioural explanations.

Underlying the analysis of social capital and communitarianism, I have argued that the heterogeneous nature of social capital is not a symptom of either a definitional chaos or theoretical emptiness of the concept. Rather it is the result of different authors enacting different realities and therefore constructing social capital in a way to fit their reality. Acknowledging this heterogeneity I have also noted that most constructions of social capital allowed the social to be tangible and calculable in order to allow them to be taken seriously in policy circles. In all cases this concern was constructed as necessary to improve human wellbeing, an appeal to the 'common good' that has become increasingly prominent in political and policy circles. Many of the authors who used social capital did so because of their concerns over the impact social relations had on human wellbeing. 


\section{Bibliography}

Adams, J. (2010). The Unknown James Coleman: Culture and History in Foundations of Social Theory. Contemporary Sociology, 39(3), 253 - 258.

Adler, P., \& Kwon, S. (2002). Social Capital: Prospects for a New Concept. Academy of Management Review, 27(1), 17 - 40.

Aimer, G. (2003). Barriers and policy interventions: The Training Incentive Allowance and the participation of sole parents and Invalids' Benefit recipients in education, training and employment. Wellington: Ministry of Social Development.

Aldrich, D., \& Meyer, M. (2015). Social Capital and Community Resilience. American Behavioral Scientist, 59(2), 254 - 269.

Alexander, J. (1992). Shaky Foundations: The Presuppositions and Internal Contradictions of James Coleman's Foundations of Social Theory. Theory and Society, $21(2), 203-217$.

Amin, A. (2005). Local community on trial. Economy and Society, 34(4), 612 - 633.

Arrow, K. (2000). Observations on social capital. In P. Dasgupta \& I. Serageldin (Eds.), Social Capital: A Multifaceted Perspective: World Bank Publications.

Astone, N., Nathanson, C., Schoen, R., \& Kim, Y. (1999). Family Demography, Social Theory, and Investment in Social Capital. Population and Development Review, 25(1), $1-31$.

Bagnasco, A. (2003). Social capital in changing capitalism. Social Epistemology: A Journal of Knowledge, Culture and Policy, 17(4), 359 - 380.

Ball, K., Cleland, V., Timperio, A., Salmon, J., Giles-Corti, B., \& Crawford, D. (2010). Love thy neighbour? Associations of social capital and crime with physical activity amongst women. Social Science and Medicine, 71(4), 807 - 814.

Barker, G. (1997). Social Capital and Policy Development. In D. Robinson (Ed.), Social Captial and Policy Development. Wellington: Institute of Policy Studies.

Barrett, D. (1999). A Health Promotion Project for Tamariki Maori - Maori Women's Welfare League. In D. Robinson (Ed.), Social Capital in Action. Wellington: Institute of Policy Studies.

Barry, A., Osborne, T., \& Rose, N. (1996). Introduction. In A. Barry, T. Osborne \& N. Rose (Eds.), Foucault and Political Reason. Chicago: The University of Chicago Press. 
Basaure, M. (2011). An interview with Luc Boltanski: Criticism and the expansion of knowledge. European Journal of Social Theory, 14(3), 361 - 381.

Baum, F. (1999). Social Capital: is it good for your health? Issues for a public health agenda. Journal of Epidemology and Community Health, 53(4), 195 - 196.

Bebbington, A., Guggenheim, S., \& Woolcock, M. (2006). Concepts: Their Contexts and Their Consequences. In A. Bebbington, M. Woolcock, S. Guggenheim \& E. Olsen (Eds.), The Search for Empowerment: Social Capital as Idea and Practice at the World Bank (pp. 261 - 288). Bloomfield, CT: Kumarian Press.

Bebbington, A., Woolcock, M., Guggenheim, S., \& Olsen, E. (2006). The Search for Empowerment: Social Capital as Idea and Practice at the World Bank. Bloomfield: Kumarian Press.

Becchetti, L., Bruni, L., \& Zamagni, S. (2015). Human Values, Civil Economy, and Subjective Well-being. In J. Helliwell, R. Layard \& J. Sachs (Eds.), World Happiness Report 2015 (pp. 132 - 151). New York: United Nations.

Becker, G. (1996). Accounting for Tastes. Cambridge and London: Harvard University Press.

Bell, D. (1993). Communitarianism and its Critics. Clarendon Press: Oxford.

Bell, K., \& Green, J. (2016). On the perils of invoking neoliberalism in public health critique. Critical Public Health, 26(3), 239 - 243.

Belliveau, M., O'Reilly, C., \& Wade, J. (1995). Social Capital at the top: Effects of social similarity and status on CEO compensation. Academy of Management Journal, 39(6), $1568-1593$.

Bénatouil, T. (1999). A Tale of Two Sociologies: The Critical and Pragmatic Stance in Contemporary French Sociology. European Journal of Social Theory, 2(3), 379 - 396.

Berry, H., \& Welsh, J. (2010). Social capital and health in Australia: An overview from the household, income and labour dynamics in Australia survey. Social Science and Medicine, 70(4), 588 - 596.

Best, J., \& Walters, W. (2013). Translating the Sociology of Translation. International Political Sociology, 7(3), 345 - 349.

Bickerton, J., Brooks, S., \& Gagnon, A. (2006) Freedom, Equality, Community. Montreal: McGill-Queen's University Press.

Black, D., Morris, J., Smith, C., \& Townsend, P. (1982). Inequalities in Health: The Black Report. Harmondsworth: Penguin Books. 
Blakeley, R., \& Suggate, D. (1997). Public Policy Development. In D. Robinson (Ed.), Social Captial and Policy Development. Wellington: Institute of Policy Studies.

Blok, A. (2013). Pragmatic sociology as political ecology: On the many worths of nature(s). European Journal of Social Theory, 16(4), 492 - 510.

Blok, A., \& Jensen, T. (2011). Bruno Latour: Hybrid thoughts in a bybrid world. London and New York: Routledge.

Boas, T., \& Gans-Morse, J. (2009). Neoliberalism: From New Liberal Philosophy to AntiLiberal Slogan. Studies in Comparative International Development, 44, 137 - 161.

Boggs, C. (2001). Social Capital and Political Fantasy: Robert Putnam's "Bowling Alone". Theory and Society, 30(2), 281 - 297.

Bogusz, T. (2014). Why (Not) Pragmatism? In S. Susen \& B. turner (Eds.), The Spirit of Luc Boltanski: Essays on the 'Pragmatic Sociology of Critique' (pp. 129 - 152). London: Anthem.

Bolger, J. (1998). A View from the Top: My seven years as Prime Minister. Auckland: Viking Press.

Boltanski, L. (2011). On Critique: A sociology of Emancipation (G. Elliott, Trans.). Cambridge and Malden: Polity Press.

Boltanski, L., \& Chiapello, E. (1999 [2005]). The New Spirit of Capitalism (G. Elliott, Trans.). London and New York: Verso.

Boltanski, L., \& Thévenot, L. (1999a). On Justification: Economies of Worth (C. Porter, Trans.). Princeton: Princeton University Press.

Boltanski, L., \& Thévenot, L. (1999b). The Sociology of Critical Capacity. European Journal of Social Theory, 2(3), 359 - 377.

Borgatti, S., \& Forster, P. (2003). The network paradigm in organizational research: A review and tyology. Journal of Management, 29(6), 991 - 1013.

Bossert, T. (1998). Analyzing the Decentralization of Health Systems in Developing Countries: Decision Space, Innovation and Performance. Social Science and Medicine, 47(10), $1513-1527$.

Boulila, G., Bousrih, L., \& Trabelsi, M. (2008). Social capital and economic growth: empirical investigations on the transmission channels. International Economic Journal, 22(3), 399-417.

Bourdieu. (1986). The Forms of Capital. In J. Richardson (Ed.), Handbook of Theory and Research for the Sociology of Education (pp. 241 - 258). New York. 
Bourdieu. (2005). The Social Structures of the Economy (C. Turner, Trans.). Cambridge and Malden: Polity Press.

Bowers, J., \& Iwi, K. (1993). The Discursive Construction of Society. Discourse \& Society, $4,357-393$.

Brown, S., \& Capdevila, R. (1999). Perpetuum Mobile: substance, force and the sociology of translation. In J. Law \& J. Hassard (Eds.), Actor Network Theory and after (pp. 26 50). Oxford and Malden: Blackwell Publishers.

Browne, C. (2014). The institution of critique and the critique of institutions. Thesis Eleven, 124(1), 20 - 52.

Brüderl, J., \& Preisendörfer, P. (1998). Network Support and the Success of Newly Founded Businesses. Small Business Economics, 10(3), 213 - 225.

Brunner, E., \& Marmot, M. (1999). Social organisation, stress, and health. In M. Marmot \& R. Wilkinson (Eds.), Social Determinants of Health. Oxford: Oxford University Press.

Brunton, W. (2005). The place of public inquireries in shaping New Zealand's national health policy 1858 - 1996. Australia and New Zealand Health Policy, 2, 24 - 39.

Burt, R. (1997). The Contingent Value of Social Capital. Administrative Science Quarterly, 42, $339-365$.

Burt, R. (2005). Brokerage and Closure: An Introduction to Social Capital. Oxford: Oxford University Press.

Butterworth, G., \& Butterworth, S. (1998). Reforming Education: The New Zealand Experience 1984 - 1996. Wellington: Ministry of Education.

Callon, M. (1986). Some elements of a sociology of translation: domestication of the scallops and the fishermen of St Brieuc Bay. In J. Law (Ed.), Power, action and belief: a new sociology of knowledge (pp. pp. 196 - 223). London: Routledge.

Campbell, C., \& Cornish, F. (2010). Towards a "fourth generation" of approaches to HIV/AIDS management: creating contexts for effective community mobilisation. AIDS Care, 22(2), 1569 - 1579.

Carey, S., Lawson, B., \& Krause, D. (2011). Social capital configuration, legal bonds and performance in buyer-supplier relaitonships. Journal of Operations Management, 29(4), $277-288$.

Carpiano, R. (2006). Toward a neighborhood resource-based theory of social capital for health: Can Bourdieu and sociology help? Social Science and Medicine, 62, 165 - 175. 
Cattell, V. (2001). Poor people, poor places, and poor health: the mediating role of social networks and social capital. Social Science and Medicine, 52, 1501 - 1516.

Chang, H., \& Chuang, S. (2011). Social capital and individual motivations on knowledge sharing: Participant involvement as a moderator. Information and Management, 48(1), $9-18$.

Chen, C., Chen, X., \& Huang, S. (2013). Chinese Guanxi: An Integrative Review and New Directions for Future Research. Management and Organization Review, 9(1), 167 - 207.

Cheong, P., Edwards, R., Goulbourne, H., \& Solomos, J. (2007). Immigration, social cohesion and social capital: A critical review. Critical Social Policy, 27(1), 24 - 49.

Clark, A. (2012). The Easterlin Paradox Paper presented at the Wellbeing and Public Policy, Wellington.

Clark, A., Frijters, P., \& Shields, M. (2008). Relative Income, Happiness, and Utility: An Explanation for the Easterlin Paradox and Other Puzzles. Journal of Economic Literature, 46(1), 95 - 144.

Coburn, D. (2000). Income inequality, social cohesion and the health status of populations: the role of neo-liberalism. Social Science and Medicine, 51(1), 135 - 146.

Coburn, D. (2004). Beyond the income inequality hypothesis: class, neo-liberalism, and health inequalities. Social Science and Medicine, 58, $41-56$.

Cody, J. (2002). Conceptualising Social Capital - Frameworks. In D. Robinson (Ed.), Building Social Capital (pp. 31 - 40). Wellington: Institute of Policy Studies.

Coleman, J. (1988). Social Capital in the creation of Human Capital. The American Journal of Sociology, 94(Supplement: Organizations and Institutions: Sociological and Economic Approaches to the Analysis of Social Structure), S95 - S120.

Coleman, J. (1990). Foundations of Social Theory. Cambridge, Massachusetts and London: Harvard University Press.

Cooke, P., \& Wills, D. (1999). Small Firms, Social Capital and the Enhancement of Business Performance Through Innovation Programmes. Paper presented at the Science Policy Support Group Workshop on Collaboration and Networking in European Science and Technology, London.

Coole, D. (2009). Repairing Civil Society and Experimenting with Power: A Genealogy of Social Capital. Political Studies, 57, 374 - 396.

Corredoira, R., \& Rosenkoff, L. (2010). Should Auld Acquaintance be forgot? The Reverse Transfer of Knowledge Through Mobility Ties. Strategic Managment Journal, 31, 159 - 181. 
Cox, E. (2002). Australia: Making the Lucky Country. In R. Putnam (Ed.), Democracies in Flux: The Evolution of Social Capital in Contemporary Society (pp. 333 - 358). Oxford: Oxford University Press.

Craig, D., \& Cotterell, G. (2007). Periodising neoliberalism. Policy \& Politics, 35(3), 497 514.

Craig, D., \& Porter, D. (2004). The Third Way and the Third World: Poverty Reduction and Social Inclusion Strategies in the Rise of 'Inclusive' Liberalism. Review of International Political Economy, 12(2), 226 - 263.

Crampton, P. (1997). Social Capital and Health. In D. Robinson (Ed.), Social Capital and Policy Development. Wellington: Institute of Policy Studies.

Daly, M., \& Silver, H. (2008). Social exclusion and social capital: A comparison and critique. Theoretical Sociology, 37, 537 - 566.

Davey, J. (2006). "Ageing in place": The views of older homeowners about housing maintenance, renovaton and adaption. Wellington.

Davies, W. (2011). The Political Economy of Unhappiness. New Left Review, 71, 65 - 80.

Davies, W. (2015). The return of social government: From 'socialist calculation' to 'social analytics'. European Journal of Social Theory, 1 - 20.

De Silva, M., McKenzie, K., Harpham, T., \& Huttly, S. (2005). Social capital and mental illness: a systematic review. Journal of Epidemology and Community Health, 59, 619 627.

Dean, M. (1994). Critical and Effective Histories. London: Routledge.

Dean, M. (2008). Governing Societies: Perspectives on domestic and international rule. Maidenhead: Open University Press.

Dean, M. (2010). Governmentality: Power and Rule in Modern Society (2nd ed.). London, Thousand Oaks, New Delhi, Singapore: Sage

Deneulin, S., \& McGregor, A. (2010). The capability approach and the politics of a social conception of wellbeing. Europen Journal of Social Theory, 13(4), 501 - 519.

Department of Prime Minister and Cabinet. (2003). Sustainable Development for New Zealand: Programme of Action. Wellington.

Deuchar, R. (2009). Gangs: Marginalised youth and social capital. London: Trentham Books. 
Dew, K., \& Kirkman, A. (2002). The Sociology of Health in New Zealand. Melbourne: Oxford University Press.

Douglas, T. (1997). On the Notion of Social Capital: The Perspective of the Maori Congress. In D. Robinson (Ed.), Social Capital and Policy Development. Wellington: Institute of Policy Studies.

Driver, S. M., L. (1997). New Labour's Communitarianisms Critical Social Policy, 17, 27 46.

Duncan, G. (2014). After Neo-Liberalism, What Could Be Worse? New Zealand Sociology, 29(1).

Duncan, J., Bowden, C., \& Smith, B. (2005). Early Childhood centres and family resilience. Wellington.

Dwyer, M., \& Gray, A. (2000). Factors Affecting the Ability of Older People to Live Independently: A literature review. Wellington.

Easterlin, R. (1974). Does Economic Growth Improve the Human Lot? Some Empirical Evidence. In P. David \& M. Reder (Eds.), Nations and Households in Economic Growth. New York: Academic Press.

Edwards, B., \& Foley, M. (1998). Civil Society and Social Capital Beyond Putnam. The American Behavioral Scientist, 42(1), 124 - 139.

Edwards, L. (2009). Ideational Social Capital and the Civic Culture: Extricating Putnam's Legacy from the Social Capital Debates. Social Epistemology: A Journal of Knowledge, Culture and Policy, 23(2), 125 - 144.

Egelston, A. (2013). Sustainable Development: A History: Springer.

Elstad, J. (2002). The Psycho-social Perspective on Social Inequalities in Health In S. Nettleton \& U. Gustafsson (Eds.), The Sociology of Health and Illness Reader. Cambridge: Polity Press.

English, B. (2002). Making Choices, Changing Roles. In D. Robinson (Ed.), Building Social Capital. Wellington: Institute of Policy Studies.

Escobar, A. (1995). Encountering Development: The Making and Unmaking of the Third World. New Jersey: Princeton University Press.

Etzioni, A. (1988). The Moral Dimension: Towards a New Economics. London and New York: The Free Press.

Etzioni, A. (2014). Communitarianism revisited. Journal of Political Ideologies, 19(3), 241 260. 
Evans, A., Strezov, V., \& Evans, T. (2015). Measuring Tools for Quantifying Sustainable Development. European Journal of Sustainable Development, 4(2), 291 - 300.

Fairclough, N. (2000). New Labour New Language? London: Routledge.

Fang, R., Duffy, M., \& Shaw, J. (2011). The Organizational Socialization Process: Review and Development of a Social Capital Model. Journal of Management, 37(1), 127- 152.

Farr, J. (2004). Social Capital: A Conceptual History. Political Theory, 32(1), 6 - 33.

Farr, J. (2007). In Search of Social Capital: A Reply to Ben Fine. Political Theory, 35(1).

Farr, R. (1991). The long past and the short history of social psychology. European Journal of Social Psychology, 21, 371 - 380.

Ferguson, J. (2009). The Uses of Neoliberalism. Antipode, 41(S1), 166 - 184.

Fine, B. (1980). Economic Theory and Ideology. London: E. Arnold.

Fine, B. (2001). Social Capital versus Social Theory: Political economy and social science at the turn of the millennium. London and New York: Routledge.

Fine, B. (2007a). Eleven Hypotheses on the Conceptual History of Social Capital: A Response to James Farr. Political Theory, 35(1), 47 - 53.

Fine, B. (2007b). Social Capital. Development in Practice, 17(4 - 5), 566 - 574.

Fine, B. (2010). Theories of Social Capital: Researchers Behaving Badly. London: Pluto Press.

Fine, B., \& Green, F. (2000). Economics, Social Capital, and the Colonization of the Social Sciences. In S. Baron, T. Schuller \& J. Field (Eds.), Social Capital: Critical Perspectives. Oxford: Oxford University Press.

Fitzsimons, P. (2000). Neoliberalism and 'Social Capital': Reinventing Community. Paper presented at the Neo-liberalism, Welfare and Education: "The New Zealand Experiment": Critique and Critical Transformations, New Orleans.

Flew, T. (2014). Six theories of neoliberalism. Thesis Eleven, 122(1), 49 - 71.

Foley, M., \& Edwards, B. (1997). Escape From Politics?: Social Theory and the Social Capital Debate. The American Behavioral Scientist, 40(5), 550 - 561.

Foucault, M. (1972). The Archaeology of Knowledge (A. Sheridan Smith, Trans.). London: Tavistock. 
Frecker, K. (2005). Beyond GDP: Enabling Democracy with Better Measures of Social Well-being: Trudeau Centre for peace and conflict studies.

Frey, B. (2008). Happiness: A Revolution in Economics. Cambridge, Massachusetts: MIT Press.

Fukuyama, F. (1995). Trust: The Social Virtues \& The Creation of Prosperity. New York, London: The Free Press.

Fyfe, N. (2005). Making Space for "Neo-communitarianism"? The Third Sector, State and Civil Society in the UK. Antipode, 37(3), 536 - 557.

Gad, C., \& Jensen, C. (2010). On the Consequences of Post-ANT. Science, Technology \& Human Values, 35(1), 55 - 80.

Gadrey, J., \& Jany-Catrice, F. (2006). The New Indicators of Well-being and Development. Basingstoke and New York: Palgrave MacMillan.

Garlick, T. (2012). Social Developments: An organisational bistory of the Ministry of Social Development and its Predecessors, 1860 - 2011. Wellington: Steele Roberts.

Giddens, A. (1998). The Third Way: The Renewal of Social Democracy. Cambridge: Polity Press.

Giddens, A. (2000). The Third Way and its Critics. Cambridge: Polity.

Gillies, P. (1998). Effectiveness of alliances and partnerships for health promotion. Health Promotion International, 13(2), 99 - 120.

Gillies, V., \& Edwards, R. (2006). A Qualitative Analysis of Parenting and Social Capital: Comparing the Work of Coleman and Bourdieu. Qualitative Sociology Review, 2(2), $42-60$.

Gilling, A. (2002). Governance, not Politics: The Statecraft of the New Zealand Labour Party, 1990 - 2002. (Master of Arts), Victoria University of Wellington.

Gilson, L. (2003). Trust and the development of health care as a social institution. Social Science and Medicine, 56(7), 1453 - 1468.

Giordano, G., \& Lindstrom, M. (2010). The impact of changes in different aspects of social captial and material conditions on self-rated health over time: A longitudinal cohort study. Social Science and Medicine, 70(5), $700-710$.

Gleisner, B., Llewellyn-Fowler, M., \& McAlister, F. (2011). Broadening our Understanding of Living Standards: Treasury's New Policy Framework. Policy Quarterly, 7(3), 13 - 19. 
Gleisner, B., McAlister, F., Galt, M., Beaglehole, J. (2012). A Living Standards approach to public policy. New Zealand Economic Papers, 46(3), 211 - 238.

Gold, A., Malhotra, A., \& Segars, A. (2001). Knowledge management: An organizational capabilities perspective. Journal of Management Information Systems, 18(1), 185 - 214.

Goldfinch, S. (2000). Remaking New Zealand and Australian Economic Policy. Wellington: Victoria University Press.

Goldfinch, S., \& Roper, B. (1993). Treasury's Role in State Policy Formulation During the Post-War Era. In B. Roper \& C. Rudd (Eds.), State and Economy: in New Zealand. Auckland: Oxford University Press.

Good, R. (2000). Social Capital and Policy Development edited by David Robinson, Social Capital in Action edited by David Robinson. Social Policy Journal of New Zealand(14).

Granovetter, M. (1973). The Strength of Weak Ties. American Journal of Sociology, 78(6), $1360-1380$.

Grootaert, C., \& Bastelaer, T. (2001). Understanding and Measuring Social Capital: A Synthesis of Findings and Recommendations from the Social Capital Initiative. Washington: World Bank.

Guggenheim, M., \& Potthast, J. (2011). Symmetrical twins: On the relationship between Actor-Network theory and the sociology of critical capacities. European Journal of Social Theory, 15(2), 157 - 178.

Hacking, I. (1986). Making Up People. In T. Heller, M. Sosna \& D. Wellerby (Eds.), Reconstructing Individualism: Autonomy, Individuality, and the Self in Western Thought (pp. 222 - 236). Stanford: Stanford University Press.

Hacking, I. (1990). The Taming of Chance. Cambridge: Cambridge University Press.

Hacking, I. (1991). How should we do the history of statistics. In G. Burchell, C. Gordon \& P. Miller (Eds.), The Foucault Effect: Studies in Governmentality. London: Havester Wheatsheath.

Halpern, D. (2005). Social Capital. Cambridge and Malden: Polity.

Hammer, J., \& Pritchett, L. (2006). Scenes from a Marriage: World Bank Economists and Social Capital. In A. Bebbington, M. Woolcock, S. Guggenheim \& E. Olsen (Eds.), The Search for Empowerment: Social Capital as Idea and Practice at the World Bank (pp. 63 - 90). Bloomfield, CT: Kumarian Press.

Hanifan, L. (1916). The Rural School Community Center. The ANNALS of the American Academy of Political and Social Science, 67, 130 - 138. 
Harpham, T., Grant, E., \& Thomas, E. (2002). Measuring social capital within health surveys: key issues. Health Policy and Planning, 17(1), 106 - 111.

Hawe, P., \& Shiell, A. (2000). Social capital and health promotion: a review. Social Science and Medicine, 51, $871-885$.

Hayek, F. (1942). Scientism and the Study of Society, Part 1. Economica, 9(35), 267 - 291.

Haynes, K., \& Hillman, A. (2010). The Effect of Board Capital and CEO Power on Strategic Change. Strategic Managment Journal, 31, 1145 - 1163.

Helliwell, J. (2006). Well-Being, Social Capital and Public Policy: What's New? The Economic Journal, 116(March), C34 - C45.

Helliwell, J., Layard, R., \& Sachs, J. (2012). World Happiness Report 2012. New York: United Nations.

Helliwell, J., Layard, R., \& Sachs, J. (2013). World Happiness Report 2013. New York: United Nations.

Helliwell, J., Layard, R., \& Sachs, J. (2015). World Happiness Report 2015. New York: United Nations.

Herman, P. (2011). Hayden White. Cambridge: Polity.

Hill, J. (2003). Young People Not in Education, Training or Employment. Wellington.

Honneth, A. (1991). The Limits of Liberalism: On the Political-ethical dsicussion on Communitarianism. Thesis Eleven, 28(1), 18 - 34.

Huang, C., Vaneckova, P., Wang, X., FitzGerald, G., Guo, Y., \& Tong, S. (2011). Constraints and Barriers to Public Health Adaption to Climate Change. American Journal of Preventative Medicine, 40(2), 183 - 190.

Hughes, O. (2013). Discourses of Neo-Liberalisation in New Zealand: From the 'Managed Economy' to the 'Mum and Dad Investor', Prime Ministers' Speeches of 1987-2011 (a Critical Discourse Analysis) (Masters of Arts in Sociology), Victoria University of Wellington, Wellington.

Humpage, L. (2006). An 'inclusive' society: a 'leap forward' for Maori in New Zealand? Critical Social Policy, 26(1), 220 - 242.

Humpage, L. (2015). Policy Change, Public Attitudes and Social Citizenship. Bristol: Policy Press. 
Huysman, M., \& Wulf, V. (2004). Social Capital and Information Technology: Current Debates and Research. In M. Huysman \& V. Wulf (Eds.), Social Capital and Information Technology. Cambridge \& London: MIT Press.

Inkpen, A., \& Tsang, E. (2005). Social Capital, Neworks, and Knowledge Transfer. Academy of Management Review, 30(1), 146 - 165.

Joblin, R. (1997). Can Singing Save Your Life? Social Capital, Justice and the Control of Crime. In D. Robinson (Ed.), Social Captial and Policy Development. Wellington: Institute of Policy Studies

Kalil, A. (2003). Family Resilience and Good Child Outcomes: A Review of the Literature. Wellington.

Kankanhalli, A., Tan, B., \& Wei, K. (2005). Contributing knowledge to electronic knowledge repositories: An empirical investigation. MIS Quarterly, 29(1), 113 143.

Karacaoglu, G. (2012). Improving the Living Standards of New Zealanders: Moving from a Framework to Implementation. Paper presented at the Public Policy and Wellbeing, Wellington.

Kawachi, I. (1999). Social Capital and Community Effects on Population and Individual Health. Annals of the New York Academy of Sciences, 896, 120 - 130.

Kawachi, I., \& Berkman, L. (2001). Social Ties and Mental Health. Journal of Urban Health: Bulletin of the New York Academy of Medicine, 78(3), 458 - 467.

Kawachi, I., Kennedy, B., \& Glass, R. (1999). Social Capital and Self-Rated Health: A Contextual Analysis. American Jounrnal of Public Health, 89(8), 1187 - 1193.

Kawachi, I., Kennedy, B., Lochner, K., \& Prothrow-Stith, D. (1997). Social Capital, Income Inequality, and Mortality. American Journal of Public Health, 87(9), 1491 1498 .

Kawachi, I., Kennedy, B., \& Wilkinson, R. (1999). Crime: social disorganization and relative deprivation. Social Science and Medicine, 48, 719 - 731.

Kawachi, I., Subramanian, S., \& Kim, D. (2008). Social Capital and Health: A Decade of Progress and Beyond. In I. Kawachi, Subramanian, S., Kim, D. (Ed.), Social Capital and Health (pp. 1 - 26): Springer.

Kelsey, J. (1995). The New Zealand Experiment: A World Model for Structural Adjustment? Auckland: Auckland University Press. 
Kennedy, B., Kawachi, I., Prothrow-Stith, D., Lochner, K., \& Gupta, V. (1998). Social Capital, Income Inequality, and Firearm Violent Crime. Social Science and Medicine, 47(1), 7 - 17.

Kumar, K., van Dissel, H., \& Bielli, P. (1998). The Merchant of Prato-Revisited: Toward a Third Rationality of Information Systems. MIS Quarterly, 22(2), 199- 226.

Larner, W. (1998). Sociologies of Neo-liberalism: Theorising the 'New Zealand Experiment'. Sites: A Journal for South Pacific Cultural Studies, 36, 5 - 21.

Larner, W. (2005). Neoliberalism in (Regional) Theory and Practice: the Stronger Communities Action Fund in New Zealand. Geographical Research, 43(1), 9 - 18.

Larner, W., \& Craig, D. (2005). After Neoliberalism? Community Activism and Local Partnerships in Aotearoa New Zealand. In N. Laurie \& L. Bondi (Eds.), Working the spaces of Neoliberalism (pp. 9 - 32). Oxford: Blackwell Publishing.

Latour, B. (1986). Drawing things together. In H. Kuklick \& E. Long (Eds.), Knowledge and Society: Studies in the Sociology of Culture Past and Present (Vol. 6). Greenwich: Jai Press.

Latour, B. (1987). Science in Action. Cambridge: Harvard University Press.

Latour, B. (1988). The Pasteurization of France (A. Sheridan \& J. Law, Trans.). Cambridge: Havard University Press.

Latour, B. (1993). We have never been modern (C. Porter, Trans.). Cambridge, MA.: Havard University Press.

Latour, B. (1999). On recalling ANT. In J. Law \& J. Hassard (Eds.), Actor Network Theory and after (pp. 15 - 25). Oxford: Blackwell Publishers.

Latour, B. (2004). Why Has Critique Run out of Steam? From Matters of Fact to Matters of Concern. Critical Inquiry, 30(2), 225 - 248.

Latour, B. (2005). Reassembling the Social: An Introduction to Actor-Network-Theory. Oxford: Oxford University Press.

Law, J. (1999). After ANT: complexity, naming and topology. In J. Law \& J. Hassard (Eds.), Actor Network Theory and after. Oxford: Blackwell Publishers.

Law, J. (2002). On Hidden Heterogeneities: Complexitiy, Formalism, and Aircraft Design. In J. Law \& A. Mol (Eds.), Complexities: Social Studies of Knowledge Practices (pp. 116 - 141). Durham and London: Duke University Press.

Law, J. (2005). After Method: mess in social science research. London and New York: Routledge. 
Law, J. (2009). The Greer-Bush Test: On Politics in STS.

Law, J., \& Mol, A. (2002). Complexities: An Introduction. In J. Law \& A. Mol (Eds.), Complexities: Social Studies of Knowledge Practices. Durham and London: Duke University Press.

Law, J., \& Singleton, V. (2005). Object Lessons Organization Studies, 12(3), 331 - 355.

Law, J., \& Singleton, V. (2013). ANT and Politics: working in and on the World. Qualitative Sociology, 36(4), 485 - 502.

Layard, R. (2006). Happiness and Public Policy: A Challenge to the Profession. The Economic Journal, 116(March), C24 - C33.

Leana, C., \& van Buren, H. (1999). Organisational Social Capital and Employment Practices. Academy of Management Review, 24(3), 538 - 555.

Legatum Institute. (2015). Legatum Prosperity Index 2015. Legatum Institute Retrieved from http://media.prosperity.com/2015/pdf/publications/PI2015Brochure_WEB.p df.

Leonard, R., \& Onyx, J. (2004). Social Capital and Community Building: Spinning Straw into Gold. London: Janus Publishing Company.

Levin, D., \& Cross, R. (2004). The strength of weak ties you can trust: The mediating role of trust in effective knowledge transfer. Management Science, 50(11), 1477 - 1490.

Levitas, R. (2004). Let's hear it for Humpty: social exclusion, the third way and cultural capital. Cultural Trends, 13(2), 41 - 56.

Lin, N. (1999). Building a Network Theory of Social Capital. Connections, 22(1), 28 - 51.

Lin, N. (2001). Social Capital: A Theory of Social Structure and Action. Cambridge: Cambridge University Press.

Linley, P. A., Joseph, S., Harrington, S., \& Wood, A. (2006). Positive psychology: Past, present, and (possible) future. The Journal of Positive Psychology, 1(1), 3 - 16.

Lochner, K., Kawachi, I., \& Kennedy, B. (1999). Social capital: a guide to its measurement. Health and Place, 5, 259 - 270.

Lomas, J. (1998). Social Capital and Health: Implications for Public Health and Epidemiology. Social Science and Medicine, 47(9), 1181 - 1188. 
Loury, G. (1977). A Dynamic Thoery of Racial Income Differences. In P. Wallace \& A. LaMond (Eds.), Women, Minorities, and Employment Discrimination. Lexington, Massachusetts: Lexington Books.

MacGillivray, A., \& Walker, P. (2000). Local Social Capital: Making it Work on the Ground. In S. Baron, J. Field \& T. Schuller (Eds.), Social Capital: Critical Perspectives (pp. 197 - 211). Oxford: Oxford University Press.

Marx, K. (1957). Capital Volume II. Moscow: Foreign Languages Publishing House.

Maynard, D., \& Schaeffer, N. (2000). Toward a Sociology of Social Scientific Knowledge: Survey Research and Ethnomethodology's Asymmetric Alternatives. Social Studies of Science, 30(3), 323 - 370.

McLennan, G. (2004). Travelling with vehicular ideas: The case of the third way. Economy and Society, 33(4), 484 - 499.

Meadowcroft, J., \& Pennington, M. (2007). Rescuing Social Capital from Social Democracy. Westminster: Institute of Economic Ideas.

Meier, G. (2001). The Old Generation of Development Economists and the New. In G. S. Meier, J. (Ed.), Frontiers of Development Economics: The Future in Perspective (pp. 13 60). Oxford: Oxford University Press.

Meijer, M., Röhl, J., Bloomfield, K., \& Grittner, U. (2012). Do neighbourhoods affect individual mortality? A systematic review and meta-analysis of multilevel studies. Social Science and Medicine, 74(8), 1204 - 1212.

Miller, P., Kurunmäki, L., \& O'Leary, T. (2010). Calculating Hybrids. In V. Higgins \& W. Larner (Eds.), Calculating the Social: Standards and the Reconfiguration of Governing. Basingstoke: Palgrave Macmillan.

Miller, P., \& Rose, N. (2008). Governing the Present. Cambridge, Malden: Polity Press.

Ministry of Social Development. (2001a). The Social Development Approach. Wellington.

Ministry of Social Development. (2001b). The Social Report. Wellington: Ministry of Social Development.

Ministry of Social Development. (2002). New Zealand's Agenda for Children. Wellington.

Ministry of Social Development. (2003). The Social Report. Wellington: Ministry of Social Development.

Ministry of Social Development. (2004a). 2004 the social report: indicators of social wellbeing in New Zealand. Wellington. 
Ministry of Social Development. (2004b). Statement of Intent 2004. Wellington.

Ministry of Social Development. (2005). Statement of Intent 2005. Wellington.

Ministry of Social Development. (2006). Statement of Intent 2006. Wellington.

Ministry of Social Development. (2007). Statement of Intent 2007. Wellington.

Ministry of Social Development. (2009). 'In A Place I Call My Own': Support Networks of Older People Ageing in the Community. Wellington.

Ministry of Social Development. (2010). The Social Report 2010. Wellington.

Ministry of Social Development, Ministry of Economic Development, \& Department of Labour. (2003). Population and Sustainable Development 2003. Wellington.

Mixon, F., Loftus, J., \& Keenel, W. (2004). The decay of norms and the production of social order: conceptual and empirical models. Applied Economic Letters, 11, 725 730 .

Mohnen, S., Groenewegen, P., Völker, B., \& Flap, H. (2011). Neighborhood social capital and individual health. Social Science and Medicine, 72(5), 660 - 667.

Mol, A. (1999). Ontological Politics. A word and some questions. In J. Law \& J. Hassard (Eds.), Actor Network Theory and after (pp. 74 - 89). Oxford: Blackwell Publishers.

Mol, A. (2002). the body multiple: ontology in medical practice. Durham and London: Duke University Press.

Murayama, H., Fujiwara, Y., \& Kawachi, I. (2012). Social Capital and Health: A Review of Prospective Multilevel Studies. Journal of Epidemiology, 22(3), 179 - 187.

Nahapiet, J., \& Ghoshal, S. (1998). Social Capital, Intellectual Capital, and the Organizational Advantage. Academy of Management Review, 23(2), 242 - 256.

Nambisan, S., \& Baron, R. (2010). Different Roles, Different Strokes: Organizing Virtual Customer Environments to Promote Two Types of Customer Contributions. Organization Science, 21(2), 554 - 572.

Nash, R., \& Harker, R. (2005). The Predictable failure of school marketisation: The limitations of policy reform. In J. Codd \& K. Sullivan (Eds.), Education Policy Directions in Aotearoa New Zealand (pp. 201 - 218). Southbank, Victoria: Dunmore Press.

Navarro, V. (2002). A Critique of Social Capital. International Journal of Health Services, 32(3), $423-432$. 
New Zealand Government. http:/www.beehive.govt.nz/. Retrieved 10/10/2014

Neyland, D. (2006). Dismissed Content and Discontent: An Analysis of the Strategic Aspects of Actor-Network Theory. Science, Technology \& Human Values, 31(1), 29 51.

Nicholls, K. (2011). Beyond Neoliberalism: Response to Brian Roper. New Zealand Sociology, 26(2), 77 - 87.

Nimmo, R. (2008). Governing Nonhumans: Knowledge, Sanitation and Discipline in the Late 19th and Early 20th-Century British Milk Trade. Distinktion: Scandinavian Journal of Social Theory, 9(1), 77 - 97.

Nimmo, R. (2010). Milk, Modernity and the Making of the Human: Purifying the social. London and New York: Routledge.

Nimmo, R. (2011). Actor-network theory and methodology: social research in a morethan-human world. Methodological Innovations Online, 6(3), 108 - 119.

Norris, F., Stevens, S., Pfefferbaum, B., Wyche, K., \& Pfefferbaum, R. (2008). Community Resilience as a Metaphor, Theory, Set of Capacities and Strategies for Disaster Readiness. American Journal of Community Psychology, 41, 127 - 150.

O'Brien, M. (1997). Working on Conservation Issues: A Perspective on Social Capital. In D. Robinson (Ed.), Social Captial and Policy Development. Wellington: Institute of Policy Studies.

OECD. (2001). The Wellbeing of Nations: The Role of Human and Social Capital.

OECD. (2013). Social Capital Question Bank. from www.oecd.org/std/Social-CapitalQuestion-Bank.xlsx

Oldroyd, J., \& Morris, S. (2012). Catching Falling Stars: A Human Resource Response to Social Capital's Determental Effect of Information Overload on Star Employees. Academy of Management Review, 37(3), 396 - 418.

Paterson, L. (2000). Civil Society and Democratic Renewal. In S. Baron, J. Field \& T. Schuller (Eds.), Social Capital: Critical Perspectives. Oxford: Oxford University Press.

Paxton, P. (2002). Social capital and democracy: An interdependent relationship. American Sociological Review, 67(2), 254 - 277.

Payne, T., Moore, C., \& Griffis, S. (2011). Multilevel Challenges and Opportunities in Social Capital Research. Journal of Management, 37(2), 491 - 520.

Pennings, J., Lee, K., \& Witteloostujn, A. (1998). Human Capital, Social Capital, and Firm Dissolution. Academy of Management Journal, 1998(41), 4. 
Phelan, S. (2007). Messy Grand Narrative or Analytic Blind Spot? When Speaking of Neoliberalism. Comparative European Politics, 5, 328 - 338.

Phelan, S. (2014). Neoliberalism, the Media and the Political. Basingstoke: Palgrave MacMillan.

Porter, T. (1995). Trust in Numbers: The Pursuit of Objectivity in Scientific and Public Life. Princeton: Princeton University Press.

Portes, A. (1998). SOCIAL CAPITAL: Its origins and Applications in Modern Sociology. Annual Review of Sociology, 24, 1 - 24.

Portes, A., \& Sensenbrenner, J. (1993). Embeddedness and Immigration: Notes on the Social Determinants of Economic Action. American Journal of Sociology, 98(6), 1320 $-1350$.

Powell, K. A., P., Cullen, J., Butler, P. D., J., \& Marshall, K. (2005). Report to the New Zealand Playcentre Federation: The Effect of Adult Playcentre Participation on the Creation of Social Capital in Local Communities.

Puketapu, K. (1999). Social Capital - 'It is Us': The Tu Tangata Programme. In D. Robinson (Ed.), Social Capital in Action. Wellington: Institute of Policy Studies.

Pusen, M. (1996). Economic Rationalism and the Contest for Civil Society. Thesis Eleven, $44,69-86$.

Putnam, R. (1995). Tuning In, Tuning Out: The Strange Disappearance of Social Capital in America. Political Science and Politics, 28(4), 664 - 683.

Putnam, R. (2000). Bowling Alone: The Collapse and Revival of American Community (Vol. New York): Touchstone.

Putnam, R. (2007). E Pluribus Unum: Diversity and Community in the Twenty-first Century The 2006 Johan Skytte Prize Lecture. Scandinavian Political Studies, 30(2), $137-174$.

Putnam, R., \& Goss, K. (2002). Introduction. In R. Putnam (Ed.), Democracies in Flux: The Evolution of Social Capital in Contemporary Society (pp. 3 - 20). Oxford: Oxford University Press.

Putnam, R., Leonardi, R., \& Nanetti, R. (1993). Making Democracy Work: Civic Traditions in Modern Italy. Princetown: Princetown University Press.

Putnam, R., \& Lim, C. (2010). Religion, Social Networks, and Life Satisfaction. American Sociological Review, 75(6), 914 - 933. 
Quéré, L., \& Terzi, C. (2014). Did You Say Pragmatic? Luc Boltanski's Sociology from a Pragmatist Perspective. In S. Susen \& B. Turner (Eds.), The Spirit of Luc Boltanski: Essays on the 'Pragmatic Sociology of Critique' (pp. 91 - 128). London: Anthem Press.

Randerson, R. (1992). Heards and Minds: A Place for People in a Market Economy. Wellington: Social Responsibility Commission of the Anglican Church in Aotearoa, New Zealand \& Polynesia.

Reagans, R., \& McEvily, B. (2003). Network structure and knowledge transfer: The effects of cohesion and range. Administrative Science Quarterly, 48(2), 240 - 267.

Reid, M. (1997). A Local Government Perspective on Social Capital. In D. Robinson (Ed.), Social Captial and Policy Development. Wellington: Institute of Policy Studies.

Renalds, A., Smith, T., \& Hale, P. (2010). A Systematic Review of Built Environment and Health. Family Community Health, 33(1), 68 - 78.

Rhodes, T., Singer, M., Bourgois, P., Friedman, S., \& Strathdee, S. (2005). The social structural production of HIV risk among injected drug users. Social Science and Medicine, 61, 1026 - 1044.

Riddell, M. (1997). Bringing Back Balance: The Role of Social Capital in Public Policy. In D. Robinson (Ed.), Social Capital and Policy Development (pp. 13 - 33). Wellington: Institute of Policy Studies.

Rip, A. (1986). Mobilising Resources Through Texts. In M. Callon, J. Law \& A. Rip (Eds.), Mapping the Dynamics of Science and Technology Sociology of Science in the Real World (pp. 84 - 99). Basingstoke \& London: The MacMillan Press.

Robinson, B., \& Robinson, D. (2002). Possible Aids from Physics and Engineering to Assist Understanding Social Capital. In D. Robinson (Ed.), Building Social Capital (pp. 41 - 66). Wellingon: Institute of Policy Studies.

Robinson, D. (1997a). Introduction. In D. Robinson (Ed.), Social Capital and Social Policy (pp. 1 - 12). Wellington: Institute of Policy Studies.

Robinson, D. (2002a). Introduction. In D. Robinson (Ed.), Building Social Capital. Wellington: Institute of Policy Studies.

Robinson, D. (Ed.). (1997b). Social Capital and Policy Development. Wellington: Institute of Policy Studies.

Robinson, D. (Ed.). (1999). Social Capital in Action. Wellington: Institute of Policy Studies.

Robinson, D. (Ed.). (2002b). Building Social Capital. Wellington: Institute of Policy Studies. 
Rose, N. (1988). Calculable minds and manageable individuals. History of the Human Science, 1(2), 179 - 200.

Rose, N. (1996). Inventing Our Selves: Psychology, Power, and Personhood. Cambridge: Cambridge University Press.

Rowley, T., Behrens, D., \& Krackhardt, D. (2000). Redundant governance structures: An analysis of structural and relational embeddedness in the steel and semiconductor industries. Strategic Managment Journal, 21(3), 369 - 386.

Runyan, D., Hunter, W., Socolar, R., Amaya-Jackson, L., English, D., Landsverk, J., . . . Mathew, R. (1998). Children Who Prosper in Unfavorable Environments: The Relationship to Social Captial. Pediatrics, $101(1), 12$ - 18.

Sachs, J. (2015). Investing in Social Capital. In J. Helliwell, R. Layard \& J. Sachs (Eds.), World Happiness Report 2015. New York: United Nations.

Sage, D. (2012). A challenge to liberalism? The communitarianism of the Big Society and Blue Labour. Critical Social Policy, 32(3), 365 - 382.

Sander, T., \& Putnam, R. (2010). Still Bowling Alone? The Post-9/11 Split. Journal of Democracy, 21(1), 9 - 16.

Saville-Smith, K. (2000). Familial Caregiver's Physical Abuse and Neglect of Children: A Literature Review. Wellington: Ministry of Social Policy.

Schuller, T., Baron, S., \& Field, J. (2000). Social Capital: A Review and Critique. In T. Schuller, S. Baron \& J. Field (Eds.), Social Capital: Critical Perspectives. Oxford: Oxford University Press.

Scott, J. (1998). Seeing Like a State: How Certain Schemes to Improve the Human Condition Have Failed. New Haven: Yale University Press.

Scrivens, K., \& Smith, C. (2013). Four Interpretations of Social Capital: An Agenda for Measurement. OECD Publishing.

Seibert, S., Kraimer, M., \& Liden, R. (2001). A Social Capital Theory of Career Success. Academy of Management Journal, 44(2), 219 - 237.

Seligman, M. E. P., \& Csikszentmihalyi, M. (2000). Positive Psychology: an Introduction. American Psychology, 55(1), 5 - 14.

Sen, A. (2001). Development as Freedom. Oxford: Oxford University Press.

Sica, A. (1992). The social world as a countinghouse: Coleman's irrational worldview. Theory and Society, 21(2), $243-262$. 
Silk, J., Beehner, J., Bergman, T., Crockford, C., Engh, A., Moscovice, L., . . Cheney, D. (2009). The benefits of social capital: close social bonds among female baboons enhance offspring survival. Proceedings of the Royal Society of Biology, 276, 3099 - 3104.

Smith, N., \& Laitinen, A. (2009). Taylor on Solidarity. Thesis Eleven(99), 48 - 70.

Smith, S., \& Kulynych, J. (2002). It May be Social, But Why is it Capital? The Social Construction of Social Capital and the Politics of Language. Politics \& Society, 30, $149-186$.

Sobel, J. (2002). Can We Trust Social Capital? Journal of Economic Literature, 40(March), 139 $-154$.

Somers, M. (2005). Let them Eat Social Capital: Socializing the Market versus Marketizing the Social. Thesis Eleven, 81, 5 - 19.

Speich, D. (2008). Travelling with the GDP Through Early Development Economics' History. Zürich.

Speich, D. (2011). The use of global abstractions: national income accounting in the period of imperial decline. Journal of Global History, 6, 7 - 28.

Spellerberg, S. (1997). Towards a Framework for the Measurement of Social Capital. In D. Robinson (Ed.), Social Capital and Policy Development (pp. 42 - 53). Wellington: Institute of Policy Studies.

Spellerberg, S. (2001). Framework for the Measurement of Social Capital in New Zealand. Wellington: Statistics New Zealand.

Spies-Butcher, B. (2005). Understanding the concept of social capital: Neoliberalism, social theory, or neoliberal social theory. (Ph.D.), University of Sydney.

Spies-Butcher, B. (2009). The Concept of Social Capital: Understanding its economic origins and political implications in Australia. Saarbrücken: VDM Verlag Dr. Müller.

Spies-Butcher, B. (2011). Social Capital. In G. Argrous \& F. Stilwell (Eds.), Readings in Political Economy: Economics as a Social Science (pp. 43 - 48). Australia: Tilde University Press.

Statistics New Zealand. (2008). Statistics New Zealand's Framework for Measuring Sustainable Development. Wellington: Statistics New Zealand.

Statistics New Zealand. (2009). Measuring New Zealand's Progress Using a Sustainable Development Approach: 2008. Wellington. 
Stephan, U., \& Lorraine, U. (2010). Performance-based vs socially supportive culture: A cross-national study of descriptive norms and entrepreneurship. Journal of International Business Studies, 41(8), 1347 - 1364.

Stinchcombe, A. (1992). Simmel Systematized: James S. Coleman and the Social Forms of Purposive Action in His Foundations of Social Theory. Theory and Society, 21(2), $183-202$.

Stöcklová, T. (2012). Immutable Mobiles Derailed: STS, Geopolitics, and Research Assessment. Science, Technology \& Human Values, 37(2), 286 - 311.

Strategic Social Policy Group. (2004). Attachement 1: Reducing Inequalities Indicators for Mäori and Pacific Peoples. Wellington.

Strategic Social Policy Group. (2008). Diverse Communities - Exploring the Migrant and Refugee Experience in New Zealand. Wellington.

Suzuki, E., Takao, S., Subramanian, S., Komatsu, H., Doi, H., \& Kawachi, I. (2010). Does low workplace social capital have detrimental effect on workers' health? Social Science and Medicine, 70(9), 1367 - 1372.

Swiss Federal Statistics Office. (2012). Sustainable Development Report 2012. Neuchâtel.

Szreter, S., \& Woolcock, M. (2004). Health by Association? Social capital, social theory, and the political economy of public health. International Journal of Epidemiology, 33, $650-667$.

The Treasury. (1987). Government Management: brief to the incoming government 1987. Wellington: Treasury.

The Treasury. (2001a). Geography and the Inclusive Economy: A Regional Perspective. (01/17). Wellington.

The Treasury. (2001b). Human Capital and the Inclusive Economy. (01/16). Wellington.

The Treasury. (2001c). Towards an Inclusive Economy. (01/15). Wellington.

The Treasury. (2011). Working Towards Higher Living Standards for New Zealanders.

The Treasury. (2015). Social Captial. Retrieved 27/03/2015, from http://www.treasury.govt.nz/publications/researchpolicy/tp/higherlivingstandards/15.htm

Tittenbrun, J. (2014). Social Capital: Neither social, nor capital. Theory and Methods, 53(4), $452-461$. 
Treasury. (2012). As Short Guide to Increasing Equity. Wellington.

Tsai, W., \& Ghoshal, S. (1998). Social Capital and Value Creation: The Role of Intrafirm Networks. Academy of Management Review, 41(4), 464-476.

UNECE/OECD/Eurostat Working Group. (2008). Measuring Sustainable Development. New York and Geneva.

UNECE/OECD/Eurostat Working Group. (2013). Framework and suggested indicators to measure sustainable development.

UNECE/OECD/Eurostat Working Group. (2015). Joint UNECE/Eurostat/OECD Working Group on Statistics on Sustainable Development Terms of Reference. Retrieved 11/09/2015, from http://www.unece.org/stats/groups/wgssd.tor.html

United Nations. (2012). Report of the United Nations Conference on Sustainable Development. Paper presented at the Rio+20, Rio de Janeiro.

Veenhoven, R. (2000). Well-being in the Welfare State: Level Not Higher, Distribution Not More Equitable. Journal of Compartive Policy Analysis, 2, 91 - 125.

Veenhoven, R. (2004). Subjective measures of well-being. United Nations University.

Veenhoven, R. (2009). Well-Being in Nations and Well-Being of Nations: Is There a Conflict Between Individual and Society? Social Indicators Research, 91, 5 - 21.

Veenstra, G. (2000). Social capital, SES and health: an individual-level analysis. Social Science and Medicine, 50(5), 619 - 629.

Villena, V., Revilla, V., \& Choi, T. (2011). The dark side of buyer-supplier relationships: A social capital perspective. Journal of Operations Management, 29(6), 561 - 576.

Wagner, P. (2001a). A History and Theory of the Social Sciences. London, Thousand Oaks, New Delhi: Sage.

Wagner, P. (2001b). Theorizing Modernity: Inescapability and Attainability in Social Theory. London, Thousand Oaks: Sage.

Walker, G., Kogut, B., \& Shan, W. (1997). Social Capital, Structural Holes and the Formation of an Industry Network. Organization Science, 8(2), 109 - 125.

Wasko, M., \& Faraj, S. (2005). Why should I share? Examining social capital and knowledge contribution in electronic networks of practice. MIS Quarterly, 29(1), $35-57$. 
Wellington Region Emergency Management Office. (2012). Community Resilience Strategy: Building Capacity - Increasing Connectedness - Fostering Cooperation. Wellington.

Westlund, H. (2006). Social Capital in the Knowledge Economy: Theory and Empirics. Berlin, Heidelberg, New York: Springer.

White, H. (1973). Metahistory: The Historical Imagination in Nineteenth-Century Europe. Baltimore: Johns Hopkins University Press.

White, S., \& Giaimo, S. (2001). Conclusion: New Labour and the Uncertain Future of Progressive Politics. In S. White (Ed.), New Labour: The Progressive Future? Basingstoke: Palgrave.

Whitehead, J. (25 May 2011). Working Towards Higher Living Standards for New Zealand.

Whitehead, J., \& Annesley, B. (2005). The Context for Māori Economic Development: A background paper for the 2005 Hui Taumata. Wellington.

Whittle, A., \& Spicer, A. (2008). Is Actor Network Theory Critique? Organization Studies, $29(4), 611-629$.

Wickes, R., Zahnow, R., Taylor, M., \& Piquero, A. (2015). Neighborhood Structure, Social Capital, and Community Resilience: Longitudinal Evidence from the 2011 Brisbane Flood Disaster. Social Science Quarterly, 96(2), 330 - 353.

Wilkinson, R. (1996). Unhealthy Societies: The Afflications of Inequality. London: Routledge.

Wilkinson, R. (2000). Deeper than "neoliberalism": A reply to David Coburn. Social Science and Medicine, 51(7), 997 - 1000.

Williams, I. (1997). Choral Societies and Export Growth. In D. Robinson (Ed.), Social Capital and Policy Development. Wellington: Institute of Policy Studies.

Williams, T., \& Robinson, D. (2002). Social Capital-based Partnerships: A Maori Perspective and a Comparative Approach. In D. Robinson (Ed.), Building Social Capital (pp. 14 - 31). Wellington: Institute of Policy Studies.

Witten-Hannah, S. (1999). Social Capital, Community Initiatives and Local Government. In D. Robinson (Ed.), Social Capital in Action. Wellington: Institution of Policy Studies.

Woolcock, M. (1998). Social capital and economic development: Towards a theoretical synthesis and policy framework. Theory and Society, 27, 151 - 208.

Woolcock, M. (2010). The Rise and Routinization of Social Capital, 1988-2008. Annual Review of Political Science, 13, 469-487. 
Woolcock, M., \& Narayan, D. (2000). Social Capital: Implications for Development Theory, Research, and Policy. The World Bank Research Observer, 15(2), 225 - 249.

Woolcock, M., \& Narayan, D. (2006). Social Capital: Implications for Development Theory, Research, and Policy Revisited. In A. Bebbington, S. Guggenheim \& M. Woolcock (Eds.), The Search for Empowerment: Social Capital as Idea and Practice at the World Bank. Bloomfield: Kumarian Press.

World Commission on Environment and Development. (1987). Our common future: Report of the World Commission on Environment and Development. Oxford: Oxford University Press.

Yli-Renko, H., Autio, E., \& Sapienza, H. (2001). Social Capital, Knowledge Acquisition, and Knowledge Explotation in Young Technology-Based Firms. Strategic Managment Journal, 22, 587 - 613.

Zheng, W. (2010). A Social Capital Perspective of Innovation from Individuals to Nations: Where is Empirical Literature Directing Us? International Journal of Management Reviews, 12(2), 151 - 183.

Zuern, E. (2003). Social Capital and Modernity. Transformations, 53, 69 - 75. 


\section{Appendix 1: List of Public Health and Management Studies Articles}

\section{Public Health}

(Kawachi, Kennedy, Lochner, \& Prothrow-Stith, 1997)

(Bossert, 1998)

(Gillies, 1998)

(Kennedy et al., 1998)

(Lomas, 1998)

(Baum, 1999)

(Kawachi, 1999)

(Kawachi, Kennedy, \& Glass, 1999)

(Kawachi, Kennedy, \& Wilkinson, 1999)

(Lochner et al., 1999)

(Hawe \& Shiell, 2000)

(Veenstra, 2000)

(Cattell, 2001)

(Kawachi \& Berkman, 2001)

(Harpham et al., 2002)

(Gilson, 2003)

(Szreter \& Woolcock, 2004)

(De Silva et al., 2005)

(Rhodes et al., 2005)

(Norris et al., 2008)

(Ball et al., 2010)

(Berry \& Welsh, 2010)

(Campbell \& Cornish, 2010)

(Giordano \& Lindstrom, 2010)

(Renalds et al., 2010)

(Suzuki et al., 2010)

(Huang et al., 2011)

(Mohnen et al., 2011)

(Meijer et al., 2012) 
(Murayama, Fujiwara, \& Kawachi, 2012)

\section{Management Studies}

(Belliveau et al., 1995)

(Burt, 1997)

(Walker et al., 1997)

(Brüderl \& Preisendörfer, 1998)

(Kumar et al., 1998)

(Nahapiet \& Ghoshal, 1998)

(Pennings, Lee, \& Witteloostujn, 1998)

(Tsai \& Ghoshal, 1998)

(Cooke \& Wills, 1999)

(Leana \& van Buren, 1999)

(Rowley et al., 2000)

(Gold et al., 2001)

(Yli-Renko et al., 2001)

(Adler \& Kwon, 2002)

(Borgatti \& Forster, 2003)

(Reagans \& McEvily, 2003)

(Levin \& Cross, 2004)

(Kankanhalli et al., 2005)

(Inkpen \& Tsang, 2005)

(Wasko \& Faraj, 2005)

(Zheng, 2010)

(Haynes \& Hillman, 2010)

(Nambisan \& Baron, 2010)

(Stephan \& Lorraine, 2010)

(Corredoira \& Rosenkoff, 2010)

(Villena et al., 2011)

(Chang \& Chuang, 2011)

(Payne, Moore, \& Griffis, 2011)

(Carey et al., 2011)

(Chen, Chen, \& Huang, 2013) 


\section{Appendix 2: Participant Consent Form}

SCHOOL OF SOCIAL AND CULTURAL STUDIES

TE KURA MAHUNGA TANGATA

LEVEL 9, MURPHY BUILONG, KELBUAN PARADE, KELBURY CAMPUS, WELLINGTON

PO Bax 600, Wellingion 6140, New Zealand

Phone + 64-4-4635317 Fax +64-4-463 5064 Email sacs@gvuw.sc.nz Websitewww. victoris.ac.nz/sacs

\section{Participant Consent Form}

Research Project Title: Discourses of Social Capital in Academia and Policy

\section{Researcher: Josh Barton, School of Social and Cultural Studies, Victoria University of} Wellington

By signing this consent form, I agree to be interviewed by Josh Barton as part of research on social capital in Aotearoa/New Zealand. I have been given and have understood an explanation of this research project. I have had an opportunity to ask questions and have them answered to my satisfaction.

I understand that I may withdraw myself (or any information I have provided) from this project, without having to give reasons, by e-mailing Josh Barton at Josh.Barton@vuw.ac.nz.

I understand that it is possible that I will be identifiable due to the nature of the information being provided. I understand that any information I provide will, on request be kept confidential to the researcher and his supervisors. Any information I provide will be made anonymous and still included in the outputs of this research, or excluded entirely from the research if I request it before the $1^{\text {st }}$ January 2016.

I understand that the data I provide will not be used for any other purpose or released to others.

I understand that, if this interview is audio recorded, the recording and transcripts of the interviews will be erased at the conclusion of the project. Furthermore, I will have an opportunity to check the transcripts of the interviews and/or focus groups.

Please indicate (by ticking the boxes below) which of the following apply:

$\square \quad$ I would like to receive a summary of the results of this research when it is completed.

$\square \quad$ I agree to this interview being audio recorded.

$\square \quad$ I would like to receive a copy of the transcript of this interview.

$\square \quad$ I wish to not be identified in any of the outputs from this research

Signed:

Name of participant:

Date: 


\section{Appendix 3: List of New Zealand Political Speeches}

$4^{\text {th }}$ National Government 1996 - 1999

Jim Bolger

04/05/1997 The Art of Association

09/05/1997 Knowing Who We Are

17/05/1997 Together Communities

17/05/1997 Family Well-being

24/05/1997 Nurturing the Individual

28/05/1997 Staying Clear of the Rollercoaster

06/06/1997 Association of Proprietors of Integrated Scools

09/06/1997 RSA Dominion Conference

27/06/1997 Post-Budget Breakfast

27/06/1997 Post Budget Luncheon

02/08/1997 The Millenium Agenda

08/08/1997 University of Auckland MBA Class Dinner

14/08/1997 From Welfare to Wellbeing

19/08/1997 Safer Community Council Co-Ordinators Conference

20/08/1997 Rotary Club of Wellington South

25/09/1997 New Zealand in the Next Century

25/09/1997 Opening of Marist Brothers Sports Centre

30/09/1997 New Zealand Council of Social Services $10^{\text {th }}$ Annivesary 15/10/1997

Sound Economics, Good Politics

11/11/1997 Population Conference

20/11/1997 Rotary Club Wellington

\section{Max Bradford}

11/11/1997 Population Conference

\section{Bill English}

03/09/1997 Opening Address Royal College of Psychiatrists Conference

15/10/1998 Action for Health and Independence Conference 


\section{Christine Fletcher}

19/04/1997 Celebrating the Past and Looking Forward

\section{Simon Upton}

23/05/1997 Focusing Government on What it Does Best

\section{Maurice Williamson}

12/05/1999 Launch of "Blueprint for Change"

\section{$5^{\text {th }}$ Labour Government $1999-2008$}

\section{Steve Maharey}

26/09/2000 Innovation, Cooperation and Differentiation: Polytechnics in the Emerging System

01/11/2000 More than just good works: Inspirational Philanthropy

21/01/2001 The state we're in: Economic Growth and Social Equity

05/06/2001 Where for Welfare? Social development and the refurbishment of the Welfare State

31/07/2001 THIRD REPORT OF THE TERTIARY EDUCATION ADVISORY COMMISSION - Shaping the System full report $10 / 17$

11/08/2001 Communities and Government: Realising the potential

07/09/2001 Building Social Capital

07/11/2001 Fourth Report of the Tertiary Education Advisory Commission full report $29 / 58$

23/11/2001 Maharey: Government to respond to challenge of social entrepreneurs (press release)

23/11/2001 Enabling social entrepreneurs - a partnership between government and community

21/02/2002 The social development agenda and the importance of social research

03/06/2003 The Third Way and how I got on to it

26/06/2003 Valuing connection

03/07/2003 The population and sustainable development connection 
28/07/2003 Social Outlook - 10 years in the Future: Social Development in a Knowledge Society

05/11/2003 Connected Communities: A Journey to our Future

13/11/2003 Social capital and social dvelopment - enabling New Zealanders

01/12/2003 Helping Migrants and Refugees into Work

29/11/2004 Social policy and a strong, prosperous New Zealand

23/03/2005 Social and economic goals of labour market policy

21/04/2005 An Enduring Partnership

\section{Michael Cullen}

11/02/2000 Community Trust Conference - New Zealand

20/11/2001 Address to the NZ Assocation of Philanthropic Trusts

21/05/2002 Socially Responsible Investment

08/02/2002 Canterbury Manufacturing Association

29/07/2004 Debate contribution: Social responsibility and fiscal accountability

07/05/2005 Address to Diabetes Conference

\section{Lianne Dalziel}

30/03/2000 Adult and Community Education Association Conference Towards Effective Partnership

09/03/2000 Canterbury Branch of the Adult and Community Education Association.

07/09/2000 Waitakere Branch of Adult and Community Education Associations 04/09/2003 Thinking Heads ... what's a the Heart

\section{Tariana Turia}

25/09/2001 Speech to open Te Tauihu Economic Summit

27/09/2003 Social Cohesion and the Constitutional Status of Tangata Whenua

\section{Annette King}

08/08/2001 Symposium on explanations for socio-economic differences in health

25/05/2005 Launch of Let's Beat Diabetes plan 


\section{Damien O’Conner}

23/11/2004 Launch of Ngati Whanaue Tribal Land Incorporated's Sustainable Farms Project

\section{Ruth Dyson}

28/06/2004 National Advisory Council on Employment of Women (NACEW)

16/06/2008 Volunteer Recognition Awards

31/07/2008 NZ Federation of Women's Institutes AGM

\section{Jim Anderton}

08/09/2002 Anderton on Peters and Immigration

16/03/2004 Address to CAYAD first national hui

22/09/2006 The Opuha Dam Report shows impressive results

\section{Luamanuvao Winnie Laban}

23/02/2006 Launch of Pacific women's economic well-being report

13/03/2006 A week aware of volunteers

22/04/2006 Tai Tokerau Pasifika Expo

01/05/2006 ASB Trust Board speech

02/05/2006 Speech to Philanthropy NZ Funders' Forum

08/05/2006 World Red Cross Day reception

$22 / 05 / 2006$ Laban celebrates $20^{\text {th }}$ anniversary of community volunteering

25/05/2006 Strengths-based mentoring works for youth

30/05/2006 Launch of Youthlinke Ongoing Education Programme

30/05/2006 Fundraising Institute of NZ Conference

05/07/2006 Leading social development in Wellington

30/08/2006 Pacific Futures Symposium

01/10/2006 Presbyterian General Assembly 2006

18/11/2006 Pacific Training Compliance Day

30/11/2006 Southern Perspectives on Development: Dialogue or Division 06/12/2006 North Shore Age Concern Xmas Party

01/02/2007 Launch of the Charities Register: a new era for charities in New Zealand 
01/02/2007 Launch of the Charities Register: a new era for charities (press release)

26/02/2007 Funding available for community internships

27/04/2007 Violence Free Pasifika Network Fono

30/04/2007 Launch of Mahi Aroha: Māori Perspectives on Volunteering and Cultural Obligations

14/05/2007 "Talk-Back on the Terrace” speaker series

17/05/2007 PACIFICA Porirua $30^{\text {th }}$ Anniversary celebration

\section{Mark Bunton}

28/02/2006 Local Government NZ workshop for newly elected mayors

02/06/2006 Making every family free from violence

\section{$5^{\text {th }}$ National Government $2008-2014$}

Tariana Turia

11/03/2009 Associations of Non-Governmental Organisations of Aotearoa

11/11/2009 National Community-Government Forum

29/10/2009 Valuing People - Creating Value

11/03/2010 Fit 4 Funding

\section{Jo Goodhew}

26/03/2013 Minister congratulates Community Awards Winners

21/06/2013 Waikato Volunteer Recognition Awards

24/03/2014 Speech: TrustPower National Community Awards Dinner

\section{Nikki Kaye}

22/05/2013 Speech to the Plenary Session Community Resilience: The Foundation of Resilient Nations, Geneva, Switzerland 


\section{Appendix 4: The Growth of Social Capital in the Scholarly literature}

Whilst social capital undoubtedly went through a period of intense growth in the 1990s and early 2000s, the numbers quoted and graphs used in histories can overemphasise this. Web of Science (the same database that Halpern used) indicates that the four disciplines in which social capital is most commonly used are sociology, management studies, public health and economics. The total number of articles that Web of Science records shows a rapid growth in all of these disciplines. Sociology doubled from 1925 articles in 1990 to 4131 articles in 2012, public health and economics tripled from 6183 to 2156 articles in public health, and 5577 to 16622 in economics over the same period, and management studies more than tripled from 2166 to 7728 articles. Partly because of this growth the percentage of total articles published is a better indicator of social capital's impact on the scholarly literature.

Figure 7 shows the percentage of articles on the Web of Science database with the topic of 'social capital' per year aggregated across the four disciplines. It indicates that social capital did indeed become far more popular after the 1990s, however even in the most common fields social capital was used in less than $0.7 \%$ of articles in 2012 . It also suggests that the concept's growth may have slowed down after the mid-2000s.

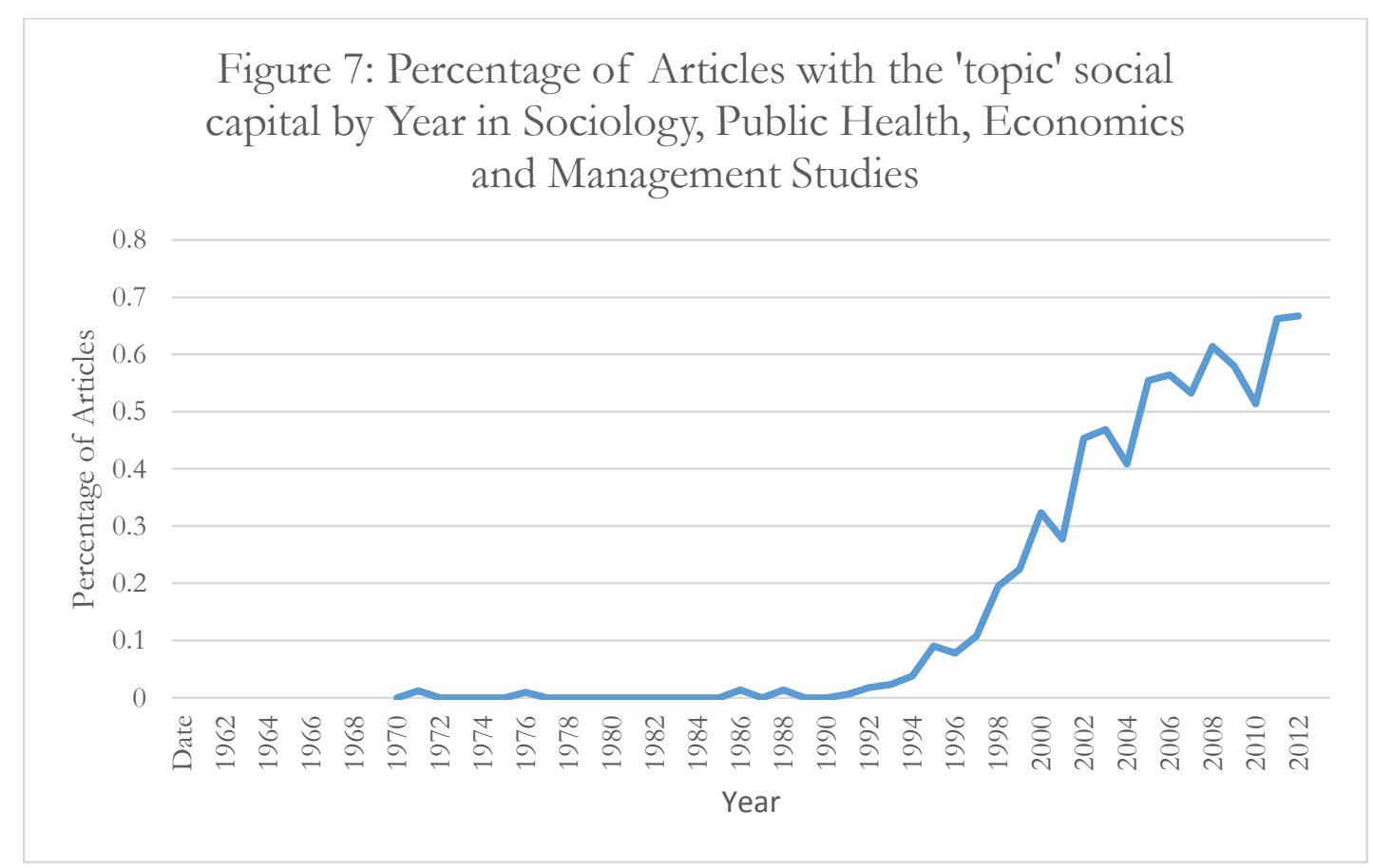


As far more articles are published in public health and economics than in sociology or management studies, figure 8 divides up social capital's use by discipline. It suggests that social capital has been far more prevalent in sociology than in other fields, being used in over $2 \%$ of articles in 2005, 06, 07, 08, 09, 11 and 12 . However it also suggests that the percentage of articles in both sociology and economics which identify social capital as a 'topic' has been stagnant since the early 2000s. Uses of social capital in Public health may have slowed since the mid-2000s although it still grew from a peak of $0.38 \%$ in 2005 to $0.46 \%$ in 2012. Management studies is the one discipline of the four which continues to see substantial growth during this time, nearly reaching 1\% of articles in 2011 . The graph also indicates that the concept 'took off' earlier in sociology than in the other disciplines.

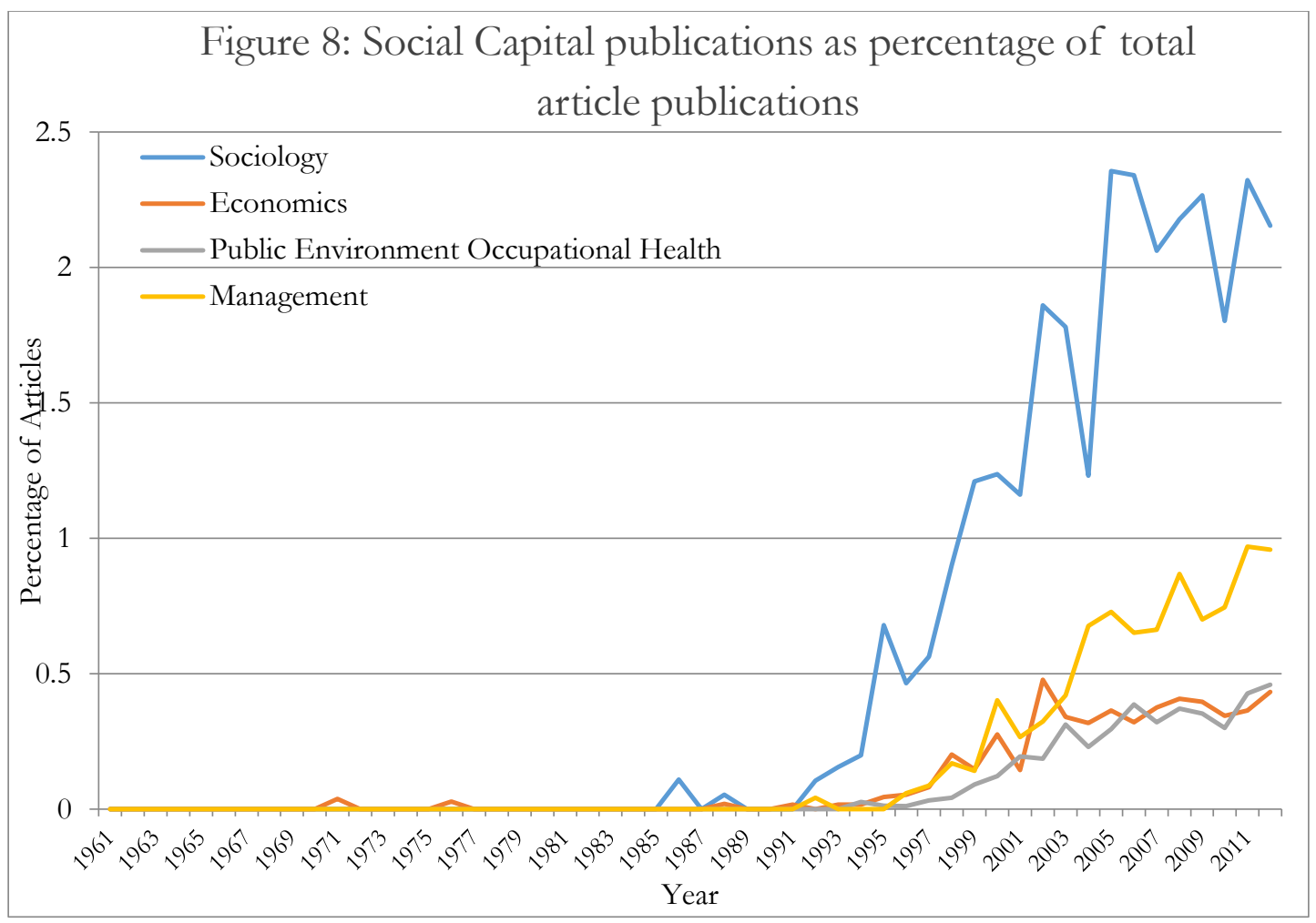

Such an analysis is limited, but it does support the narrative of social capital growing rapidly in the 1990s and early 2000s before growth slowed in the mid-2000s. At the same time that use of the concept has not declined in any of these disciplines after 25 years, it perhaps more clearly suggests that the concept is not a 'fad'. I discuss in chapters 8 and 9 that the concept has out-lived the Third Way political vehicle that it is commonly associated with, and it also seems to have a certain longevity in scholarly literature as well. This, coupled with the almost paradigmatic nature of the concept's use within both Public Health and Management Studies (see chapter 5), supports Woolcock's (2010) assertion that the concept has been 'routinized' after a rapid rise in the 1990s. 